\title{
कूले Battelle
}

Pacific Northwest Laboratories

Richland, Washington 99352

DECEMBER 1972

Prepared for the U.S. Atomic Energy Commission under Contract AT(45-1):1830 


\title{
NOTICE
}

This report was prepared as an account of work sponsored by the United States Covernment. Neither the United States nor the United States Atomic Energy Commission, nor any of theit employees, makes any watranty, express of implied, or assumes any legal liability or responsibility for the accuracy, completeness or usefulness of any information, apparatus. product, or process disclosed, of represents that its use would not intringe privately-owned rights.

\author{
PACIFIC NORTHWEST LABORATORY \\ operated by \\ BATTELLE \\ for the
}

U.S. ATOMIC ENERGY COMMISSION

Under Contract AT(45-1)-1830

Printed in the United States of America

Available from

National Technical Information Service

U.S. Department of Commerce

5285 Port Royal Road

Springfield, Virginia 22151

Price: Printed Copy 53.00; Microliche $\$ 0.95$ 


\title{
33679000621286
}

BNWL-1651 PT1

UC-53 Meteorology

PACIFIC NORTHWEST LABORATORY

ANNUAL REPORT FOR 1971

to the

USAEC Division of Biology and Medicine

VOLUME II: PHYSICAL SCIENCES

Part 1. Atmospheric Sciences

\author{
By \\ C. L. Simpson, Manager \\ and Staff of \\ Atmospheric Sciences Program
}

December 1972

BATTELLE

PACIFIC NORTHWEST LABORATORIES

RICHLAND, WASHINGTON 99352 
Volume I of this report to the USAEC Division of Biology and Medicine, covering work in the Biological and Ecological Sciences, is issued as BNWL-1650, Parts 1 and 2, repectively. Volume II of the report covers work in the physical sciences and is issued in this present part, Atmospheric Sciences, and in Part 2, Radiological Sciences, BNWL-1651. 


\section{FOREWORD}

The results of the studies reported in this 1971 Annual Report are essential to evaluations for siting nuclear facilities, to assessment of exposures from routine low level releases during operations, and to describing hazards resulting from accidental release of significant quantities of radioactive materials to the atmosphere. Such studies are also important in evaluating consequences of releasing other pollutants routinely or accidentally to the atmosphere in connection with conventional power generation, fuel storage, shipment, and processing. In all such cases, an understanding of the processes in the atmosphere which transport, diffuse and deposit pollutants in order to estimate the dose that a given distribution of population will receive and the amount of material left on the surface which would enter into ecological processes of concern or be resuspended into the atmosphere at some later time where it could once more become a direct exposure hazard, is necessary.

The distance and time scale over which the processes of contaminant transport, diffusion, deposition and resuspension must be considered is very important. The nature and relative importance of these processes can change when considering the impact of pollutant releases over various distance and time scales. For example, models for atmospheric dispersion currently in general use are primarily empirical and based on data collected over short distances from near surface releases. These have been extrapolated to distances where larger scale motions are significant to the diffusion and extrapolated to heights where entirely different turbulence structure controls the diffusion than that present in the experiments from which models were developed. In addition, the experimental data on which most models have been based contain the effects of deposition in varying degrees, but the models fail to separate those effects from the turbulent diffusion in producing a given concentration and diffusion is generally assumed to be solely responsible for the resultant concentration.

The ongoing dispersion research and associated turbulence and deposition studies are aimed at independently accounting for the turbulent diffusion and the turbulent transfer and deposition of pollutants on the surface which jointly causes the reduction in plume concentration. The diffusion is being related to theoretical considerations of its dependence on turbulence structure and to models of turbulence under development from experimental programs, rather than depending on strict empiricism. Evaluations of deposition in field experiments together with laboratory and theoretical studies are leading to models of deposition describing dependence on turbulence, particle characteristics, and surface conditions. Ultimately, the model will be applicable for 
areas having various surface roughness characteristics (from mountainous terrain to sea surface), for conditions of various atmospheric stability, for various heights of release, and for a variety of pollutant types (including particulates which deposit in varying degrees depending on particle size, reactive gases which deposit readily, and noble gases which should not deposit appreciably at al1).

The dispersion of short term releases such as puffs is also under investigation. Present models do not adequately account for wind shear which elongates and dilutes the cloud to varying extents, depending on the stability, the distance from the source, and the depth of the layer through which the cloud has diffused. The dispersion of instantaneous and continuous releases in near calm conditions is an area where little information is available. Relationships of the dispersion to residual air motions has been difficult to establish until recent developments in sensitive anemometery have allowed detection of these motions.

The study of the instantaneous variations in continuous plume characteristics is another important research area being pursued. Until the development and application of the continuously monitoring $\mathrm{Kr}-85$ tracer system, information on plume behavior dealt almost exclusively with average characteristics. Now short term variations peak-to-mean ratios are being described which have already found application to problems where instantaneous aspects must be known, such as washout of gases in diffusing plumes where nonlinear reactions preclude the use of an average plume description.

Precipitation scavenging research is also progressing vigorously. In the past, much emphasis was placed on the below-cloud "washout" of contaminants. This year some in-cloud "rainout" experiments are reported. These results represent the first successful in-cloud scavenging experiments performed in frontal storms; the few other successful in-cloud experiments performed under other AEC contracts and in other countries, were performed in convective storms. The results of these experiments are immediately and directly applicable to evaluating the fate of any pollutant dispersed within precipitating storms.

Many other important scavenging results are described in this report: continued monitoring and explorations of natural and anthropogenic radioactivity has revealed several new phenomena; significant progress has been made toward characterizing background and radioactive aerosols; new levels of understanding have been reached in the study of the washout of both aerosols and gases; new instrumentation and techniques have been developed. However, rather than elaborating on these here, the reader is referred to the specific reports that follow. 


\section{CONTENTS}

Precipitation Scavenging of Tracers Released into Frontal Storms D. G. Atkinson, W. E. Davis, L. F. Radke, B. C. Scott,

W. G. N. Slinn, T. M. Tanner, J. M. Thorp, N. A. Wogman and

J. A. Young .

Computer Results for an In-Cloud Release of Indium on 11 March 1971 W. E. Davis.

Raindrop Trajectories Through Wind Shear - W. G. N. Slinn and T. J. Bander.

Initiation of the Ice Phase in a Seeded Cloud - A. J. Alkezweeny. . . 22

An Analysis of Diffusion in Wind Shear - W. G. N. S1inn . . . . . 25

Natural Precipitation Washout of Sulfur Dioxide - M. T. Dana,

J. M. Hales and M. A. Wolf . . . . . . . . . . 30

Precipitation Washout of Gaseous Tritium Compounds - J. M. Hales. . . 33

Washout of Rhodamine Dye Particles - M. Terry Dana . . . . . . 36

Aerosol Particle Size Distributions in the Northwest -

On the Dry Deposition of Sea Salt Nuclei - W. G. N. Slinn . . . . 51

Cloud Condensation Nuclei and Visible Pollution in Los Angeles -

A. J. Alkezweeny and T. J. Lockhart. . . . . . . . . . . . 56

Fluctuations in Trace Gas Concentrations in the Troposphere -

A. G. Gibbs and W. G. N. Slinn. . . . . . . . . . . 61

Prognostic Isentropic Trajectories - W. E. Davis, J. L. Heffter . . . 65

Hourly Low-Level Isentropic Trajectories - W. E. Davis . . . . . 66

Climatological Measurements on the Arid Lands Ecology

Reserve in 1971 - J. M. Thorp and W. T. Hinds . . . . . . . 70

Kinematically Possible Flows Exterior to Jets and Plumes -

Airborne Release of Plutonium and Its Compounds During

Overheating Incidents - J. Mishima and L. C. Schwendiman. .. . . . 82

Characterization of Radioactive Particles in a Plutonium

Processing Plant Exhaust System - J. Mishima and L. C. Schwendiman . . 88

Aircraft Instrumentation for Atmospheric Research - Staff . . . . 91

Techniques Used to Stabilize Tracer Solutions for Aerosol

Generation - C. W. Thomas . . . . . . . . . . . . . . . .

An Inexpensive Infusion Sampler for Atmospheric Tracer Studies -

J. M. Hales and D. W. Glover. . . . . . . . . . . . . . . . .

Analytical Procedures for Measurement of ${ }^{214} \mathrm{~Pb}$ and ${ }^{214} \mathrm{Bi}$ in

Rainwater - C. W. Thomas, J. A. Young, and N. A. Wogman. . . . .103 
Fallout Rates and Mechanisms - R. W. Perkins . . . . . . . $\quad .104$

A Comparison of Measured and Predicted Exposures from Elevated Sources - R. K. Woodruff and C. E. Elderkin.

Comparison of Maximum Exposures at Ground Level Resulting from Simultaneous Release of Tracers from Two Elevations -

A ${ }^{85} \mathrm{Kr}$ Field Monitoring System and Its Application to Maximum Air Dose Measurements of a Radioactive Gas - J. D. Ludwick and 
Turbulence Measurements on the Bonneville Salt Flats -

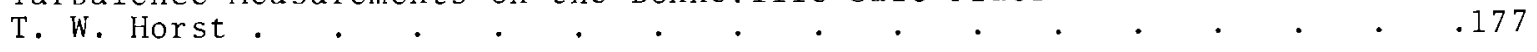

Turbulence Measurement and Analysis Capabilities - C. E. Elderkin,

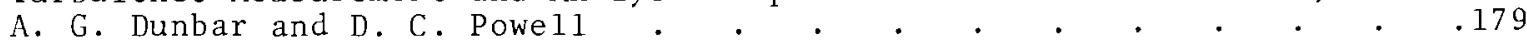

\begin{tabular}{l} 
A Computer Algorithm for Correcting Noncosine Response in the \\
Gill Anemometer \\
\hline
\end{tabular}

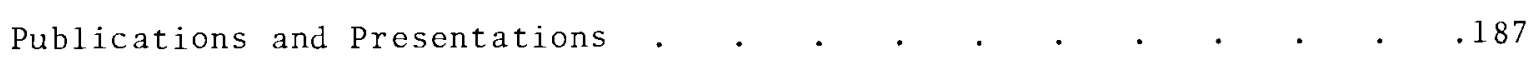


$-$

$\therefore$

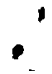

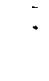




\title{
PRECIPITATION SCAVENGING OF TRACERS RELEASED INTO FRONTAL STORMS*
}

\section{G. Atkinson, ${ }^{*}$ W. E. Davis, L. F. Radke,** B. C. Scott, W. G. N. Slinn,} T. M. Tanner, J. M. Thorp, N. A. Wogman and J. A. Young

\begin{abstract}
Two field projects were undertaken to evaluate the feasibizity of in-cloud precipitation scavenging experiments in frontal storms and to compare the rainout rates for aerosol tracers of different physical and chemical properties. The field system included PPI and RHI radar coverage, hourly radiosondes, airborne cloud physics measurements, and a sampling grid of approximately 100 collectors. The first experiment (tracers released at $21.5 \mathrm{~km})$ resulted in a well defined deposition pattern for indium (released via pyrotechnic flares) but apparentiy the chemical analysis for lithium (lithium stearate dispensed mechanically) was insufficiently sensitive. The second experiment (AgI and In released simultaneously via pyrotechnic flares at $\sim_{1} \mathrm{~km}$ ) resulted in identifiable indium and silver deposition patterns. These patterns suggest a substantially larger in-cloud removal rate for the ice nuclei than for the indium aerosol which was determined to be essentially inactive as an ice nucleus at temperatures above $-22^{\circ} \mathrm{C}$. Further experiments are in progress.
\end{abstract}

\section{INTRODUCTION}

Precipitation scavenging is probably the dominant method by which the atmosphere rids itself of particulate pollution. For reviews, see Junge, (1) and the proceedings of two recent conferences: Atmospheric Scavenging of Radioisotopes (1968)( $(2)$ and Precipitation Scavenging (1970). (3) Research in precipitation scavenging is directed toward measuring and understanding the rates at

* To be submitted for publication in the Journal of Applied Meteorology.

* Cloud Physics Group, University of washington, Seattie. which precipitation of various types removes the many different forms of atmospheric contaminants, and although considerable progress toward meeting these objectives has been made for processes which occur beneath clouds, there still remains much experimental and theoretical work to be done on the in-cloud problem. As far as we know, there are only three reports of successful in-cloud scavenging experiments: Dingle, et al.,(4) Shopauskas, et al. (5) and Burtsev, et al. (6) other experiments are in progress (Dingle, Semonin, et a 1. , and Summers). $(7,8,9)$ However, all the above experiments were performed in convective storms. The purpose of this note is to report on in-cloud scavenging experiments recently performed in frontal storms. 
The primary objective of these experiments was to determine if they were feasible. They are conceptually simple (though logistically complicated) but we were unsure of the appropriate time/distance scales. Some confidence was gained from the successful experiments of Dingle, et al., but it was clear that not much reliance could be placed on a juxtaposition of their time scale, since the processes in frontal storms are significantly different from those in convective storms. We were especially concerned about targeting the tracer material and as a result chose a sampling grid which spanned approximately an order of magnitude larger than the $8 \mathrm{~km}$ used by Dingle, et al. A second major objective was to compare the scavenging efficiencies for aerosol tracers of different physical and chemical properties.

The experiments were performed on the Olympic Peninsula of Washington, Figure 1. RHI and PPI radar coverage of the area was provided by the 758 U.S. Air Force Radar Squadron at Neah Bay, on the northwestern tip of the peninsula. Hourly soundings were provided by National Weather Service personnel at Quillayute. Tracer aerosols were released from a $B-23$ aircraft which has been equipped for cloud physics research by members of the Cloud Physics Group of the University of Washington. Figure 2 shows the locations along various roads of the approximately 100 samplers, each of which was a polyethylene bag supported by a $17 \mathrm{~cm}$ diameter carton. The samples were frozen about two hours after the tracer releases were made. Chemical analysis was by neutron activation; samples and standards were irradiated with a flux of approximately $8 \times 10^{12}$ neutrons $\mathrm{cm}^{-2}$ $\mathrm{sec}^{-1}$, using the facilities of Washington state University.

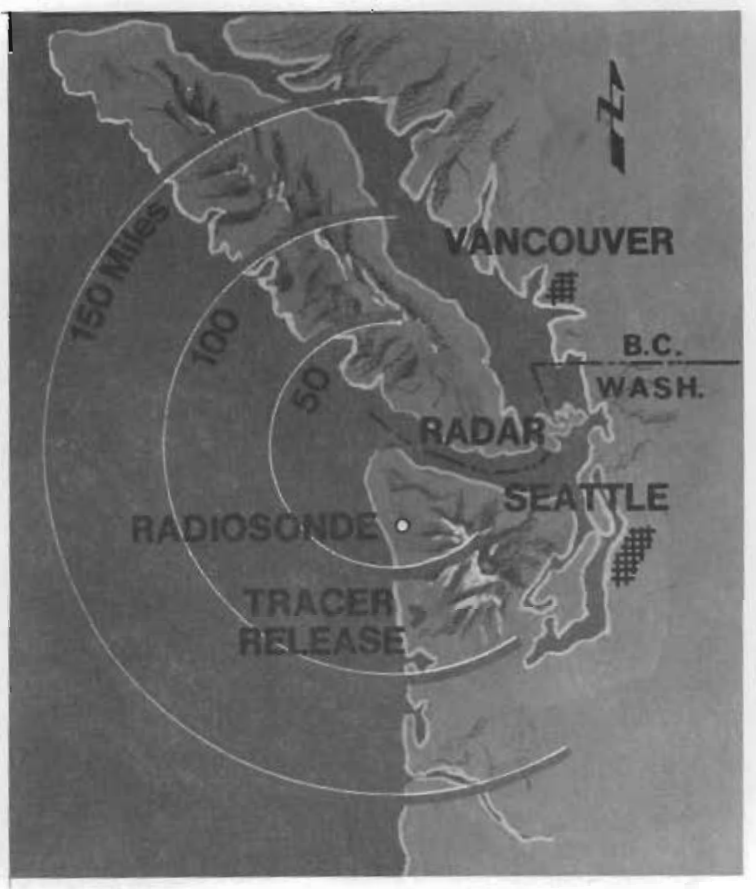

Neg 720024-9

FIGURE 1. Schematic of the Olympic Peninsula Field Site showing the Location of the Radar Site, Radiosonde Station and General Area of Tracer Releases. Distances shown are in statute miles.

\section{3/11/71 Experiment}

The first experiment was performed on 11 March 1971. It was decided to release the tracers at a low elevation (within the clouds) in the hope of improving the chances to detect the tracers in the samplers. $450 \mathrm{gms}$ of indium were released by burning 10 


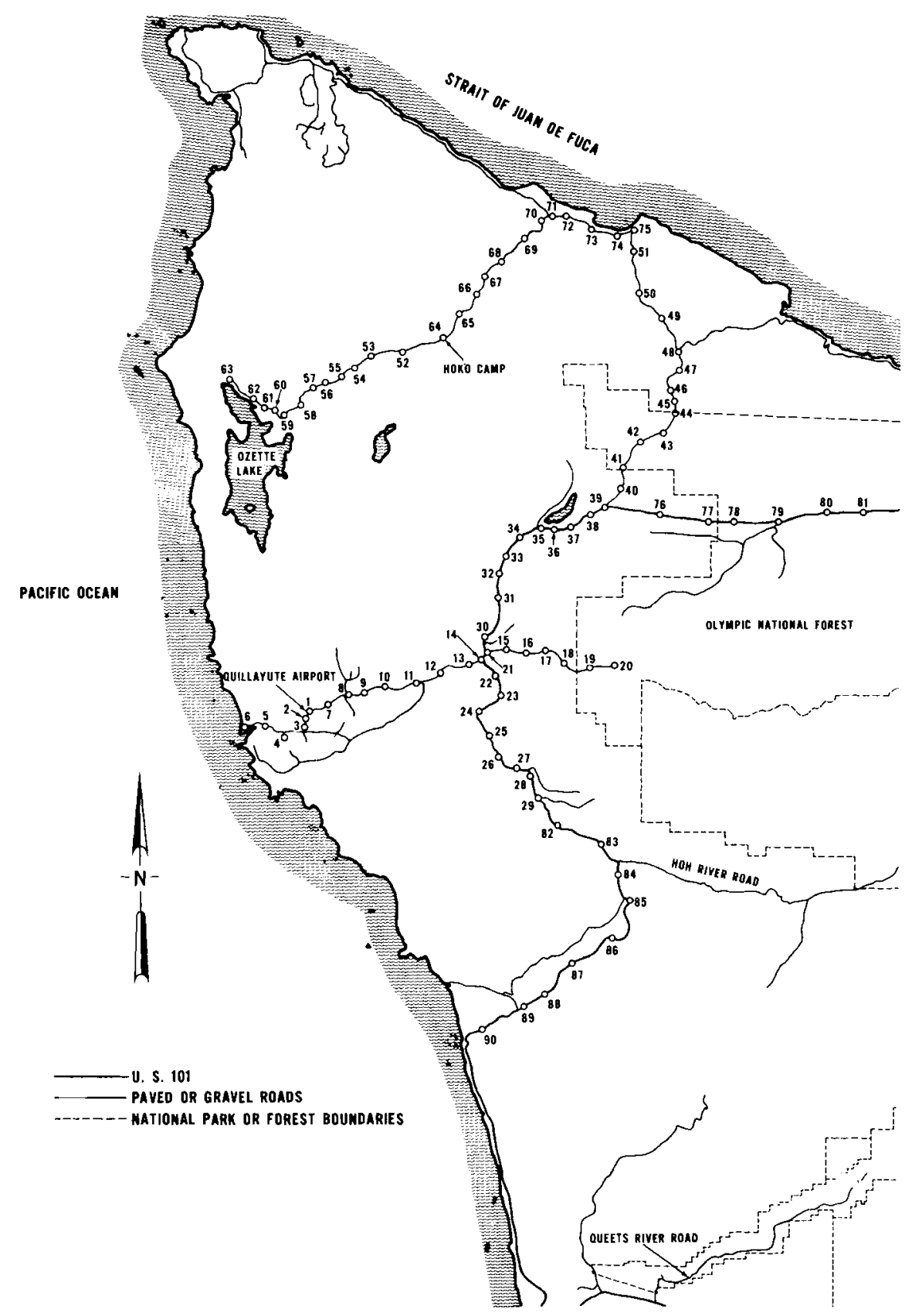

Neg 714925-1

FIGURE 2. Location of Samplers on Various Roads Throughout the olympic Peninsula 
pyrotechnic flares from 1157 to 1204 PST. In addition, approximately 1 $\mathrm{kgm}$ of lithium stearate was dispensed mechanically from 1208 to 1217 PST. Since the indium aerosol (mean particle size based on number distribution probably in the range 0.01 to $0.1 \mathrm{\mu m}$ ) is expected to be in the form of wettable $\mathrm{I}_{2} \mathrm{O}_{3}$, and since the lithium stearate $(\sim 10 \mu \mathrm{m})$ particles are non- wettable, it was hoped that a significant difference in scavenging rates would be observed.

A satelitite photo, Figure 3, taken approximately at the time of the tracer release ( 1200 PST) shows almost a textbook example of a frontal storm, with a well developed cloud shield. The front passed the olympic Peninsula approximately 4 hours after the

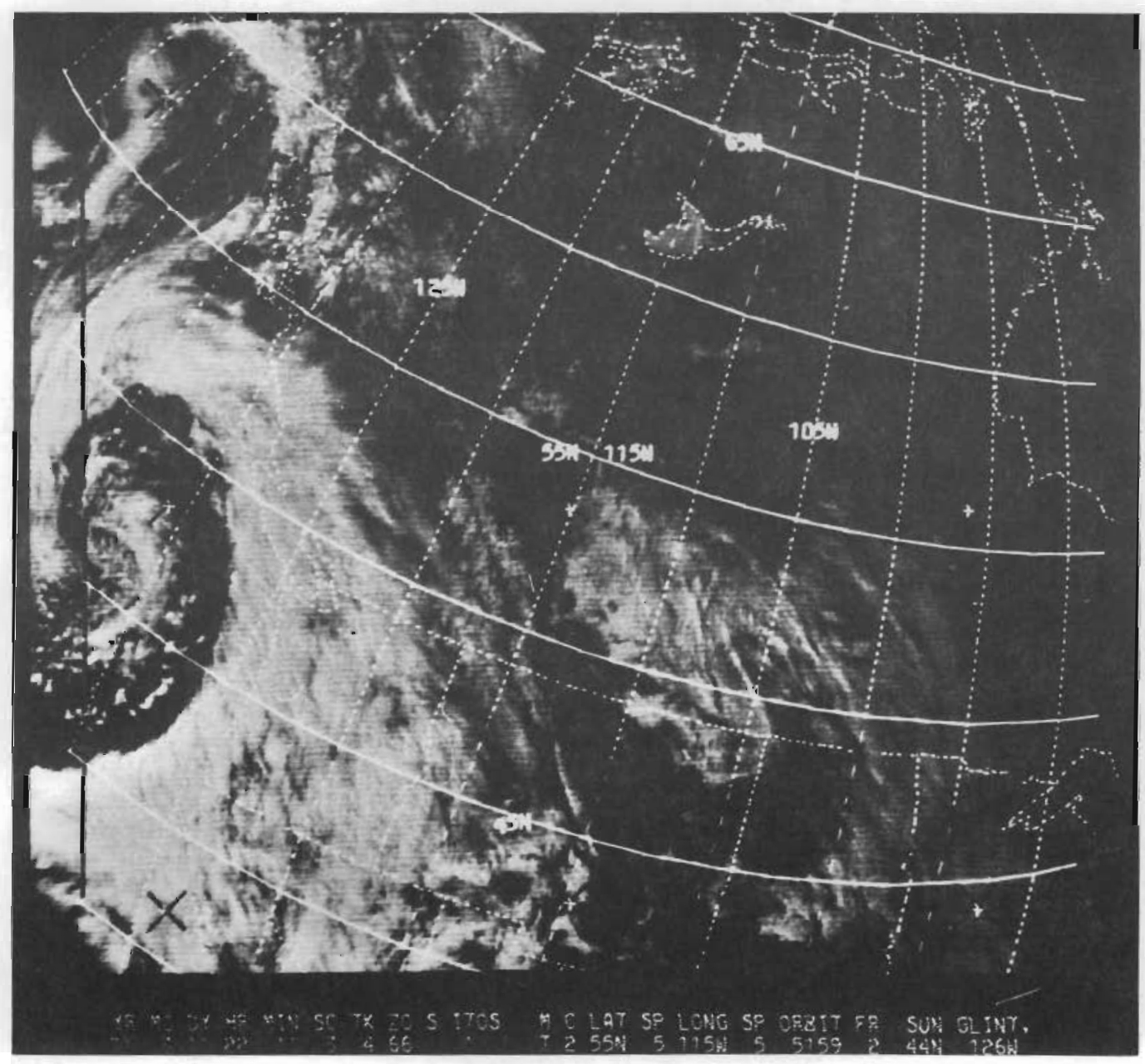

Neg $721674-2$

FIGURE 3. Satellite Photo of 11 March 1971 storm, Taken Approximately at the Time of the Tracer Release 
tracer release. The RHI radar echo displayed a typical banded structure (cf. later figures) with echo tops at approximately $10,000 \mathrm{ft}$.

On the left hand side of Figure 4 are shown the temperature profiles as measured by radiosondes released from Quillayute at 852 and 1135 PST. The stable layer from approximately 900 to $750 \mathrm{mb}$ was also observed after the time of the tracer release and transport. On the right hand side of Figure 4 is plotted the humidity measured by the 1135 sonde. The high wind speeds and large directional shear of the wind should be noted.

In Table 1 is given a description of the cloud particles which were replicated on Formvar as the aircraft spiraled down to the release elevation of approximately 5,000 ft. Figures 5 and 6 summarize the information for the relative cloud particle concentrations during the times of the tracer releases. An evaluation of the collection efficiency of the instrument has not been included in this data analysis. Typical values for the average 1 iquid water content were about $0.2 \mathrm{~g} \mathrm{~m}^{-3}$.

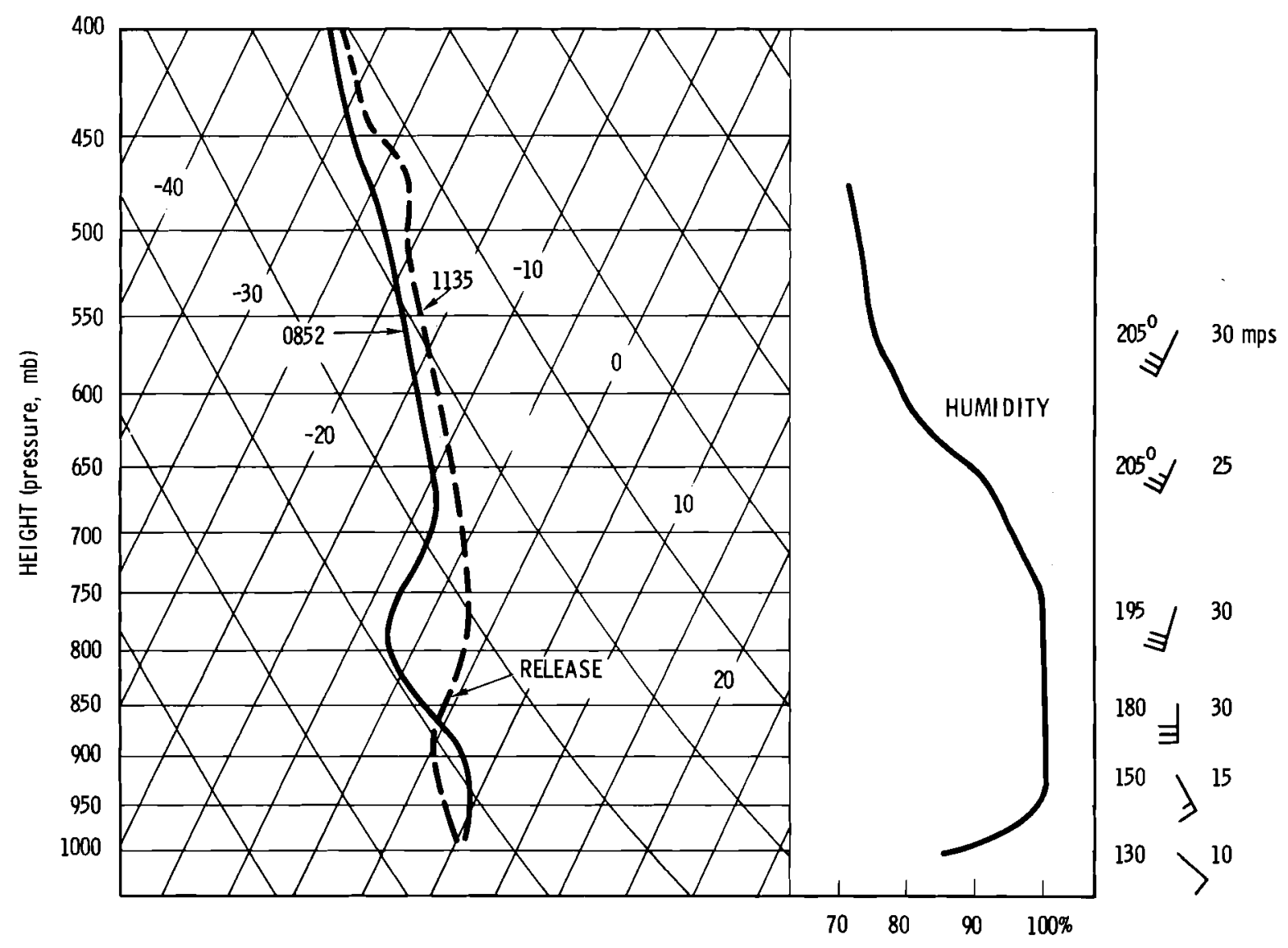

Neg 721419-12

FIGURE 4. Sounding Taken at 1135 PST 11 March 1971 at Quillayute, Washington 


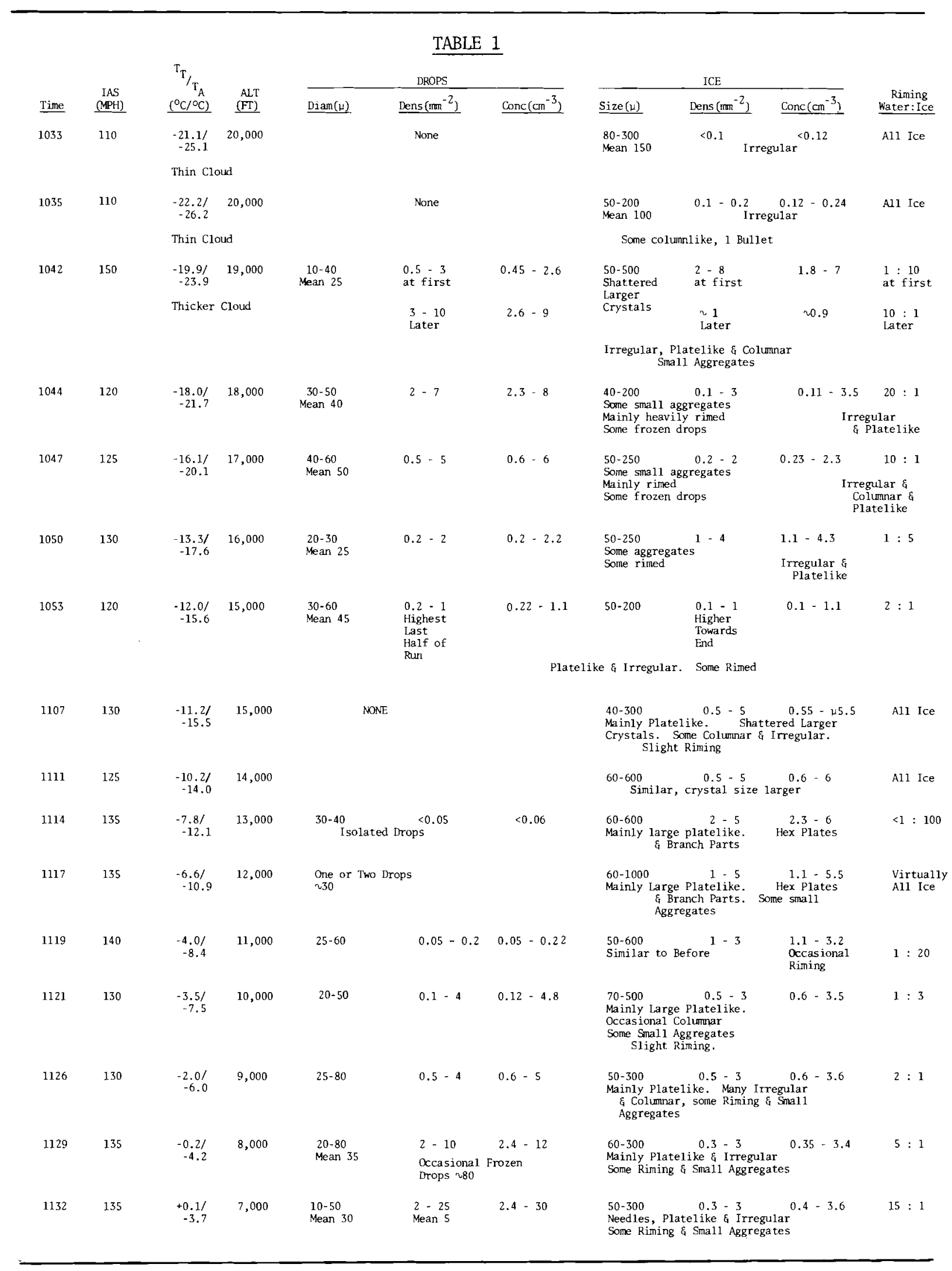




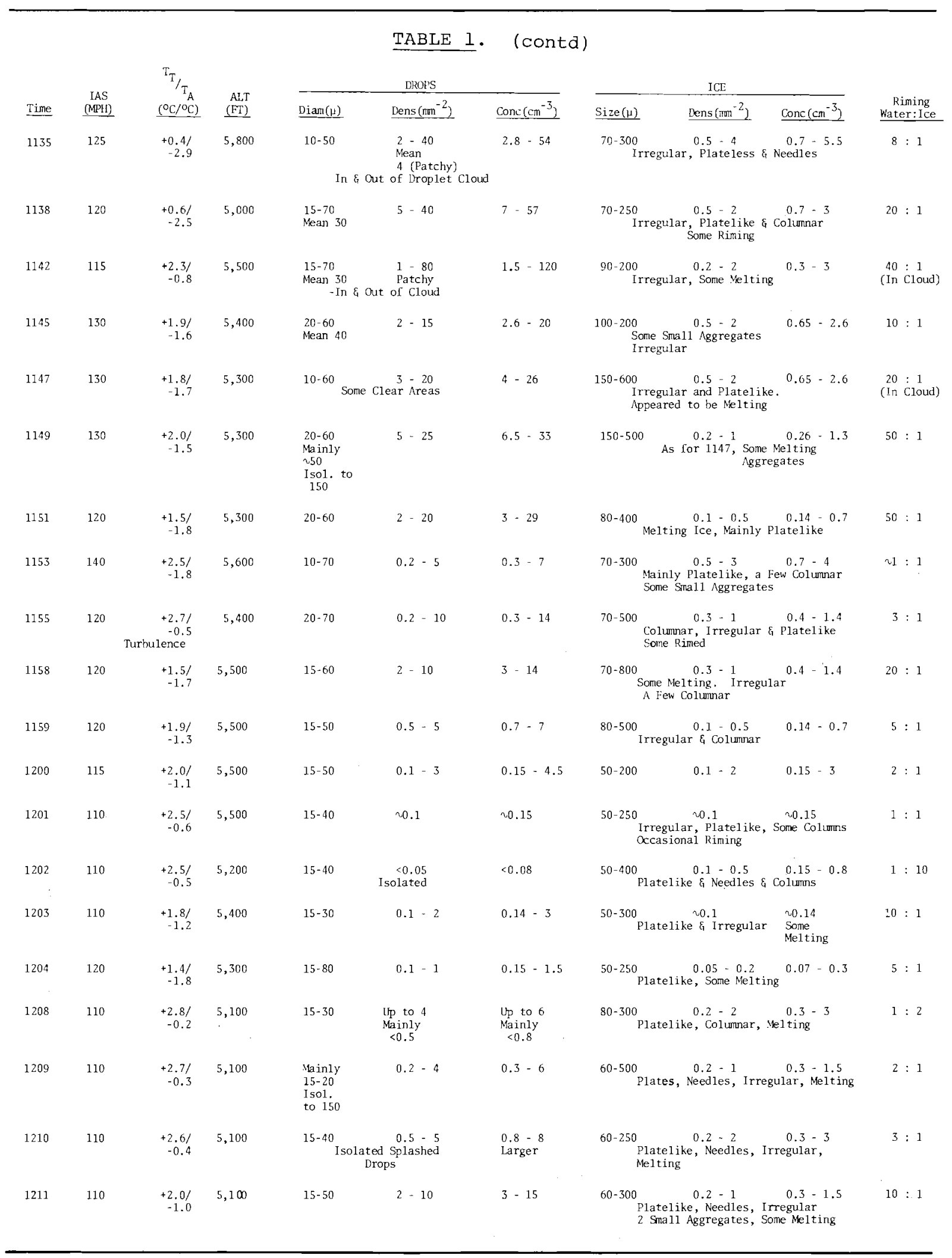




\begin{tabular}{|c|c|c|c|c|c|c|c|c|}
\hline \multirow[b]{3}{*}{ Time } & \multirow[b]{3}{*}{$\begin{array}{c}\text { IAS } \\
\text { (MPH) } \\
\end{array}$} & \multirow{3}{*}{$\begin{array}{l}\mathrm{T}_{\mathrm{T} / \mathrm{T}_{\mathrm{A}}} \\
\left({ }^{\circ} \mathrm{C} /{ }^{\circ} \mathrm{C}\right) \\
\end{array}$} & \multirow[b]{3}{*}{$\begin{array}{r}\mathrm{ALT} \\
(\mathrm{FT}) \\
\end{array}$} & \multirow{2}{*}{\multicolumn{3}{|c|}{$\frac{\text { TABLE } 1}{\text { DROPS }}$}} & \multirow{2}{*}{ ICE } & \multirow[b]{3}{*}{$\begin{array}{r}\begin{array}{r}\text { Riming } \\
\text { Water: Ice }\end{array} \\
\end{array}$} \\
\hline & & & & & & & & \\
\hline & & & & $\underline{\operatorname{Dian}(\mu)}$ & Dens $\left(\operatorname{man}^{-2}\right)$ & $\operatorname{Conc}\left(\mathrm{cm}^{-3}\right)$ & Dens $\left(\operatorname{man}^{-2}\right) \quad$ Conc $\left(\mathrm{cm}^{-3}\right)$ & \\
\hline 1212 & 110 & $\begin{array}{r}+1.6 / \\
-1.4\end{array}$ & 5,200 & $\begin{array}{l}20-70 \\
\text { One } 200\end{array}$ & $2-12$ & $3-18$ & $\begin{array}{l}60-500 \\
\text { Plates, columrs, Needles, Irregular }\end{array}$ & $5: 1$ \\
\hline \multirow[t]{2}{*}{1213} & & $\begin{array}{r}+1.7 / \\
-1.5\end{array}$ & 5,100 & $\begin{array}{l}20-80 \\
\text { Isol. }\end{array}$ & $\begin{array}{r}5-15 \\
\text { to } 150\end{array}$ & $7 \cdot 21$ & $60-400$ As Above $0.3-3$ & $10: 1$ \\
\hline & Turbulance & & & \multicolumn{4}{|c|}{$\begin{array}{l}\text { As Above } \\
\text { Concentrations Lower last Part of Pun }\end{array}$} & \\
\hline 1215 & 110 & $\begin{array}{r}+1.5 / \\
-1.5\end{array}$ & 5,000 & I5ol & 1. to $200-15$ & $3.3-25$ & 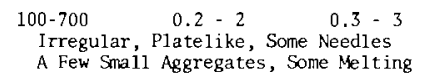 & $15: 1$ \\
\hline 1217 & 125 & $\begin{array}{r}+1.8 / \\
-1.6\end{array}$ & 5,300 & $20-60$ & $1-10$ & $1.4-14$ & 50-700 As Above ${ }^{0.5-3} \quad \begin{array}{c}0.7-4 \\
\text { Some Me1ting }\end{array}$ & $5: 1$ \\
\hline 1222 & 130 & $\begin{array}{r}+1.9 / \\
-1.6\end{array}$ & 5,700 & $20-80$ & $\begin{array}{l}2-20 \\
\text { Some to } 200 . \text { Splashed } \\
\text { Raindrops }\end{array}$ & $2.6-26$ & 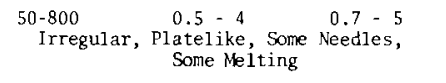 & $10: 1$ \\
\hline 1225 & 128 & $\begin{array}{r}+0.5 / \\
-3.1\end{array}$ & 7,500 & 20-80 & 1. to 150 & $1.3-10$ & $\begin{array}{c}\text { 100-1000 } \\
\text { Needles Mainly } \\
\begin{array}{c}\text { \& Platelike. } \\
\text { Some Irregular }\end{array}\end{array}$ & $2: 1$ \\
\hline 1228 & 120 & $\begin{array}{r}-1.5 / \\
-4.6\end{array}$ & 8,500 & $20-70$ & $0.5-5$ & $0.7-7$ & $\begin{array}{c}\text { 50-700 } \\
\text { Platelike, Sone Columnar }\end{array}$ & $2: 1$ \\
\hline 1231 & 140 & $\begin{array}{r}-3.1 / \\
-7.5\end{array}$ & 9,900 & $20-50$ & $\begin{array}{l}\text { Up to } 10 \\
\text { Mainly } 22\end{array}$ & $\begin{array}{l}\text { Up to } 12 \\
\text { Mainly } 2.4\end{array}$ & $\begin{array}{l}50-600 \quad 2-5 \\
\text { Some Large Hex Plates, and Branch } \\
\text { Arms, Shattered Platelike. Sone } \\
\text { Smali Aggregates }\end{array}$ & $1: 2$ \\
\hline 1234 & 130 & $\begin{array}{r}-3.0 / \\
-7.0\end{array}$ & 9,800 & $20-50$ & $0.5-2$ & $0.6-2.5$ & $\begin{array}{l}50-500 \\
\text { As Above. A Few Columar }\end{array}$ & $1: 5$ \\
\hline
\end{tabular}

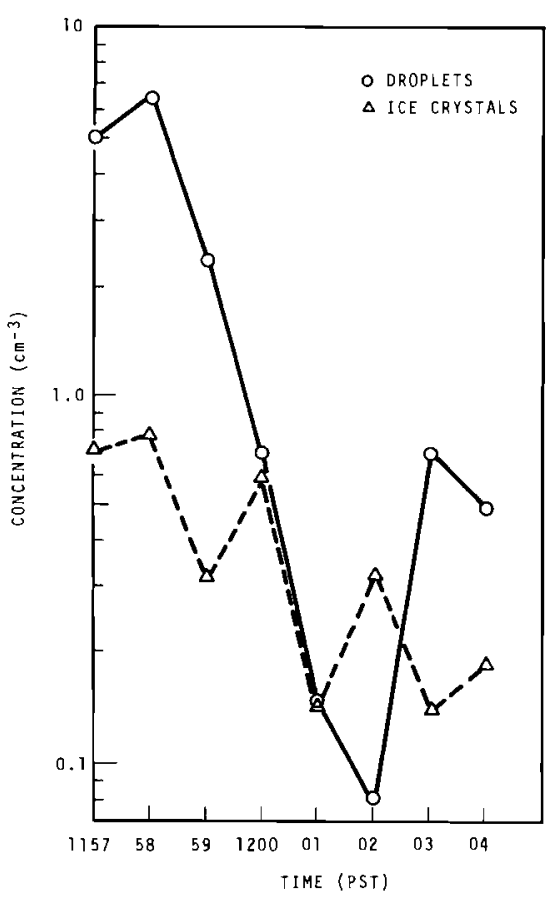

Neg 721308-4

FIGURE 5. Relative Cloud Droplet and Ice Crystal Concentrations During the Burn of the Indium Flares. To determine the concentrations, averages were taken over 15 second intervals, but an evaluation of the collection efficiency of the instrument has not been included.

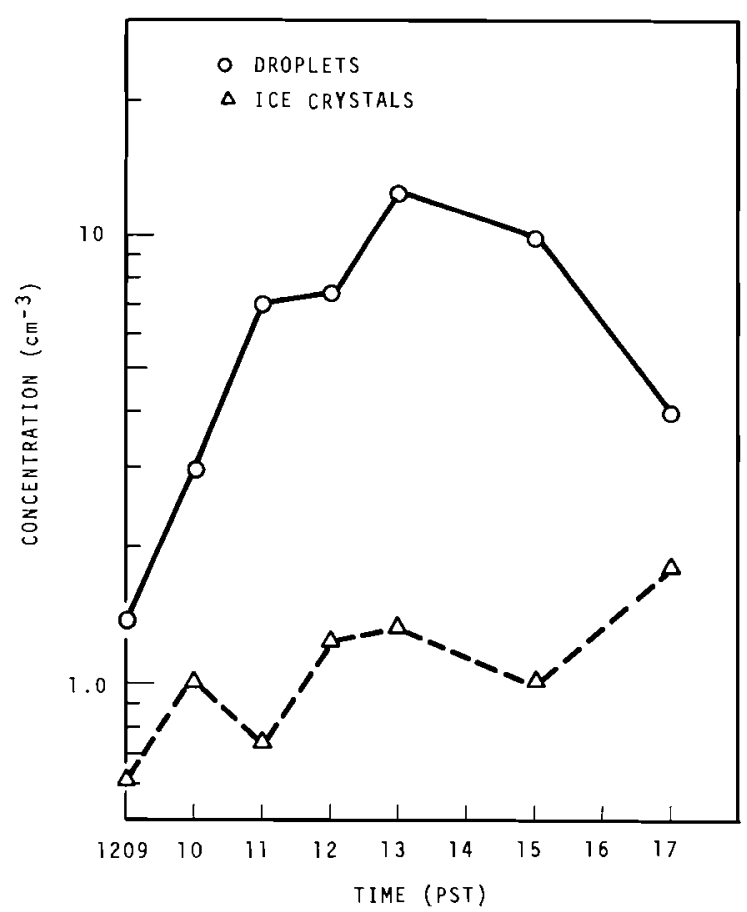

Neg 721308-1

FIGURE 6. Relative Cloud Droplet and Ice Crystal Concentrations During the Release of Lithium Stearate 
Figure 7 shows the indium deposition pattern for the $3 / 11 / 71$ experiment. The complete data for both experiments is given in Table 2 . Background concentrations of indium are typically of the order of $1 \mathrm{ng}$ $e^{-1}$, which is one to two orders of magnitude smaller than maximum recorded values. Because of the 1ogistics of deploying and retrieving the samplers, useful values of the concentration of indium in the precipitation are not available. The total water collected in each sampler was of the order of $100 \mathrm{~cm}^{3}$. Thus typical indium concentrations in the samplers were about 0.I ppb. Samples 15 through 38 and four reagent blanks were analyzed for lithium by atomic absorption spectroscopy. The concentrations were all below the detection limit of about $10 \mathrm{ppb}$.

\section{4/16/71 Experiment}

- A second in-cloud scavenging experiment was performed on 16 April 1971, during which $450 \mathrm{~g}$ of indium and about $500 \mathrm{~g}$ of $\mathrm{AgI}$ were burned between 1320 and 1327 PST. Since it was found that the indium aerosol was inactive as an ice nucleus down to $-22^{\circ} \mathrm{C}$, it was hoped that the experiment would indicate differences in scavenging rates for aerosol particles that could have different interactions with the cloud particles. The release elevation was chosen to be about at the $-15^{\circ} \mathrm{C}$ level, at which temperature AgI acts as an efficient ice nucleus.

The temperature and dewpoint from the 1310 sounding are shown in Figure 8 . Winds were lighter than on

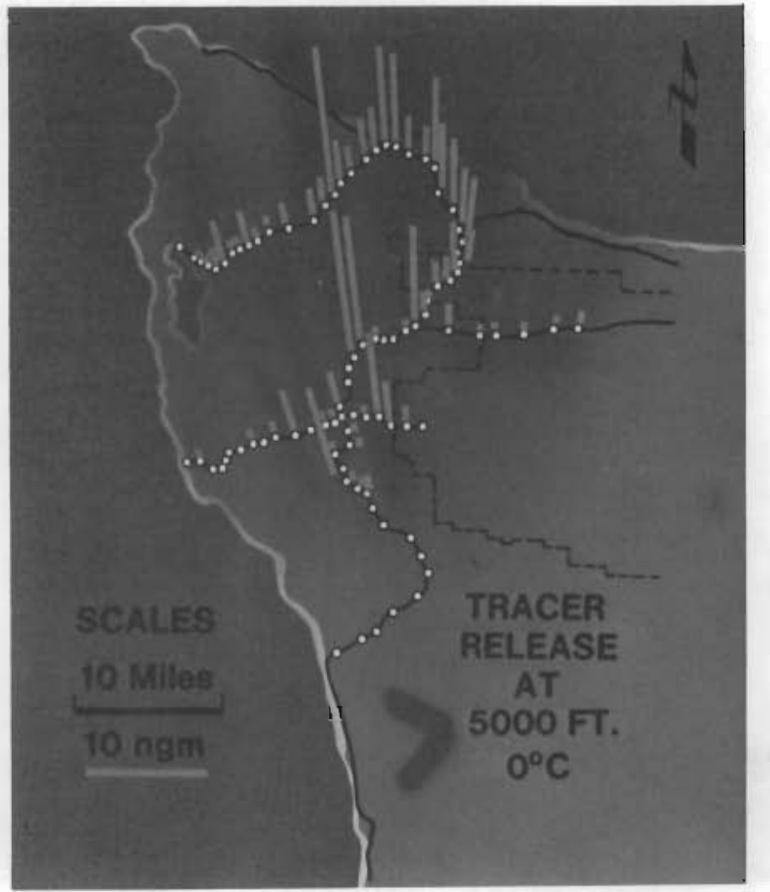

Neg 720024-6

FIGURE 7. Indium Deposition Pattern for the ll March 1971 Experiment. The length of the solid line at each sampler indicates the total amount of indium collected at each site.

$3 / 11$ and the lapse rate near the release height was close to the wet adiabatic.

A portion of the PPI echo for 1245 PST is shown in Figure 9. A portion of the $170^{\circ}$ RHI echo for 1329 PST is shown in Figure 10. The specific cell within the frontal storm, into which the tracers were released, is indicated by the vertical cross hair. The distorted echoes at 1350 and 1406 PST, shown in Figure 11 suggest that the AgI enhanced the growth of the cell. Figure 12 shows a convective cell growing out of the otherwise stratified cloud deck, as observed at about 1400 PST from the 


\begin{tabular}{|c|c|c|c|c|c|}
\hline \multirow[b]{2}{*}{$\begin{array}{l}\text { Sample } \\
\text { Number } \\
\end{array}$} & \multicolumn{2}{|c|}{$\begin{array}{c}\frac{\text { TABLE 2 }}{\text { for the } 11 \text { March and } 16} \\
3-11-71 \\
\end{array}$} & \multicolumn{3}{|c|}{$\begin{array}{l}\text { Tracer Detected in Each Sampler } \\
\text { April } 1971 \text { Experiments } \\
4-16-71 \\
\end{array}$} \\
\hline & $\begin{array}{l}\text { Weight } \\
\text { Water } \\
(\mathrm{g}) \\
\end{array}$ & $\begin{array}{l}10^{-9} \mathrm{~g} \\
\text { Indium }\end{array}$ & $\begin{array}{l}\text { We ight } \\
\text { Water } \\
(\mathrm{g}) \\
\end{array}$ & $\begin{array}{l}10^{-9} \mathrm{~g} \\
\text { Indium }\end{array}$ & $\begin{array}{l}10^{-9} \mathrm{~g} \\
\text { Silver }\end{array}$ \\
\hline 1 & 130 & 0.05 & 75.0 & N.D.* & $<1$ \\
\hline 2 & 82 & $<0.001$ & 64.0 & N.D. & $3 \pm 3$ \\
\hline 3 & 92 & 0.17 & 65.0 & $0.52 \pm 0.27$ & $<1$ \\
\hline 4 & 80 & 0.12 & 71.0 & $2.93 \pm 0.21$ & $<1$ \\
\hline 5 & 102 & 0.52 & 65.0 & $0.73 \pm 0.37$ & $<1$ \\
\hline 6 & 44 & 0.06 & 8.0 & N.D. & $30 \pm 10$ \\
\hline 7 & 155 & 0.10 & 48.0 & N.D. & $<1$ \\
\hline 8 & 153 & 0.77 & 52.5 & $0.55 \pm 0.28$ & $<1$ \\
\hline 9 & 173 & $<0.001$ & 50.0 & $22.52 \pm 0.45$ & $6 \pm 4$ \\
\hline 10 & 219 & 0.29 & 61.8 & $0.89 \pm 0.45$ & $<1$ \\
\hline 11 & 244 & 3.51 & 66.5 & N.D. & $<1$ \\
\hline 12 & 251 & $<0.003$ & 57.0 & N.D. & $<1$ \\
\hline 13 & 306 & 0.4 & 55.0 & N.D. & $4 \pm 3$ \\
\hline 14 & 272 & 0.87 & 53.0 & N.D. & $7 \pm 5$ \\
\hline 15 & 306 & 0.112 & -- & N.D. & $32 \pm 7$ \\
\hline 16 & 322 & 0.200 & 66.0 & N.D. & $<1$ \\
\hline 17 & 351 & 6.8 & 56.5 & $3.0 \pm 1.5$ & $<1$ \\
\hline 18 & 344 & 3.8 & 51.0 & N.D. & $<1$ \\
\hline 19 & 372 & 0.79 & 47.0 & N.D. & $<1$ \\
\hline 20 & Lost & Lost & 52.0 & N.D. & $<1$ \\
\hline 21 & 390 & 3.1 & 56.0 & $0.85 \pm 0.11$ & $<1$ \\
\hline 22 & 168 & 0.86 & 44.5 & N.D. & $<1$ \\
\hline 23 & 172 & 0.95 & 53.0 & N.D. & $<1$ \\
\hline 24 & 163 & 0.46 & 58.0 & N.D. & $<1$ \\
\hline 25 & 195 & 6.6 & 62.0 & N.D. & $<1$ \\
\hline 26 & 196 & 0.36 & 60.0 & $0.63 \pm 0.34$ & $5 \pm 3$ \\
\hline 27 & 223 & 0.84 & 58.0 & $0.81 \pm 0.09$ & $<\overline{1}$ \\
\hline 28 & 197 & 1.2 & 55.5 & N.D. & $<1$ \\
\hline 29 & 170 & $<0.02$ & 50.0 & $1.31 \pm 0.66$ & $<1$ \\
\hline 30 & 364 & 0.25 & 44.5 & $1.16 \pm 0.58$ & $<1$ \\
\hline 31 & 241 & 0.14 & 44.0 & $1.15 \pm 0.58$ & $<1$ \\
\hline 32 & 224 & $<0.002$ & 41.0 & N.D. & $<1$ \\
\hline 33 & 243 & 12.11 & 28.0 & N.D. & $<1$ \\
\hline 34 & 387 & 10.94 & 39.0 & N.D. & $20 \pm 10$ \\
\hline 35 & 276 & 0.57 & 34.0 & $1.28 \pm 0.64$ & $<1$ \\
\hline 36 & 283 & 0.13 & 37.0 & N. D. & $<1$ \\
\hline 37 & 215 & 0.13 & 35.0 & N.D. & $3 \pm 4$ \\
\hline 38 & 262 & 0.55 & 21.0 & N.D. & $<1$ \\
\hline 39 & 291 & 8.14 & 24.5 & $2.0 \pm 1.0$ & $<1$ \\
\hline 40 & 244 & 1.04 & 20.0 & N.D. & $<1$ \\
\hline 41 & 228 & 0.9 & 24.0 & N.D. & $<20 * *$ \\
\hline 42 & 242 & 1.55 & 25.0 & N.D. & $<20 * *$ \\
\hline 43 & 217 & 1.83 & 19.0 & N.D. & $<1$ \\
\hline 44 & 285 & 1.74 & 34.0 & $1.12 \pm 0.56$ & $<1$ \\
\hline 45 & 299 & 1.86 & 39.0 & N.D. & $<1$ \\
\hline
\end{tabular}




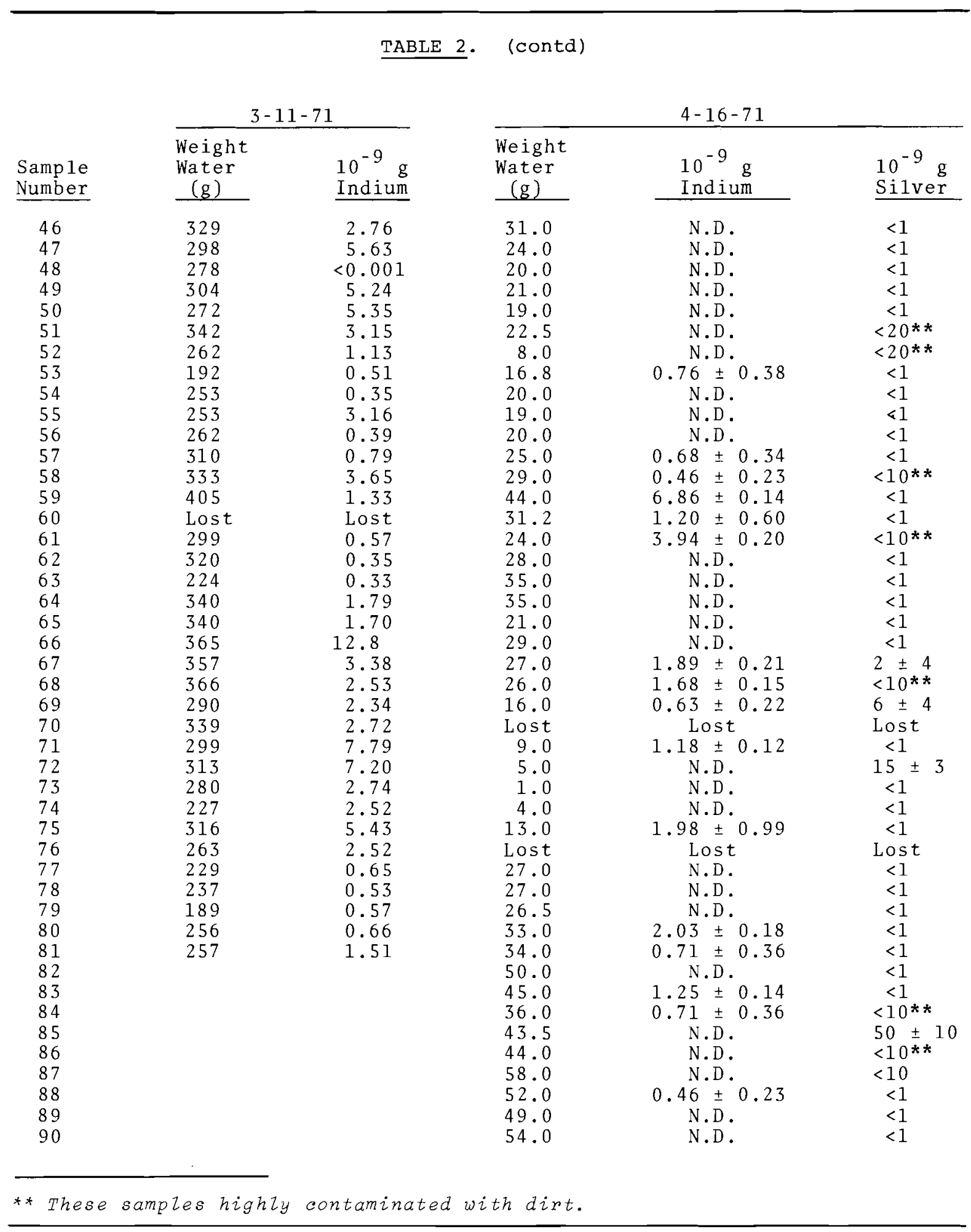




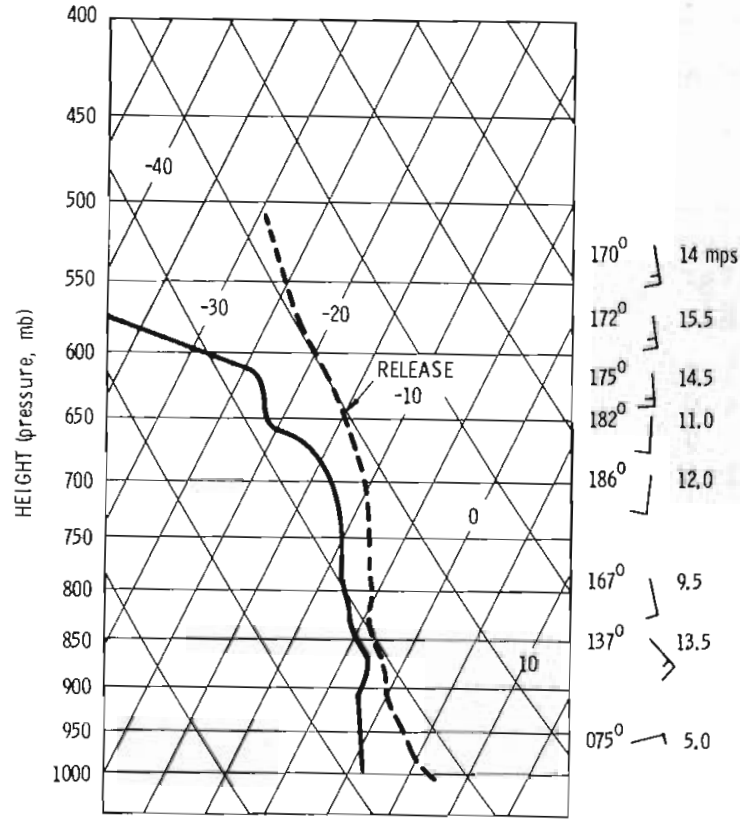

Neg $721419-8$

FIGURE 8. Sounding Taken at 1310 PST 4 April 1971 at Quillayute, Washington

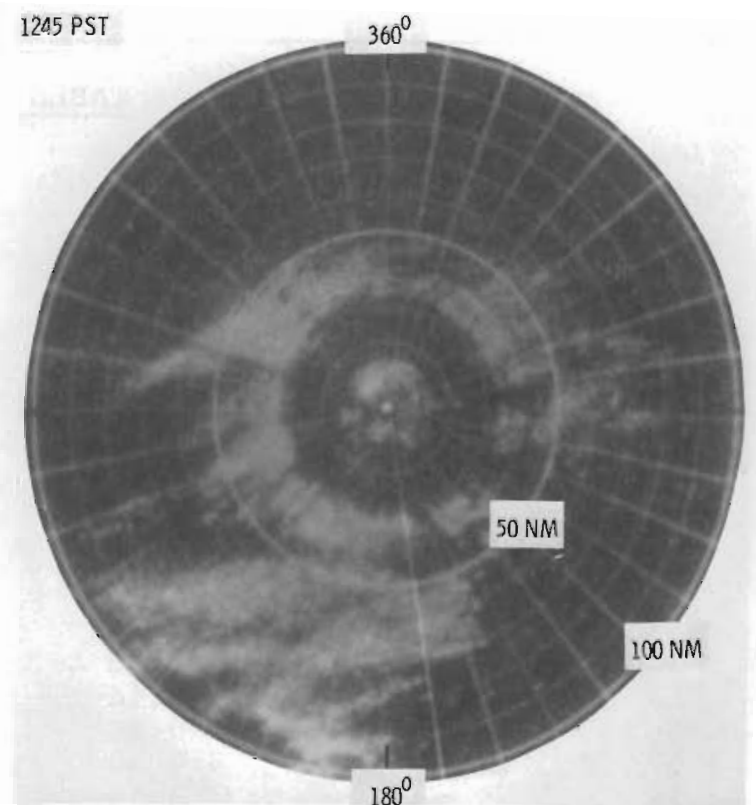

Neg 721849-1

FIGURE 9. A Portion of the PPI Probe of the 4 April 1971 storm, Taken at 2045 PST

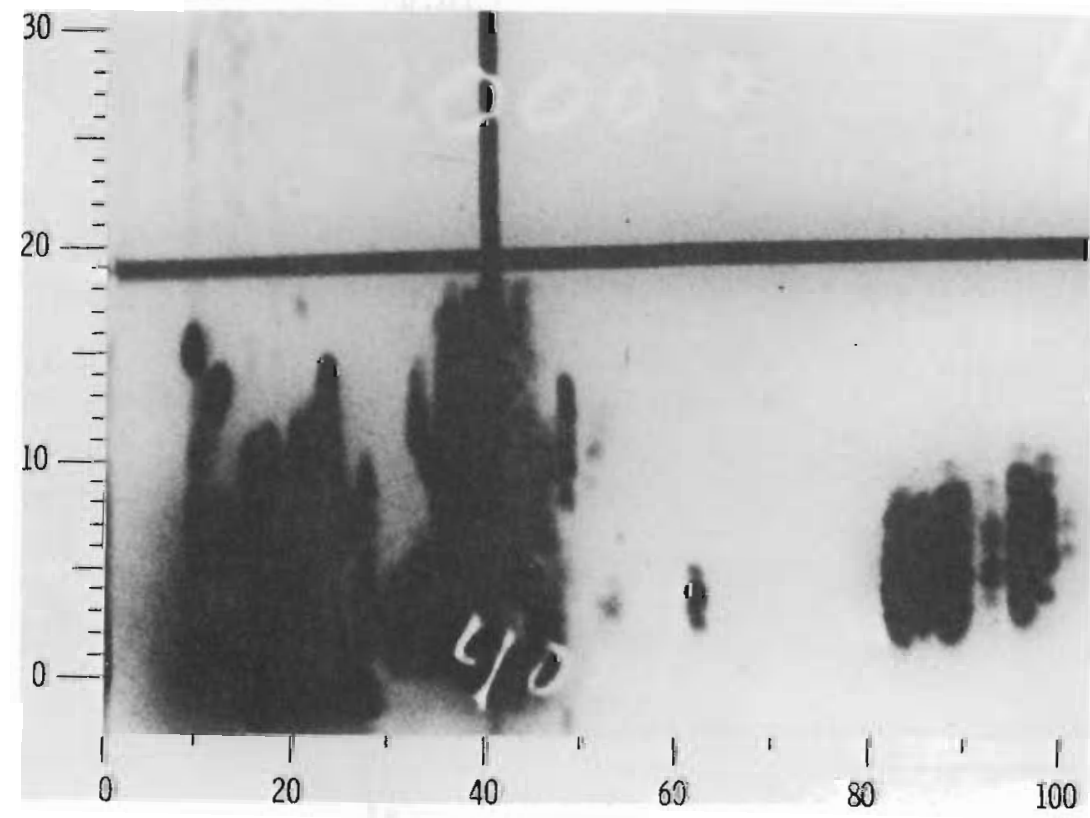

Neg 721193-3

FIGURE 10. A Portion of the $170^{\circ}$ RHI Probe Taken at 1329 PST 4 April 1971. The cell into which the tracers were released is indicated by the vertical cross hair. 

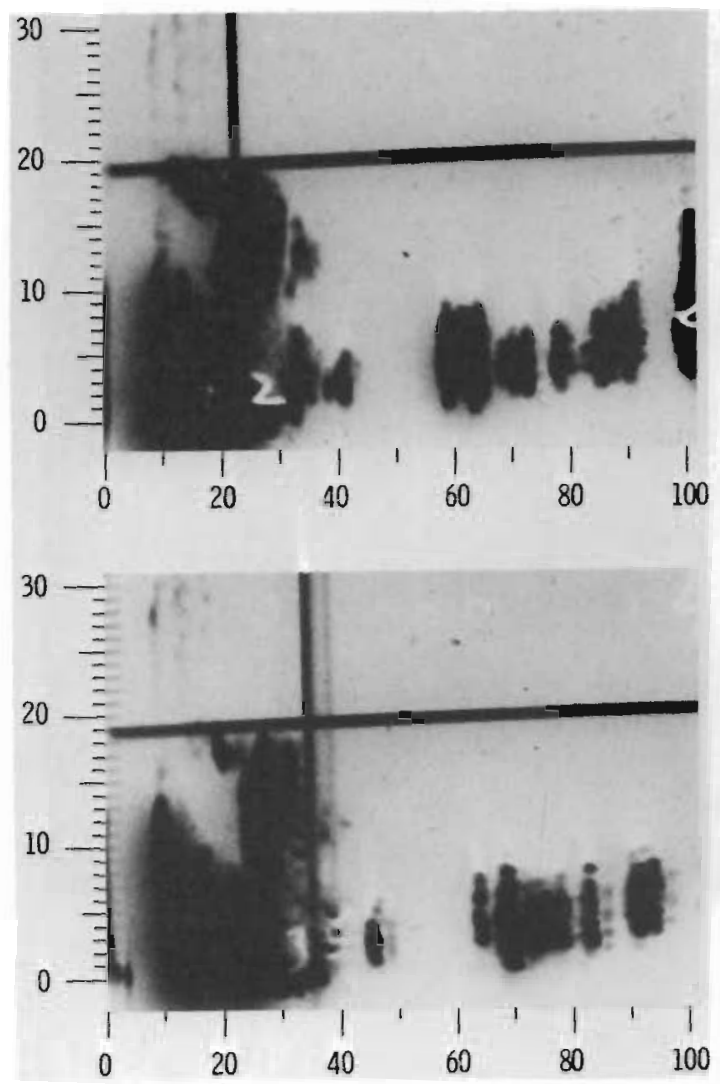

Neg 721193-1

FIGURE 11. A Composite of Portions of the 1350 PST (Lower) and 1406 PST (Upper), $170^{\circ}$ RHI Probes. Notice the development of the treated cell.

aircraft. The photograph suggests that this cell developed vigorously only briefly becoming completely glaciated due to the massive dose of $\mathrm{Ag} I$.

The mass of $\mathrm{Ag}$ and $\mathrm{In}$ detected in each sampler for the 4/16 experiment is given in Table 2. Some artistic license was taken in the shading for the possible In deposition pattern, Figure 13; the solid bars at each sampler station represent the measured data. From Table 2 it can be seen that considerably more Ag than In was scavenged by the precipitation cell - from five to ten times as much.
Although we do not yet consider this result to be an adequate evaluation of nucleation versus post-nucleation scavenging, nevertheless it is extremely encouraging.

\section{DISCUSSION}

Based on the observed indium deposition patterns the experiments were demonstrated to be feasible; however, they were only partially successful. There are a number of interesting and some surprising features of the results, most of which are being investigated during our 1972 experiments:

1. From the $3 / 11$ deposition pattern it is apparent that the sampling grid is not of optimum scale. The amount of deposited indium appears to be still increasing with distance: on the arc at about 30 miles from the release point, approximately $1.8 \mathrm{mg}$ of indium was deposited on a strip 1 meter wide, stretching across the Peninsula; on the arc at about 50 miles, approximately twice this amount fell. The 1972 sampling grid extends about twice as far as the 1971 grid.

2. The east-west spread of the deposition pattern is amazingly wide. It is highly suggestive that this cross wind spread is caused by the hydrometer trajectories through the direction wind shear.*

* See the report in this volume entitled "Raindrop Trajectories whrough wind shear." 


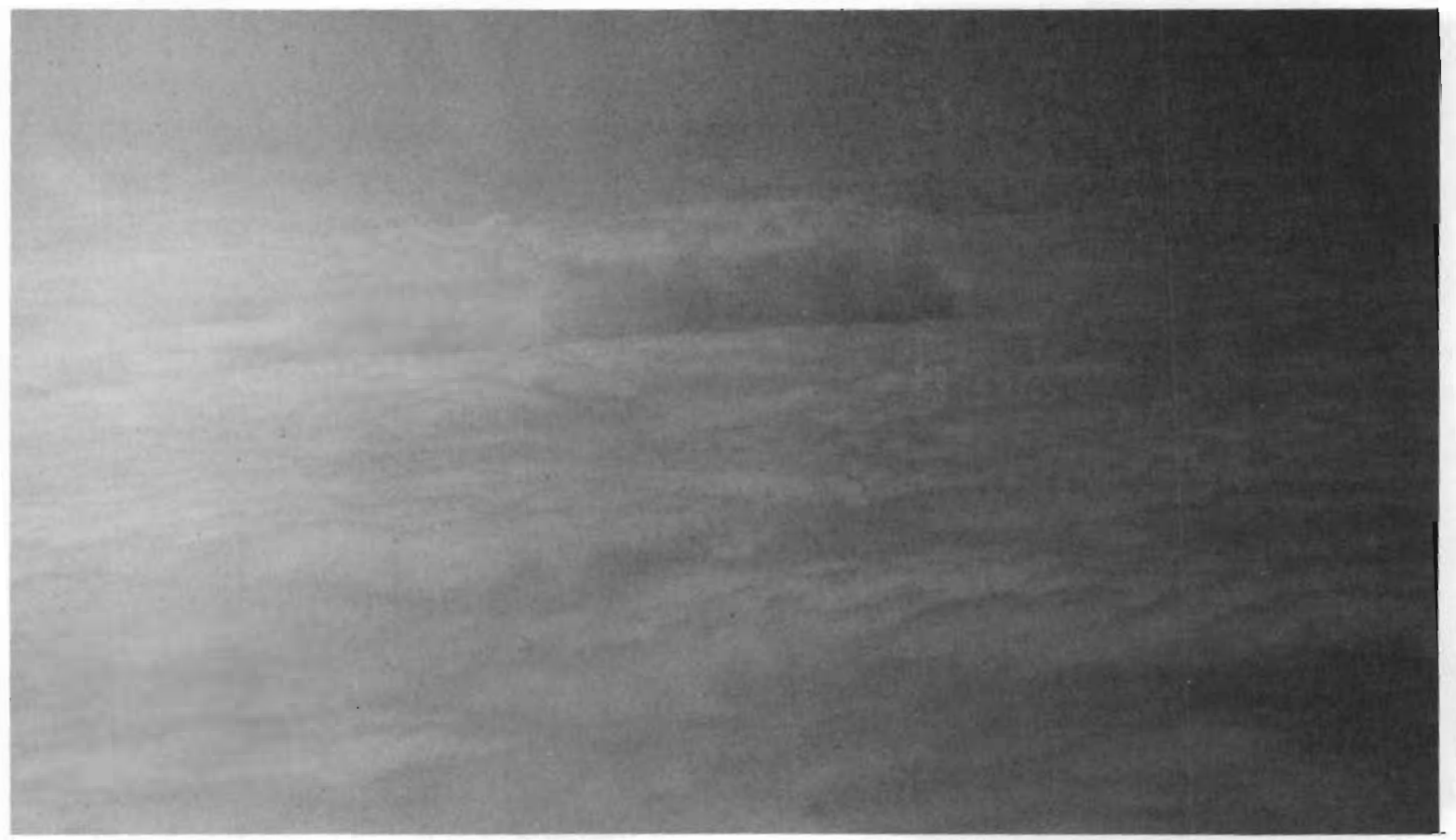

Neq 721192-2

EIGURE 12. Abnormal Appearance of the Treated cell within the Stratus Deck, as Viewed from the Aircraft

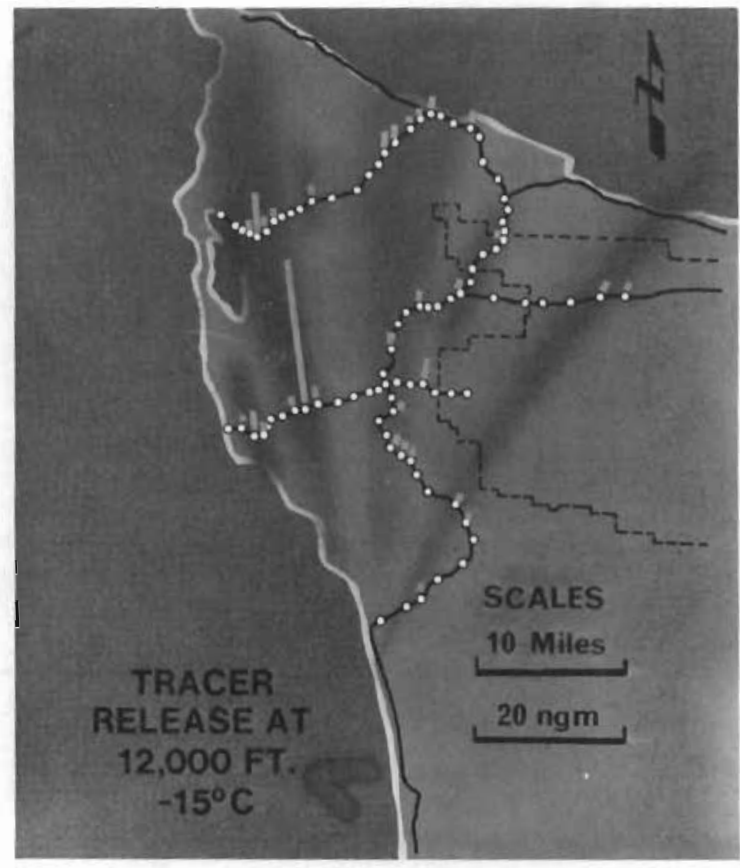

Neg 720024-2

FIGURE 13. 16 April 1971 Indium Deposition pattern
3. It is not expected that significant dry deposition occurred, even for the $3 / 11$ experiment, since otherwise the cross wind spread would not be so great. However, the possibility of dry deposition will be explored in future experiments by releasing $\mathrm{SF}_{6}$ with the aerosol tracer and collecting grab samples at ground leve1.*

4. If a single-stage, in-cloud removal process is assumed, then the $3 / 11$ results suggest a "rainout

\footnotetext{
* See the report in this volume entitled "An Inexpensive Infusion Sampler for Atmospheric macer studies."
} 
time constant" (for exponential decay of the airborne mass of indium) of about 1 hour. More satisfactory analytical methods are being developed. *

5. One of the most interesting aspects of the 4/16 experiment was the circumstantial evidence that the indium deposition was influenced by the simultaneous release of ice nuclei. Further such "targeting" experiments will be undertaken.

6. A preliminary study of the $4 / 16$ results suggests that the rainout rate for aerosols which are active ice nuclei is significantly larger than the removal rate for inert material. This is being investigated during our 1972 experiments by utilizing a denser grid near the target area and by releasing more $\mathrm{AgI}$, so that (hopefully) the concentration in the precipitation will be considerably above background.

\section{ACKNOWLEDGEMENTS}

The execution of these experiments depended on the cooperation of many individuals. The division of responsibilities among the authors was: D. G. Atkinson, collecting, reducing, and interpreting the cloud particle data; W. E. Davis, positioning the aircraft based on the radiosonde and

* See the report in this volume entitied "Computer Results for an In-Cloud Release of Indium on 11 March 1971." radar data; L. F. Radke, in charge of aircraft operations; B. C. Scott, field coordinator and radar observer; W. G. N. Slinn, project director and writer; T. M. Tanner, sampling assistance and in charge of the radiochemical analyses; J. M. Thorp, meteorology and rapid radiosonde data reduction; and N. A. Wogman and J. A. Young, conceiving, deploying, and quality controlling the ground-based sampling.

We are especially grateful for the assistance of the $758 \mathrm{U} . \mathrm{S}$. Air Force Radar Squadron, members of the Quillayute weather Station, and students and staff at the University of Washington and washington State University. Special thanks are due: M. T. Dana, A. N. Dingle, R. J. Engelmann, F. O. Gladfelder, A. M. Kahan, P. V. Hobbs, S. E. Shumway, J. W. Sloot, C. W. Thomas and F. M. Turner.

\section{REFERENCES}

1. C. E. Junge, Atmospheric Chemistry and Radioactivity, New York, Academic Press, pp. 382, 1963.

2. B. Sytra, C. Garbaliavskas and V. Lujanas, Atmospheric Scavenging of Radioisotopes, Eds., Izdatel'stvo "MINTIS", Vil'nyus, 1968. Avaizable from NTIS as TT69-55099, pp. 250, 1970 .

3. R. J. Engelmann and W.G.N. SZinn, Precipitation Scavenging (1970). Available from NTIS as CONF-700601, pp. 409, 1970 .

4. A. N. Dingle, D. F. Gatz and J. W. Winchester, "A Pilot Experiment Using Indium as Tracer in a Convective Storm,"J.Appl. Meteor., 8, pp. $236-840,196 \overline{9}$. 
5. K. K. Shopauskas, B. I. Styro, E. Yu. Verbra, B. K. Vebrene, S. S. Shalaveyus and D. A. Shopauskene, "Washout of Radioisotopes Injected into a croud from Data of Ground observations," Atmospheric Seavenging of Radioisotopes, pp. 233-848, 1968 .

6. I. I. Burtsev, I. V. Burtseva and S. G. Malakhov, "Washout Characteristies of a ${ }^{32} P$ Aerosol Injected into a Cloud," Atmospheric Scavenging of raarozsotopes, pp. $242-250,1968$.

7. A. N. Dingle, "Scavenging of

Tracer in Severe Storms," Precipitation Scavenging, 1970. Available from NTIS as CONE-700601, pp. 21-36, 1970 .
8. R. G. Semonin, Study of Rainout of Radioactivity in IIIinois, Tenth Progress Report, COO-1199-20, IItinois State water Survey, University of IZZinois, Urbana, IZZinois, 1971

9. P.W. Summers and J.H. Renick, "Case Studies of the Physical Effects of Seeding Hailstorms in Alberta," Proc. Int. Conf. on Weather Modification, Canberra, Australia, American Meteorological Society, pp. 213-218, 1971.

\title{
COMPUTER RESULTS FOR AN IN-CLOUD RELEASE OF INDIUM ON 11 MARCH 1971
}

\author{
W. E. Davis
}

\begin{abstract}
Preliminary results from a comparison of deposition with predicted deposition are that a range of ditution coefficients of $10^{-3} \mathrm{sec}-1$ to $10^{-4} \mathrm{sec}^{-1}$ would yiela a range of cloud scavenging coefficients of $10^{-3}$ to $10^{-2}$ sec-1 for indium. Considerable caution in using these numbers is required because of uncertainty of time changes of the cloud water content as well as precipitation rate.
\end{abstract}

\section{INTRODUCTION}

Experimental results for the 11 March 1971 in-cloud scavenging experiments are given in a companion paper in this volume.* The purpose of this report is to apply the model recently developed by Davis (1) in an attempt to interpret the observed deposition pattern.

* See the preceeding report.
MODEL

The in-cloud scavenging model was originally developed to explain the deposition of cosmogenic radionuclides. For nonradioactive tracers we take (see Davis): (1)

1) $\alpha$ (the radioactive decay coeffi(ient) $=0$,

2) $B$ (the production term) $=0$, and

3) $t_{0}$ (time in-cloud before precipitation) $=0$. 
With these three changes, the model was run for an $n_{0}=453$ grams. As input for $\psi$ (dilution coefficient, $\mathrm{sec}^{-1}$ ) a liquid water content of $0.29 \mathrm{~g} / \mathrm{m}^{3}$ was assumed. (2) Because of instrument failure, a measurement of liquid water content was not available. Further, a parcel precipitation rate was determined from both radiosonde and aircraft data. Using the mean rate of rise and assuming the liquid water content to be constant, a range of $\psi^{\prime} s$ was determined between $2 \times 10^{-4} \mathrm{sec}^{-1}$ to $\sim 1 \times 10^{-3} \mathrm{sec}^{-1}$.

For each computer run, $\psi$ and $\lambda$ [ the in-cloud scavenging coefficient, $\left(\sec ^{-1}\right)$ ] were assumed constant (Figure 1). These values were compared to the

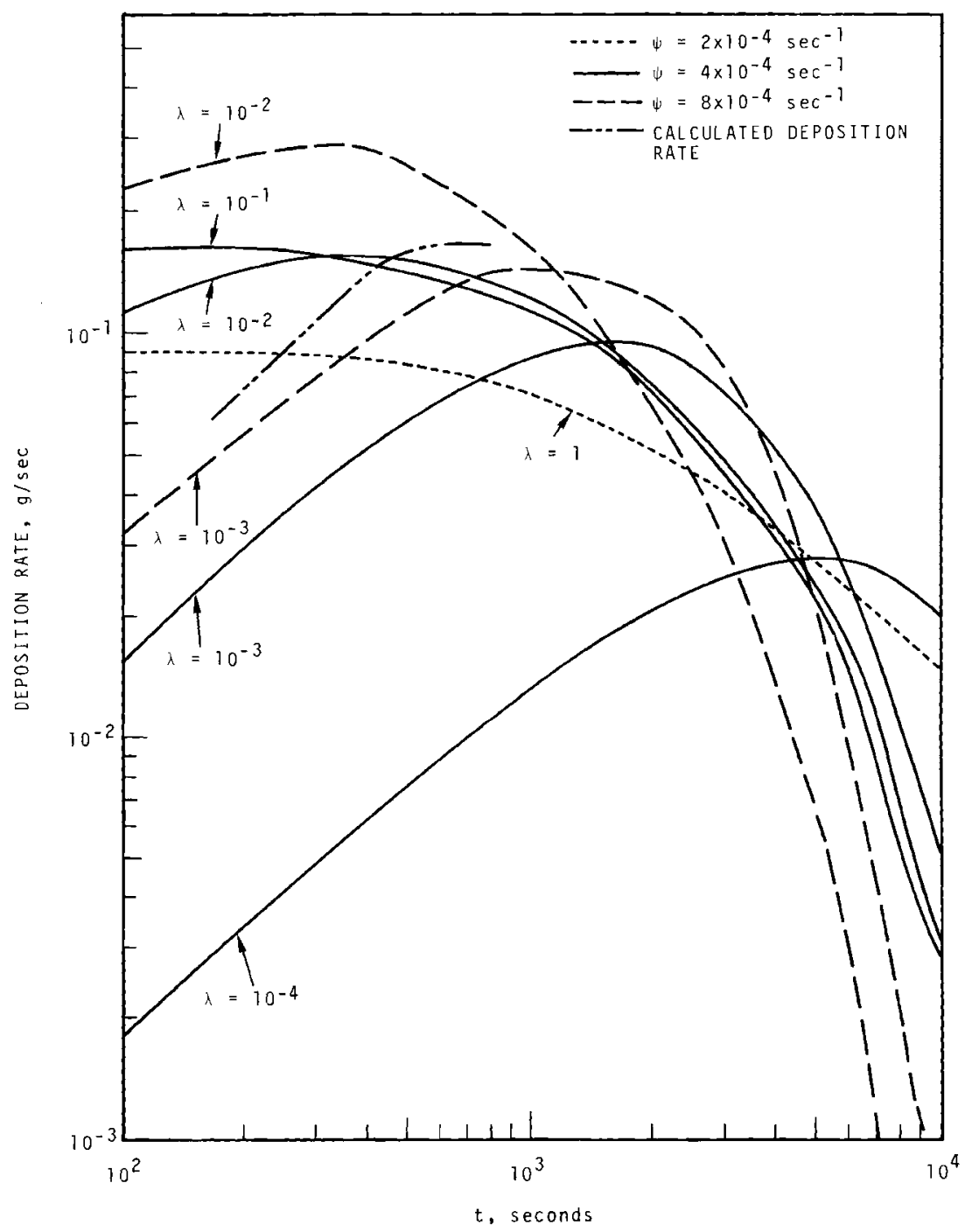

Neg 721562-3

FIGURE 1. Deposition Rate of Indium as a Function of Time After Release 
observed pattern. As one can see, they seem to fit curves for $\lambda>10^{-3} \mathrm{sec}^{-1}$ and $\psi \geq 4 \times 10^{-4} \mathrm{sec}^{-1}$.

Another interesting point can be made by looking at the time of maximum deposition. From

$$
\frac{d^{2} n}{d t^{2}}=\frac{\psi \lambda n_{o}}{\psi-\lambda}\left[\psi e^{-\psi t}-\lambda e^{-\lambda t}\right]=0,
$$

where $n$ is the mass of indium deposited on the ground, then

$$
t_{\max }=\frac{1}{\psi-\lambda} \ln \left(\frac{\psi}{\lambda}\right) .
$$

where $t_{\max }$ is the time of maximum deposition. Figure 2 was then drawn.

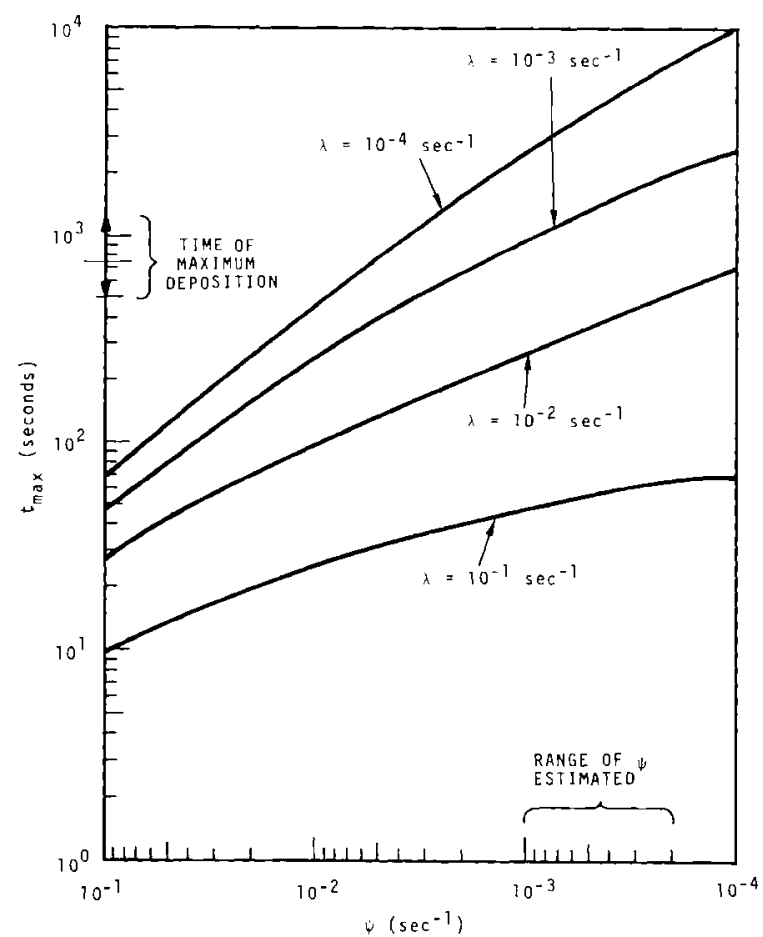

Neg 722061-1

FIGURE 2. Time of Maximum Indium Depostion versus Dilution Coefficient
The calculation of the deposition rate from the observed pattern ind $i-$ cated that at 2750 seconds the rate was still increasing. Figure 2 would indicate that a range of values for $\lambda$ could be arrived at based on this observation. For a $\psi$ range of $2 \times 10^{-4}$ to $10^{-3} \mathrm{sec}^{-1}$ this would yield a range for $\lambda$ of $10^{-3}$ to $10^{-2} \mathrm{sec}^{-1}$. A value for $\psi<2 \times 10^{-4}$ would not explain the deposition pattern because, as can be seen in Figure 1, all values for deposition rates would be below those calculated from observed concentrations.

\section{SUMMARY}

A range of $\lambda$ from $10^{-3}$ to $10^{-2} \mathrm{sec}^{-1}$ was found for a range of $\psi$ of $2 \times 10^{-4}$ to $10^{-3} \mathrm{sec}^{-1}$. Also a comparison of times of maximum depositions for a range of $\psi^{\prime} s$ and $\lambda^{\prime} s$ was presented. Considerable care must be used in drawing conclusions from these results. The initial aim of the field experiment was to determine whether detectable quantities of indium would be seen at the ground from an in-cloud release. Data such as 1 iquid water content, rainfall and snowfall rate through the plume were not observed. Thus what we are presenting at this time is an initial estimate which will be revised with further measurements. There are now planned experiments to determine changes in $\psi$ by measuring the 1 iquid water content associated with the plume throughout the period in which scavenging is taking place. With this information, the model will be rerun to determine the in-cloud scavenging coefficient for indium. 


\section{REFERENCES}

1. W. E. Davis, "An Interpretation of the In-Cloud Scavenging of Particulate," Pacific Northwest Laboratory Annual Report for 1969 to the USAEC Division of Biology and Medicine, Battelle-Northwest, Richland, Washington, Volume II, Part 1 , Atmospheric Sciences, BNWL-1307, pp. 107-110, June 1970.

2. I. N. Ponomarenko and T. N. Zabolotskaia, "Experimental
Data on the Liquid-Water Content of Frontal Clouds over the Steppe Portion of the Ukraine," Kiev. Ukrainski Nauchno-Issledovatel'ski Gidrometeorologicheski Institut, Trudy, vol. 48, pp. 58-66, 1965. $A D$ 690173. Translation from Russian was produced by the American Meteorological Society under Contract $A F$ 19(688)-3880, through the support and sponsorship of the Air Force Cambridge Research Laboratories Office of Aerospace Research, L. G. Hanscom Field, Bedford, Massachusetts.

\title{
RAINDROP TRAJECTORIES THROUGH WIND SHEAR
}

\author{
W. G. N. Slinn and T. J. Bander
}

\begin{abstract}
Trajectories and terminal locations were calculated for raindrops falling through the wind shear measured by the 1135 PST, 11 March 1971 radiosonde released from quillayute on the olympic Peninsula. Updraft velocities were parameterized. The results suggest that the spread of the deposition pattern for the indium tracer released into the storm could have been caused by the raindrops' trajectories through the wind shear.
\end{abstract}

The deposition pattern for the indium released into the 11 March 1971 coastal storm between 1157 and 1204 PST shows the indium spread over a distance of about 30 miles cross wind, after traveling only about 30 miles downwind.* In an attempt to explain these observations, an analysis was made of the raindrop trajectories through the measured wind shear (see the 1135 PST 11 March 1971 sounding in the companion paper).* Since the

* "Precipitation Scavenging of Tracers Released into Frontal Storms." indium was released at the $0^{\circ} \mathrm{C}$ level, it would probably have been appropriate to include in the analysis that over a part of their trajectories, the hydrometeors were frozen. However, in this first look at the problem, this aspect was ignored.

The influence of two other parameters was explored. One was the possible influence of various magnitudes of updrafts which might have been induced by condensation on the wettable, indium aerosol particles; another was the effect of various 
"times of attachment" of the indium to precipitable hydrometeors. Both these parameters will be accounted for more completely in a developing "aerosol evolution code," which hopefully will lead to accurate predictions of the in-cloud scavenging of aerosol particles from frontal storms.

The origin of the coordinates was taken at ground elevation beneath the indium release point, which was at $1650 \mathrm{~m}$ elevation. The indium was then assumed to drift with the mean wind as given by the Quillayute sounding, and at various updrafts $\mathrm{w}=0.05,0.5,1$, 2 , or $5.0 \mathrm{~m} \mathrm{sec}^{-1}$. After times $\tau=100,200,500,1000$, or $2000 \mathrm{sec}$, the indium was assumed to be attached to precipitable cloud drops of radii $\mathrm{R}=0.1,0.2,0.5,1$ and $2 \mathrm{~mm}$.

The trajectory of each raindrop is dictated by

$\frac{d \vec{R}}{d t}=\vec{V}$

$\frac{d \vec{V}}{d t}=g(-\hat{k})-\frac{\vec{D}}{\bar{M}}$,

where $\vec{R}$ is its position vector, $\vec{V}$ its velocity, $g$ is the acceleration of gravity and $[1]$

$$
\begin{array}{r}
\frac{\vec{D}}{M}=\frac{3}{8}\left(1.1 \times 10^{-3}\right) \frac{v^{2}}{R} C_{0} \\
{\left[1+\frac{\delta_{0}}{(\operatorname{Re})^{1 / 2}}\right]^{2} \frac{\vec{v}}{v}}
\end{array}
$$

in which $\delta_{0}=9.06, C_{0}=24 / \delta_{0}$, $\operatorname{Re}=2 \mathrm{Rv} / \nu, \nu=0.153 \times 10^{-4} \mathrm{~m}^{2} \mathrm{sec}^{-1}$, and $\vec{v}=\vec{V}-\vec{U}, v=\mid \vec{v}\}$, where $\vec{U}$ is the mean wind as given by the sounding.
In the calculations, a numerical Simpson's integration routine was used which was accurate to the nearest meter. The wind speed and direction at any height were obtained with a quadratic interpolation between the data given by the sounding. The trajectories were found by solving the six differential equations using a fourth-order Runge-Kutta routine.

Typical results are shown in Figure 1. Along each thick solid line

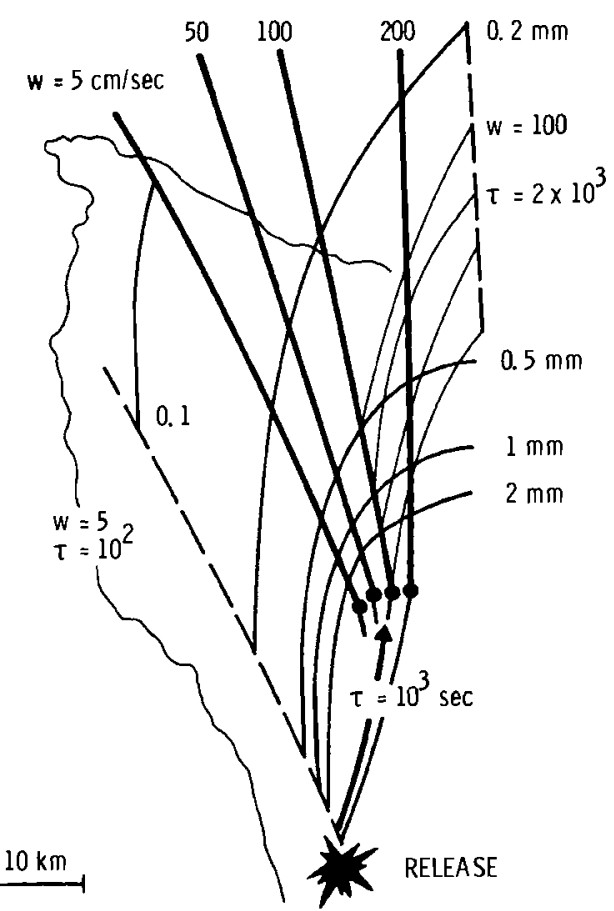

Neg 721170-1

FIGURE 1. The Terminal Location of Drops Falling Through the Wind Shear as Measured by the 1135 PST, 11 March 1971 Quillayute Sounding. The lines $\mathrm{w}=5 \mathrm{~cm} / \mathrm{sec}, 50,100,200$, show the lines along which different raindrops (radii, 2, $1,0.5$ and $0.2 \mathrm{~mm}$ ) would fall if they intercepted the indium $10^{3}$ seconds after its release into the updrafts given by the w values. The dotted lines show the effect of different attachment times $\left(\tau=10^{2}\right.$ and $2 \times 10^{3} \mathrm{sec}$ ) for specific updraft velocities. 
is the terminal position of those raindrops which picked up the indium 1000 seconds after its release. On each 1 ine is indicated where a $2 \mathrm{~mm}$, $1 \mathrm{~mm}, 0.5 \mathrm{~mm}$, and $0.2 \mathrm{~mm}$ drop would land. The different locations of the lines reflect the effects of different updraft velocities. The dotted line which is farthest south on the map, shows where the raindrops would have landed if $\mathrm{w}=5 \mathrm{~cm} \mathrm{sec}-1$ and $\tau=10^{2}$ sec. The most easterly dotted line is for $w=100 \mathrm{~cm} \mathrm{sec}^{-1}$, and $\tau=2 \times 10^{3}$ sec.

It is interesting that for specific values of $w$ and $\tau$, the terminal locations of raindrops of radii larger than about $0.2 \mathrm{~mm}$ lie on essentially straight lines. To see why this is so, consider the components of Equations (1) and (2). For drops larger than about $0.2 \mathrm{~mm}$ and 1 ess than $2 \mathrm{~mm}$, it is adequate to use the empirical fit to the terminal velocity: $\mathrm{w}_{\mathrm{t}}=$ $8000 \mathrm{R}\left(\mathrm{sec}^{-1}\right)$. Thus we use $\vec{D} / \mathrm{M}=$ $\mathrm{g} \vec{V} /(8000 \mathrm{R}) \equiv \overrightarrow{c v}$. The $\mathrm{x}$ (i.e., northerly) component of (2) then becomes

$\frac{d u}{d t}+c u=c U$.

Ignoring the initial $x$-component of the drop's velocity, (4) integrates to

$$
\begin{aligned}
u(z)= & \frac{c}{w_{t}} \int_{z}^{H} U\left(z^{\prime}\right) \\
& \exp \left\{-c\left(z^{\prime}-z\right) / w_{t}\right\} d z^{\prime},
\end{aligned}
$$

where $H$ is the initial height of the drop. If $U\left(z^{\prime}\right)$ is expanded in a Taylor series about its value at $z$,
$U\left(z^{\prime}\right)=U(z)+\frac{\partial U}{\partial z}\left(z^{\prime}-z\right)+\ldots$

and (5) is integrated term by term, it is seen that for the 11 March 1971 sounding, the first order correction is

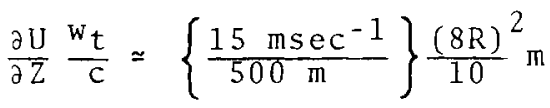

where $R$ is the radius of the raindrop in $\mathrm{mm}$. Even for a $2 \mathrm{~mm}$ drop, for which the "relaxation" length is approximately 25 meters, the correction, equation (7), is less than $1 \mathrm{~m} \mathrm{sec}^{-1}$ which is only 3\% of the first order term. Thus

$u(z) \simeq \frac{c}{w_{t}}(H-z) U(z)$.

Substituting this into $\mathrm{dx} / \mathrm{dt}=\mathrm{u}(\mathrm{z})$ and similarly the $y$ (westerly) components of equations (1) and (2) leads to a ratio of final $x$ to final $y$ locations which is independent of $R, x$, and $y$ and therefore raindrops of different radii fall along a straight line.

In summary, it appears that the width of the indium deposition pattern from the 11 March 1971 experiment could have been caused by the spread of the raindrop trajectories falling through the shear flow. If this was the cause and if the Quillayute sounding gives an accurate picture of the winds above the entire Peninsula, then apparently some updraft velocity was either present or induced, since otherwise it is difficult to understand how the material was deposited so far to the east of the release 
point. It is also apparent from Figure 1 that the time constant for attachment of the indium to precipitable hydrometeors must have been of the order of $10^{3}$ seconds. Further experiments are in progress; in particular, measurements will be made in an attempt to ascertain the influence of mesoscale diffusion on the deposition patterns.

\section{REFERENCES}

1. W.G.N. Slinn and B. C. Scott, "The Effect of Wind on Rain Scavenging," Pacific Northwest Laboratory Annual Report for 1970 to the USAEC Division of Biology and Medicine, Volume II: Physical Sciences, Part 1. Atmospheric Sciences, BNWL-1551, Vol. II, Part 1 . Battelle, Pacific Northwest Laboratories, Richland, Washington, June 1971 .

\title{
INITIATION OF THE ICE PHASE IN A SEEDED CLOUD*
}

\author{
A. J. Alkezweeny
}

\begin{abstract}
A recently described contact nucleation model is improved to account for variations with height of the updraft speed, liquid water content, and droplet size distribution. The model is now capable of calculating the concentration and size distribution of ice crystals produced in a cloud seeded with AgI particles below the cloud base.
\end{abstract}

\section{INTRODUCTION}

Recently Alkezweeny $(1)$ presented a simple model to describe the contact nucleation of cloud droplets, caused by seeding at the base of a cumulus cloud. Previously, applications of the model were restricted to cases with constant updraft speed,

\footnotetext{
* Work supported in part by the U.S. Department of Interior, Bureau of Reclamation, under Contract 14-06 D-6581 with Meteorology Research, Inc., and in part by the USAEC Contract $A T$ (45-1)-1830, with Pacific Northwest Laboratory.
}

constant liquid water content, and a monodisperse cloud droplet size distribution. In the present report these restrictions are removed by postulating arbitrary updrafts and liquid water contents and by discretizing the Khrgian-Mazin (2) cloud droplet size distribution. In the future it is hoped that this input data will be supplied by coupling the model with a dynamical model of a cumulus cloud.

\section{INPUT DATA}

Since a description of the model is available elsewhere ${ }^{(1)}$ it will not be 
reviewed here. Special features of the present calculations include the height of the cloud base $(640 \mathrm{mb})$, vertical grid step $(100 \mathrm{~m})$, maximum cloud life (3000 sec) cloud top height $(5 \mathrm{~km})$, initial concentration of AgI particles $\left(1.2 \times 10^{11} \mathrm{~m}^{-3}\right)$, particle diffusion coefficient ( 1.35 $\times 10^{-4} \mathrm{~cm}^{2} \mathrm{sec}^{-1}$ ) and total number density of cloud droplets $\left(500 \mathrm{~cm}^{-3}\right)$.

The assumed vertical profiles of liquid water content and updraft speed are shown in Tables 1,2 and 3 . Values at intermediate $z$ levels were found by interpolation .

TABLE 1. Iiquid Water Content Profiles Used in the Calculation

\begin{tabular}{|c|c|c|c|}
\hline \multirow{3}{*}{$\begin{array}{c}\text { Height Above } \\
\text { Cloud Base } \\
\text { Meter } \\
\end{array}$} & \multirow{2}{*}{\multicolumn{3}{|c|}{$\begin{array}{c}\text { Liquid Water } \\
\text { Content } W_{c} \text { in } \\
\qquad \mathrm{g} / \mathrm{m} 3^{c}\end{array}$}} \\
\hline & & & \\
\hline & $w_{c 1}$ & $W_{c 2}$ & $w_{c 3}$ \\
\hline 0.0 & & 0.0 & 0.0 \\
\hline & & & 3 \\
\hline & 75 & $\begin{array}{l}1.5 \\
1.8\end{array}$ & 3.6 \\
\hline 4600 & 1.0 & 2.0 & 4 \\
\hline 520 & & 2.1 & 4.2 \\
\hline & & 0.0 & 0.0 \\
\hline 7000 & 0.0 & 0.0 & 0.0 \\
\hline
\end{tabular}

TABLE 2. Updraft Speed Profiles Used in the calculation

\begin{tabular}{|c|c|c|c|}
\hline \multirow{2}{*}{$\begin{array}{l}\text { Height Above } \\
\text { Cloud Base } \\
\text { Meter } \\
\end{array}$} & \multicolumn{3}{|c|}{$\begin{array}{c}\text { Updraft Speed } \\
\mathrm{u} \text { in } \mathrm{m} / \mathrm{s}\end{array}$} \\
\hline & $\mathrm{u}_{1}$ & $\mathrm{u}_{2}$ & $\mathrm{u}_{3}$ \\
\hline 0 & 1.5 & 2.0 & 3.0 \\
\hline 1600 & 2.5 & 3.5 & 5.0 \\
\hline 3600 & 5.0 & 7.0 & 10.0 \\
\hline 4600 & 7.0 & 10.0 & 14.0 \\
\hline 5200 & 8.5 & 12.0 & 17.0 \\
\hline 5700 & 0.0 & 0.0 & 0.0 \\
\hline 6000 & -2.0 & -3.0 & -4.0 \\
\hline
\end{tabular}

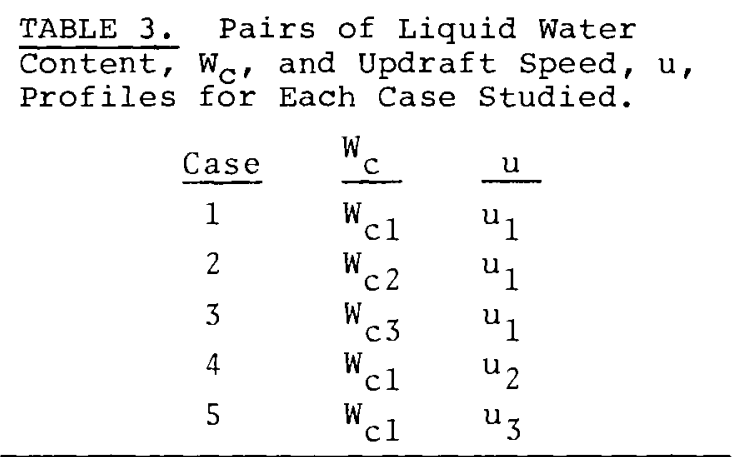

RESULTS

The computed results for the five cases are numerous and will not be presented here. Detailed results of the computations for Case 2 can be found elsewhere. (3) In this report only a comparison between the five cases will be described.

The heights above cloud base, at which droplets in each class first made contact with $\mathrm{AgI}$ particles are shown for each case in Table 4 . It can be seen from the table that increasing the liquid water content for the same updraft speed causes larger droplets to contact AgI particles at a lower height. However, no change in the heights was found with changing updraft speed. The total concentrations of droplets which contacted AgI particles at each level changed only by less than a factor of three from one case to the other.

In order to use the model output, a certain assumption concerning the activation temperature of AgI particles should be made. For example, it was assumed that only droplets 
TABLE 4. The Height (M) Above Cloud Base at Which Droplets in Each Class First Made Contact with AgI Particles for Each of the Five Cases Studied

Droplet

Size $(\mu \mathrm{m})$

Case 1

Case 2

Case 3

Case 4

Case

\begin{tabular}{c}
$0-20$ \\
\hline 50 \\
50 \\
50 \\
50 \\
50
\end{tabular}

$\underline{40-60}$

450

15

150
450

450

\begin{tabular}{|c|c|}
\hline $60-80$ & $80-100$ \\
\hline 1450 & 2750 \\
\hline 450 & 1050 \\
\hline 250 & $55 i$ \\
\hline 1450 & 275 \\
\hline 1450 & 27 \\
\hline
\end{tabular}

making contact above the $-5^{\circ} \mathrm{C}$ temperature level would freeze. The amount of heat released due to droplet freezing was calculated and shown in Figure 1 for the first three cases.

It seems that the heat released changes 1 inearly with height and increases with an increase in the liquid water content. Changing the updraft speed has little effect on it. This result may be of value for input into existing dynamical models of cumulus clouds.

\section{CONCLUSIONS}

With assumptions on the activation temperature of $\mathrm{AgI}$ particles, the model is capable of calculating the initial concentration and size distribution of ice crystals in a seeded cloud as a function of height. Before it can be compared with observations, the model should be included in a

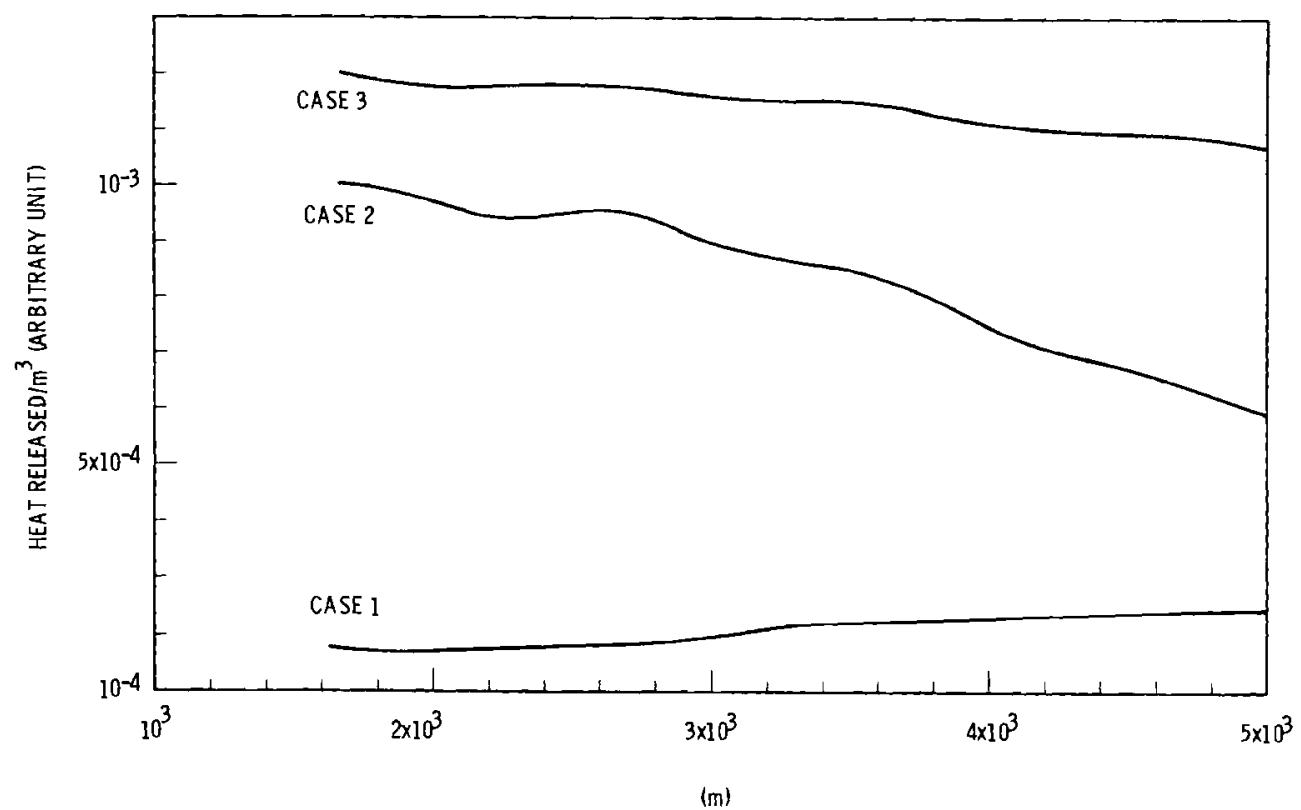

Neg 715708-1

FIGURE 1. Heat Released as a Function of Height Above Cloud Base 
growth model where the final sizes and concentration of ice crystals can be obtained for each level.

\section{REFERENCES}

1. A. J. Alkezweeny. "A Contact Nucleation Model for Seeded Clouds," J.Appl. Meteor., vol. 10, pp.732-738. 1971.
2. A. Kh. Khrgian, et al. Cloud. Physics, Translated from Russian, Israel Program for Scientific Translations Jeruselem, 1963.

3. In Res. Rept. Arizona Weather Modification Research Program, Annual Rept., FY-1971. Meteorology Research Inc., Contract No. 14-06-D-6581.

\title{
AN ANALYSIS OF DIFFUSION IN WIND SHEAR* \\ W. G. N. Siinn**
}

\begin{abstract}
A theoretical framework is presented to describe turbulent diffusion in an atmosphere with a nonzero gradient of the mean wind. Moments of the convective diffusion equation are taken and if these are terminated at the second moment, then the contaminant concentration is approximated to be Gaussian with specified covariance matrix. A special case is evaluated to demonstrate the resulting diffusion ellipsoid and the $t, t^{2}$ and $t^{3}$ regimes of $\sigma_{y}{ }^{2}$.
\end{abstract}

Although the importance of wind shear to the diffusion of atmospheric contaminants is well established, (1) nevertheless the theoretical evaluation of diffusion in wind shear has apparently made essentially no progress.(2)t We use the term "wind

* To be submitted for publication in Atmospheric Environment.

* Work supported in part by Battelle Memorial Institute's Physical Sciences Program.

+ Note added in proof: F. A. Gifford has called the author's attention to two significant analyses of diffusion in wind shear, listed as references (5) and (6). shear" to describe both the directional change and variation in magnitude of the mean wind. In particular, we shall consider the linear variation (with height) of the wind given by

$\vec{V}=\left(U+\frac{u_{o}}{1_{x}} z\right) \hat{i}+\frac{v_{o}}{1_{y}} z \hat{j}+w_{o} \hat{k}$.

A constant updraft velocity, $w_{0}$, is included in Equation (1), for application of the theory to the diffusion within a cloud of material upon which condensation might occur. 
The present analysis is based on a reinterpretation of the convective diffusion equation

$\frac{\partial x}{\partial t}=-\nabla \cdot \vec{F}$

where $\vec{F}$ is the flux of the contaminant. Here, rather than treating $x$ as the contaminant concentration, we interpret $x$ to be a probability density function. For example, let $x\left(\vec{r}, t ; \vec{r}_{0}, o\right) d \tau$ be the probability that a single contaminant aerosol particle (or gas molecule) will be in the volume element $d \tau$ about $\vec{r}$ at time $t$, if it were known to be at $\vec{r}_{0}$ at $t=o$. Alternatively if $x$ is multiplied by $N$, the total number of contaminant particles released, then NXd $\tau$ is interpreted to be the probability that $\mathrm{NX}$ contaminant particles are within $d \tau$ at time $t$.

proceeding from this interpretation of (2), we seek to obtain various moments of $x$, such as the mean position

$\langle\overrightarrow{\mathrm{r}}\rangle=\int \overrightarrow{\mathrm{r}} \times \mathrm{d} \tau$

the mean square, etc., from which we can derive the covariance,

$\tilde{\sigma}^{2}=\langle\vec{r} \vec{r}\rangle-\langle\vec{r}\rangle^{2}$,

skewness, kurtosis, etc., of the distribution. In (3), the integration is over all space.

To obtain expressions for these moments we multiply (2) through by various powers of $r$ and integrate over all space. For example, multiplying through by $\vec{r}^{\circ}=1$ leads to $\frac{\partial}{\partial t} \int x \mathrm{~d} \tau=-\int \nabla \cdot \overrightarrow{\mathrm{F}} \mathrm{d} \tau$.

Utilizing Green's theorem on the rhs of (5) and assuming that the flux is zero at infinity gives

$\frac{\partial}{\partial t} \int x d \tau=-\oint \vec{F} \cdot d \vec{\sigma}=0$.

Thus the probability that a contaminant particle is somewhere in the whole space (or the total number of particles in the whole space) is constant. Choosing the first interpretation, we take this constant to be 1 , i.e., the particle is certain to be somewhere.

The mean position of the particle is given by

$\frac{\partial}{\partial \tau} \int \vec{r} \times d \tau=-\int \vec{r} \nabla \cdot \vec{F} d \tau$.

Utilizing Green's theorem and assuming that $\vec{r} \vec{F}$ vanishes at infinity leads to

$\frac{\partial}{\partial \bar{t}}\langle\vec{r}\rangle=\int \vec{F} d \tau$.

Similarly, the mean square is given by

$\frac{\partial}{\partial t}\langle\vec{r} \vec{r}\rangle=\int(\vec{r} \vec{F}+\vec{F} \vec{r}) d \tau$

where $\vec{r} \vec{r}$, etc., are second order tensors.

To proceed, a specification of the flux is needed. As is customary in the "K-theory" of turbulent diffusion, we take

$\overrightarrow{\mathrm{F}}=-\stackrel{\tilde{K}}{\mathrm{~K}} \cdot \nabla \chi+\overrightarrow{\mathrm{V}}_{X}$ 
where $\tilde{K}$ is the (symmetric, second order tensor) turbulent diffusivity and $\vec{V}$ is the mean wind (plus sedimentation velocity, which here we take to be zero).

As an example of the application of this theory, consider the case when the mean wind is given by (1). Then from (8) and (10) the mean position of the particle is given by

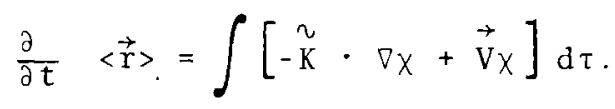

Since

$\nabla \cdot \stackrel{\sim}{\mathrm{K} x}=\stackrel{\sim}{\mathrm{K}} \cdot \nabla x+x \nabla \cdot \stackrel{\sim}{\mathrm{K}}$

then upon a further application of Green's theorem, (11) becomes

$\frac{\partial}{\partial t}\langle\vec{r}\rangle=\int[\vec{v}+\nabla \cdot \stackrel{v}{K}] x d \tau$

If $\widetilde{K}$ were a constant, then using $\vec{V}$ given by (1), we obtain

$$
\begin{aligned}
& \langle\vec{r}\rangle=\left[u t+\frac{u_{o}}{1_{x}} \frac{w_{o} t^{2}}{2}\right] \hat{i} \\
& +\left[\frac{v_{o}}{I_{y}} \frac{w_{o} t^{2}}{2}\right] \hat{j}+\left[w_{o} t\right] \hat{k}
\end{aligned}
$$

which expresses the rather obvious result that the mean position of an aerosol particle (or of the cloud of aerosol particles) is dictated by the mean wind in a straightforward manner. It is interesting that if $\widetilde{K}$ is dependent on height, for example, if

$\tilde{K}=\tilde{K}_{0}+\kappa \frac{z}{I_{z}} \hat{k} \hat{k}$ then

$\nabla \cdot \tilde{K}=\frac{K}{1_{z}} \hat{k}$

and (14) is changed by replacing the updraft velocity by $w_{0}+\left(k / 1_{z}\right)$. Thus a vertical gradient in the diffusivity causes an effective increase in the updraft. Usually this is small and can be ignored. However if $\tilde{K}$ were to vary as much as an order of magnitude (mks units) in a distance of 10 meters, as might occur in the lowest regions of the atmospheric boundary layer, then this effective updraft velocity could be

$0\left(10 \mathrm{~m}^{2} \mathrm{sec}^{-1} / 10 \mathrm{~m}\right)=1 \mathrm{~m} \mathrm{sec}^{-1}$

which is significant.

It is a little more tedious to determine the six components of the (symmetric) second order tensor $\langle\overrightarrow{\mathrm{r}} \overrightarrow{\mathrm{r}}\rangle$. Using the mean wind as given by (1) and assuming that $\tilde{K}$ is diagonal, then from (9) we obtain, for example, $\frac{\partial}{\partial t}\left\langle x^{2}\right\rangle=2 K_{x x}+2\langle x\rangle U+2\langle x z\rangle \frac{u_{0}}{l_{x}}$

$\frac{\partial}{\partial t}\langle x z\rangle=\langle x\rangle w_{0}+\langle z\rangle U+\left\langle z^{2}\right\rangle \frac{u_{0}}{I_{x}}$

$\frac{\partial}{\partial t}\left\langle z^{2}\right\rangle=2 K_{z z}+2\langle z\rangle w_{0}$.

Substituting the results for $\langle x\rangle,\langle y\rangle$, $\langle z\rangle$ as given by (14) into the above, solving them in the order (20), (19) and (18), subtracting appropriate 
terms of $\langle\vec{r}\rangle{ }^{2}$, and evaluating the other three terms of $\left\langle\vec{r}^{2}\right\rangle$ in a similar manner, gives, for the terms in the covariance matrix $\mu=\tilde{\sigma}^{2}=\left\langle\overrightarrow{\mathrm{r}}^{2}\right\rangle-\langle\overrightarrow{\mathrm{r}}\rangle^{2}$, the result
It is interesting that the updraft velocity, $w_{0}$, does not appear in the covariance matrix.

It becomes increasingly tedious to proceed analytically. However there

$$
\left[\begin{array}{ccc}
2 k_{x x} t+\frac{2}{3} k_{z z} t\left(\frac{u_{o} t}{1_{x}}\right)^{2} & \frac{2}{3} k_{z z} t \frac{u_{o} t}{1_{x}} \frac{v_{o} t}{1_{y}} & k_{z z} t \frac{u_{o} t}{1_{x}} \\
\sigma_{x y}^{2} & 2 k_{y y} t+\frac{2}{3} k_{z z} t\left(\frac{v_{0} t}{1_{y}}\right)^{2} & K_{z z} t \frac{v_{o} t}{1_{y}} \\
\sigma_{x z}^{2} & \sigma_{y z}^{2} & 2 K_{z z} t
\end{array}\right]
$$

appears to be no theoretical obstacle to obtaining higher order moments of the distribution. If we stop at the second moment then we have that the distribution is Gaussian with mean given by (14) and covariance, by (21). Thus, with $|\mu|$ the determinant of the covariance matrix $\mu$, and $\mu^{-1}$ its inverse, we have that

$$
\begin{array}{r}
x(\vec{r}, t)=\left[(2 \pi)^{3}|\mu|\right]^{-1 / 2} \\
\exp \left(-\frac{1}{2} \underline{x} \mu^{-1} \underline{x}^{t}\right)
\end{array}
$$

where $\vec{x}=\vec{r}-\langle\vec{r}\rangle$ and $\underline{x}$ and $\underline{x}^{t}$ are appropriate row and column matricies.

Specific applications of these results should probably proceed via a numerical evaluation of $\mu, \mu^{-1}$ and $|\mu|$, since it is not easy to derive the characteristic values of $\mu$ in the general case. For the specific case $\tilde{K}=\mathrm{KI}$, where $\tilde{I}$ is the identity tensor, and for $u_{0}=0$, then the variances along the principal axes are given by

$$
\sigma_{\mathrm{xx}}^{2}=\lambda_{\mathrm{P}_{1}}=2 \mathrm{Kt}
$$

$$
\begin{aligned}
& \lambda_{P_{2}, P_{3}=2 K t}\left\{1+\frac{1}{6}\left(\frac{v_{o} t}{1_{y}}\right)^{2} \pm \frac{1}{2} \frac{v_{o} t}{1_{y}}\right. \\
& {\left.\left[1+\frac{1}{9}\left(\frac{v_{o} t}{1_{y}}\right)^{2}\right]^{1 / 2}\right\} . }
\end{aligned}
$$

The principal axes are located at angles $\theta_{P}$ from the $y$ axis, given by

$\tan 2 \Theta_{p}=\frac{3}{\left(v_{o} t / 1_{y}\right)}$

At small times (i.e., $t \ll 1_{y} / v_{0}$ )

these reduce to

$\lambda=2 \mathrm{Kt}$ 


$$
\begin{aligned}
& \lambda_{\mathrm{P}_{2}}=2 \mathrm{Kt}\left(1+\frac{1}{2} \frac{v_{\mathrm{o}} t}{1_{y}}\right) \\
& \lambda_{\mathrm{P}_{3}}=2 \mathrm{Kt}\left(1-\frac{1}{2} \frac{v_{\mathrm{o}} t}{1_{y}}\right) \\
& { }_{\mathrm{P}_{2}, \mathrm{P}_{3}}=\pi / 4,3 \pi / 4 .
\end{aligned}
$$

At large times they become

$$
\begin{aligned}
& \sigma_{x x}^{2}=\lambda_{P_{1}}=2 \mathrm{Kt} \\
& \sigma_{y y}^{2}=\lambda_{P_{2}}=2 \mathrm{Kt}\left[1+\frac{1}{3}\left(\frac{{ }_{0} t^{t}}{1}\right)^{2}\right] \\
& \sigma_{z z}^{2}=\lambda_{P_{3}}=2 \mathrm{Kt} \\
& { }_{\mathrm{P}_{2}, \mathrm{P}_{3}}=0, \pi / 2 .
\end{aligned}
$$

Notice that at large time, the principal axes of the diffusion ellipsoid are again $x, y, z$ and that diffusion in the crosswind direction is enhanced.

The major feature of the present result is the demonstration that for turbulent diffusion, as for Brownian diffusion in a nonuniform gas, (3) a gradient in the mean velocity of the fluid influences the diffusion. Instead of spherical, the diffusion about the mean position is ellipsoidal, with principal axes orientation dictated by the gradient of the wind. An essential difference of the present result from that in Brownian diffusion is the appearance of the time in the correction terms, of course we are intrigued to inquire if this time dependence [cf., e.g., the rhs of (27) or (31)] might explain the observed $t^{2}$ and $t^{3}$ dependence of $\sigma_{y}{ }^{2}$ observed in the upper troposphere and stratosphere. (4)

In conclusion we should point out that the restriction of the analysis, to mean winds which vary at most linearly with the coordinates [cf., (1)], appears to be an essential restriction, since otherwise closure of the moment equations would not be obtained.

I wish to thank S. A. Slinn for her valiant attempt to diagonalize (21) in the general case.

\section{REFERENCES}

1. M. L. Barad and J. J. Fuquay, "Diffusion in shear Flow," J. Applied Met., vol. 1, pp. \&57$264,1962$.

2. F. Pasquizl, Atmospheric Diffusion, D. Van Norstrand Co., N. Y., 1968 .

3. W. G. N. Slinn and S. F. Shen, "Brownian Diffusion in a Nonuniform Gas," J. Stat. Phys., vol. 3, pp. $29 \overline{1-305,1971 .}$

4. F. A. Gifford, "Relative Atmospheric Diffusion of Smoke Puffs," J.Met., vol. 14, p. 410, 1957 .

5. P. G. Saffman, "The Effect of Wind Shear on Horizontal Spread from an Instantaneous Ground Source," Quart. J. Roy. Met. Soc., vol. 88 , pp. 382-393, 1962.

6. F. B. Smith, "The Role of Wind Shear in Horizontal Diffusion of Ambient Particles," Quart. J. Roy. Met. Soc., vol. 91, pp. 318-329, 1965 . 
NATURAL PRECIPITATION WASHOUT OF SULFUR DIOXIDE*

M. T. Dana, J. M. Hales and M. A. Wolf

A field investigation and a modeling effort are being conducted as components of an ongoing program for the study of sulfur-compound washout from power-plant plumes. The theoretical analysis of $\mathrm{SO}_{2}$ washout developed in this work was shown to agree fairly well with field measurements of washout of $\mathrm{SO}_{\mathrm{a}}$ from controlled releases from towers.

Research described in this report was undertaken to elucidate several aspects of $\mathrm{SO}_{2}$ washout identified in a previous study. (1) This research consisted of three parts, including a field investigation of $\mathrm{SO}_{2}$ washout, a laboratory study of $\mathrm{SO}_{2}$ solubility in water, and a program to develop a means of predicting $\mathrm{SO}_{2}$ washout from plumes on the basis of emission data and atmospheric characteristics.

The field investigation was conducted at the Quillayute site in western Washington. It consisted of re- leasing controlled amounts of $\mathrm{SO}_{2}$ from two towers during rain periods and measuring the resulting concentrations in ground-level rain as a function of spatial location beneath the plumes. Release heights were variable, ranging from $7.6 \mathrm{~m}$ to $30.5 \mathrm{~m}$. Ten separate dual tower experiments were conducted during this study.

The laboratory phase was conducted to establish experimentally the relationship between $\mathrm{SO}_{2}$ solubility, concentration, and solution $\mathrm{pH}$. It was found that the equation

$$
\mathrm{c}_{\mathrm{SO}_{2}}=\frac{\left[\mathrm{SO}_{2}\right]_{\mathrm{g}}}{\mathrm{H}}+\frac{-\left[\mathrm{H}_{3} \mathrm{O}+\right]_{\mathrm{ex}}+\sqrt{\left[\mathrm{H}_{3} \mathrm{O}+\right]_{\mathrm{ex}}^{2}+4 \mathrm{~K}_{1}\left[\mathrm{SO}_{2}\right]_{\mathrm{g}} / \mathrm{H}}}{2}
$$

* This work was supported by the Environmental Protection Agency via a related services agreement with the U.S. Atomic Energy Commission. provides good agreement with experiment for the concentration range studied ( 0.05 part per million and above), provided the results of Johnstone and 
Leppla(2) are used for the solubility parameters $\mathrm{H}$ and $\mathrm{K}_{1}$. In Equation (1) the bracketed terms denote concentrations in moles/1iter, $\mathrm{C}_{\mathrm{SO}_{2}}$ is the total dissolved $\mathrm{SO}_{2}$ concentration, and $\mathrm{H}_{3} \mathrm{O}_{\text {ex }}^{+}$denotes the concentration of acid donated by sources other than dissolved $\mathrm{SO}_{2}$.

The modeling program has resulted in two models of $\mathrm{SO}_{2}$ washout. The first of these is based on the assumption of 1 inear transport and equilibrium properties, and was developed in conjunction with the tritium washout study described earlier. (3) The second model is more general and can account for nonlinear behavior. It also can correct for sloping trajectories of the rain as it encounters the plume. This mode1, however, requires computer solution; this contrasts with the linear mode1, which is amenable to hand calculation.

Comparison of the nonlinear mode 1 with results for one of the field experiments is shown in Figure 1. The

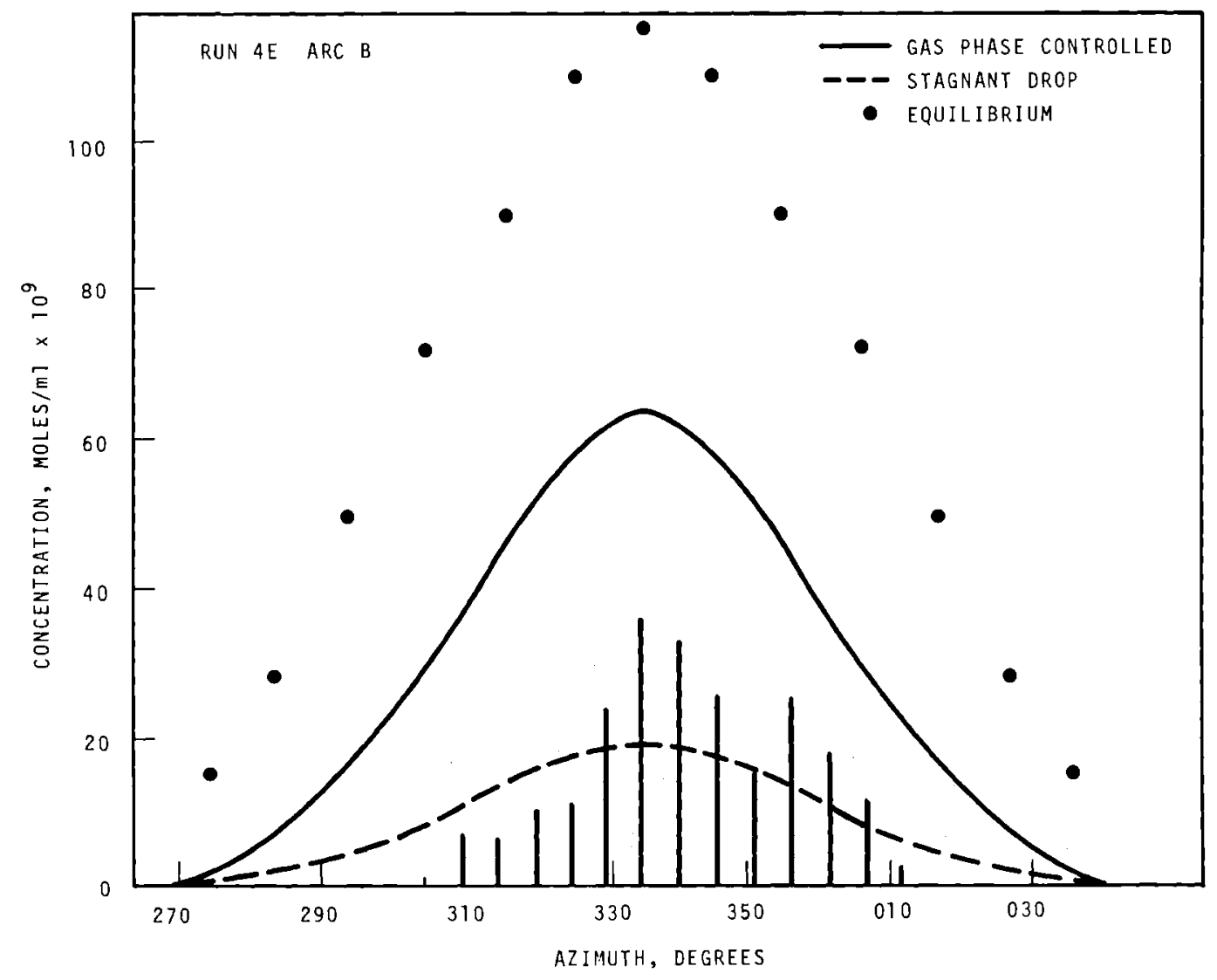

Neg 721308-6

FIGURE 1. Comparison of Measured $\mathrm{SO}_{2}$ Washout Concentrations with Those Predicted on the Basis of the Nonlinear Model and a Time Averaged Plume. Downwind Distance $=200$ feet. 
dashed and solid lines pertain, respectively, to model predictions based on gas-phase limited and stagnant drop behavior [c.f.(1)]. The vertical lines show measured $\mathrm{SO}_{2}$ concentrations and the circular dots denote concentrations in rain that would be in equilibrium with the calculated ground-level concentration of $\mathrm{SO}_{2}$ in the plume.

Calculations leading to Figure 1 were based upon average dispersion parameters for the experiment period. since such averages are not totally appropriate for computing nonlinear washout from fluctuating plumes (1), an attempt was made to define the system in a more "instantaneous" fashion by computing washout for incremental time periods during the experiment. These incremental predictions were averaged to obtain the estimates of washout for the total experiment period, which are shown in Figure 2. Here it is observed that washout predictions under these circumstances do not deviate markedly from those predicted on the basis of time-averaged conditions. Predicted ground-level equilibrium concentrations, however, do exhibit large deviations. This is somewhat perplexing since the close proximity of

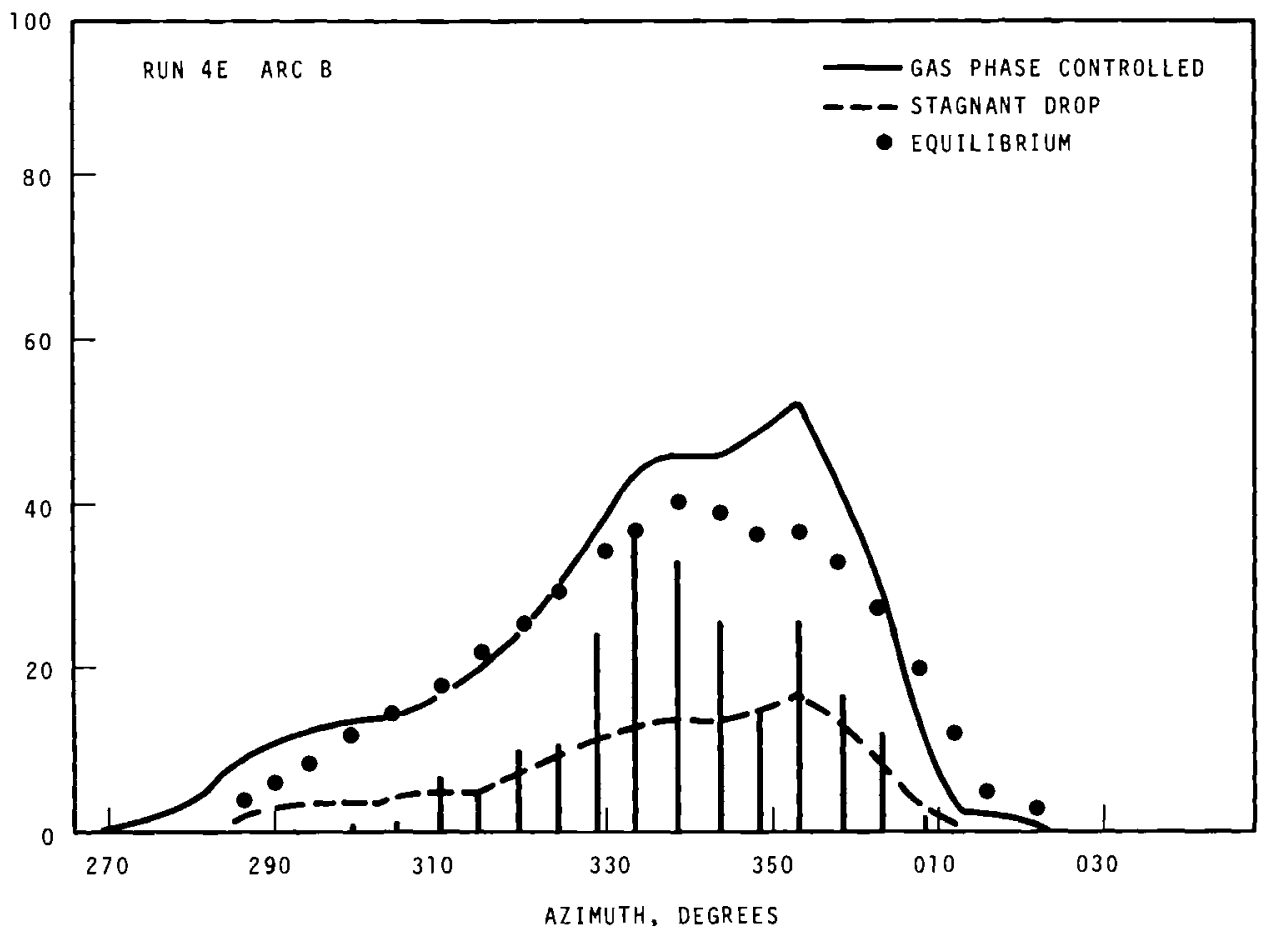

Neg 721308-3

FIGURE 2. Comparison of Measured $\mathrm{SO}_{2}$ Washout Concentrations with Those Predicted Using the Nonlinear Model for Incremental Time Periods. Downwind Distance = 200 feet. 
equilibrium predictions to actual measured washout shown in Figure 2 suggests that the observations can be explained in two ways - - either by a simple equilibrium situation or by the more complex behavior suggested by the general washout models. Although the data obtained from the field experiments suggest that the latter explanation is correct, further measurements are needed to confirm this completely.

The washout models formulated in this investigation will be used in the near future to examine washout of $\mathrm{SO}_{2}$ from a commercial power plant plume.

\section{REFERENCES}

1. J. M. Hales, J.M. Thorp and M. A. Wolf, Field Investigation. of Sulfur Dioxide Washout from the Plume of a large Coal-Fired Power Plant by Natural Precipitation, Final Report to Environmental Protection Agency, Contract CPA 22-69-150, 1971 .

2. H. F. Johnstone and P. W. Leppla, J.Am. Chem. Soc., vol. 56, p. 2233, 1934 .

3. J. M. Hales, Scavenging of Gaseous Tritium Compounds by Rain, BNWL-1659, Battelie, Pacific Northwest Laboratories, Richland, Washington, 1972 .

PRECIPITATION WASHOUT OF GASEOUS TRITIUM COMPOUNDS

\title{
J. M. Hales
}

\begin{abstract}
A theoretical analysis of the washout of tritium compounds from plumes has been completed. Based upon reversible gaswashout theory this analysis provides a means for calculating washout concentrations from plumes of various geometries, including the bivariate-normal distribution. At present no field measurements exist to check the validity of this analysis for tritium compounds; data for SO, washout, however, indicate that agreement between theory and measurement should be acceptable under most circumstances.
\end{abstract}

The investigation of precipitation washout of gaseous tritium compounds (HT, $\mathrm{T}_{2}$, HTO, and $\mathrm{T}_{2} \mathrm{O}$ ) described in the 1970 annual report ${ }^{(1)}$ has been completed. The equations presented in that report have been modified and solved for hypothetical example situations. This work has been completed in conjunction with a related analysis of $\mathrm{SO}_{2}$ washout conducted for the environmental Protection Agency. (2) The equations formulated during this study 
are based upon reversible washout theory (3) and provide expressions for the concentration of scavenged material in rain at ground level. If the mate- rial being scavenged occurs in the atmosphere as a normally distributed plume (with reflection at the ground) then the basic equations are

$$
\begin{aligned}
& c_{A_{O}}(a)=-\frac{Q F \xi}{2 \sqrt{2 \pi} \sigma_{y} \bar{u}} \exp \left(-\frac{y^{2}}{2 \sigma_{y}^{2}}+\frac{\sigma_{z}^{2} \zeta^{2}}{2}\right) \\
& {\left[\exp (\zeta \mathrm{h}) \operatorname{erfc}\left(\frac{-\mathrm{h}-\zeta_{z}{ }^{2}}{\sqrt{2} \sigma_{z}}\right)+\exp (-\zeta \mathrm{h}) \operatorname{erfc}\left(\frac{\mathrm{h}-\zeta_{z}{ }^{2}}{\sqrt{2} \sigma_{z}}\right)\right]} \\
& \zeta=\frac{3 K_{y} H^{\prime}}{v_{t}{ }^{a}} \\
& \xi=-\frac{3 E m}{4 a H^{\prime} \rho_{w}}+\frac{3 K_{y}}{v_{t}{ }^{a}} \text {. }
\end{aligned}
$$
$H^{\prime}=$ partition coefficient for pollutant, $\ell^{3} /$ mole.

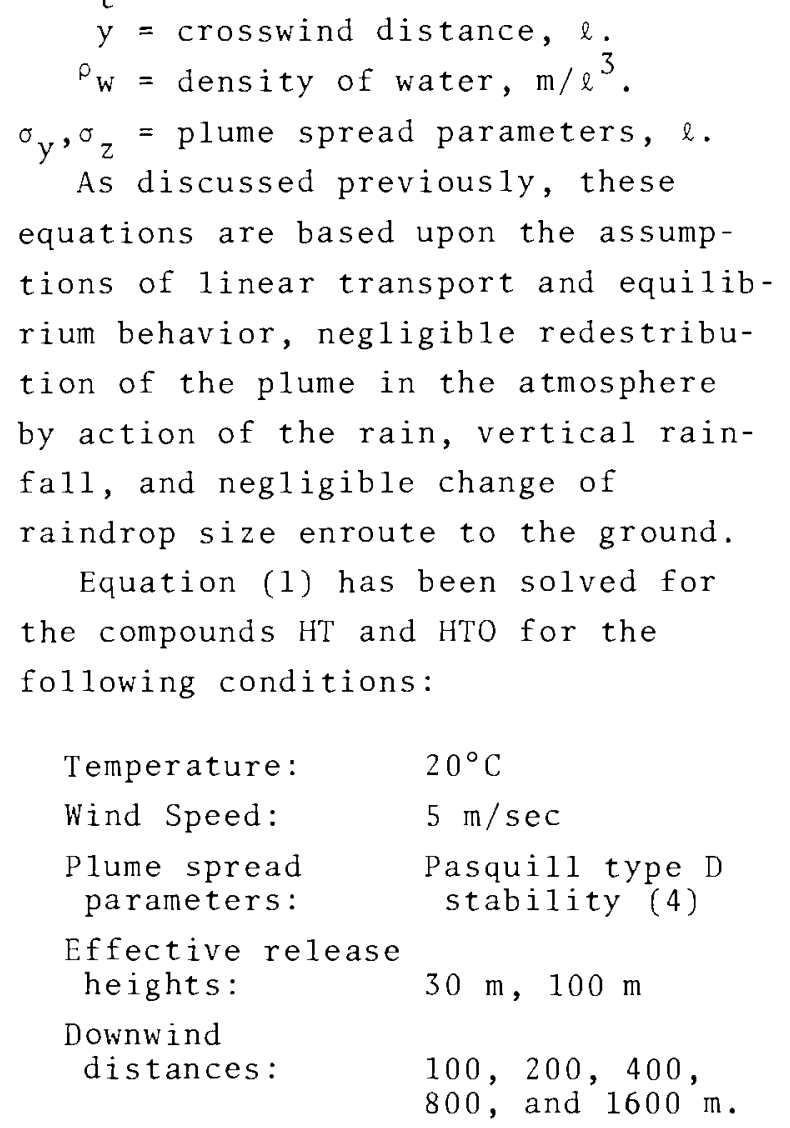




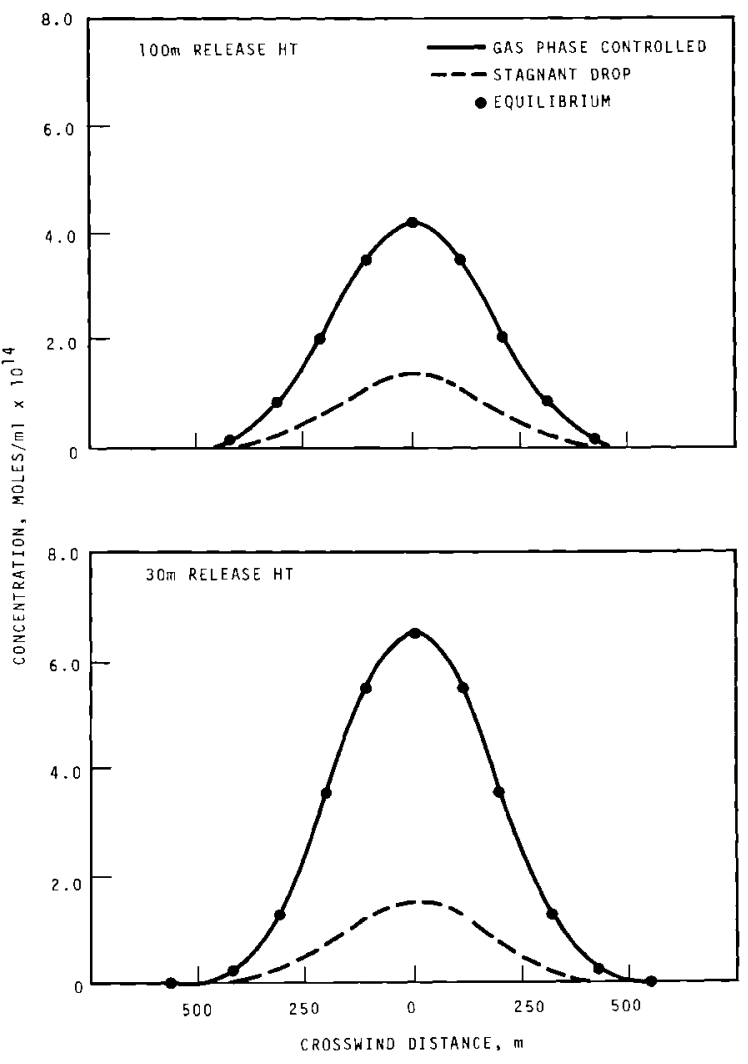

Neg 721308-5

FIGURE 1. Calculated Average Concentrations of HT in Rain at Ground Level, $1600 \mathrm{~m}$ Downwind from Source

concentrations for a typical rainfall. These pertain to HT and HTO in the cross-plume direction for release heights of $30 \mathrm{~m}$ and $100 \mathrm{~m}$ and a downwind distance of $1600 \mathrm{~m}$. A more thorough documentation of results is available elsewhere. (4)

These results predict behavior that differs from that predicted by traditional washout theory in several respects. The most important of these differences are listed as follows:

1. Source height may have a significant effect on washout rates.

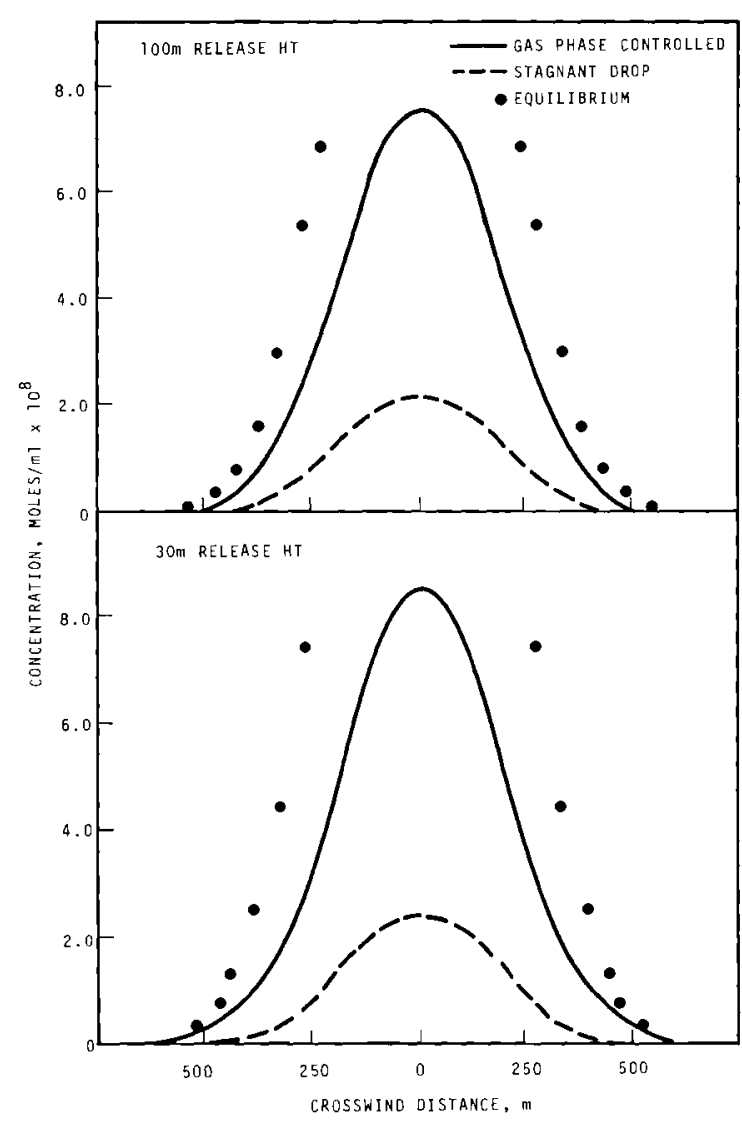

Neg 721308-7

FIGURE 2. Calculated Average Concentrations of HTO in Rain at Ground Level, $1600 \mathrm{~m}$ Downwind from Source

2. Dispersion affects washout significantly.

3. Tritiated water vapor is washed out much more effectively than tritium gas; this occurs because of the greater "solubility" of the former in rainwater.

4. Washout rates can increase with distance from the source under some circumstances.

At present no experimental data exist to indicate how closely these equations agree with actual behavior 
of tritiated compounds. Field data from the related study of $\mathrm{SO}_{2}$ washout however, suggest that agreement within a factor of two may be attained in a majority of cases.

\section{$\underline{\text { REFERENCES }}$}

1. J. M. Hales and L. C. Schwendiman. "Precipitation Scavenging of Tritium and Tritiated Water," $D B M$ Annual Report, vol. II, Part I, p. 82. 1971 .
2. M. T. Dana, J. M. Hales and

M. A. Wolf. Natural Precipitation Washout of Sulfur Dioxide, BNW-389. Report to Environmental Protection Agency, February 1972.

3. J. M. Hales, J.M. Thorp and

M. A. Wolf. Field Investigation of Sulfur Dioxide Washout from the Plume of a Large coat-Fired Power Plant by Natural Precipitation, Einal Report to Environmental Protection Agenoy, contract CPA 22-69-150. 1971.

4. J. M. Hales. Scavenging of Gaseous Tritium Compounds by Rain, BNWL-1659, Battelle Pacific Northwest Laboratories; Richland, WA. 1972 .

\title{
WASHOUT OF RHODAMINE DYE PARTICLES
}

\section{Terry Dana}

\begin{abstract}
An ultrasonic nozzle aerosol dispenser was used in conducting nine additional washout experiments in the rhodamine dye series. Particle mass median radii from 0.08 to 0.21 were dispensed by atomization of methanol-rhodamine solution droplets of initial radii $2.5 \mathrm{\mu}$. An analysis of several physical processes which might have affected the experiments in the series demonstrates that the results of many of them could have represented washout of solution droplets larger than the desired dry particles.
\end{abstract}

This report introduces results of a series of washout experiments in which submicron-sized rhodamine dye particles were dispensed by an ultrasonic nozzle. Completion of the nozzle calibration study (1) has led to a revision of the likely particle sizes generated by the nozzle. In addition, results of previously reported experiments, (2) along with the current results, are analyzed in terms of the effect upon them of washout of not ful1y evaporated methanol-dye solution droplets. 


\section{ULTRASONIC NOZZLE CALIBRATION}

The original calibration of the ultrasonic nozzle relied upon measurements of particle size from electron microscope grids exposed in an electrostatic precipitator. The reported relationship was derived without results of the concurrent sizing made by cascade impactor. The latter sizing effort has been subsequently analyzed. Calculations of effective cutoff radii for the various stages of the six-stage Anderson impactor were done using the theory of Ranz and Wong (3) for the operating conditions of the runs. The average mass median radii of the particles for runs made with various tracer solution concentrations are 1 isted in Table 1 , along with similar results from electrostatic precipitator samples.
The satisfactory agreement between the mass distributions computed two ways for $\mathrm{C}=1$ samples, and the consistency of the values A computed from the cascade impactor runs led to a choice of $\mathrm{A}=2.5 \mu$ for the effective initial droplet diameter of the ultrasonic nozzle.

\section{RECENT EXPERIMENTAL RESULTS}

A series of washout experiments using the ultrasonic nozzle was conducted at Quillayute Airport in Washington. Table 2 lists experimental details for the nine successful experiments of the series. Of two others, one was aborted because of an unacceptable change in weather, and one resulted in too-low tracer concentrations in the rain because of insufficient mass dispensed.

TABLE 1. Ultrasonic Nozzle Particle Sizes

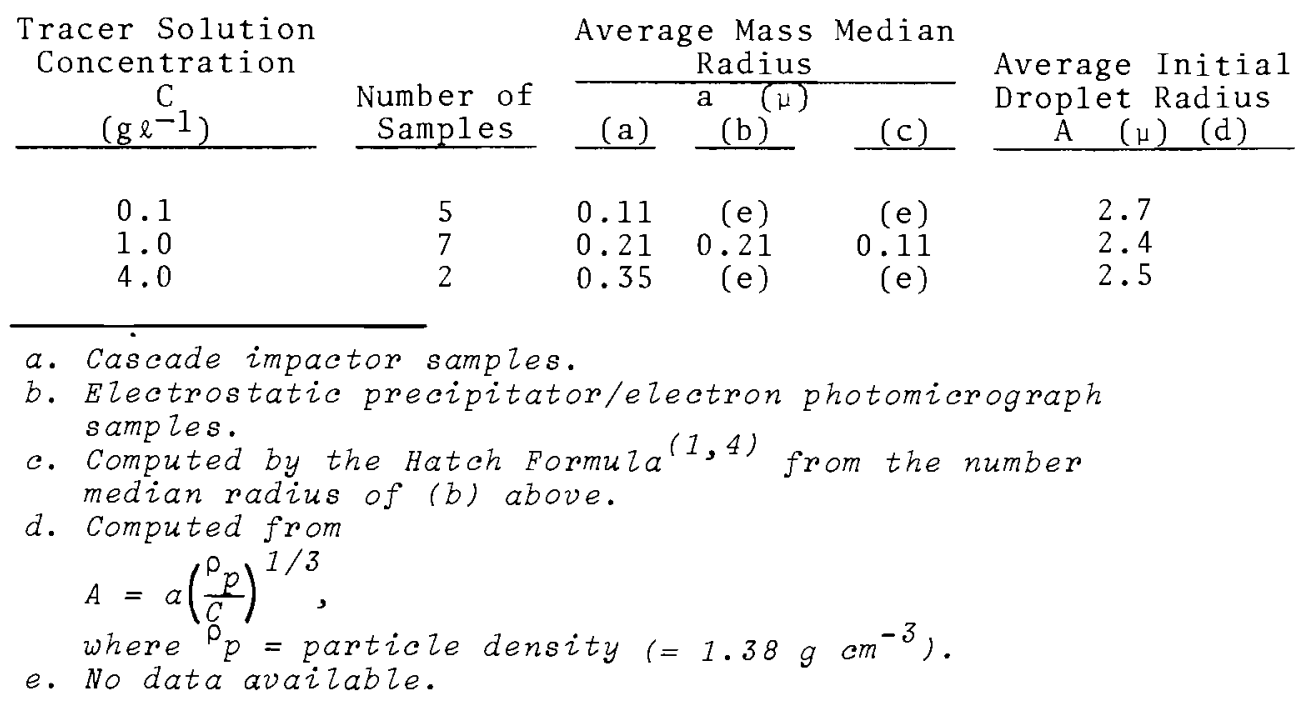

0.35

(e)
(e)
0.11

(e)

$A \quad(\mu) \quad(d)$

a. Cascade impactor samples.

b. Electrostatic precipitator/electron photomicrograph

c. Computed by the Hatch Formuza(1,4) from the number median radius of (b) above.

d. Computed from

$A=\alpha\left(\frac{\rho_{p}}{C}\right)^{1 / 3}$,

where $\rho_{p}=$ particle density $\left(=1.38 \mathrm{~g} \mathrm{~cm}^{-3}\right)$.

e. No data available. 
TABLE 2. Experimental Details: Ultrasonic Nozzle Experiments

\begin{tabular}{|c|c|c|c|c|c|c|}
\hline $\begin{array}{c}\text { Experi- } \\
\text { ment }\end{array}$ & $\begin{array}{c}\text { Particle } \\
\text { Radius } \\
\text { a } \\
(\mu) \\
\end{array}$ & $\begin{array}{c}\text { Mass of Tracer } \\
\text { Released } \\
\text { Q } \\
(\mathrm{g}) \\
\end{array}$ & $\begin{array}{l}\text { Rainfall } \\
\text { Intensity } \\
\mathrm{J} \\
(\mathrm{mm} \mathrm{hr}-1) \\
\end{array}$ & $\begin{array}{c}a / J \\
\left(\mathrm{~mm}^{-1}\right)\end{array}$ & $\begin{array}{c}{ }^{\mathrm{A}} \\
\left(\mathrm{hr} \mathrm{r}^{-1}\right) \\
\end{array}$ & $\begin{array}{c}{ }^{\mathrm{B}} \\
\left(\mathrm{h} \mathrm{r}^{-1}\right) \\
\end{array}$ \\
\hline UR -3 & 0.10 & 0.06 & 2.1 & $1.25(\mathrm{a})$ & 0.22 & 0.23 \\
\hline UR - 4 & 0.10 & 0.05 & 6.3 & 1.25 (a) & 0.20 & (b) \\
\hline UR - 5 & 0.21 & 0.53 & 1.8 & 1.51 & 0.10 & (b) \\
\hline UR - 6 & 0.21 & 0.95 & 2.2 & 1.38 & 0.30 & (b) \\
\hline UR - 7 & 0.21 & 0.43 & 3.6 & 2.2 (a) & 0.10 & 0.25 \\
\hline UR - 8 & 0.10 & 0.28 & 0.81 & 1.65 & 0.12 & 1.3 \\
\hline UR - 9 & 0.21 & 1.48 & 0.44 & 1.60 & 0.28 & 1.3 \\
\hline UR - 10 & 0.08 & 0.14 & 1.8 & 1.20 & 0.24 & 0.64 \\
\hline UR - 11 & 0.10 & 0.23 & 2.1 & 1.50 & 0.38 & 2.0 \\
\hline
\end{tabular}

a. Estimated from other Quillayute experience.

b. No data available.

The experimental "apparent" washout coefficients for Arc A (radius $22.9 \mathrm{~m})$ and $\operatorname{Arc} B(45.7 \mathrm{~m})$ are indicated as ${ }^{\Lambda} A$ and ${ } B$, respectively. The quantity $\alpha$ is defined by

$$
\Lambda=\alpha \mathrm{E}
$$

where $E$ is a mean collection efficiency for the particle spectrum and a given raindrop spectrum. $\alpha$ - - the washout coefficient if $\mathrm{E}$ is unity -is a description of the rainfall:

$$
\alpha=\frac{\pi}{4} \quad \mathrm{~F} \quad \mathrm{D}_{2}^{2}
$$

where $F$ is the total rain flux $\left(\mathrm{mm}^{-2} \mathrm{hr}^{-1}\right.$ ) and $\mathrm{D}_{2}$ is the mean areal raindrop diameter (mm); $\alpha$ is generally proportional to rainfall rate in continuous prefrontal rain. Thus the usually observed rate dependency of $\Lambda$ is attributable to $\alpha$, and for raindrop sizes in the range of interest here, the collection efficiency -. for inertial washout - is practically independent of raindrop size. The dependency is chiefly on particle size and density. (5)

\section{ANALYSIS}

Experimental collection efficiencies for the current runs and previous experiments (pneumatic atomization), (2) are listed in Table 3 , and are plotted in Figure 1, as a function of expected particle radius a. The solid lines represent the inertial washout theory as compiled by Slinn, (5) for particle densities appropriate to solid rhodamine $\left(1.38 \mathrm{~g} \mathrm{~cm}^{-3}\right)$ and methanol $\left(0.8 \mathrm{~g} \mathrm{~cm}^{-3}\right)$. Three potentially influential processes were considered in an attempt to explain the divergence between experiment and theory. 
TABLE 3. Data Summary: Rhodamine Dye Experiments

\begin{tabular}{|c|c|c|c|c|c|c|c|c|c|c|c|c|c|c|c|c|}
\hline Run & a & $\mathrm{E}_{\mathrm{A}}$ & $\mathrm{E}_{\mathrm{B}}$ & $\mathrm{v}_{\mathrm{MA}}$ & $v_{M B}$ & $\overline{11}$ & $\mathrm{D}_{\mathrm{CO}}$ & $\mathrm{D}_{2}$ & $\mathrm{D}_{2}^{\prime}$ & $\mathrm{E}_{\mathrm{A}}^{\prime}$ & $\mathrm{E}_{\mathrm{A}}^{\prime}\left(\mathrm{v}_{\mathrm{D}}=1\right)$ & $E_{B}\left(v_{D}=1\right)$ & $a_{A}^{\prime}$ & $t_{A}^{\prime}$ & $t_{B}$ & $a_{B}$ \\
\hline & $\overline{(\mu)}$ & & & & sec & & & $(\mathrm{mm})$ & & & & & (N) & $\bar{r}_{\mathrm{s}}$ & & $\overline{(\mu)}$ \\
\hline UIL -23 & 0.36 & 0.91 & 0.67 & 13. & 0.45 & 376 & 0.35 & 0.52 & 0.76 & 1.09 & 1.00 & 0 & $\geq 10$ & 3.3 & 8.0 & 7.2 \\
\hline-24 & 0.61 & 0.33 & 1.14 & 0.94 & 2.27 & 618 & 0.58 & 0.81 & 1.20 & 0.40 & 0 & 0.64 & 0 & 1.9 & 4.8 & 1.8 \\
\hline-25 & 4.5 & 0.95 & 2.28 & 1.65 & 1.10 & 670 & 0.63 & 0.52 & 1.06 & 1.14 & 0.44 & 0.21 & 3.6 & 1.4 & 2.7 & 4.5 \\
\hline-26 & 0.45 & 0.77 & 1.09 & 4.2 & 1.79 & 882 & 0.83 & 0.79 & 1.46 & 0.92 & 0.70 & 0.48 & 5.5 & 1.1 & 2.5 & 4.5 \\
\hline-27 & 0.45 & -- & 0.82 & - & 5.20 & 1152 & 1.08 & 0.73 & 1.70 & -- & - & 0.66 & -- & 0.7 & - & 8. \\
\hline-31 & 0.65 & 0.23 & 0.69 & 5.74 & 0.93 & 420 & 0.39 & 0.63 & 0.88 & 0.24 & 0.20 & 0 & 2.3 & 3.0 & 7.5 & 0.65 \\
\hline-32 & 0.65 & 0.29 & 0.80 & 1.39 & 0.86 & 354 & 0.33 & 0.63 & 0.81 & 0.30 & 0.084 & 0 & 1.5 & 3.8 & 9.5 & 0.65 \\
\hline-33 & 2.0 & 0.27 & 1.26 & 35. & 3.42 & 422 & 0.40 & 0.63 & 0.88 & 0.28 & 0.27 & 0.89 & 2.7 & 3.0 & 7.4 & 2.0 \\
\hline-34 & 0.68 & 0.49 & 0.52 & 8.02 & 4.02 & 370 & 0.35 & 0.60 & 0.80 & 0.51 & 0.45 & 0.39 & 3.7 & 3.5 & 8.8 & 0.68 \\
\hline-35 & 0.68 & 1.0 & 2.2 & 1.30 & 2.10 & 800 & 0.75 & 0.59 & 1.24 & 1.24 & 0.29 & 1.15 & 2.8 & 1.1 & 2.1 & 2.2 \\
\hline-36 & 1.9 & 0.33 & 0.63 & 17.6 & 8.45 & 820 & 0.77 & 0.52 & 1.15 & 0.44 & 0.41 & 0.55 & 3.5 & 0.9 & 1.5 & 3.2 \\
\hline-37 & 1.9 & 0.49 & 1.9 & 4.75 & 3.09 & 900 & 0.84 & 0.47 & 1.42 & 0.68 & 0.54 & 1.29 & 4.3 & 1.0 & 0.5 & 4.6 \\
\hline-38 & 4.5 & 0.87 & 0.70 & 39. & 5.29 & 900 & 0.84 & 0.63 & 1.18 & 1.24 & 1.00 & 0.57 & $\geq 10$ & 0.7 & 1.7 & 9.5 \\
\hline-39 & 0.68 & 0.23 & 0.27 & 65.5 & 1.97 & 305 & 0.29 & 0.74 & 0.84 & 0.23 & 0.23 & 0.13 & 2.5 & 5.0 & 12.1 & 0.58 \\
\hline-40 & 1.9 & 0.26 & 0.32 & 29.2 & 1.86 & 290 & 0.27 & 0.82 & 0.87 & 0.26 & 0.25 & 0.15 & 2.6 & 5.4 & 13.1 & $1 . y$ \\
\hline-41 & 1.9 & 0.31 & 0.31 & 2.60 & 1.22 & 325 & 0.30 & 0.67 & 0.80 & 0.31 & 0.19 & 0.06 & 2.3 & 4.4 & 10.9 & 1.9 \\
\hline-42 & 4.5 & 0.35 & 0.54 & 9.60 & 3.52 & 475 & 0.45 & 0.71 & 0.79 & 0.36 & 0.32 & 0.39 & 3.0 & 2.1 & 6.6 & 4.5 \\
\hline-43 & 0.45 & 0.52 & 0.62 & 252 . & 8.06 & 580 & 0.54 & 0.60 & 0.90 & 0.59 & 0.59 & 0.55 & 4.6 & 1.7 & 4.3 & 3.0 \\
\hline-44 & 0.45 & 0.63 & 0.42 & 15.7 & 7.13 & 575 & 0.54 & 0.73 & 0.79 & 0.58 & 0.55 & 0.36 & 4.3 & 1.3 & 5.0 & 2.0 \\
\hline UR-3 & 0.10 & 0.084 & 0.088 & 3.4 & 0.42 & 605 & 0.57 & 0.70 & 1.12 & 0.084 & 0.059 & 0 & 1.25 & 1.9 & 4.5 & 0.10 \\
\hline-4 & 0.10 & 0.025 & -- & 2.0 & -- & 493 & 0.46 & 0.71 & 0.96 & 0.029 & 0.015 & -- & 0.61 & 2.4 & 6.3 & 0.10 \\
\hline-5 & 0.21 & 0.037 & -- & 0.48 & - & 586 & 0.55 & 0.75 & 1.07 & 0.037 & 0 & -- & 0 & 2.6 & 5.0 & 0.21 \\
\hline-6 & 0.21 & 0.10 & -- & 1.9 & -- & 547 & 0.51 & 0.75 & 1.09 & 0.100 & 0.047 & -- & 1.10 & 2.2 & 5.5 & 0.21 \\
\hline-7 & 0.21 & 0.013 & 0.032 & 0.73 & 0.16 & 752 & 0.71 & 0.65 & 1.23 & 0.013 & 0 & 0 & 0 & 1.3 & 2.8 & 0.21 \\
\hline-8 & 0.10 & 0.09 & 0.97 & 0.62 & 1.08 & 457 & 0.43 & 0.65 & 0.78 & 0.097 & 0 & 0.068 & 0 & 2.3 & 6.7 & 0.10 \\
\hline-9 & 0.21 & 0.40 & 1.8 & 7.55 & 0.88 & 506 & 0.47 & 0.42 & 0.98 & 0.60 & 0.53 & 0 & 4.2 & 2.3 & 3.9 & 2.7 \\
\hline-10 & 0.08 & 0.14 & 0.30 & 12.3 & 1.28 & 797 & 0.75 & 0.65 & 1.39 & 0.14 & 0.13 & 0.066 & 1.9 & 1.3 & 2.4 & 0.70 \\
\hline-11 & 0.10 & 0.12 & 0.64 & 1.83 & 1.59 & 775 & 0.73 & 0.65 & 1.21 & 0.18 & 0.081 & 0.24 & 1.5 & 1.2 & 2.6 & 0.50 \\
\hline
\end{tabular}

\section{Dry Deposition}

The "raw" collection efficiencies $E_{A}$ and $E_{B}$ describe the total deposition, and may be expected to contain a component due to dry deposition.

The deposition velocity, $V_{D}$, is defined by:

$$
\mathrm{V}_{\mathrm{D}}=\frac{\mathrm{F}_{\mathrm{D}}}{\mathrm{x}} \text {. }
$$

where $x$ is the air concentration of tracer $\left(\mathrm{g} \mathrm{cm}^{-3}\right)$ and $\mathrm{F}_{\mathrm{D}}$ is the dry component of the tracer flux $\left(\mathrm{g} \mathrm{cm}^{-2} \mathrm{sec}^{-1}\right)$. Washout measurements provide a flux $F_{T}$ (total wet and dry) to the precipitation collector. If $x$ is suitably measured or calculated, a maximum dry deposition velocity can be calculated:

$$
\mathrm{V}_{\mathrm{M}}=\frac{\mathrm{F}_{\mathrm{T}}}{\mathrm{x}} \text {. }
$$

$V_{M}$ was evaluated for each arc of each run; these are 1 isted in Table 3 .

The air concentration at the plume centerline, ground level, was calculated* from the bivariate normal plume with reflection:

$$
x=\frac{Q}{T} \frac{1}{\pi \sigma_{y}{ }_{z} \overline{\mathrm{u}}} \exp \left[-\frac{1}{2}\left(\frac{\mathrm{h}}{\sigma_{z}}\right)^{2}\right]
$$

where:

$$
\begin{aligned}
Q= & \text { mass of tracer released in } \\
& \text { time } T \text {; }
\end{aligned}
$$

* Air concentrations were measured with filters on several of the runs. The results were scattered and the filter air flow rates were not precisely known. Agreement with calculations was within a factor of two or three, however. Measurements at simizar distances from the source by Dana, et al(6) showed similar agreement with $\mathrm{SO}_{2}$ as the tracer. 


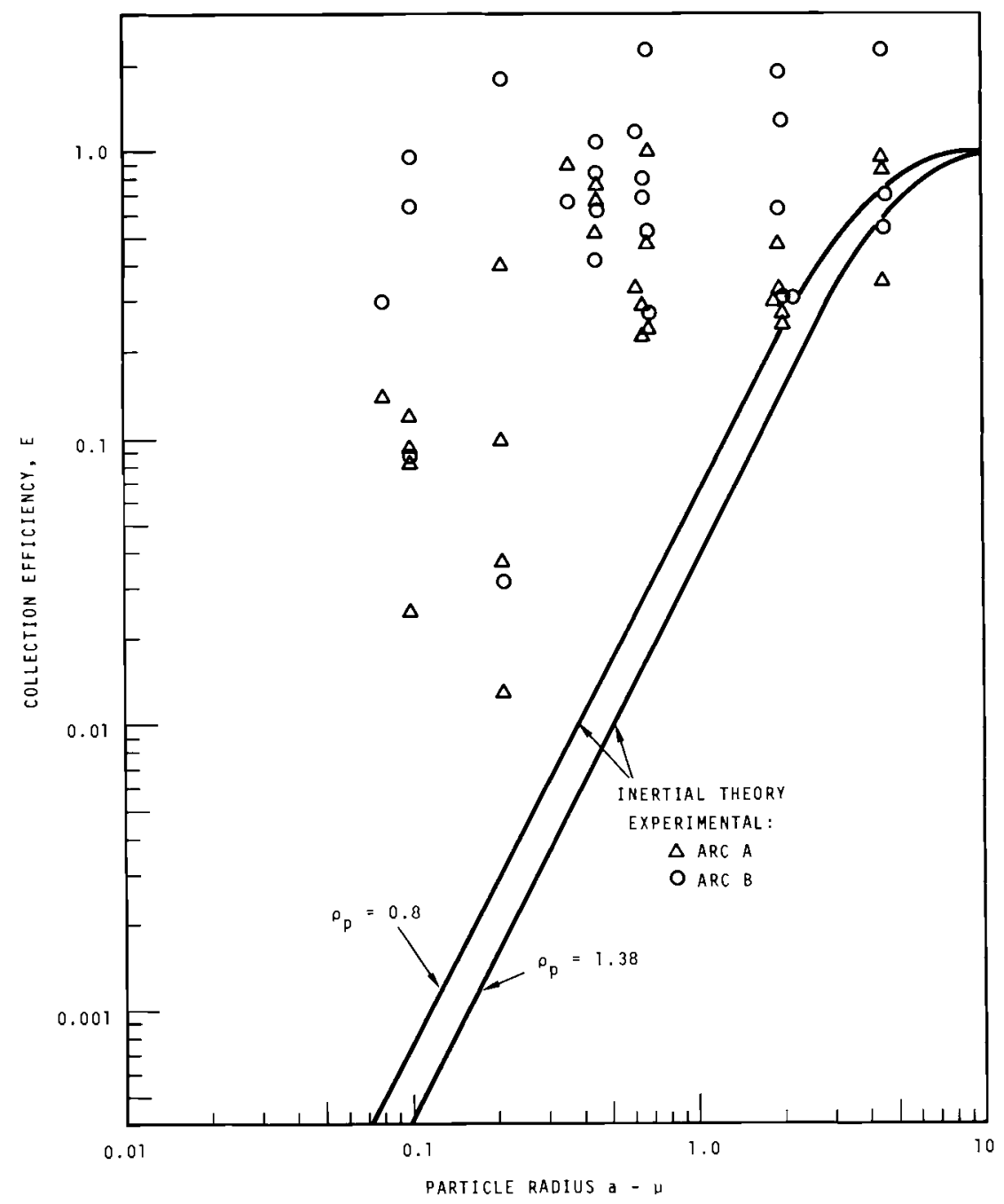

Neg 721170-6

FIGURE 1. Experimental Apparent and Theoretical Collection Efficiencies for Rhodamine Dye Particles

$\sigma_{y}, \sigma_{z}=$ plume distribution parameters (determined from the deposited mass distributions, and through $\sigma_{y}=\sigma_{\theta} \theta^{x}$

$\sigma_{z}=\frac{2}{3} \sigma_{y}$, where $x$ is the range from the source).

Values of $V_{M}$ comparable to a reasonable choice of deposition velocity (e.g., $1 \mathrm{~cm} \mathrm{sec}^{-1}$ ) would indicate the likelihood of a considerable dry component in the observed deposition.
The values of $V_{M}$ in Table 3 are generally greater (especially for ArC A) than $1 \mathrm{~cm} \mathrm{sec}^{-1}$; i.e., they are such that a considerable dry deposition velocity is required for the dry component to constitute a significant portion of the total deposition. Consequently, dry deposition appears to be a minor contributor to ArC A results and does not completely explain the divergence from the theory. 
2. Undercutting of the Plume by Precipitation

Figure 2 schematizes the process by which the rain which falls onto Arc A may be significantly that which has not encountered the tracer plume. The cutoff diameter, the diameter of a raindrop which just passes the tower top enroute to Arc A, was calculated for each run. From Figure 2 , it is evident that

$$
v_{t c o}=\frac{h \bar{u}}{x_{A}}
$$

where $V_{\text {tco }}$ is the terminal velocity of the cutoff raindrop, h the tower height, $\bar{u}$ the mean wind speed, and $x_{A}$ the distance from the source to Arc A. For raindrop sizes of interest here, $V_{t} \simeq 4000 D$, so

$$
D_{C O}=\frac{h \bar{u}}{4000 x_{A}} \text {. }
$$

A11 raindrops smaller than $\mathrm{D}_{\text {co }}$ were eliminated from the rain spectra, and new values of the "washout-effective" rain flux and mean areal diameter $\left(D_{2}^{\prime}\right)$ were compiled. By (2), this leads to new washout factors $\alpha^{\prime}$, and thus new collection efficiencies $\mathrm{E}_{A}^{\prime}$. The latter are shown in Table 3 . The increase in washout is relatively smal1--even when $90 \%$ of the raindrops are eliminated by the cutoff--because while $D_{2}$ increases, $F$ decreases.

The trajectory of the new mean raindrop diameter defines an interception time

$$
t_{A}^{\prime}=\frac{x_{A}}{\bar{u}}-\frac{h}{4000 D_{2}^{\prime}}
$$

The cutoff effect is slight for Arc B, and was neglected; thus the interception time for Arc B is:

$$
t_{B}=\frac{x_{B}}{\vec{u}}-\frac{h}{4000 D_{2}} \text {. }
$$

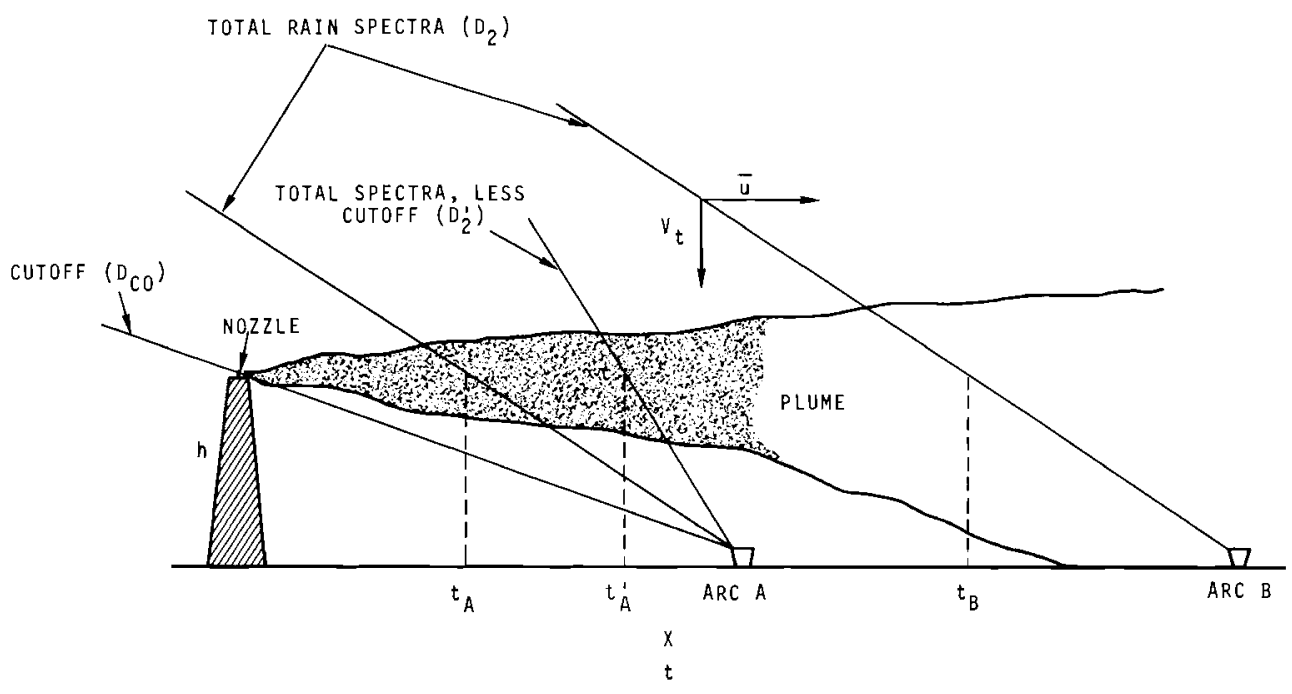

Neg 721419-7

FIGURE 2. Mean Raindrop Trajectories and Plume Interception Times 
This cutoff effect, a combination of rain spectra and wind characteris tics, serves to provide an increased value of the collection efficiency on Arc $A$, and an interception time for Arc A which is still quite short in most cases. Perhaps most significantly, the cutoff effect tends to bring the interception times for Arc A and $B$ closer together. Thus, any aerosol characteristics which may be relatively slowly changing in time may be influential upon the washout results for both arcs.

\section{Washout of Unevaporated Methano1 Droplets}

Concern arose from the above since in the event that the methanol droplets (initially $\sim 20 \mu$ radius for pneumatic atomization, $2.5 \mu$ for ultrasonic atomization) do not evaporate quickly, they could be washed out, and undesirably increase the arc deposition results. Assuming that the washout for $\operatorname{Arc} A$ does conform to the inertial theory for methanol $\left(\rho_{p}-0.8\right)$, the appropriate effective radii for washout were found from Figure 1 , and plotted vs. $t_{A}^{\prime}$ in Figure 3. Since dry deposition should not be dismissed, the values $\mathrm{E}_{\mathrm{A}}^{\prime}$ were adjusted for an arbitrary deposition velocity of $V_{D}=1 \mathrm{~cm} \mathrm{sec}-1$. This adjustment can be made by using a variation of (3):

$$
E_{A}^{\prime}\left(V_{D}\right)=E_{A}^{\prime}\left(1-V_{D} / V_{M}\right) .
$$

Figure 3 demonstrates the plausibility of the assumption of methanol droplet washout, and indicates that the evaporation rate is sufficiently slow in some cases to affect the wash-

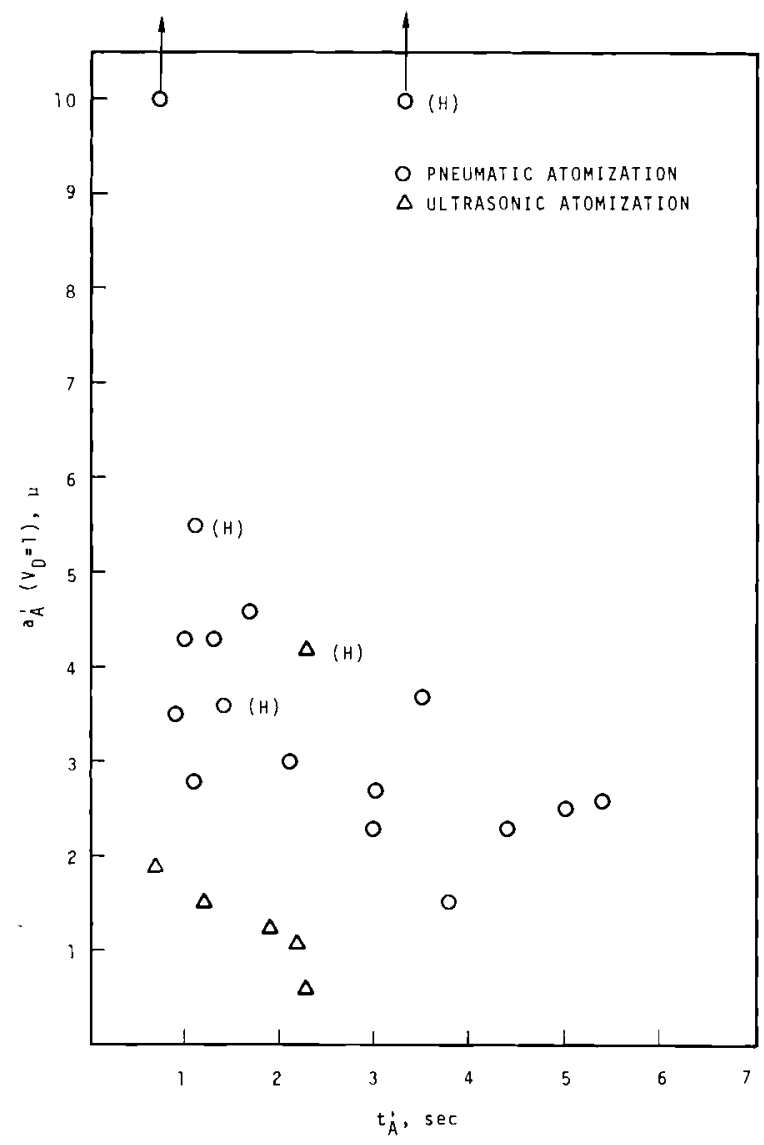

Neg 721419-6

FIGURE 3. Methanol/Rhodamine Droplet Evaporation.

out on Arc B as well. The points marked "H" are for runs in which the methanol release rate was significantly higher than the others; these points suggest a tendency for slower evaporation as the release rate is increased.

It is clear that the atomized methanol droplets immediately begin to evaporate upon introduction into the methanol-vapor-free atmosphere, decreasing in size sharply. But at some point the rate of evaporation slows due to the increase of the methanol vapor pressure to which the droplets are exposed. 
Using the apparent evaporation rates indicated by Figure 3 , values of $a_{B}$ were found that correspond to $t_{B}$. Applying (10) to B --

$$
E_{B}\left(V_{D}\right)=E_{B}\left(1-V_{D} / V_{M}\right)
$$

with $V_{D}=1 \mathrm{~cm} \mathrm{sec}^{-1}--1$ ed to the values of $E_{B}\left(V_{D}=1\right)$ plotted in Figure 4 versus $a_{B}$. For some of the runs (those for which $V_{M} \leq 1$ ) washout was eliminated completely, the suggestion being that dry deposition could have accounted for all of the observed deposition.

There remain several points on Figure 4 which diverge from the theory. It is interesting to note that four of these $(33,34,39,8)$ were runs where $t_{B}$ was relatively large: the particles

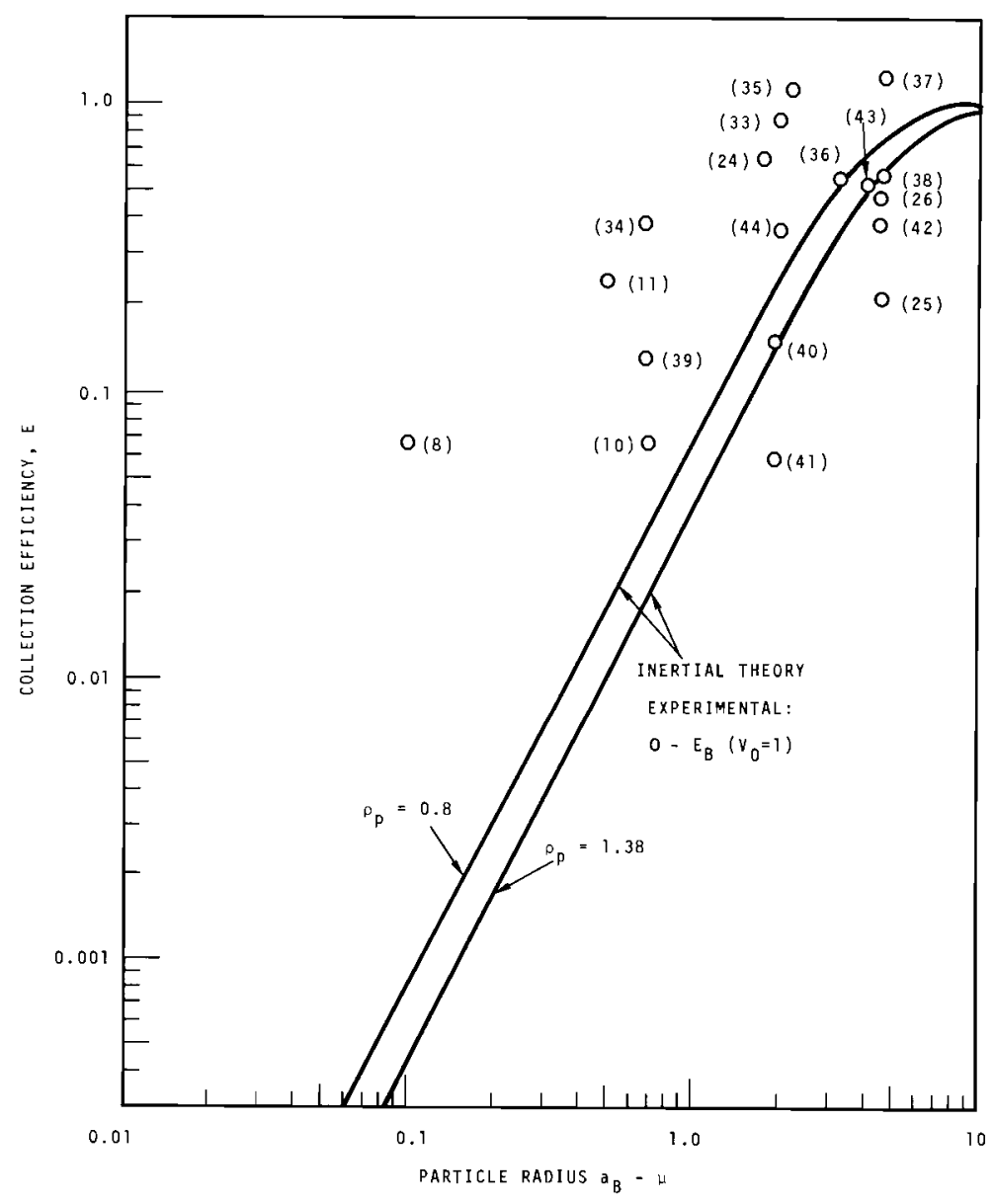

Neg 721170-5

FIGURE 4. ArC B Experimental (with Dry Deposition Correction) and Theoretical Collection Efficiencies for Rhodamine Dye Particles 
were exposed to the atmosphere for a longer time than in most other experiments. The indication of high washout then may be due to another size-increase effect, namely that of condensation growth of the soluble rhodamine particles. The ability of rhodamine particles to grow in this manner in a near-saturated water vapor environment is expected to be evaluated soon.

\section{THEORETICAL CONSIDERATIONS}

While it seems plausible that the observed washout is compatible with the above analysis, additional theoretical developments should not be dismissed. For small particles $(\stackrel{<}{\sim} 0.1 \mu)$ Brownian diffusion comes into play as a washout mechanism, leading to higher values of the collection efficiency than those due to inertial effects alone. Thermophoresis may be an important enhancer of washout in the range of particle size up to about $1 \mu$, if the temperature of the raindrop is significantly cooler than that of its surroundings. (7) Electrical effects may also be significant for this size range. Enhanced collection efficiencies have been observed (8) for electrical conditions which may have been extant at the time of the experiments reported here. (9) Finally, in the particle size range $\gtrsim 10 \mu$, the inertial theory can allow collection efficiencies in excess of unity. $(10,11)$ The approximation to the inertial theory used in Figures 1 and 4 predicts collection efficiencies approaching unity as ymp totical1y.

\section{REFERENCES}

1. M. T. Dana. "Calibration of an Ultrasonic Nozale for Aerosol Generation," Pacific Northwest Laboratory Annual Report for 1970 , vol. II: Physical Sciences, Part 1, Atmospheric Sciences, BNWL-1551-1, pp.98-101. BattelzePacific Northwest Laboratories, Richland, Washington. June, 1971.

2. M. T. Dana. "Washout of Soluble Dye Particles," Pacific Northwest Laboratory Annual Report for 1970, vol. II: Physical Sciences, Part 1, A tmospheric Sciences, BNWL-1551-1, pp. 63-6?, BattellePacific Northwest Laboratories, Richiand, Washington. June, 1971.

3. W. E. Ranz and J. B. Wong. "Jet Impactors for Determining the Particle-siae Distributions of Aerosols," Arch. Ind. Hyg. Occup. Med., vol. 5, pp.464-477, 1952.

4. T. F. Hatch and S. Choate. "Statistical Description of the Size Properties of Non-Uniform Particulate Substances," J. Franklin Inst., vol. 207,

5. W.G.N. Slinn. "Numerical Exploration of Washout of Aerosol Particles," Pacific Northwest Laboratory Annual Report for 1970 . vol. II: Physical Sciences, Part 1. A tmospheric Sciences, BNWL-1551-1, pp. 75-81, BattellePacific Northwest Laboratories, Richland, washington. June, 1971.

6. M. T. Dana, J. M. Hales and M. A. Wolf. Natural Precipitation Washout of Sulfur Dioxide, Report to the Division of Meteor., Environmental Protection Agency, BNW-389. February, 1972.

7. W.G.N. Slinn and J. M. Hales. "Phoretic Processes in Scavenging," Precipitation Scavenging (1970), $\bar{R}$. J. Engelmann and W.G.N. Slinn, Coord's., pp. 411-422, AEC Symposium Series, No. 22, Available from NTIS as CONF-700601. 1970. 
8. J. R. Adam and R. G. Semonin. "Collection Efficiencies of Raindrops for Submicron Particulates," Precipitation Scavenging (1970), $R$. J. Engelman and W.G.N. Slinn, Coord's., pp. 151-160, AEC Symposium Series No. 22, Available from NTIS as CONE-700601. 1970.

9. M. T. Dana. "Raindrop Electric Charge: Continuous versus Showery Rainfazz," Pacific Northwest Laboratory Annual Report for 1970 , vol. II: Physical Sciences, Part 1. Atmospheric Sciences,
BNWL-1551-1, pp. 91-97, BattellePacific Northwest Laboratories, Richland, Washington. June, 1971.

10. B. J. Mason. The Physics of Clouds, oxford University Press, London. pp. 422-424, 1957 .

11. P. K. Das. "The Growth of Cloud Droplets by Coalescence," Indian J. Met. Geophys., vol. 1, p. 137, 1950 .

\title{
AEROSOL PARTICLE SIZE DISTRIBUTIONS IN THE NORTHWEST*
}

A. J. Alkezweeny and W. G. N. Slinn

\begin{abstract}
Surface level, aerosol particle size distributions were measured at several sites in washington state: near Richland, at Seattle, and on the olympic Peninsula. The Richland data are representative of an unpoliuted continental atmosphere and for particle diameter, $D$, in the range 0.2 to 2 microns, $d N / d D \sim$ D-a, with an 5. The data obtained on the olympic Peninsula have characteristics expected of a maritime aerosol. Preliminary results are also given of the effect of wind on resuspension of aerosol particles from a desert terrain.
\end{abstract}

\section{INTRODUCTION}

Knowing the characteristics of background atmospheric aerosols and gases is important for the evaluation of the effect of contaminant releases. To see this, consider some of the possible

* Work supported in part by Battelze Memorial Institute, Physical Sciences Program atmospheric interactions for a particular release. Its physical and chemical properties may be modified within the atmosphere via interactions with trace gases; it may attach to background aerosol particles and its subsequent dry deposition may depend on the size of the aerosol particle to which it attached; it may enter into cloud forming processes and either its behavior in the cloud will be dictated by the 
cloud droplet and ice crystal nucleation capabilities of the background aerosol particle to which it is attached and/or it will be in competition with the background concentration of these nuclei; if it is not removed by precipitation scavenging, then its properties upon leaving the cloud environment will probably be significantly different from its properties when it entered, as a result of enhanced in-cloud coagulation with other background aerosol particles and gases, within the cloud droplets. This scenario could obviously be continued but perhaps the above sufficiently illustrates the essential roles played by background aerosols and gases.

Toward determining more information on background aerosols, and to circumvent past difficulties encountered with developing an airborne research platform, we have obtained the size distribution of background aerosol particles measured near ground elevation. Little is known about continental and maritime aerosols in an unpolluted atmosphere. Here, we report on several size distributions, over the particle size range 0.015 to $5 \mathrm{\mu} \mathrm{ra-}$ dius, measured at three sites in Washington state: near Richland, at Seattle, and on the Olympic Peninsula Some preliminary studies of the influence of wind on resuspension from a desert terrain are also reported.

The three instruments used to char acterize the aerosol particles were a General Electric Aitken nuclei counter, a Royco Optical Counter (model PC 200 A), and a Whitby Aerosol Analyzer. Temperature, relative humidity and sur- face level ( $2 \mathrm{~m}$ ) winds were either measured on site or obtained from nearby weather stations.

\section{SIZE DISTRIBUTION MEASUREMENTS}

The Richland surface measurements (probe height of about 3 meters) were made on the AEC reservation $50 \mathrm{~km}$ north of the city, and about $300 \mathrm{~km}$ east of the Pacific Ocean, on October 7, and 8, 1971 (See Figure 1).

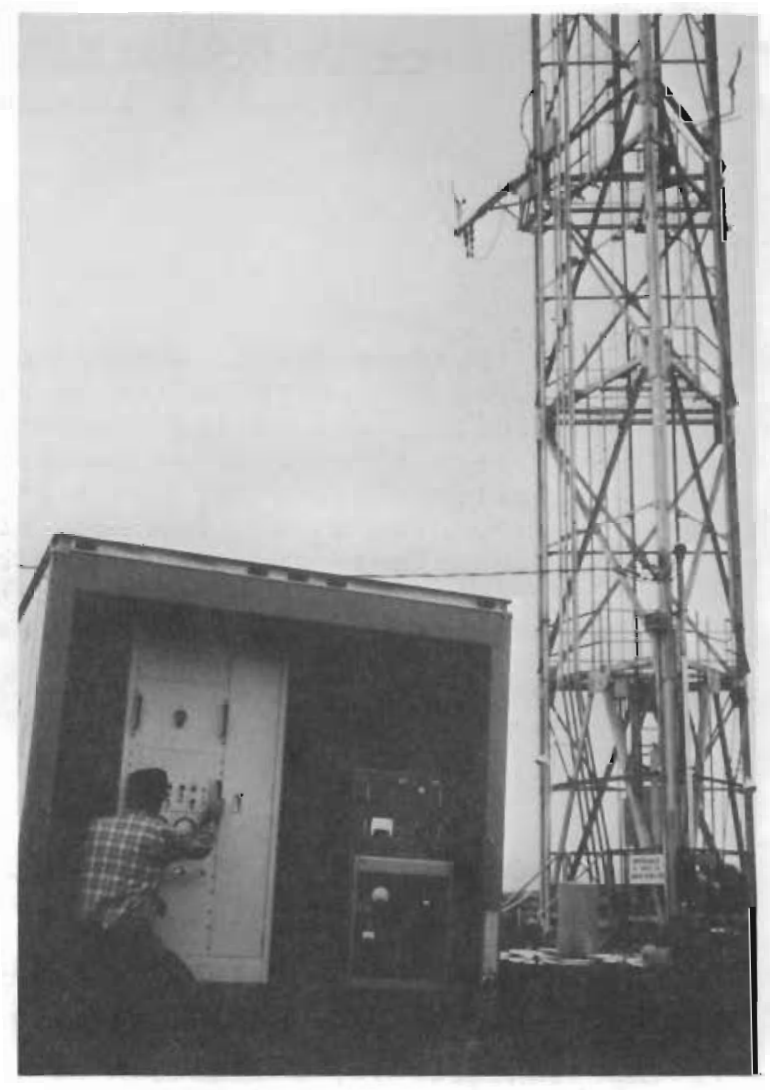

Neg 720583-I

FIGURE 1. The Three Instruments Used in this study (Whitby Aerosol Analyzer, Royco Counter and G. E. Aitken Nuclei Counter) on Site near the 410 Foot Hanford Meteorology Tower. 
During this period the wind speed was less than $7 \mathrm{mph}$ and the relative humidity was less than $50 \%$. Visibility was excellent; the Aitken nuclei counter recorded concentrations in the range 2 to $3 \times 10^{3}$ particles/ $\mathrm{cm}^{3}$. A total of four size distributions was obtained, each being an average over several distributions.

The resulting distributions are plotted in Figure 2. It can be seen from the figure that the Royco Optical Counter and the Whitby Aerosol Analyzer agree quite well in the size range where they overlap. The concentrations of particles of a specific size measured at different times, differ at most by a factor of two.

The data for the size distribution for particles between 0.2 to 2 microns in diameter, can be approximated by

$$
\frac{\mathrm{dN}}{\mathrm{d} \overline{\mathrm{D}}}=\mathrm{C} \mathrm{D}^{-\alpha},
$$

where $\frac{d N}{d D}$ is the number of particles per $\mathrm{cm}^{3}$ per micron interval; $\mathrm{C}$ is constant; D is the particle diameter; and $\alpha$ is about 5 . This data can be considered as representative for a continental atmosphere with 1ittle pollution, as indicated by the good visibility and the low Aitken nuclei count. Therefore, such a value for $\alpha$ is reasonable. (1)

In Seattle, the aerosol size distributions were obtained at two sites on October 19: one, at the Battelle Seattle Research Complex near the University of Washington, and the other from the observation deck of the Space Needle (Figure 3) 520 feet above ground level. Prior to the measure-

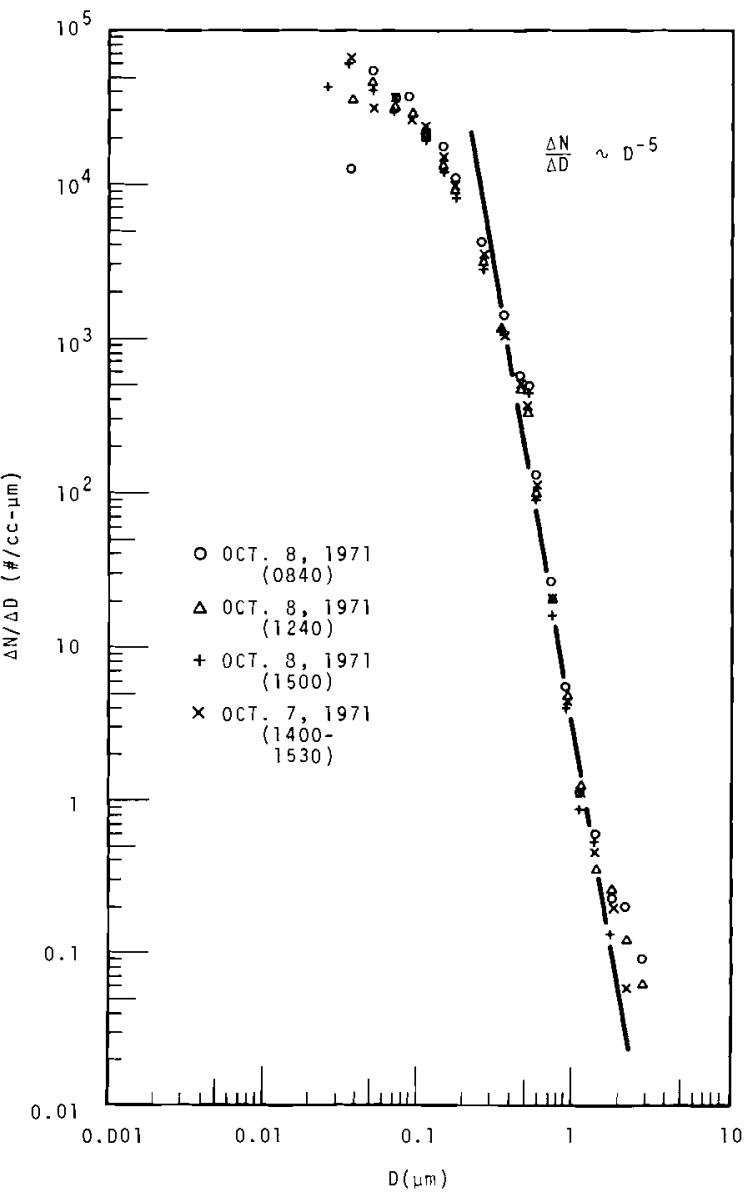

Neg 721170-4

FIGURE 2. Aerosol Particle Size Distribution near Richland, washington.

ments it was raining but during the measurements the clouds were dissipating. The visibility was good; the Aitken Nuclei Counter indicated about $4 \times 10^{4}$ particles $/ \mathrm{cm}^{3}$. Figure 4 shows the size distribution measured at the two locations.

The third measurements were made at two locations on the olympic Peninsula. The first site was about 50 feet from the ocean at LaPush, and the second site was located at the Quillayute 


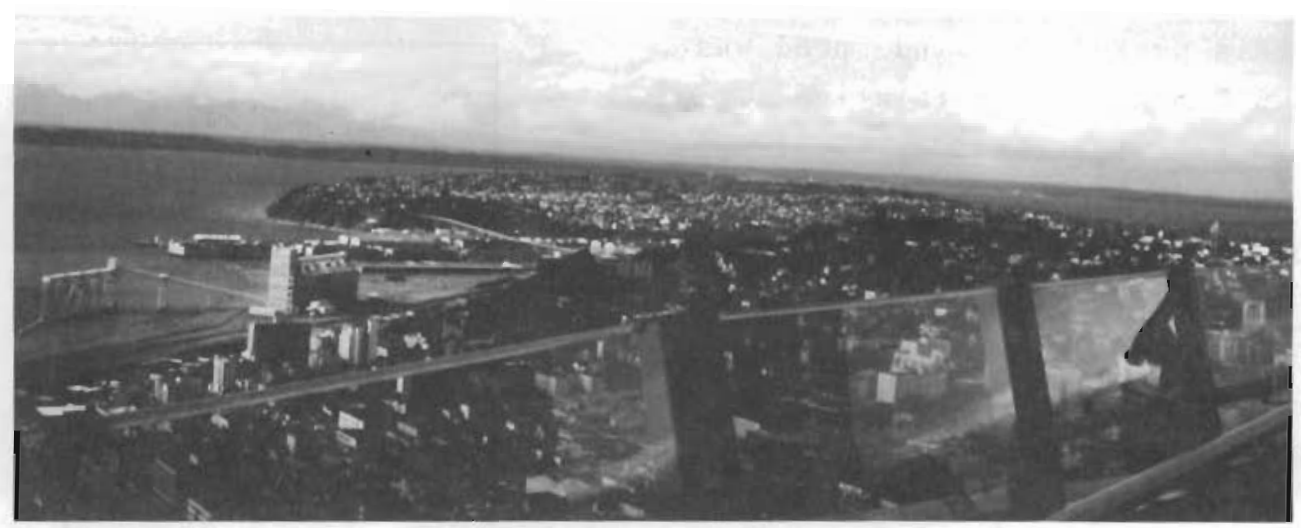

Neg $720583-2$

FIGURE 3. Measurement Site on the Observation Deck of the Space Needle, Seattle, Washington.

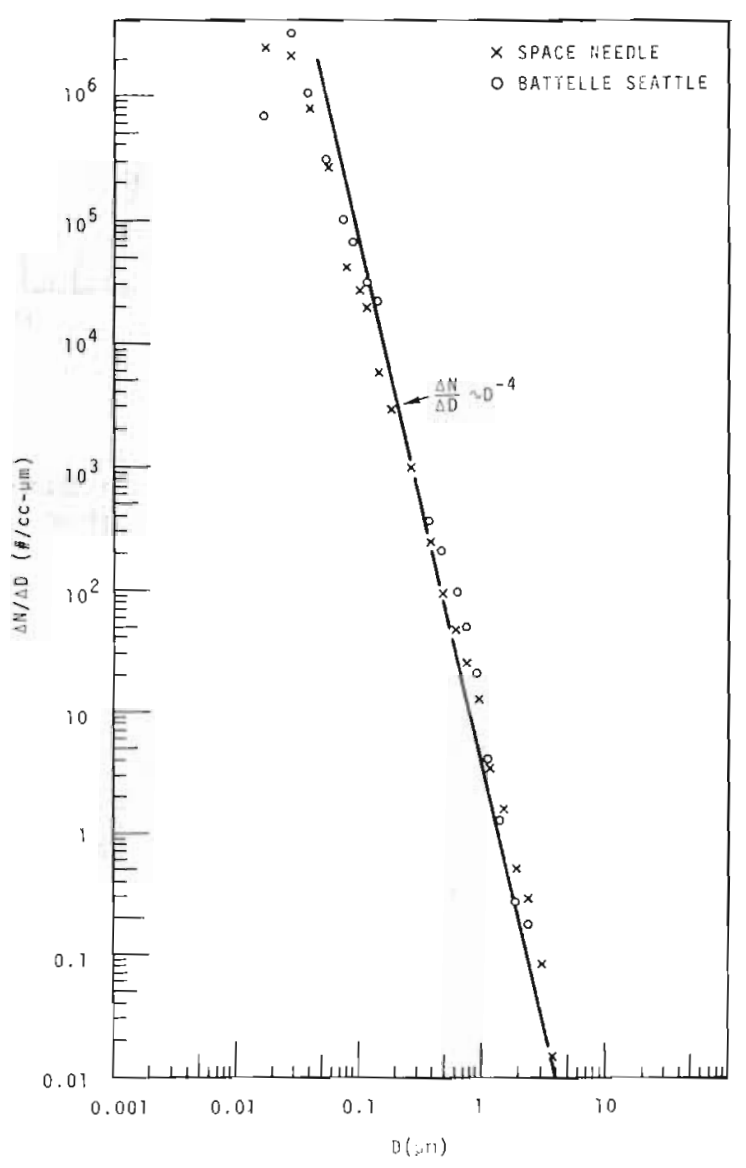

Neg $721170-3$

FIGURE 4. Aerosol Particle Size Distributions at Battelle seattle Research Center and the Space Needie, seattle, Washington. emergency landing field, about $10 \mathrm{~km}$ from the ocean. Because of instrument difficulties only the Royco Counter was used in the study.

At Lapush the measurements were made on October 20, 1971. During the morning considerable rain had fallen in the area. The data were collected just after the rain had stopped. The wind was calm ( $<5 \mathrm{mph}$, temperature $52^{\circ} \mathrm{F}$ ), and the relative humidity decreased to $70 \%$ during the period of measurement. A slight increase in the particle concentration was observed during the measurement period. Averages of ali the data points collected over a period of two hours are shown in ligure 5. The distribution shows a peak at about 0.7 micron diameter which is typical of sea-spray distribution. (2)

In the morning of the next day another series of measurements was made at Quillayute. The wind fluctuated between 5 and $15 \mathrm{mph}$, temperature was $50^{\circ} \mathrm{F}$ and the relative humidity was $64 \%$. Average of all the distribution is shown in Figure 5. It can be 


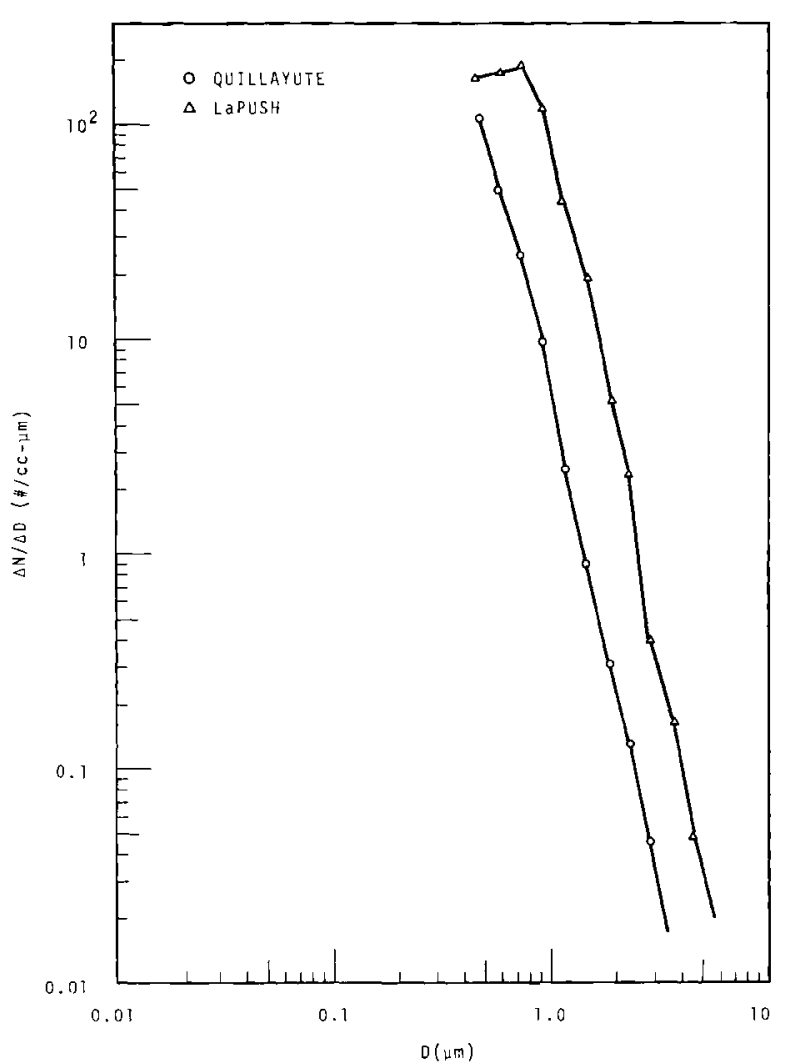

Neg $721170-2$

FIGURE 5. Aerosol Particle Size Distributions at LaPush (on the coast) and at Quillayute (about $10 \mathrm{~km}$ inland) on the Olympic Peninsula.

seen from the figure that the concentrations of particles of all sizes decreased considerably, and no peak was found in comparison with the LaPush distribution. It is possible that dry deposition on foliage between the two locations is responsible for this effect; this will be studied further.

\section{EFFECT OF THE WIND ON THE PARTICLE CONCENTRATION}

Particles larger than one micron in diameter are of particular interest in cloud physics. Those which are active as a cloud condensation nuclei may produce large cloud droplets, enhance droplet growth by coalescence, and hence increase area precipitation. On the other hand, because of their large surface area, they are most likely to act as ice nuclei. Ice nucleation activity of large particles has been demonstrated experimentally by Rosinski et al. (3) They have shown that the percentage of soil particles active as ice nuclei increases with increase in particle size and that the concentration of particles larger than 1.5 microns in diameter on the ground increased by several orders of magnitude during severe storms.

In Table 1 , the concentrations of particles larger than $0.4 \mathrm{micron}$ in diameter are shown for different surface $(2 \mathrm{~m})$ wind speeds. For wind speeds in the range of 2 to $7 \mathrm{mph}$, no significant change in the concentrations was detected.

TABIE 1. The Effect of Wind speed on Aerosol Particle Concentration ( $\# / \mathrm{cm}^{3}$ )

\begin{tabular}{|c|c|c|c|c|c|}
\hline $\begin{array}{l}\text { Particle } \\
\text { Diameter }\end{array}$ & & & Aspeed, & $\mathrm{mph}$ & \\
\hline Range, $\mu$ & 2 & 3 & 4 & 7 & 25 \\
\hline $0.4-0.5$ & 43 & 49.8 & 46.9 & 51.7 & 4.2 \\
\hline $0.5-0.64$ & 12.3 & 14.5 & 14.3 & 17.6 & 3.7 \\
\hline $0.64-0.8$ & 2.5 & 3 & 3.3 & 4.1 & 3.67 \\
\hline $0.8-1.0$ & 0.82 & 0.88 & 0.91 & 1.08 & 4.4 \\
\hline $1.0-1.3$ & 0.26 & 0.32 & 0.36 & 0.35 & 4.3 \\
\hline $1.3-1.6$ & 0.16 & 0.14 & 0.11 & 0.19 & 3.8 \\
\hline $1.6-2.0$ & 0.05 & 0.08 & 0.10 & 0.09 & 2.5 \\
\hline $2.0-2.5$ & & 0.03 & 0.065 & 0.105 & 1.56 \\
\hline $2.5-3.2$ & & & 0.04 & 0.065 & 1.03 \\
\hline $3.2-4.0$ & & & & & 0.55 \\
\hline $4.0-5.0$ & & & & & 0.23 \\
\hline $5.0-6.4$ & & & & & 0.15 \\
\hline $6.4-8$ & & & & & 0.03 \\
\hline
\end{tabular}


However, for a wind speed of $25 \mathrm{mph}$ there is a considerable increase in the concentration of particles larger than one micron. A decrease in the concentration of particles smaller than 0.5 micron was also observed. No explanation for this effect is available at this time; instrument inadequacies are not yet dismissed. Further experiments to determine the entrainment/resuspension of aerosol particles are in progress.

\section{CONCLUSIONS}

Even though the data are preliminary a few conclusions may be drawn:

1. The size distribution of background aerosol particles near Richland for particles between 0.2 to 2 microns in diameter can be approximated by $\mathrm{D}^{-\alpha}$ where $\mathrm{D}$ is the particle diameter and $\alpha$ is about 5 .

2. Significant variations in particle size distributions were observed on different days near the coast, at sites separated by only a few tens of kilometers and under similar meteorological

conditions.

3. Resuspension of aerosol particles by winds can be relatively easily studied by determining the changes in the size distribution.

\section{ACKNOWLEDGEMENT}

We wish to thank the managers of the Seattle space Needle for their hospitality.

\section{REFERENCES}

1. C. E. Junge, Comments on "Concentration and Size Distribution Measurements of Atmospheric Aerosols and a Test of the Theory of Self Preserving Size Distribution," J.Atmos. Sci., vol. 26, 603608. 1969 .

2. C. E. Junge, E. Robinson, and F. L. Ludwig, "A Study of Aerosols in Pacific Air Masses," J. Appl. Meteor., vol. 8, 340-347. 1969 .

3. J. Rosinski, G. Langer, G. T. Nagamoto, T. C. Kerrigan, and F. Prodi, "Natural Ice-Forming Nuclei in Severe Convective Storms," J.Atmos. Sci., vol. 28, 391-401. 1971. 


\title{
ON THE DRY DEPOSITION OF SEA SALT NUCLEI *
}

\author{
W. G. N. Si inn**
}

\begin{abstract}
An analysis is made of the dry deposition of sea salt nuclei in an attempt to estimate the time constant for the removal of sea salt by dry deposition, under the assumption that the rate limiting process is the turbulent diffusion of the nuclei to the earth's surface. A general analytical solution is found to the appropriate convective diffusion equation for power-zaw profizes of the diffusivity and mean wind. The resulting time constant for the exponential decrease of sea salt nuclei concentrations over continents is of the order of 10 hours.
\end{abstract}

\section{INTRODUCTION}

It is a gross understatement to say that an adequate evaluation of the influence of dry deposition on the budgets of atmospheric contaminants is yet to be determined. Not only is there not an adequate evaluation, there are uncertainties of orders of magnitudes. For example, there is the often quoted estimate that precipitation scavenging accounts for approximately $90 \%$ of the removal of bomb debris, while dry deposition, only the remaining $10 \%$ (Sma 11$),(1)$ and yet there is conjecture (e.g., see Junge, (2) pp. 307-311) that precipitation scavenging of sea salt nuclei is only $1 / 2$ to $1 / 4$ as important, over a long time period, as dry deposition.

* Submitted for publication in Atmos. Envir.

* Work supported in part by Battelle Institute's Physical Sciences Program and in part by U.S. Atomic Energy Commission Contract AT $(45-1)-1830$
The uncertainties appear to arise because of different vertical profiles of the contaminants, their different chemical and physical properties, and different dry deposition receptors and precipitation types.

It is not even clear what is the rate limiting stage of the dry deposition process. Presumably for a chemically inert substance such as ${ }^{85} \mathrm{Kr}$, the rate limiting stage would be the final biological / chemical / physical interaction at the collector - atmosphere interface. Apparent1y, for the case of dry deposition of aerosol particles on surfaces in wind tunnels, it i.s various microphysical processes (Brownian diffusion, phoretic effects, etc.) acting within the viscous sublayer, (Davies, (3) Sehme1, (4) as apparently it is also, for the dry deposition of gaseous radioiodine onto carbon plates in the atmosphere (Markee). (5) On the other hand, if one accepts Chamberlain's (6) theoretical prediction, then perhaps 
turbulent transfer through the atmospheric boundary layer is the rate limiting mechanism for the deposition of ${ }^{131}$ I onto grass (Markee, (5) Pasqui11).(7)

But for global contaminant budget considerations perhaps the dry deposition problem should be viewed from a different perspective. Perhaps the vegetation cover of a continent should be viewed as a huge fibre filter, of thickness which varies from a few centimeters (cut grass) to as much as a hundred meters (rain forest). What this filter loses because of its relative inefficiency, it makes up for in length. From this view it seems reasonable to inquire: what would be the dry deposition velocity and thereby, the appropriate time constant for removal of contaminants, if a continent's surface were treated as a perfect sink and the rate limiting process were the turbulent diffusion of the contaminant to the "filter" at the surface? Seeking an answer to this question for the case of sea salt nuclei is the subject of this brief note.

\section{PROBLEM}

The specific problem we consider is that of the profile and dry deposition of sea salt nuclei. We choose this example because appropriate experiments are in progress. Mathematically we approximate the problem by attempting to solve the two dimensional convective diffusion equation

$$
U \frac{\partial x}{\partial x}=\frac{\partial}{\partial z}\left(K \frac{\partial x}{\partial z}\right)
$$

subject to specific boundary conditions, where $U=U(z)$ is the mean wind speed in the $x$ direction, $K=$ $K(z)$ is the eddy diffusivity and $x$ is the concentration of the contaminant. Diffusion in the $x$ direction is ignored as is any gravitational sett1ing of the contaminant. The boundary conditions imposed are: (1) at $x=0$, for example at the sea coast, $x(x=$ $0, z)=x_{0} ;(2) x(x>0, z=0)=0$, that is, we assume that the vegetation is a perfect sink for the sea salt nuclei, and (3) $\times(x \rightarrow \infty$, $z \rightarrow \infty)=0$. Actually, it would be more realistic to introduce a mixing layer height, $h$, above which the concentration of nuclei is zero. To circumvent this added complication, the solution will be considered for inland distances $x$ for which $x(x$, $z=h$ ) is still essentially $x_{0}$, where $\mathrm{h}$ is 5 to $10 \mathrm{~km}$. Power law profiles are used for $U$ and $K$;

$U=u_{o}\left(\frac{z}{1_{u}}\right)^{1 / n} \quad ; \quad K=k_{\circ}\left(\frac{z}{1_{k}}\right)^{1 / m}$.

Equation (1) has been the subject of a number of investigations. However, the problem as stated above apparently has not been solved previously. Our method is to take a Laplace transform in $x$ (parameter $s$ ), which leads to

$$
\begin{gathered}
u_{0}\left(\frac{z}{1_{u}}\right)^{1 / n}\left[-x_{0}+s \hat{x}\right] \\
=\frac{\partial}{\partial z}\left[k_{0}\left(\frac{z}{l_{k}}\right)^{1 / m} \frac{\partial \hat{x}}{\partial z}\right] .
\end{gathered}
$$


The solution to (3) which satisfies the boundary conditions at $z=0$ and $\mathrm{z} \rightarrow \infty$ is

$\hat{x}(s, z)=\frac{x}{s}_{0}\left[1-\frac{2}{\Gamma(\nu)}\left(\frac{\lambda}{2}\right)^{\nu} \quad K_{\nu}\left(\lambda z^{\mu}\right)\right]$

where $K_{v}$ is a modified Bessel function of order $v$ and where

$$
\begin{aligned}
\nu & =\frac{m-1}{2 \mu m} \\
2 \mu & =2-\frac{1}{m}+\frac{1}{n} \\
\lambda & =\frac{(\rho s)^{1 / 2}}{\mu} . \\
\rho & =\frac{u_{o}{ }_{k}^{1 / m}}{k_{0}{ }^{1 / n}} .
\end{aligned}
$$

and $\Gamma(\nu)$ is the usual gamma function. Inverting (4) gives the desired solution

$$
x(x, z)=x_{0} P(\nu, \xi)
$$

where

$$
\xi=\frac{\rho z^{2 \mu}}{4 \mu^{2} x}
$$

and

$$
P(\nu, \xi)=\frac{1}{\Gamma(\nu)} \int_{0}^{\xi} e^{-t} t^{\nu-1} d t
$$

in an incomplete gamma function.

The flux of the nuclei at any elevation is given by

$F=-K(z) \frac{\partial X}{\partial z}$
Evaluating this one obtains

$$
F(z)=-\frac{k_{o}}{1_{k}^{1 / m}} \frac{x_{o}}{\Gamma(\nu)} 2 \mu\left[\frac{p}{4 \mu^{2} x}\right]^{\nu} \exp \{-\xi\} .
$$

It is interesting both that the flux as given by (13) is essentially independent of $z$ for small $z$ [provided $\left.x>>\rho z^{2 \mu} /\left(4 \mu^{2}\right)\right]$ and that for the assumed profile of $K(z)$, even though $K(z) \rightarrow 0$ as $z \rightarrow 0$, yet the flux remains finite at the surface.

DEPOSITION VELOCITIES FOR SPECIAL

\section{CASES}

I. $\quad m=n=\infty$

If the mean wind and eddy diffusivity are assumed to be independent of height, i.e.,

$\mathrm{U}=\mathrm{u}_{\mathrm{o}}\left(\frac{\mathrm{z}}{1_{\mathrm{u}}}\right)^{1 / \mathrm{n}}, \mathrm{K}=\mathrm{k}_{\mathrm{o}}\left(\frac{\mathrm{z}}{1_{\mathrm{k}}}\right)^{1 / \mathrm{m}}$

with $\mathrm{m}, \mathrm{n} \rightarrow \infty$, then the general solution, (9), reduces to

$x(x, z)=x_{0} p\left(\frac{1}{2}, \xi\right)=x_{0} \operatorname{erf}\left(\frac{u_{o} z^{2}}{4 k_{0} x}\right)^{1 / 2}$

If we define the deposition velocity to be the magnitude of the surface flux, divided by the concentration at some reference height $z_{0}$, and if this height and $x$ are chosen such that the argument of the error function is sma 11 compared with unity $\left(\mathrm{e} . \mathrm{g} \cdot, \mathrm{u}_{0}=\right.$ $10 \mathrm{~m} \mathrm{sec}^{-1}, \mathrm{k}_{\mathrm{o}}=10^{6} \mathrm{~cm}^{2} \mathrm{sec}^{-1}$, $x \geq 1 \mathrm{~km}$, then $z_{0}<100 \mathrm{~m}$ ), then we obtain

$v_{d}=\frac{|F(x, z=0)|}{x\left(x, z=z_{0}\right)}=\frac{k_{0}}{z_{0}}$. 
II. $m=1, n$ arbitrary

If the diffusivity increases 1 inearly with height $(m=1)$, and the wind profile is an arbitrary power law, then writing the general solution (9) in the form

$$
x(x, z)=x_{0} \xi^{\nu} y^{*}(\nu, \xi) .
$$

where

$$
r^{*}(\nu, \xi)=e^{-\xi} \sum_{n=0}^{\infty} \frac{\xi^{n}}{\Gamma(\nu+n+1)} .
$$

and taking $v=\frac{m-1}{2 m \gamma}=0$.

leads to the surprising result

$x(x, z)=x_{0} h(z)$.

where $h(z)$ is the Heaviside function. Thus the concentration is uniform with height and drops sharply to zero at $z=0$. It remains $x_{0}$ even though there is deposition because we have assumed $x=x_{0}$ at $x=0$, for all $z$. Thus there is an infinite reservoir. From (13), the deposition velocity based on $x_{0}$ becomes

$v_{d}=\frac{n+1}{n} \frac{k_{o}}{1_{k}}$

III. General Case (except $m \neq 1$ ) To estimate the deposition velocity in the case of arbitrary power law profiles for $U$ and $K$ (except $m \neq 1$ ), we expand (9) for small $\xi$ as in Case I. Then

$v_{d}=\frac{|F(x, z=0)|}{x\left(x, z=z_{0}\right)}=\frac{m-1}{m} \frac{k_{0}}{z_{0}}\left(\frac{z_{0}}{1_{k}}\right)^{1 / m}$

\section{DISCUSSION}

In the above analysis an attempt has been made to determine what deposition velocities would result for sea salt nuclei, under the condition that dry deposition from the atmosphere is controlled (i.e., rate limited) by the turbulent diffusive transfer of the sea salt to the collecting surface. The result is that if this were true then $v_{d}=O\left(k_{o} / 1_{k}\right)$. Numerically, if we use values suggested by Pasquill(7) then $v_{d} \simeq$ $5 \times 10^{3} \mathrm{~cm}^{2} \mathrm{sec}^{-1} / 200 \mathrm{~cm}=25 \mathrm{~cm}$ $\mathrm{sec}^{-1}$; or using values as given by Markee ${ }^{(8)}$ for a neutral atmosphere, then $v_{\mathrm{d}} \simeq 3 \mathrm{~m}^{2} \mathrm{sec}^{-1} / 10 \mathrm{~m}=30 \mathrm{~cm}$ $\mathrm{sec}^{-1}$; or if we assume that momentum and contaminants have diffusivities of similar magnitudes, then $v_{d} \simeq k_{*}$, where $\mathrm{k}$ is von Kármán's constant and $u_{*}$ is the friction velocity, which leads to similar numerical values. Although these depositon velocities are typically an order of magnitude larger than the few values which have been obtained experimentally for material other than sea salt nuclei, nevertheless this author believes that it is not justifiable to conclude that turbulent diffusion is not the rate 1 imiting stage for the dry deposition of sea salt nuclei. If the calculated results correctly describe nature then, for example, the concentration of sea salt nuclei in a column of height $h$ and base area A, moving with the mean wind speed, would decrease according to $d(x h A) /$ $\mathrm{d} t \simeq-\chi A v_{d}$ or $x \simeq x_{0} \exp (-t / \tau)$ where $\tau=h / v_{d}$. If $h \simeq 5 \mathrm{~km}$ and $v_{d} \simeq 20 \mathrm{~cm} \mathrm{sec}^{-1}$, then $\tau \simeq 10$ hours. 
It is not yet clear whether or not this is an unrealistic time constant. But even if it is, the objective of this inquiry has been met: we have determined within the approximations utilized, what the deposition velocity would be if turbulent diffusion were the rate limiting stage of the dry deposition of sea salt nuclei.

\section{REFERENCES}

1. S. H. Smazl, "Wet and Dry Deposition of Fallout Materials at Kjelzer." Telzus 12, pP. 308-314. 1960 .

2. C. E. Junge, Air Chemistry and Radioactivity, Academic Press, New York. 1963 .

3. C. N. Davies (EA.), "Deposition from Moving Aerosols." Aerosol Science, Academic Press, New York. 1966 .
4. G. A. Sehmel, "Particle Diffusivities and Deposition Velocities over a Horizontal Smooth Surface." J. of Colzoid and Interface Science, vol. 37, No. 4, pp. $891-$ 906.1971 .

5. E. H. Markee, "A Parametric Study of Gaseous Plume Depletion by Ground Surface Adsorption. (1967a) Proc. USAEC Met. Info. Meeting, September 11-14, 1967, AECL-2787. Edited by C. A. Mawson. 1967.

6. A. C. Chamberlain, "Transport of Gases to and from Grass and Grasslike Surfaces." Proc. Roy. Soc., Series $A, p p .236-265.1966$.

7. F. Pasquizl, Atmospheric Diffusion, Pp. 226-234; D. Van Norstrand Co., New York. 1962.

8. E. H. Markee, "A Parametric Study of Gaseous Plume Depletion by Ground Surface Adsorption." (1967b) Proc. USAEC Met. Info. Meeting September 11-14, 1967. AEC-2787, pp.602-613. 1967. 


\title{
CLOUD CONDENSATION NUCLEI AND VISIBLE POLLUTION IN LOS ANGELES*
}

\author{
A. J. Alkezweeny and T.J. Lockhart**
}

\begin{abstract}
Simultaneous measurements of cloud condensation nuclei and light scattering in Los Angeles down to a visibility of 7.5 miles are presented. It is shown that, in Los Angeles, air pollution is a good source of nuclei. Their concentration increases with decrease in visibility.
\end{abstract}

\section{INTRODUCTION}

A change in the concentration of cloud condensation nuclei can play an important role in the cloud formation and precipitation development. For example, Warner(1) reported a decrease in precipitation downwind of a sugar plantation during the past 60 years. He associated this decrease with an increase in sugar cane production. He also pointed out that this effect is caused by the increase in the concentration of cloud condensation nuclei. On the other hand, Hobbs, et al., (2) have reported an increase in precipitation downwind of pulp mills in washington state. They have also shown that these mills are a good source of cloud condensation nuclei.

* Accepted for publication in Atmospheric Environment. Work supported in part by the U.S. Department of Interior, Bureau of Reclamation, under Contract 14-06D-6581 with Meteorology Research, Inc. and in part by the USAEC Contract $A T(45-1)-1830$, with Pacific Northwest Laboratory.

* Meteorology Research, Inc., Altadena, California.
Although cloud formation and precipitation development is a complex process, it is generally accepted that cloud condensation nuclei could decrease or increase precipitation depending upon the sizes and concentrations of the nuclei. An increase in the concentration may produce more small cloud droplets with a narrow size distribution which would impede drop growth by coalescence, coalescence being an essential mechanism for warm rain production. However, the production of giant nuclei leads to the formation of large cloud droplets and thus a wider size distribution which could enhance coalescence (Fletcher). (3)

Several observations on the effect of air pollution, in the Los Angeles area, on the concentration of cloud condensation nuclei have been published (Alkezweeny and Green, (4) Hidy, et al., (5) and Alkezweeny and Smith). (6) However, all these measurements were either preliminary or lacking quantitative measurements of pollution levels. In this paper simultaneous measurements of cloud condensation nuclei concentrations and 
light scattering coefficients are presented and discussed.

\section{METHOD OF OBSERVATION}

The data were collected in Altadena, California, during the months of January, February and April, 1971. Two instruments were used in this study. A cloud condensation nuclei (CCN) counter and an integrating nephelometer. The CCN counter is similar in design to that developed at the University of Washington (Radke and Hobbs). (7) In this instrument the air is drawn into a diffusion chamber where the supersaturation is controlled. The active nuclei at the fixed supersaturation, grow into uniform size droplets. Their number is measured by an optical scattering technique and recorded on a chart recorder. In the integrating nephelometer (Charlson, et al.,) ${ }^{(8)}$ the aerosols are drawn into the instrument, the light scattering from all the particles is measured and recorded.

The two instruments were located inside the building of Meteorology Research, Inc., and sampled air from the same port connected to a 2 inch diameter tube bringing air from outside the building. They were operated continuously. No corrections were made on the data as to the losses of particles in the tube and the effect of relative humidity. However, in view of the size of the tube, the losses are expected to be very sma11; probably less than the losses in the sampling tube of the instruments. Furthermore, the relative humidity of the sampled air will probably be de- creased considerably before reaching the instruments because of the temperature increase of the sampled air, within the tube inside the building.

\section{RESULTS AND DISCUSSION}

In Figure 1 the concentration of cloud condensation nuclei active at 0.5 percent supersaturation are plotted as a function of time. $\mathrm{Nu}$ clei concentrations fluctuate from about $100 / \mathrm{cc}$ to about $7000 / \mathrm{cc}$. The fluctuation is effected by the degree of pollution in the atmosphere, change in air masses, and the presence of precipitation. For example, on the 17 th of April, a concentration in excess of $1000 / c c$ was recorded. However, after a rain shower, the count dropped by an order-of-magnitude, indicating a removal of the nuclei by the rain drops or change in air mass and pollution history. The large change in the nuclei concentration was accompanied by a large change in the aerosol light scattering at the same time as detected by the nephelometer.

The positive correlation between the periods of 1ow CCN concentration shown in Figure 1 and pressure troughs at nearby west Los Angeles (see top of Figure 1) suggests that an air mass change associated with a frontal passage could account for the large variation in numbers of CCN. Other phenomena associated with frontal or trough passages such as turbulent mixing and precipitation may also be the cause of large changes in the distribution of total numbers of cloud condensation nuclei. 


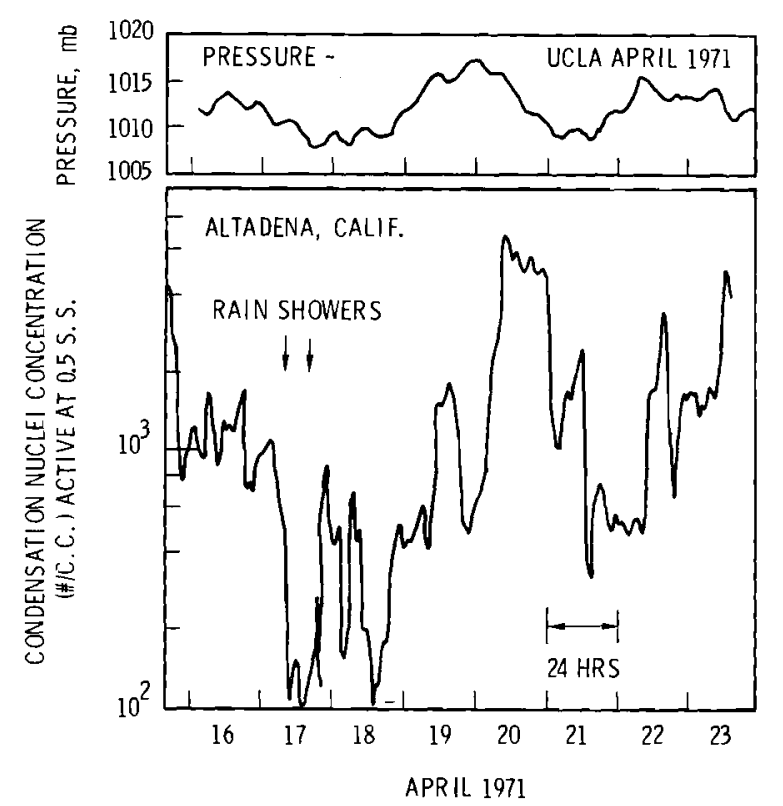

Neg 720419-1

FIGURE 1. Variation in $\mathrm{CCN}$ Concen tration with Time

The two instruments were tracking each other, and roughly experienced the same variation. The values of the light scattering coefficient and the corresponding values of the CCN concentration active at 0.5 percent supersaturation obtained over a period of about 80 hours are shown in Figure 2. It is clear from the figure that an increase in the light scattering coefficient is associated with an increase in the CCN concentration. A similar effect was found by Alkezweeny and Smith ${ }^{(6)}$ in the same location for nuclei activation of 0.65 percent supersaturation. The best fit between all pairs was calculated by the least squares method, and gives the following relation

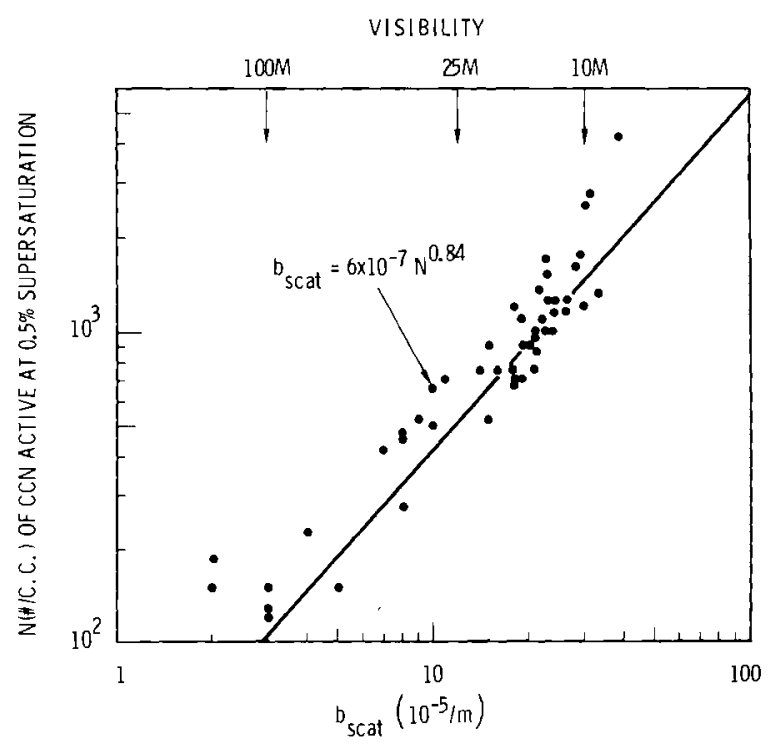

Neg $714602-3$

FIGURE 2. CCN Concentration as a Function of Light Scattering Coefficient

$b_{\text {scat }}=6 \times 10^{-7} \mathrm{~N}^{0.84}$.

where $b_{\text {scat }}$ is the light scattering coefficient in $\mathrm{m}^{-1}$, and $\mathrm{N}$ is the CCN concentration in \#/cc active at 0.5 percent supersaturation. The best fit line shows a better correlation in the CCN concentration range about 700 to 2000 nuclei/cc than outside this range. The reason for this is that most of the data were obtained in this range, and each point may represent several points from different times.

The $b_{\text {scat }}$ is related to the visibility $\left(\mathrm{L}_{\mathrm{v}}\right)$ in meters, and mass concentration of suspended aerosol particles (M) in $\mu \mathrm{g} / \mathrm{m}^{3}$ through the following relations (Charlson, et a1): (8) 
$\mathrm{L}_{\mathrm{v}}=\frac{4.7}{\mathrm{~b}_{\text {scat }}}$.

$M=3.8 \times 10^{5} b_{\text {scat }}$.

On the top of Figure 2 the visibilities corresponding to 10,25 , and 100 miles are shown by arrows.
Severa1 CCN spectra and light scattering coefficients were a1so measured. A summary of a11 the data points is shown in Table 1 , and the CCN spectra are plotted on Figure 3 . Visibility values were calculated from Equation (2). The five curves for January $26 t h$,

TABLE 1. Summary of $\mathrm{CCN}$ Spectra and Light Scattering

Coefficient ( $b_{\text {scat }}$ )

\begin{tabular}{|c|c|c|c|c|c|c|}
\hline Date & Time & $\begin{array}{c}\text { Average } \\
\text { Number of } \\
\text { CCN/cc } \\
\end{array}$ & $\begin{array}{c}\text { Number of } \\
\text { Points } \\
\end{array}$ & $\because$ S.S. & $\begin{array}{r}b_{\text {scat }} \\
10^{-4} / \mathrm{m} \\
\end{array}$ & $\begin{array}{c}\text { Visibility } \\
\text { Mile }\end{array}$ \\
\hline \multirow[t]{3}{*}{$1-26-71$} & $1503-1507$ & 197 & 16 & 0.2 & 0.5 & 58.8 \\
\hline & $1520-1529$ & 415 & 42 & 0.5 & 0.5 & 58.8 \\
\hline & $1553-1602$ & 3460 & 44 & 1.0 & 1.3 & 22.6 \\
\hline \multirow[t]{5}{*}{$1-26-71$} & $0830-0840$ & 1710 & 49 & 1.0 & 1.5 & 19.6 \\
\hline & $0900-0903$ & 219 & 11 & 0 & 1.8 & 16.3 \\
\hline & $0903-0907$ & 241 & 19 & 0.1 & 1.7 & 17.3 \\
\hline & $0907-0913$ & 268 & 25 & 0.2 & 1.3 & 22.6 \\
\hline & $0915-0925$ & 500 & 45 & 0.5 & 1.4 & 21 \\
\hline \multirow[t]{5}{*}{$1-27-71$} & $0852-0900$ & 296 & 37 & 0.5 & 1.0 & 29 \\
\hline & $0904-0910$ & 169 & 25 & 0.1 & 1.0 & 29 \\
\hline & $0912-0916$ & 197 & 17 & 0.2 & 1.0 & 29 \\
\hline & $0922-0932$ & 356 & 47 & 0.5 & 0.9 & 32 \\
\hline & $0950-0958$ & 2155 & 39 & 1.0 & 1.4 & 21 \\
\hline \multirow[t]{4}{*}{$1-28-71$} & $0839-0842$ & 103 & 13 & 0.1 & 0.9 & 32 \\
\hline & $0845-0849$ & 144 & 15 & 0.2 & - & \\
\hline & $0853-0900$ & 229 & 32 & 0.5 & - & \\
\hline & $0906-0916$ & 675 & 50 & 1.0 & 1.2 & 25 \\
\hline \multirow[t]{4}{*}{$1-28-71$} & $1410-1420$ & 263 & 45 & 0.5 & 0.6 & 49 \\
\hline & $1425-1429$ & 166 & 18 & 0.2 & - & \\
\hline & $1434-1442$ & 262 & 36 & 0.5 & - & \\
\hline & $1450-1458$ & 688 & 39 & 1.0 & 0.7 & 42 \\
\hline \multirow[t]{3}{*}{$2-2-71$} & $0930-1030$ & 1700 & - & 0.5 & 5.2 & 5.6 \\
\hline & $1035-1100$ & 1200 & - & 0.2 & 5.2 & 5.6 \\
\hline & $1115-1200$ & 5100 & - & 1.0 & 5.2 & 5.6 \\
\hline \multirow[t]{3}{*}{$2-3-71$} & $0900-1030$ & 1800 & - & 0.5 & 4.4 & 6.7 \\
\hline & $1100-1145$ & 1000 & - & 0.2 & 4.4 & 6.7 \\
\hline & $1200-1300$ & 5200 & - & 1.0 & 4.4 & 6.7 \\
\hline
\end{tabular}




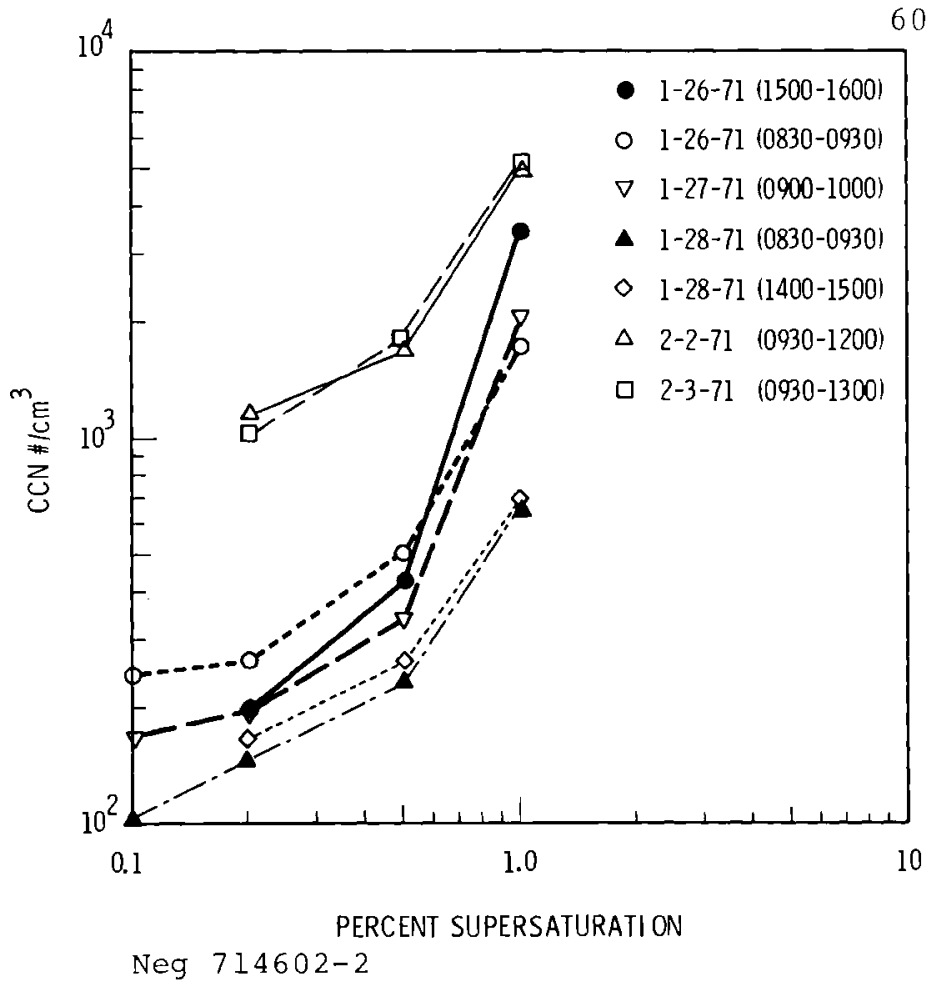

FIGURE 3. CCN Spectra

$27 \mathrm{th}$, and $28 \mathrm{th}$ were obtained where the visibility was greater than 16 miles. The average concentration of nuclei active at 0.5 percent supersaturation from the five curves generally are in agreement with that from Figure 2 . The slopes of these curves between 0.5 to 1 percent supersaturation are higher than that below 0.5 . This is in disagreement with observations from other areas of similar visibility. However, it can be shown that particles which contribute to the CCN concentration at about one percent supersaturation are of sizes about 0.03 micron. Particles of such sizes have a negligible light scattering, and therefore, do not affect visibility. The authors' experiences with Aitken nuclei measurements at the same location have shown that even on clear days with high visibilities, the con-
BNWL-1651 PT 1

centrations were in the order of $10^{4}$ particles/cc. However, on a few occasions the concentration was about $10^{3}$ particles/cc. The lowest observed CCN concentrations in this area were $75 / \mathrm{cc}, 250 / \mathrm{cc}$ and $490 / \mathrm{cc}$ at supersaturations of $0.5,0.75$ and 1.0 percent, respectively.

The top curves in Figure 3 were taken on February 2nd and 3rd with a moderately smoggy day. Visibility was less than 10 miles.

\section{CONCLUSIONS}

From the data presented in this paper we can conclude that Los Angeles air pollution is a good source of $\mathrm{CCN}$. More data are needed to establish the generality of Equation (1) in Los Angeles, and at a different supersaturation. It is also desirable to conduct similar investigations at different locations characterized by different types and different concentrations of pollution.

\section{REFERENCES}

1. J. Warner, "A Reduction in Rainfail with smoke from sugar-Cane Fires - An Inadvertent weather Modification?" J.Appl. Met. vol. ?, pp. 247-251. 1968.

2. P. V. Hobbs, L. E. Radke, and S. E. Shumway, "Cloud Condensation Nuclei from Industrial Sources and Their Apparent Influence on Precipitation in Washington state." J.Atmos. Sei., vol. 27, pp. 81-89. 1970 .

3. N. H. Fletcher, the Physics of Rain Clouds. Cambridge University Press. 390 pp. 1966.

4. A. J. Alkezweeny and W. D. Green, "The Effect of Air Pollution on the Concentration of Ice and condensation Nuclei." J. Rech.

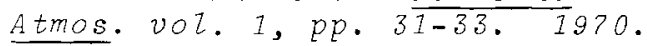


5. G. M. Hidy, W. D. Green, and A. J. Alkezweeny, "Inadvertent Weather Modification and Los Angeles Smog." Accepted for publication in J. Colzoid and Interface Sci. 1971 .

6. A. J. Alkezweeny and T. B. Smith, "The Relation Between Polluted Air and Cloud Nuclei." Proceedings of Conference on Air Pollution Meteorology, Raleigh, N.C., Apriz 5-9, 1971, pp. 104-107. 1971.
7. L. F. Radke and P. V. Hobbs, "An Automatic Cloud Condensation Nuclei Counter." J. Appl. Met., vol. 8, pp. 105-109. 1969 .

8. R. J. Charzson, N. C. Ahzquist, H. Selvidge, and P. B. MacCready, Jr., "Monitoring of Atmospheric Aerosol Parameters with the Integrating Nephelometer." J.Air Poll. Control Assoc., vol. 19, pp. $937-942.1969$.

\title{
FLUCTUATIONS IN TRACE GAS CONCENTRATIONS IN THE TROPOSPHERE*
}

\author{
A. G. Gibbs and W. G. N. Siinn**
}

\begin{abstract}
A simple model is devised and approximations are made in an attempt to explain the observed dependence on removal rates of fluctuations in trace gas concentrations in the troposphere. The model suggests that the coefficient of dispersion $\left(\sigma_{\chi} /\langle x\rangle\right)$ of the fluctua-

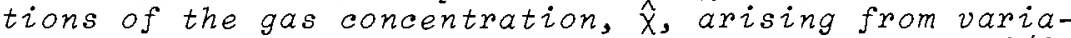
tions in the production rate are proportional to $r 1 / 2$ where $r$ is the rate of removal of the gas.
\end{abstract}

Junge, et a1. (1) recently remarked that "There is a general tendency for time and space fluctuations of atmospheric trace gases within the free troposphere to decrease as the residence time of the component increases."

* Submitted for publication in J. Geophys. Res.

* Work supported in part by Battelle Memorial Institute's Physical Sciences Program and in part by U.S. Atomic Energy Commission Contract No. AT (45-1)-1830.
Earlier, Junge (2) suggested "If the space and time distribution of sources and sinks were the same for all gases, the time and space variations of a 11 constituents would be proportional to (their removal rate) r."

This is certainly a reasonable result. If the removal rate is slow, then the influence of sources and sinks would have time to "spread" throughout the entire troposphere, and therefore the concentration fluctuations would be smaller than if the removal rate 
were fast. It is also a potentially useful result for global contaminant budget evaluations, since it provides a simple estimate of the removal rate, based on measured fluctuations in the trace gas concentrations. Junge, et al. (1) used this method to estimate the removal rate for co.

\section{THE MODEL}

The purpose of this note is to explore a simple model in the hope that it might shed a little light on this atmospheric phenomenon. Toward this end, suppose that the concentration of a particular trace gas in a specific tropospheric air mass is the random variable $\underset{v}{x}(t ; \xi)$. The symbol " $\sim$ " under a variable will be used to indicate that is a stocastic variable; the parameter $\xi$ labels a specific air mass or a specific realization of the stochastic process.

As a specific air mass moves, the trace gas concentration varies because of time-dependent production and removal processes. Thus, if we use a coordinate system moving with the air mass, and ignore diffusion, then

$\frac{d}{d t} X(t ; \xi)=\underbrace{p}_{\sim}(t ; \xi)-\underset{\sim}{R}(t ; \xi)$,

where $\underset{\sim}{p}$ and $\underset{\sim}{R}$ describe the production and removal processes experience by the air mass. We propose to consider only the case of first order removal processes; i.e., those for which $\mathrm{R}=\underset{\imath}{\mathrm{r} x}$. Then (1) becomes

$\frac{d}{d t} \underset{\nu}{x}(t ; \xi)+\underset{\nu}{r}(t ; \xi) \underset{\imath}{x}=\underset{v}{p}(t ; \xi)$.

\section{LINEAR I ZATION}

Unfortunately we have not been able to make much headway trying to gain information from the complete Equation (2). What we seek is at least the first two moments of $x$ : its mean, $\langle x\rangle$ and mean square $\left\langle\chi^{2}\right\rangle$ (or variance, $\sigma \tilde{x}=\left\langle x^{2}\right\rangle-\langle x\rangle^{2}$ ) where the averages in the above operations are taken over different realizations, $\xi$; i.e., over different air masses. From the longtime $\left(t>r^{-1}\right)$ solution to (2)

$$
\begin{array}{r}
\underset{\sim}{x}(t ; \xi)=\int_{0}^{t} \exp \left\{-\int_{t^{\prime}}^{r}\left(t^{\prime \prime} ; \xi\right) d t^{\prime \prime}\right\} \\
\underset{\sim}{p}\left(t^{\prime} ; \xi\right) d t^{\prime},
\end{array}
$$

it is relatively easy to find $\langle\underset{\sim}{\langle x}$ if $\underset{r}{r}$ and $p$ are uncorrelated, but we have been unable to evaluate $\sigma_{x}^{2}$.

Instead, we linearize (2). If the fluctuations are small quantities about the mean value, then we write (2) as

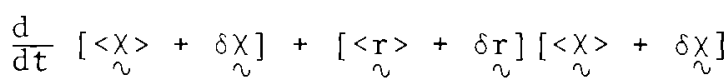

$$
\begin{aligned}
& =\left\langle\underline{\sim}^{p}\right\rangle+\delta \underbrace{}_{\imath} .
\end{aligned}
$$

and ignore the term $\delta \mathrm{r} \delta x$ which is of second order in small quantities. The lowest order terms in (4), i.e., the terms that exist if there are no fluctuations, satisfy

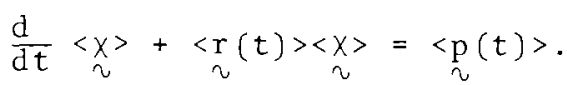


It seems reasonable to treat $\underset{\sim}{\sim}\rangle$ and $\langle p\rangle$ in (5) as the time-independent, global-averaged removal rate, $r$, and production rate, $p$. In this case, the solution to (5) for $t>>r^{-1}$ is

$$
\langle x\rangle=\mathrm{p} / \mathrm{r} .
$$

which is a familiar result.

If there is a fluctuation in $\underset{n}{p}$ or $\underset{\sim}{r}$, then from (4) it "propagates" to $\underset{\sim}{x}$ via $\frac{d}{d t} \delta \underset{\sim}{x}+r \delta \underset{\sim}{\chi}=\delta p-\frac{p}{r} \delta \underset{\sim}{\delta} \equiv g(t ; \xi)$.

The large-time solution to (7) is

$\delta \underset{\sim}{x}(t)=e^{-r t} \int_{0}^{t} e^{-r t^{\prime}} \underset{\sim}{g}\left(t^{\prime} ; \xi\right) d t^{\prime}$.

Notice that $\underset{\sim}{\langle\chi \chi}\rangle=0$ since $\langle g\rangle=0$. From (8) the autocorrelation of $\delta \underset{\sim}{x}$ at large time is

$$
\langle\delta \chi_{\sim}\left(t_{1}\right) \delta \underbrace{}_{\sim}\left(t_{2}\right)\rangle=e^{-r\left(t_{1}+t_{2}\right)} \int_{0}^{t_{1}} d t^{\prime} e^{r t^{\prime}} \int_{0}^{t_{2}} d t^{\prime \prime} e^{r t^{\prime \prime}}\left\langle\underset{d}{g}\left(t^{\prime}\right) \underset{\sim}{g}\left(t^{\prime \prime}\right)\right\rangle .
$$

\section{STAT IONARITY}

We are particularly interested in the variance of $\delta \underset{\imath}{x}$ and therefore set $t_{1}=t_{2}=t$. Progress can be made

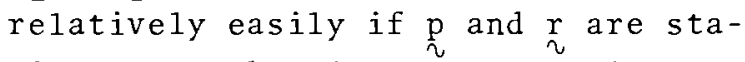
tionary stochastic processes, i.e., if

$\left\langle\underset{\tau}{g}\left(t^{\prime}\right) \underset{\tau}{g}\left(t^{\prime \prime}\right)\right\rangle=\langle\underset{\tau}{g}(0) \underset{\tau}{g}(\tau)\rangle$,

where $\tau=t^{\prime \prime}$ - $t^{\prime}$. In this case we transform the variables of integration to $\tau$ and $t^{\prime}$. From simple geometric considerations we see that for $\tau>0$, the integral over $t$ ' becomes

$$
\int_{0}^{t-\tau} e^{2 r t^{\prime}} d t^{\prime}=\frac{1}{2 r}\left\{e^{2 r(t-\tau)}-1\right\}
$$

and for $\tau<0$ it is

$$
\int_{-\tau}^{t} e^{2 r t^{\prime}} d t^{\prime}=\frac{1}{2 r}\left\{e^{2 r t}-e^{-2 r \tau}\right\} .
$$

Using these results in (9), recalling that

$\langle g(0) \underset{\sim}{g}(-\tau)\rangle=\langle\underset{\sim}{g}(0) g(\tau)\rangle$,

for a stationary process, and then upon collecting terms and letting $t \rightarrow \infty$, leads to

$$
\left\langle(\delta x)^{2}\right\rangle=\frac{1}{r} \int_{0}^{\infty} e^{-r \tau}<\underset{q}{g}(0) \underset{\tau}{g}(\tau)>d \tau
$$




\section{ASSUMPTIONS}

To proceed, a specification of the autocovariance of the fluctuations in the production and removal rates is needed. For want of something better, we assume that they decay exponentia11y:

$$
\begin{aligned}
& \langle\delta \underbrace{}_{\sim}(0) \delta \underset{\sim}{p}(\tau)>=\sigma_{p}^{2} e^{-\lambda} p^{\tau},
\end{aligned}
$$

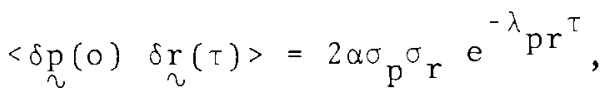

$$
\begin{aligned}
& \left\langle\delta \underset{\sim}{r}(0) \delta \underset{\tau}{\operatorname{r}}(\tau)>=\sigma_{\mathrm{r}}^{2} \mathrm{e}^{-\lambda} \mathrm{r}^{\tau}\right. \text {. }
\end{aligned}
$$

Note that it may be reasonable to take the correlation coefficient, $\alpha$, to be zero since production and removal rates could be expected to be uncorrelated. Substituting the above into (7) and (11) and evaluating the integrals gives

$$
\begin{aligned}
\frac{\langle(\delta x)\rangle^{2}}{\langle x\rangle^{2}}= & \left(\frac{r}{r+\lambda}\right) \frac{\sigma_{p}^{2}}{p^{2}}-2 \alpha\left(\frac{r}{r+\lambda p r}\right) \frac{{ }_{p}^{\sigma} r}{p r} \\
& +\left(\frac{r}{r+\lambda}\right) \frac{\sigma_{r}^{2}}{r^{2}} .
\end{aligned}
$$

We expect that the average over different air masses of the "memory" of fluctuations in production or removal rates is short compared with the removal rates, themselves; i.e., $\lambda>>r$. If this is true then (12) reduces to

$\mathrm{f}_{x}^{2}=\frac{\mathrm{r}}{\lambda_{\mathrm{p}}} \mathrm{f}_{\mathrm{p}}^{2}-\frac{2 \alpha \mathrm{r}}{\lambda_{\mathrm{pr}}} \mathrm{f}_{\mathrm{p}} \mathrm{f}_{\mathrm{r}}+\frac{\mathrm{r}}{\lambda_{\mathrm{r}}} \mathrm{f}_{\mathrm{r}}^{2}$,

where the f's are the coefficients of dispersion (standard deviation divided by the mean) of the appropriate quantities.

\section{SUMMARY}

In summary, the objective of this brief study was to determine a relationship between the fluctuations in trace gas concentrations and their removal rates. We linearized the general expression (2), and note that the resulting theory is self consistent insofar as the solution (13) does predict that the neglected term, $\delta \mathrm{r} \delta x$, is much smaller than those which were retained, $O(x \delta r)$. Thus from (13)

$\left\langle\delta \underset{\sim}{r} \delta \underset{\sim}{x}><\underset{\sim}{\chi x}>=O\left(f_{\chi}\right) \ll 1\right.$

If the gas sampling is done at a single location for which the concentration fluctuations could be attributed to different long range trajectories of the air masses, then (13) suggests that fluctuations in the production rate alone would cause concentration fluctuations that vary with the removal rate according to $f_{x} \sim r^{1 / 2}$. In contrast, fluctuations in the removal rate alone would lead to $\mathrm{f}_{\mathrm{x}} \sim \mathrm{r}^{1 / 2} \frac{\sigma_{\mathrm{r}}}{\mathrm{r}}$, which is proportional either to $r^{1 / 2}$ or to $r^{-1 / 2}$, depending on whether the fluctuations in $r$ are characterized by $\sigma_{r}$ or by $f_{r}$. In the more general case when both $\underset{\sim}{r}$ and $p$ experience fluctuations, $f_{x}$ has the form given by Equation (13).

\section{REFERENCES}

1. C. E. Junge, W. Seizer and $P$. Warneck, The Atmospheric ${ }^{12} \mathrm{CO}$ and 14 Co Budget, J. Geophysical Research, vol. 76, pp. 28662879.1971.

2. C. E. Junge, Air Chemistry and Radioactivity, Academic Press, New York 1963 . 


\title{
PROGNOSTIC ISENTROPIC TRAJECTORIES
}

W. E. Davis, J. L. Heffter* and M. E. Smith*

\begin{abstract}
A kinematic, prognostic, isentropic trajectory program has been successfully run. Plans are discussed for future changes in the program as well as methods for evaluating the worth of the prognostic trajectories.
\end{abstract}

\section{INTRODUCTION}

In August, 1970, a meeting concerning prognostic trajectories was held in Silver Springs, Maryland. At the meeting it was decided that a comparison of different techniques for trajectory computations should be made. At a second meeting a decision was made for a cooperative effort between Battelle, Pacific Northwest Laboratories (PNL) and NOAA (Silver Springs, Md.) to produce a prognostic isentropic trajectory routine which would then be compared with previous techniques for computing trajectories. The following is a report of the progress made in programing prognostic isentropic trajectories.

\section{Background}

In the past, investigators have demonstrated the value of $100 \mathrm{king}$ at flow on isentropic surfaces. $(1,2,3)$

\footnotetext{
* NOAA - Silver springs, Md.

* Note: An isentropic surface is one where a moving parcel will conserve potential temperature.
}

Since flow in the first approximation is adiabatic, isentropic surfaces** should be used to describe the flow of these air parcels. The same is true when one approaches the problem of prognostic trajectories. An adiabatic surface, along which one can produce an energy balanced trajectory, needs to be constructed from the prognostic information available. Thus, the first step for a prognostic trajectory computation is to be able to construct an isentropic surface and the second is to obtain wind speed information in order to be able to move the trajectory. (Later this information can serve as the basis for diabatic trajectory analysis if a decision is made to program one.)

programing of an Isentropic Trajectory and Summary

The data used are from the Primitive Equation (P.E.) model. Temperature, height and wind fields for pressure surfaces were utilized to calculate the height and wind fields for a specific potential temperature. A series of check-out runs was made in December, 1971, and in JanuaryFebruary, 1972. After alterations 
in February, 1972, a successful computer run predicted wind and height fields which checked out successfully against the input data from the P.E. model. Several trajectories have been run using these fields. The same technique was used for computing $\mathrm{u}$ and $\mathrm{v}$ components for running the trajectories as was used by Peterson and Smith. (4) The results of one of these trajectories tested against hand calculations indicate that the program is now running successfully.

\section{Future Work}

A check-out of these trajectories on a post-facto basis is planned as well as changes in the trajectory computer program to make the trajectories energy-consistent.

\section{REFERENCES}

1. E. E. Danielsen. "Trajectories: Isobaric, Isentropic and Actual," J. of Meteorology, vol. 18, pp.479-486. 1961.

2. E. R. Reiter and J. D. Mahlman. "Heavy Radioactive Falzout over the Southern United States," Journal of Geophysical Research, vol. 70, No. 18, pp. 4501-4520. November, 1962.

3. W. E. Davis and B. C. Seott. "Radiational Cooling of Air Parcels Following the Effluent of Phoebus IB EP-IV, February 24, 1967," Pacific Northwest Laboratory Annual Report for 1970 to the USAEC Division of Biology and Medicine, Volume II: Physical Sciences, Part 1. Atmospheric Sciences, BNWL-1551, pp. 129-130, Battelie, Pacific Northwest Laboratories, Richland, Washington. June, 1971 .

4. K. R. Peterson and M. E. Smith. "ARL Trajectory Forecast Program," Air Resources Laboratories, NOAA, Silver Springs, Maryzand. 1968. (Unpublished Report.)

\title{
HOURLY LOW-LEVEL ISENTROPIC TRAJECTORIES
}

\author{
W. E. Davis
}

\section{INTRODUCTION}

Previous work on low-level isentropic and diabatic trajectories (Davis and Scott, ${ }^{(1)}$; Engelmann and Davis) (2) have been based on maps of twelve hour increments. This work using such measurements could only describe macroscale features of transport of the parcel. It was hoped that work could 
be initiated at some time on a smaller scale. This would help determine the mesoscale flow patterns affecting transport as we 11 as deposition of a material released in the lower atmosphere. The following is a report of such an attempt to reduce the scale from macroscale to mesoscale.

\section{Low-Leve1 Stream Functions}

Previously Davis and Scott computed surface potential temperatures on a hourly basis to designate mesoscale areas of increased mixing. Further study indicated that the surface data could be applied to the calculation of stream functions on isentropic sur faces near the ground.

In studying Danielsen's (3) work in which he calculated upper-level stream functions, the logical step would be to apply the same method to the surface stations. First, the altimeter setting report was used in a back calculation of surface pressure. Second, the surface pressure and the surface temperature were used to calculate the surface potential temperature $(\theta)$,

$\theta=T\left(\frac{1000}{P}\right)^{R / c_{p}}$

where $\mathrm{T}$ - Temperature ${ }^{\circ}$ absolute

$P$ - Pressure (mb)

R - Gas constant for air

$c_{p}$ - Specific heat of air

Third, the surface Montgomery stream function $(\psi)$ was calculated where

$\psi_{\text {sfc }}=c_{p} T+g z$ where $g$ - gravitational acceleration

$z$ - the height of the station.

Fourth, Danielsen's equation in which

$\Delta \psi=c_{p} \overline{\left(\frac{T}{\theta}\right)} \Delta \theta$

was changed to the computational form

$\left.\Delta \psi=c_{p} \overline{\frac{P}{1000}}^{\bar{R} / c_{p}}\right) \Delta \theta$

here the bar indicates averaging with respect to $\theta$.

To calculate $\left(\frac{\mathrm{p}}{\overline{1000})^{\mathrm{R} / \mathrm{C}}}\right.$ several methods can be used. A linear approach was used:

$$
\begin{aligned}
\overline{\left(\frac{P}{1000}\right)^{R / c_{p}}}= & \frac{1}{2}\left[\left(\frac{P_{s f c}}{1000}\right)^{R / c} p\right. \\
& \left.+\left(\frac{P_{\Theta} \text { est }}{1000}\right)^{R / c} p\right]
\end{aligned}
$$

$P_{\Theta}$ est is the estimated pressure for the $\theta$ surface. The fifth and final step is to use Equations (1) and (2) to find $\psi_{\theta}=\psi_{s f c}+\Delta \psi$. The term $\psi_{\theta}$ is the estimate of the stream function for some $\theta$ surface above the ground.

\section{Errors in $\psi_{\Theta}$}

Errors are found in the surface data and in estimating $\Delta \psi$, Equation (2), Errors in surface temperature of $0.5^{\circ} \mathrm{K}$ and 0.005 in. of $\mathrm{Hg}$ in pressure readings combine to produce errors of $\sim \pm 0.02 \times 10^{7} \mathrm{~cm}^{2} \mathrm{sec}^{-2}$ in the stream function. These are minimal errors except in cases of low wind speeds. Larger errors can be generated in Equation (2) from an erroneous estimate of $\left(\frac{p}{1000}\right)^{\mathrm{R} / \mathrm{C}_{\mathrm{p}}}$. An error in this 
term of 0.01 can generate problems if $\Delta \theta$ is $5^{\circ} \mathrm{K}$. This will cause an error in $\psi$ of $0.01 \times \Delta \theta \times 10^{7} \mathrm{~cm}^{2} \mathrm{sec}^{-2}$. An error greater than $0.05 \times 10^{7} \mathrm{~cm}^{2} \mathrm{sec}^{-2}$ can create problems in estimating wind speed and directions. Figure 1 indicates the error in geostrophic winds where $V_{g}=\frac{1}{f} \frac{\partial \psi}{\partial r}$; $f$ is the Coriolis parameter and $\partial r$ is taken normal to

the flow. are not usually expected near the ground because of the slow variation of this function with height (see Figure 2). As long as the analysis is kept near the ground (i.e., $\Delta \theta<5^{\circ}$ ) accurate hourly patterns of $\psi$ are available for an isentropic surface.

A definitive error analys is is difficult because of the nonlinearity in $\left(\frac{\mathrm{p}}{1000}\right)^{\mathrm{R} / \mathrm{C}} \mathrm{p}$. The foregoing provides guidelines for the use of an analysis so that errors can be minimized.

\section{CONCLUSIONS}

A method has been developed to estimate Montgomery stream functions on an hourly basis from surface hourly reports. Errors encountered in the method have been pointed out and procedures indicated for computing the stream functions.

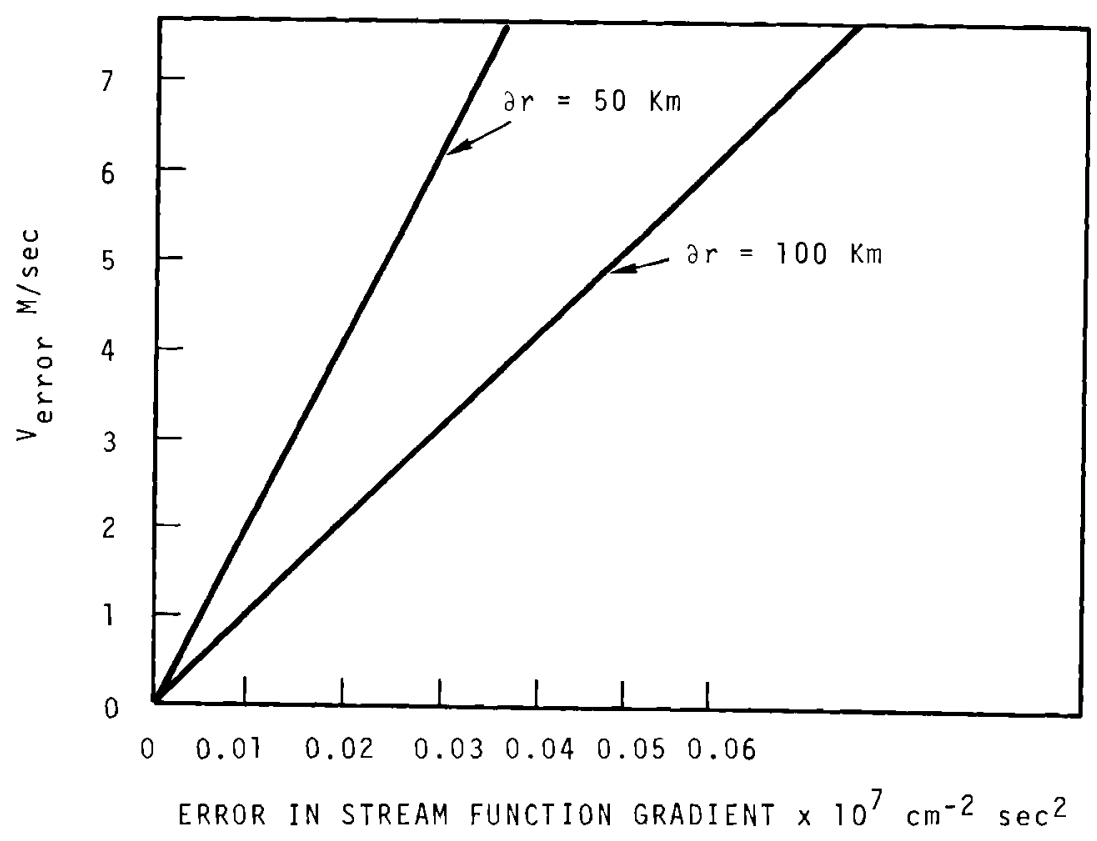

Neg 721562-1

FIGURE 1. Error in Geostrophic wind due to Errors in Stream Function 


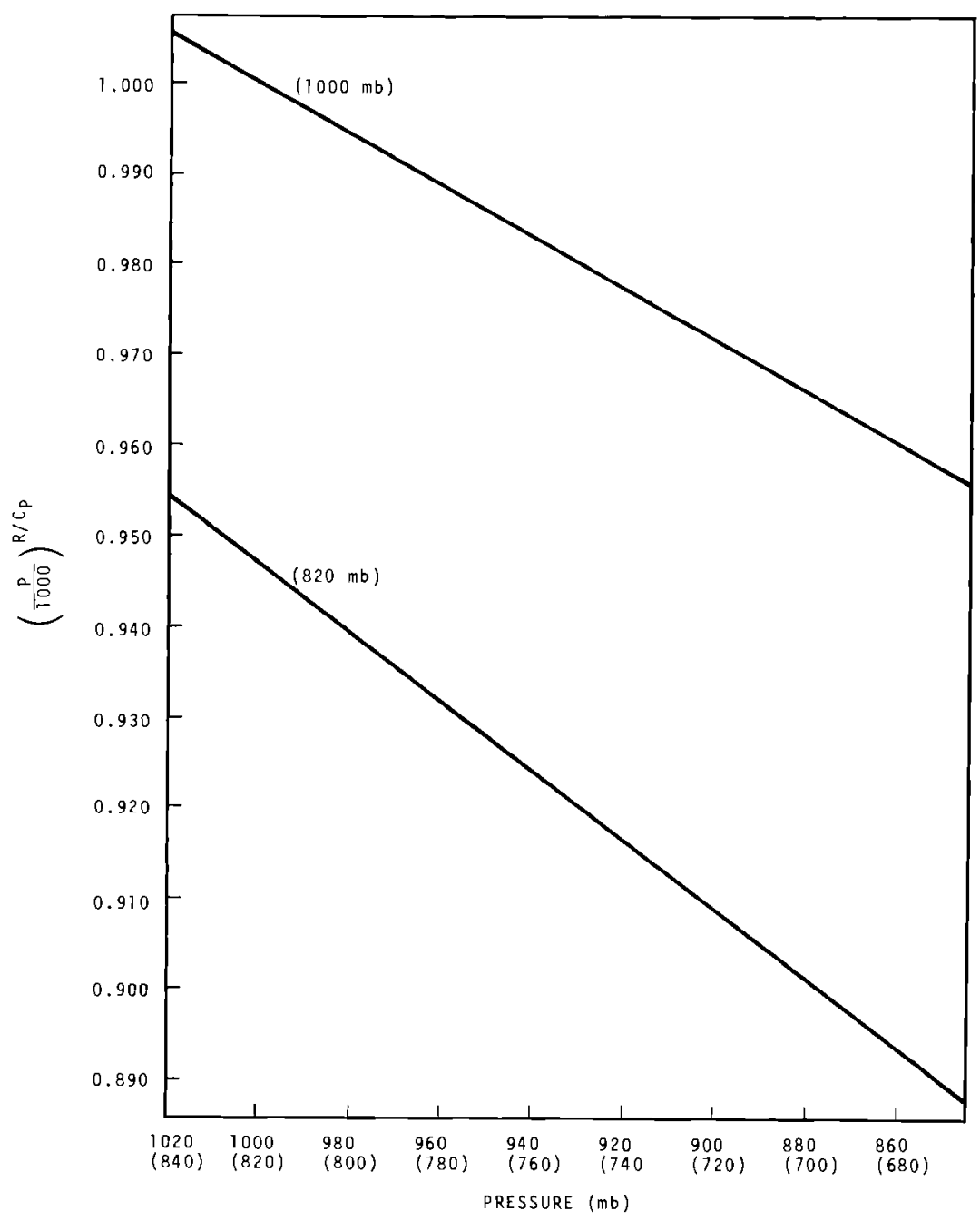

Neg 722061-2

FIGURE 2. Graph of $\left(\frac{\mathrm{P}}{1000}\right)^{\mathrm{R} / \mathrm{C}_{\mathrm{p}}}$ with Pressure

\section{REFERENCES}

1. W. E. Davis and B. C. Scott, "Radiational Cooling of Air Parcels Eollowing the Effluent of Phoebus $1 B$ EP-IV, February 24, 1967." Pacific Northwest Laboratory $A n-$ nual Report for 1970 to the USAEC Division of Biology and Medicine, Volume II: Physical Sciences, Part 1, Atmospheric Sciences, BNWL-1551, Battelie, Pacific Northwest Laboratories, Richland, Washington, June 1971.

2. R. J. Engelmann and W. E. Davis, Low-Level Isentropic Trajectories and the MIDAS Computer Program for the Montgomery Stream Function. BNWL-441, Battelle-Northwest, Richland, Washington, Apriz 1968.

3. E. F. Danielsen, "The Laminar Structure of the Atmosphere and its Relation to the Concept of a Tropopause," Archiv. fur Meteorologie, Geophysik und Bioklimatologie, pp. 293-332, 1959 . 


\title{
CLIMATOLOGICAL MEASUREMENTS ON THE ARID LANDS ECOLOGY \\ RESERVE IN 1971
}

J. M. Thorp and W. T. Hinds

\begin{abstract}
Measurements to estabiish a climatology of the ALE Reserve continue. All recorded climatological data are now being collected at a central location and summarized by computer. Resulting monthly data summaries are distributed to ALE Reserve investigators.
\end{abstract}

During the 1971 bio-year (October 1970 through May 1971) the ALE Reserve rain gages were visited on a monthly basis. The total rainfall and snow- fall (in centimeters of water) is shown in Figure 1. Precipitation totals were down from the 1970 bio-year

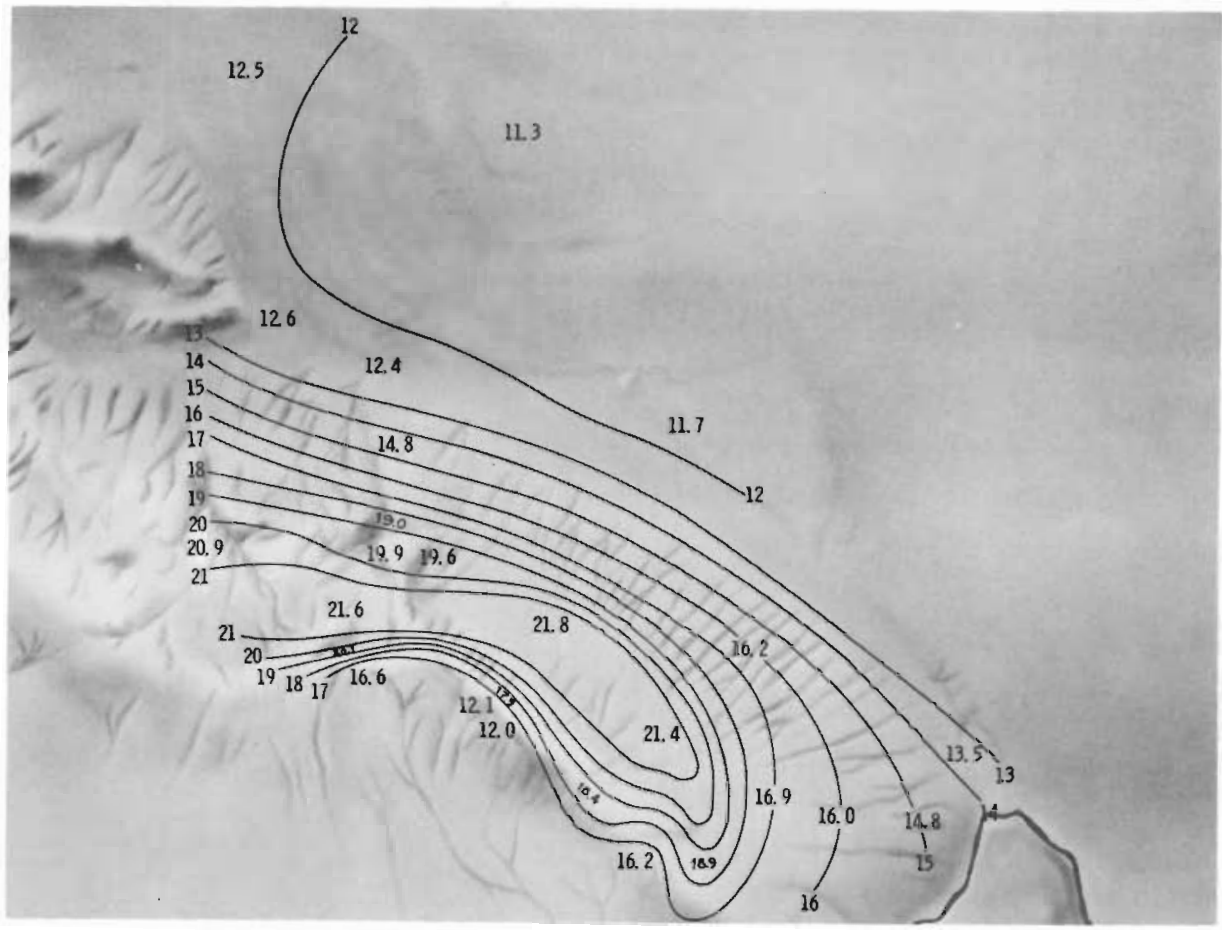

ARID LANDS ECOLOGY RESERVE

Neg 721032-3

FIGURE 1. Bio-year Precipitation (cm of Water) October 1970-May 1971 
amounts, ranging from $11 \mathrm{~cm}$ to $22 \mathrm{~cm}$ compared to $16-25 \mathrm{~cm}$ in 1970 .

The 1971 calendar year (actually December 30, 1970 to January 4, 1972) precipitation is shown in Figure 2 . As one would expect, the patterns exhibit similar distribution. Spotty summer shower precipitation probably accounts for the somewhat less regular pattern for the calendar year. Precipitation quantities on both charts represent minimum approximations of precipitation that actually fell. No corrections have been applied to account for losses occuring from evaporation, rain driven by high wind, or drifting snow. An oil film is used as an evaporation suppressant, nevertheless there is some loss of gage water by evaporation processes, especially in hot weather. Gages along the crest of Rattlesnake Mountain are particularly subject to wind error during rain or snow and it is possible for drifted snow to completely cover a gage in a location that experiences frequent drifting ( $\# 14$ is affected this way).

A computer program for ALE ciimatology has been written and all climatological data from the ALE Reserve are now being summarized by this method. Data are processed to provide applicable weekly, monthly and

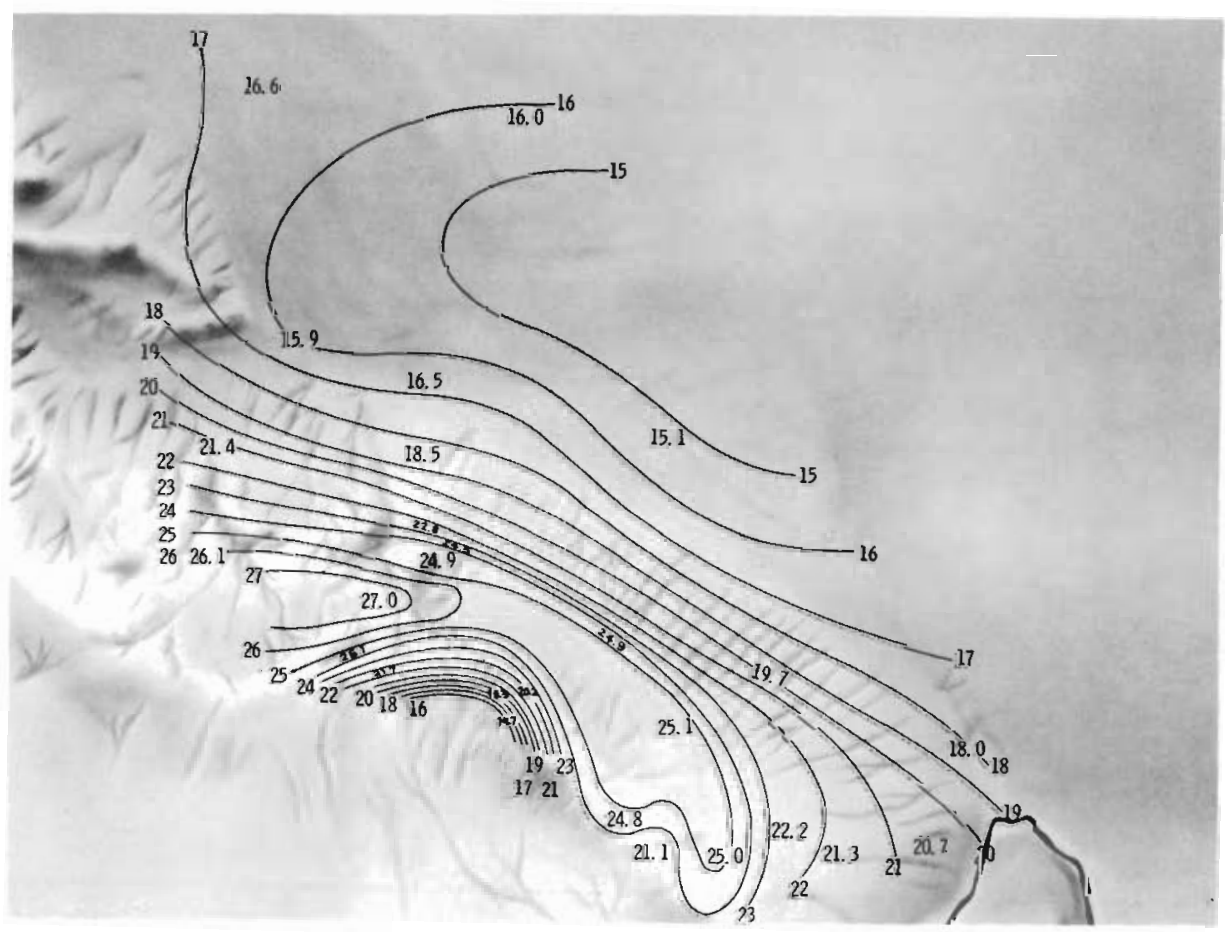

ARID LANDS ECOLOGY RESERVE

Neg 721032-2

FIGURE 2. Precipitation for 1971 ( $\mathrm{cm}$ of Water) 
annual summarizations. (1) Table I indicates the instrumentation cur- rently in use as source material for the above mentioned data summarization.

TABLE 1. Climatological Instrumentation of the ALE Reserve-1971

\begin{tabular}{|c|c|c|c|c|c|c|c|c|c|}
\hline Station & 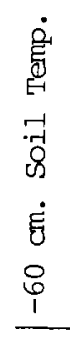 & 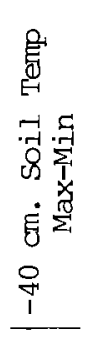 & 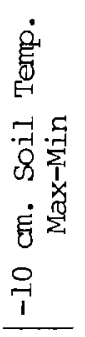 & 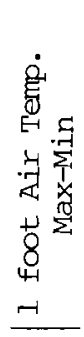 & 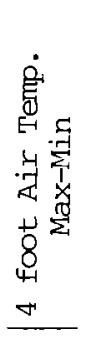 & 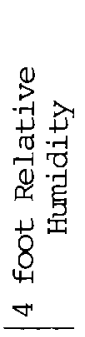 & 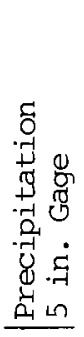 & 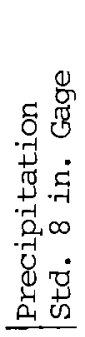 & 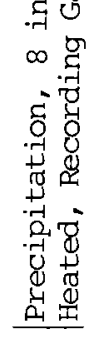 \\
\hline 1 & M & & & M & & & M & & \\
\hline 2 & M & & & M & D & D & M & & $M \& W$ \\
\hline 3 & M & D & D & M & & & M & M & W \\
\hline 4 & M & D & D & M & D & D & M & M & W \\
\hline 5 & M & D & D & M & D & D & M & & \\
\hline 6 & M & & & M & & & M & & \\
\hline 7 & M & & & M & & & M & & \\
\hline $7 a$ & M & & D & M & D & D & M & & \\
\hline 8 & M & & & M & & & M & & \\
\hline 9 & M & & & M & & & M & & \\
\hline 10 & M & & D & M & D & D & M & M & \\
\hline 11 & & & & M & & & M & & \\
\hline 12 & M & & & M & & & M & & \\
\hline 13 & M & & & M & & & M & & \\
\hline 14 & & & & M & & & M & & \\
\hline 15 & & & & M & & & M & & \\
\hline 16 & & & & M & & & M & & \\
\hline 17 & M & & & M & & & M & & \\
\hline 18 & M & $D^{*}$ & $D^{\star}$ & M & $D^{*}$ & $D^{\star}$ & M & & $W^{\star}$ \\
\hline 19 & M & & & M & & & M & & \\
\hline 20 & M & & & M & & & M & & \\
\hline 21 & M & & & M & & & M & & \\
\hline 22 & M & & & M & & & M & & \\
\hline 23 & M & & & M & & & M & & \\
\hline 24 & M & & & $M$ & & & M & & \\
\hline 25 & M & & & M & & & M & & \\
\hline
\end{tabular}

* Within 1 mile

D Daily

W Weekly

M Monthly

\section{REFERENCES}

1. W. T. Hinds and J. M. Thorp, Annual Summaries of Microclimato- logical Data from the Arid Lands Ecology Reserve, BNWL-1629, Battelle, Pacific Northwest Laboratories, Richland, Washington, November 1971. 


\title{
KINEMATICALLY POSSIBLE FLOWS EXTERIOR TO JETS AND PLUMES*
}

\author{
W. G. N. Slinn
}

\begin{abstract}
A progress report is given of analytical analyses of flows exterior to jets and plumes penetrating into the half space $z>0$. It is shown that the exterior flow is essentially horizontal near a plume and the case of nonzero mean wind and multiple plumes can then be treated using superposition. Qualitative results are presented for bifurcation and merging of plumes.
\end{abstract}

\section{INTRODUCTION}

There exist many studies of atmospheric jets, plumes, and thermals. Three review articles which also reference most of the pertinent literature are those by Turner, (1) Briggs, (2) and scorer. (3) In contrast, there are relatively few reports which concentrate on the flow exterior to jets and plumes. Such studies are intriguing when one inquires, for example, whether or not there exists an optimum arrangement of cooling towers in the neighborhood of a nuclear reactor, such that if there were an accidental release of radioactivity, it would be entrained by the cooling tower plume, brought to a higher elevation, and thereby dispersed less hazardously. Or, as another example, one wonders of potential hazards caused by entrainment into moist cooling tower plumes of pollutants from fossil-fuel-plant plumes; specifically, there is concern about possible enhanced production of sulfuric acid.

* Work supported in part by the Battelle Memorial Institute's Physical Sciences Program.
The purpose of this study was to explore the degree to which analytical analysis could provide insight into solutions of these practical problems. The only other analytical studies of exterior flows which apparently are available are that of the flow exterior to a momentum jet emerging into unbounded space (e.g., see Landau and Lifshitz(4), and those by Taylor. (5) Unfortunately the latter is just a 1 isting of results and is not of much value to the unitiated.

\section{THE TURBULENT (MOMENTUM) JET}

Before considering exterior flows, it seems appropriate to review the analyses of the interior flows. Consider first the flow within a turbulent (pure momentum) jet. Notation to be used is shown in Figure 1. At distances, $z$, large compared with the initial radius of the jet, a, the only characteristic length for the problem is $z$. Therefore, by dimensional arguments it is reasoned that the radius of the jet, $R$, will be proportional to $z$. Landau and Lifshitz (4) take 


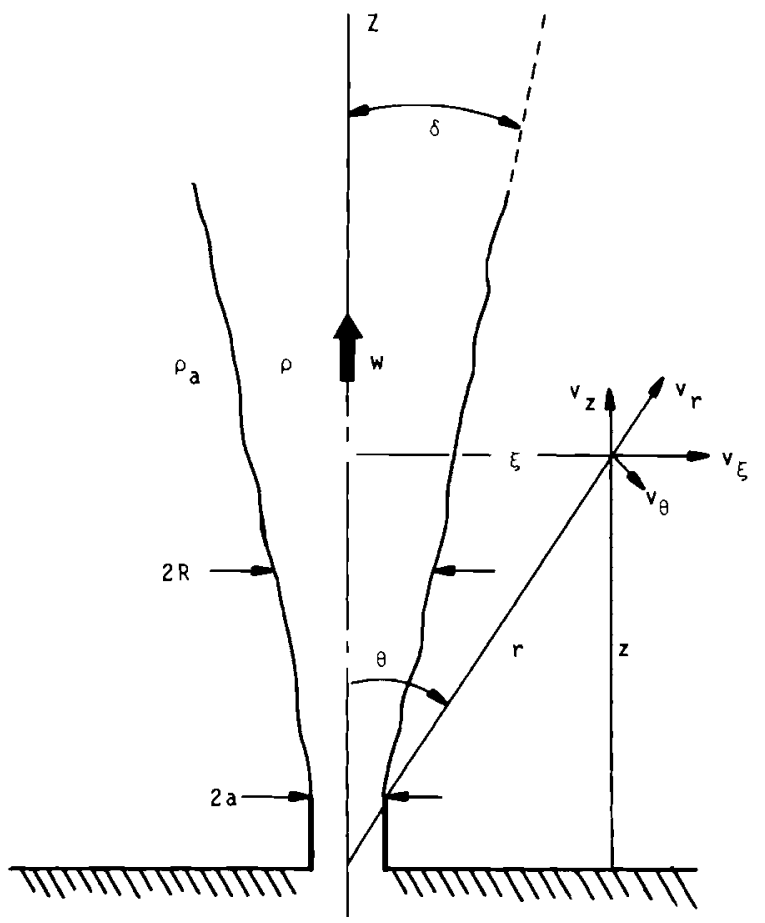

Neg 721419-1

FIGURE 1. Definition of Notation.

$$
R=z \tan \delta
$$

where from experimental evidence, $\tan \delta=0.2$. If it is assumed that the momentum flux within the jet is independent of altitude, i.e.,

$$
\rho \mathrm{w}^{2} \mathrm{R}^{2}=\text { const. }
$$

and if $\rho$ is treated as a constant, then (1) and (2) yield that the mean updraft velocity within the jet varies as $z^{-1}$ :

$$
w=\frac{w_{0} z_{O}}{z} .
$$

Throughout this paper we sha1l work only with mean quantities within the plume; i.e., we use "top-hat" profiles.
It is interesting that the above assumptions contain a prediction for the rate of entrainment of external air. To see this, note that the mass flux at any height, $Q \sim \rho w R^{2}$. If $\rho$ is independent of height, then (1) and (3) give

$$
Q=A z,
$$

where A is a constant (which Landau and Lifshitz suggest to be about 1.5 $\mathrm{Q}_{0} / \mathrm{a}$ where $\mathrm{Q}_{0}$ is the mass $f 1 u x$ emerging from the jet.) From (4), the amount of air entrained through the sides of an infinitesimal slice of the jet of height dz is

$$
d Q=A d z=A \cos \delta d r .
$$

But the amount entrained is also given by

$$
\mathrm{d} Q=-2 \pi R \rho_{\mathrm{a}} v_{\theta}(\xi=\mathrm{R}, z) \mathrm{dr},
$$

where $v_{\theta}$ is the $\theta$-component of the velocity, $\vec{v}$, of the external air and $\rho_{\mathrm{a}}$ is its density. If variations of $\rho_{\text {a }}$ with height are ignored, then using (1) and (3), (5) and (6) give

$$
v_{\theta}(R, z)=-\alpha w \text {. }
$$

That is, the two assumptions used in the construction of the theory contain the results that the entrainment is proportional to the updraft velocity.

Turning now to the exterior flow, there are a number of ways to solve for the kinematically (but not necessarily dynamical1y) feasible flow exterior to a jet emerging into the 
half space, $z>0$. Proceeding as Landau and Lifshitz, but using different boundary conditions, we solve continuity, $\nabla \cdot \vec{v}=0$ and the postulated condition of irrotationality, $\nabla \times \vec{v}=0$. The solution that vanishes at infinity, satisfies $v_{z}=0$ at $z=0$ and $v_{\theta}=-\alpha w$ on the jet boundary, is

$$
\vec{v}=-\frac{A}{2 \pi \rho_{a}} \frac{1}{r}\left[\hat{e}_{r}+\cot \theta \hat{e}_{\theta}\right] \text {. }
$$

Another way is to solve for the velocity potential; defined via $\vec{v}=-\nabla \phi$, which satisfies Laplace's equation, $\nabla^{2} \phi=0$. In the solution it is necessary to include the infrequently used Legendre polynomials of the second kind, $Q_{n}$, which have a logarithmic singularity at $\theta=0$, which is outside the flow region of interest. A third way to obtain a solution which evidently is the method used by Taylor, (5) is to solve for a Stokes' stream function. Distributing a line sink along the axis of symmetry (and from the above, $d Q \sim R w$ is independent of height and therefore the sink strength per unit length is independent of height) leads to $\mathrm{d} \Psi=\operatorname{Adz} / 2 \pi \rho_{a}$, or

$$
\Psi=-\frac{A}{2 \pi \rho_{a}} r \cos \theta
$$

from which one can obtain the velocity components.

The most interesting feature of these results is that exterior to a jet emerging into a half space there exists a kinematically possible flow which is horizonta1. Thus, for example from (9), we have

$$
\begin{aligned}
& v_{\xi}=\frac{1}{\xi} \frac{\partial \Psi}{\partial z}=-\frac{\mathrm{A}}{2 \pi \rho_{\mathrm{a}}} \frac{1}{\xi}, \\
& v_{z}=-\frac{1}{\xi} \frac{\partial \Psi}{\partial \xi}=0 .
\end{aligned}
$$

Further, the flow is not only horizontal but a1so, since $v_{\xi}$ is independent of $z$, then the flow appears to be dynamically feasible: no instabilities generated by velocity shear should develop (except in a surface boundary layer).

\section{BUOYANT PLUMES}

The case of buoyant plumes is more complicated. For the interior flow it is customary to continue to assume that

$$
R=z \tan \delta_{b}
$$

To determine $\mathrm{w}$ and $\mathrm{v}_{\theta}$, conservation equations are needed. The conservation of mass,

$$
\frac{d}{d z}\left(\rho w R^{2}\right)=-\frac{2 R \rho_{a} v_{\theta}(R)}{\cos \delta_{b}},
$$

simply equates the increase of mass within the plume to the mass entrained at the boundary; it yields $v_{\theta}$ if $\rho$ and $w$ are known. The $z$-component of the momentum equation is

$$
\begin{aligned}
& \frac{d}{d z}\left(\rho w^{2} R^{2}\right)+p \frac{d}{d z} R^{2} \\
& =\left(\rho_{a}-\rho\right) g R^{2}+2 R p \tan \delta_{b} \\
& -2 R v_{\theta}(R) \rho_{a} v_{z}(R) / \cos \delta_{b} .
\end{aligned}
$$


Upon application of the continuity equation and using $R=z \tan \delta_{b}$, we reduce (14) to

$\frac{d}{d z}\left(w^{2} R^{2}\right)=B R^{2}+v_{z}(R) \frac{d}{d z}\left(w R^{2}\right)$,

where we have used the Boussinesa approximation and defined the buoyant force per unit mass to be

$B=B(z)=\frac{\rho_{a}-\rho}{\rho} g$.

Using (12) we could solve (13) and (16) for the two unknowns $\rho$ and $w$ pro$v$ ided the external flow were known. A solution that is frequently quoted is derived using three additional assumptions:

1. The influence of $v_{z}$ on the momentum equation, (15), is negligible.

2. The difference between $\rho_{a}$ and $\rho$ in the continuity equation is negligible.

3. The buoyancy flux is a constant, i.e.,

$B w R^{2}=B_{O} w_{0} R_{O}^{2}$.

Notice that with these assumptions, we have essentially specified $\rho$, $\rho_{0}$ and $v_{z}$. Using them in (15) leads to

$w=w_{0}\left(z_{0} / z\right)^{1 / 3}$,

and using them and (18) in (13) gives

$v_{\theta}=-\alpha w$,

with $\alpha=(5 / 6)$ sin $\delta_{b}$ which from observations is about 0.1 . Thus, as for the turbulent jet, the entrainment is proportional to the updraft velocity. [Alternatively, one could have assumed (19) and derived, e.g., (12). ]
We now look at the exterior flow. Again we seek only a kinematically possible solution; i.e., one that satisfies continuity. The simplest way to do this is to find a Stokes' stream function which satisfies the boundary conditions imposed by the ground and the plume. By definition, the stream function satisfies continuity.

It is relatively easy to $f$ ind a stream function that satisfies any distribution of sinks and sources along the plume axis. A distribution that might be of particular interest is shown in Figure 2, where we have attempted to include the effect of the "sink" at the base of a cooling tower (i.e., the inlet) and a thermal inversion at height $\mathrm{H}$. The infinitely repeated mirror images of sources and sinks are used to force the boundary conditions that $v_{z}=0$ at $z=0$ and $z=H$ and to aid in the calculations.

The steam function is given by

$\Psi(\xi, z)=\frac{1}{4 \pi} \int_{\zeta=-\infty}^{+\infty} f(\zeta) \frac{z-\zeta}{\left[(z-\zeta)^{2}+\xi^{2}\right] 1 / 2} d \zeta$,

where $f(\zeta)$ is the source strength per unit length. To solve (20), $f(\zeta)$ is expanded in a series of cosines

$f(\zeta)=\sum_{n=1}^{\infty} a_{n} \cos n k \zeta$,

where $a_{n}$ are the Fourier coefficients and $k=\pi / H$. Substituting (21) into (20) and assuming uniform convergence of the resulting series, we obtain 


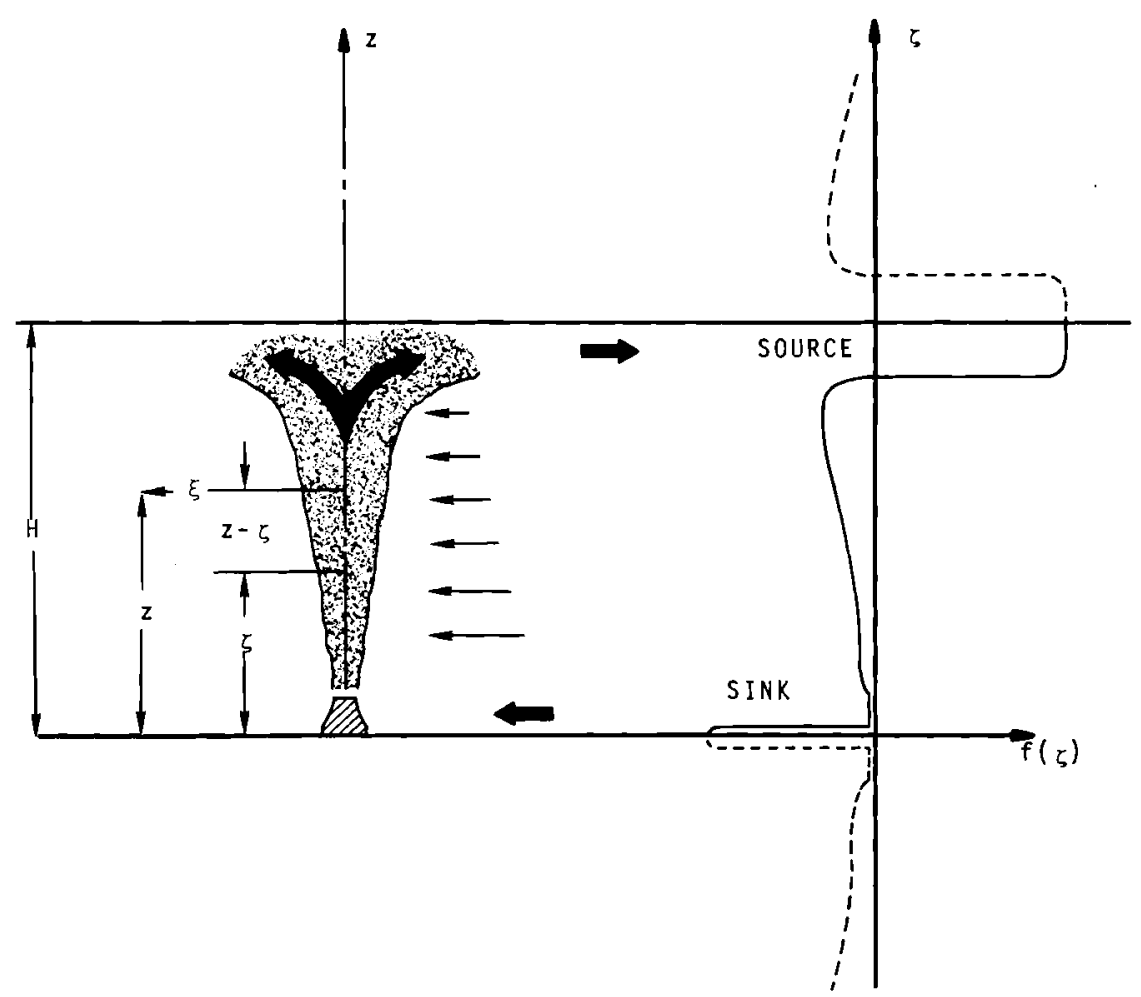

Neg 721419-2

FIGURE 2. Distribution of Sources and Sinks used to Model the Flow Exterior to a Cooling Tower, Beneath a Temperature Inversion at Height $\mathrm{H}$.

$$
\Psi(\xi, z)=\frac{1}{2 \pi} \sum a_{n} \sin n k z \quad \xi K_{1}(n k \xi),
$$

where $K_{1}$ is a modified Bessel function. From (22) we can obtain the velocity components

$v_{\xi}=\frac{1}{2 \pi} \sum a_{n} n k \cos n k z K_{1}(n k \xi)$,

and

$v_{z}=\frac{1}{2 \pi} \sum a_{n} n k \sin n k z K_{o}(n k \xi)$.

There are a number of interesting features of these results. First, $v_{z}=0$ at $z=0$ and $z=\pi k^{-1}=\mathrm{H}$, as was desired. A1so, for large

distances from the axis,

$\Psi \sim \frac{1}{2 \pi} \sum_{n=1}^{\infty} a_{n} \sin n k z \xi\left(\frac{\pi}{2 n k \xi}\right)^{1 / 2} e^{-n k \xi}$,

which vanishes. Thus at large dis-

tance the cooling tower-inversion situation appears as a dipole. At the other extreme, i.e., for distances from the axis small compared with $H$, then

$v_{\xi} \simeq \frac{1}{2 \pi} \sum a_{n} n k \cos n k z \frac{1}{n k \xi}$,

or 
$v_{\xi} \simeq \frac{f(z)}{2 \pi \xi}, \quad \xi \rightarrow 0$

To obtain information about $v_{z}$, we notice from (24) that as $\xi \rightarrow 0, v_{z}$ has a logarithmic singularity. However, this is inside the plume boundary. The streamlines are given by $\Psi=$ constant and from (22), for $\operatorname{sma} 11 \xi$,

$\Psi(\xi \rightarrow 0, z)=\frac{1}{2 \pi} \sum a_{n} \sin n k z \xi \frac{1}{n k \xi}$.

Thus, for small $\xi$, the streamlines are in surfaces of constant $z$ and therefore the flow is horizontal.

To determine if the flow might be dynamically possible, we look at the vorticity

$\vec{\omega}=\nabla \times \vec{v}=\hat{e}_{\phi}\left[\frac{\partial v_{\xi}}{\partial z}-\frac{\partial v_{z}}{\partial \xi}\right]$.

Substituting (23) and (24) into (29) gives $\vec{\omega} \equiv 0$. Thus the solution appears to be dynamically acceptable except for the inadequacy at $z=0$, where $v_{\xi} \neq 0$, whereas in reality there should be a no slip condition and a boundary layer from which vorticity diffuses into $z>0$. However, even this inadequacy is probably not too significant since the boundary layer may be thin in the favorable, stabilizing pressure gradient caused by the sink at $z=0$. Since $\vec{\omega}=0$, a velocity potential exists and it is easily found to be

$\phi=\frac{1}{2 \pi} \sum a_{n} \cos n k z K_{o}(n k \xi)$.

The reality of the above solution could be challenged, especially the significance of the infinitely repeated distribution of sources and sinks. In response to this, we note that in view of the above we have essentially solved $\nabla \cdot \vec{v}=0, \nabla \times \vec{v}=0$ and satisfied all appropriate boundary conditions. Therefore the solution we have obtained is the desired solution, and the method used to obtain it (method of images) is irrelevant. Further confidence in the result is obtained via comparison of these results with those recently obtained numerically by Trent. (6) His numerical solutions show that in the neighborhood of both jets and plumes emerging into a half space, the exterior flow is essentially horizontal.

\section{THE INFLUENCE OF A MEAN WIND AND/OR}

\section{ADJACENT PLUMES}

If there exists a mean wind then the analysis could become very complicated since the symmetry of the problem is destroyed. This lack of symmetry also precludes numerical calculations in reasonable computing times. However, we shall explore this problem for the case that the mean wind is light enough so that the dynamics of the plume are still described by the above analysis. To determine the flow exterior to the jet or plume, we utilize the above results that in both cases, the flow in the neighborhood $(\xi \ll H)$ of the jet or plume is essentially horizontal. Then, since the equations for $\phi$ or $\psi$ are linear, superposition can be used.

Then consider the flow in some plane $z=$ const. The total stream function will be the sum of the stream function for a source of strength per 
unit length, $f(z)$, and that for a uniform stream of speed $U(z)$. Taking the derivatives of the resulting stream function gives the velocity components

$v_{\xi}=\frac{f(z)}{2 \pi \xi}+U \cos \phi$

and

$\mathrm{v}_{\phi}=-\mathrm{U} \sin \phi$

where $\phi$ is the angle from the downwind direction as shown by Figure 3. There we have sketched the flow field for a particular $z$ at which the plume is still entraining fluid.
It is interesting that the higher the wind speed, the closer the stagnation point (s.p.) will move toward the plume boundary. In this naive picture the stagnation point could move inside the jet boundary and would set up two counter-rotating vorticies within the plume. It is suggestive that the ingredients of this picture are essentially correct for cases of light turbulence in the exterior flow, and that this is the cause of the frequently observed bifurcation of plumes. In this picture, bifurcation would occur at height $z$ given by $v_{\xi}(\xi=R$, $\phi=0 ; z)=0$. That is, from (31), $f(z)=-2 \pi R U$. For a jet, the source

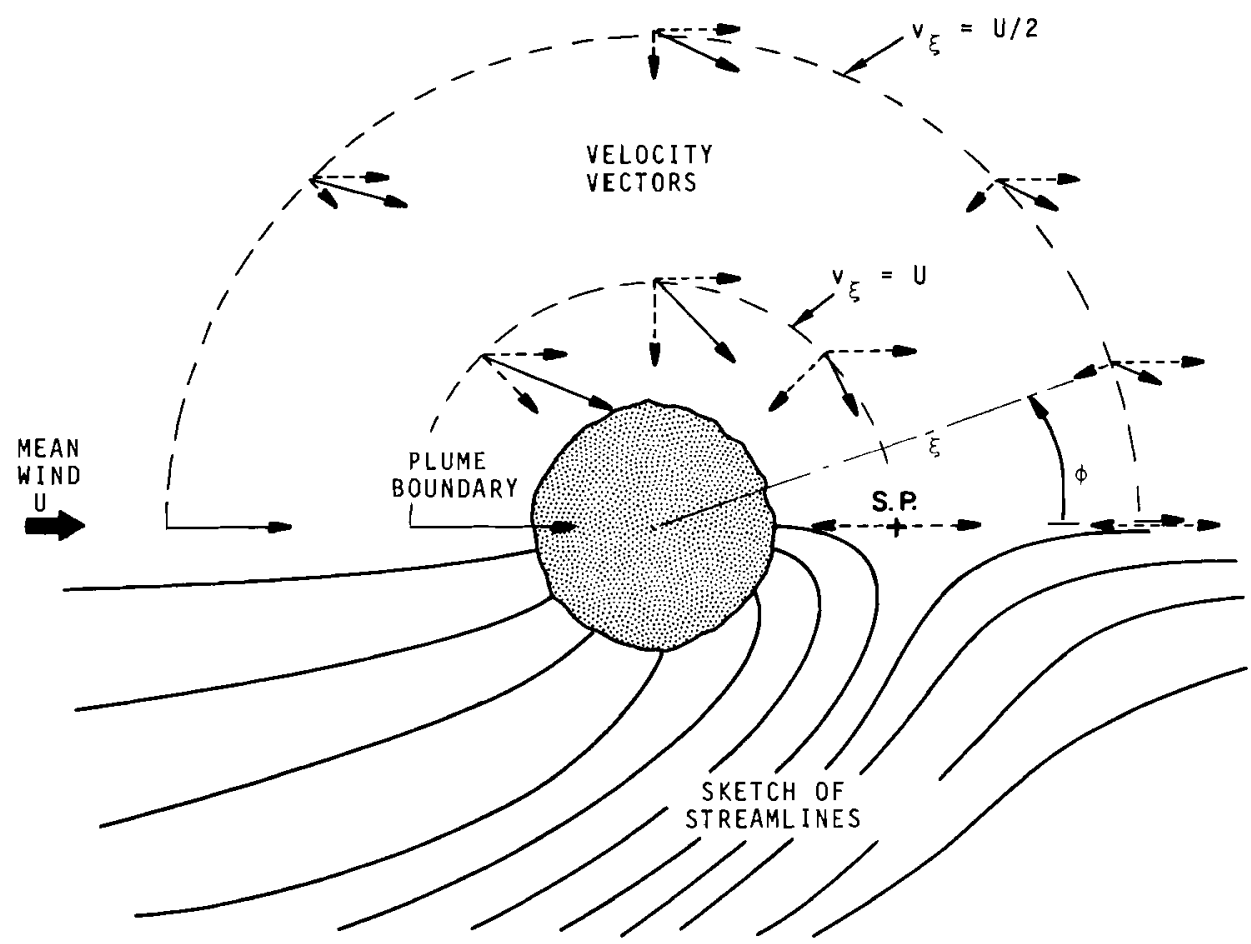

Neg 721419-3

FIGURE 3. Sketch of a Plan View of the Flow Exterior to a Jet or Plume at some Height $z$ for the Case of Nonzero Mean Wind. In the top half of the figure, the velocity vectors and components are shown at a number of locations. In the lower half, streamlines are sketched. 
strength per unit length is the constant value $\left(-A / P_{a}\right)$. Therefore, using $\mathrm{R}=\mathrm{z} \tan \delta$, it is suggested that in a light wind and for low-level turbulence in the exterior fluid, bifurcation might set in at a height

$\mathrm{z}_{\mathrm{J}}^{+}=\frac{\mathrm{C}}{2 \pi \tan \delta} \frac{\mathrm{Q}_{\mathrm{O}}}{\mathrm{a} \rho_{\mathrm{a}} \mathrm{U}} \sim \frac{\mathrm{Q}_{\mathrm{O}}}{\mathrm{a} \rho_{\mathrm{a}} \mathrm{U}} \sim \pi \frac{\mathrm{v}_{\mathrm{E}}}{\mathrm{U}} \mathrm{a}$,

where $v_{E}$ is the jet's exit velocity. For the buoyant plume discussed earlier, for which $f(z) \sim-z^{2 / 3}$, then $z_{p}^{+} \sim\left(\frac{w_{0}}{U}\right)^{3} z_{0}$, where $z_{0}$ is the height at which $w^{2}=w_{0}$. Extension of these considerations to line vorticies cast off by convective storms is

intriguing.

In reality, when the stagnation point approaches the jet or plume boundary, the inner flow would not be able to entrain fluid from the exterior flow and the assumptions of a vertical plume would have to be abandoned. To obtain a qualitative idea of the initial tilt of a plume, we can estimate the $x$ (downwind) component of the momentum equation to be

$w \frac{d}{d z}\left(R^{2} u\right)=2 \alpha w R U$.

For arbitrary $w$, using $R=z \tan \delta$, (34) leads to

$\tan \theta(z) \equiv \frac{U}{w}=\gamma \frac{U}{w}$

with $\gamma=\alpha \cot \delta \simeq 1$. The result (35) is what might have been decided by dimensional arguments.

If there exist adjacent jets or plumes, then the flow field can be found in a manner similar to the above. We look at the flow in each plane and use superposition. In Figure 4 a simple example is sketched. This example is particularly interesting in that two stagnation points appear on the centerline. If the axes of two plumes were initially a distance D apart, then they would bend toward each other and merge. From (35) an estimate of the height at which this would occur is $z=D / \epsilon$ where $\varepsilon=\gamma \tan \delta=\alpha \sim 0.1$.

\section{SUMMARY}

This above represents a progress report of a brief look at the flow exterior to jets and plumes. It contains some interesting features but the analysis is primitive and it is premature to draw any substantial conclusions. It should be reemphasized that we have considered only the case for jets or plumes emerging into the half space $z>0$. Thus, in particular for the solution to the flow exterior to a momentum jet, the results should not be applied to describe the flow exterior to a tall stack. This problem has been solved (4) but since it does not predict horizontal flow, the effect of mean wind and adjacent plumes cannot be handled so simply.

The return on the small investment of effort that has been put into this analysis is very encouraging. It has been seen that exterior to jets and plumes emerging into a half space, the flow is essentially horizontal and the speed varies as the reciprocal of the distance from the axis. Thus, an estimate of the fate of a radiation 


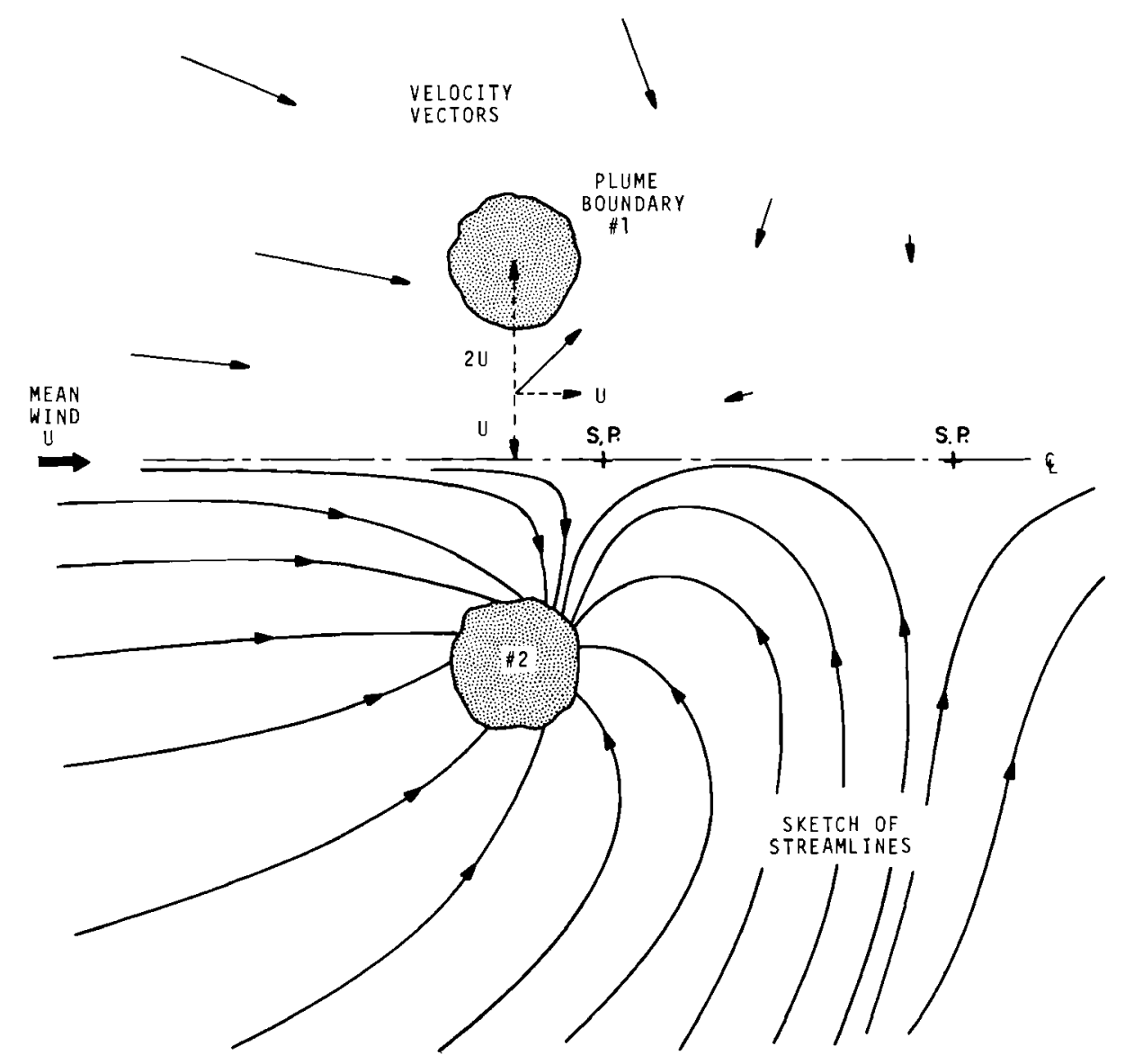

Neg 721419-9

FIGURE 4. Sketch of a Plan View of the Flow Field Exterior to two Cooling Tower Plumes at some Height $z$, for the Case of Nonzero Mean wind. A simple case for which there exists considerable symmetry has been chosen. Notice that in this case, of fairly low wind speed, two stagnation points appear on the centerline. At higher wind speeds these stagnation points can vanish and stagnation points appear downwind of each plume.

leak near a cooling tower can be evaluated. Further, because the exterior flow is essentially horizontal, the interaction between jets and plumes and the influence of a mean wind can be studied relatively easily. Thereby, interesting qualitative results have been obtained for the tilt and the merging of plumes and their bifurcation. Another effect which may be within reach of this type of analysis but which was not investigated is the frequently observed kink instability of plumes.

I wish to thank S. A. Slinn for her graphic evaluations of Equations (31) and (32) and sketches of the results (Figures 3 and 4 ).

\section{REFERENCES}

1. J. S. Turner. "Buoyant Plumes and Thermals," Annual Review of Fluid Mechanics, vol. 1, pp. 29-44, 1969. 
2. G. A. Briggs. Plume Rise, $A E C$ Critical Review Series, TID-25075, 1969 .

3. R. S. Scorer. The Microphysics and Dynamics of Convective Clouds-A Colloquim, NCAR-TN-52, National Center for A tmospheric Research, 1970.

4. L. D. Landau and E. M. Lifshitz. Fluid Mechanics, Pergamon Press 1959 .
5. G. I. Tayzor. "Elow Induced by Jets," Journal of the Aero/Space Sciences, vol. 25, pp. 264-465, 1958 .

6. D. S. Trent and J.R. Welty. "Numerical Computations of Convection Currents Induced by Eires and other Sources of Buoyancy," to be presented at a conference of the Western States Section, The Combustion Institute, Seattie, Apriz, 1972 (private communication).

\title{
AIRBORNE RELEASE OF PLUTONIUM AND ITS COMPOUNDS DURING OVERHEATING INCIDENTS*
}

J. Mishima and L. C. Schwendiman

\begin{abstract}
A series of studies to evaluate the fractional airborne release of plutonium under various postulated accident conditions has been in progress for some time. Data generated in earlier laboratory scale studies are reviewed. A larger scale facility -- The Radioactive Aerosol Release Facility - was placed in operation providing the capability for measurement of fractional airborne release of radioactive particles from burning material on a more realistic scale. The amount and aerodynamic equivalent size distribution of particles that may become airborne under conditions found in some shipping accidents were measured in experiments conducted in a special wind tunnel in the Radioactive Aerosol Release Test Facility.
\end{abstract}

As the era of nuclear power comes of age, plutonium is handled and utilized in ever-increasing amounts. An abiding interest in assuring the maximum protection to the population prompts a continuing effort to evaluate the potential consequences of situations

* Work supported by the Atlantic Richfield Hanford Company's Environmental and Reguiatory Technology Program. which can occur during the use of plutonium. Experience to date in protecting workers and people in the environment has been excellent but experience has also shown that there may be low probability occurrences that may give rise to the airborne release of plutonium and its compounds. These low probability incidents may be precipitated by or accompanied by a fire. 
Incidents in which control criteria involving plutonium and its compounds were exceeded were reviewed, (1) and existing data on the airborne release of plutonium and its compounds presented. (2) Small scale laboratory experiments yielding order of magnitude estimates of the airborne release of plutonium and its compounds ${ }^{(3-7)}$ were conducted during earlier periods. The retrospective review showed that about 70 percent of the incidents occurred during what is nominally considered chemical processing, 28 percent during handling and storage, and only 2 percent in transportation. Fire played a role in 13 of the 20 incidents resulting in airborne contamination.

Based upon the needs revealed by the review of data on the airborne release of plutonium, a laboratory program was conducted to provide information on the fractional airborne release of particles when plutonium and its compounds are subjected to thermal stress and differing airflows.

- Meta1--Some $10^{-6}$ to $10^{-5}$ percent of plutonium present as the ignited metal was entrained by air passing horizontally over oxidizing cylindrical specimens. As much as 0.03 percent of the oxide formed could be elutriated by passing air up through the residue after cooling. The fractional airborne release from large pieces of plutonium metal oxidizing at an accelerated rate was in the same range--the maximum measured value was 0.05 percent. The Median Mass Diameter (MMD) of the particles airborne was 4.2 microns Aerodynamic Equivalent Diameter (AED).
- Powders--Entrainment of particles during the heating of powders of plutonium compounds--oxide, partially oxidized oxalate, oxalate, fluoride and the solid residues from the evaporation of nitrate solutions--varied over a wide range. A fractional airborne release of the order of $10^{-6}$ percent was measured in air passed over the residues from nitrate solution evaporation, heated to $130^{\circ} \mathrm{C}$. When heated to as high as $1000^{\circ} \mathrm{C}$, as much as 0.12 percent could be carried out the chimney in an upsweep of air. The MMD of these particles was microscopically measured to be about 20 microns. The other powders heated in this manner indicated fractional airborne releases of: (a) up to 0.82 percent from the partially oxidized oxalate, (b) up to 0.9 percent from the oxalate, (c) up to 0.05 percent from fluoride, and (d) up to 0.025 percent from oxide powder less than a 325 mesh. The particles airborne were measured microscopically in some experiments and were quite coarse-a MMD of 25 microns for partially oxidized oxalate, a range of 5 to 60 microns from oxalate and MMD of 26 microns from fluoride powder.

- Nitrate Solutions--The amount airborne under the heating of aqueous plutonium nitrate solutions varied widely with the heating rate used. Aqueous plutonium nitrate was chosen as representative of solution behavior since it is frequently encountered at various processing stages. During the 
slow evaporation of shallow pools (about $3 \mathrm{~mm}$ deep) of concentrated solution at temperatures up to $130^{\circ} \mathrm{C}$, as much as $3 \times 10^{-3}$ percent was carried away by dry air (dewpoint of $-50^{\circ} \mathrm{F}$ ) flowing horizontally over the liquid at $100 \mathrm{~cm} / \mathrm{sec}$. With deeper pools (initially about $15 \mathrm{~cm}$ deep) of dilute solution as much as $6 \times 10^{-3}$ percent was airborne during the slow evaporation of 90 percent of the volume. As the heat input was increased, the amount airborne increased. Releases as high as 0.084 percent were obtained when the heat input was sufficient to cause surface disturbance and 0.18 percent at a vigorous boil. Characterization of particles airborne was not undertaken due to the small numbers collected.

- Plutonium Nitrate Dried on SandSome experiments were conducted to determine the amount of plutonium release during the heating of sand bearing dried plutonium nitrate. Small quantities of materials were indirectly heated in stainless steel cups at temperatures up to $1000^{\circ} \mathrm{C}$ for 1 hour periods. Using completely dried material--sand surfaces were completely undisturbed after the run--up to 0.002 percent was found in air drawn up and around the sample at $100 \mathrm{~cm} / \mathrm{sec}$. If moisture were present, sand particles were dislodged and some of these particles entrained in the air stream. Releases under these conditions ranged from 0.0053 to 0.028 percent.
- During Combustion of Flammable Materials Containing Active Particles--As a prelude to large engineering-scale experiments, various flammable materials; wood, paper and paper products, rubber and plastic were impregnated with plutonium or uranium nitrate solutions or finely-divided uranium dioxide powder (MMD of approximately 6 microns AED). Uranium compounds were used as a stand-in for plutonium. As much as 1 percent of the plutonium incorporated was entrained in an upsweep of air having a nominal velocity of $5.6 \mathrm{~cm} / \mathrm{sec}$. Using an upsweep of air having a nominal velocity of up to $100 \mathrm{~cm} / \mathrm{sec}, 8$ percent of the uranium incorporated as a dried nitrate could be found on the filter sealing the end of a 4 inch diameter by 30 inch long chimney. In most cases lesser amounts were entrained, generally around 1 percent. Using uranium dioxide powder, in most cases at least 10 percent was made airborne during the fire and in some cases up to 40 percent.

A larger scale facility--The Radioactive Aerosol Release Test Facility-was placed in operation providing the capability for measurement of fractional airborne release of radioactive particles from burning materials on a more realistic scale. of the several possible materials studied uranium was shown to be the most suitable stand-in for plutonium in these experiments. 
The amount and aerodynamic equivalent size distribution of particles that may become airborne under conditions found in some shipping accidents were measured in experiments conducted in a special wind tunnel in the Radioactive Aerosol Release Test Facility. Airborne release from uranium dioxide powder or nitrate liquid dispersed on four types of surfaces were evaluated in twenty-six combinations of conditions believed to be representative of circumstances which would prevail in a transportation accident. Two wind speeds less than 4 and $23 \mathrm{mph}$ were used, both with and without a fire.

The fractional airborne releases measured under these conditions are tabulated in Table 1 and 2. Table 1, "Aerodynamic Entrainment of Uranium from Various Surfaces," are fractional airborne releases in the absence of a gasoline fire, and Table 2, "Percent of Source Airborne in Respirable Range During Gasoline Fires," are for the experiments involving a gasoline fire. These values were obtained by averaging the three samples obtained in each experiment - - two filters and an 8 stage cascade impactor. Since inhalation is the principal hazard, the gross quantity airborne was weighted by the fraction less than 10 microns AED (nominal respirable range) to give the percent of source airborne in the respirable range. Two areas of burning (approximately 2.9 and $1.2 \mathrm{sq} f t$ )

were used.

No single variable of those encompassed appeared to exert an over-riding controlling influence on the fractional

TABLE 1. Aerodynamic Entrainment of Uranium from Various Surfaces (Percent of source per hour in respirable size range.)**

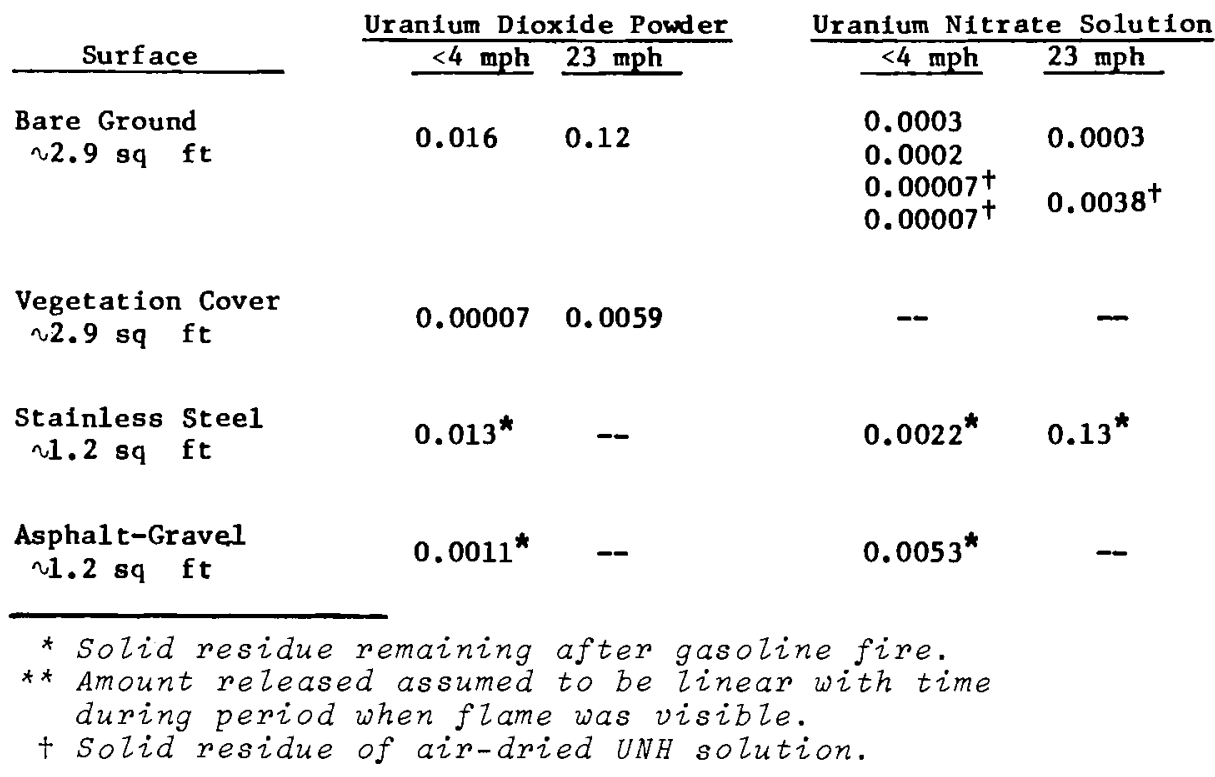


TABLE 2. Percent of Source Airborne in Respirable Range During Petroleum Fires

\begin{tabular}{|c|c|c|c|c|c|c|}
\hline 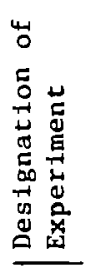 & Source & 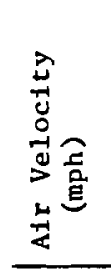 & 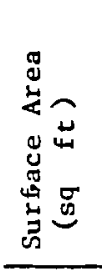 & 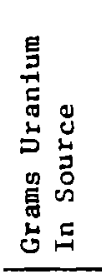 & 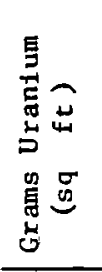 & 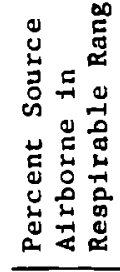 \\
\hline $18 \mathrm{a}$ & UNH solution on stainless steel & 23 & 1.23 & 25.5 & 20.7 & 4.3 \\
\hline $19 \mathrm{a}$ & UNH solution on stainless steel & $<4$ & 1.23 & 25.5 & 20.7 & 0.44 \\
\hline 14 & $\mathrm{UO}_{2}$ powder on vegetation cover & 23 & 2.89 & 69.5 & 24 & 0.59 \\
\hline 15 & UNH solution on vegetation cover & 23 & 2.89 & 51.1 & 17.7 & 0.17 \\
\hline $20 a$ & UNH solution on asphalt/gravel mixture & $<4$ & 1.23 & 25.5 & 20.7 & 0.16 \\
\hline $17 a$ & $\mathrm{UO}_{2}$ powder on stainless steel & $<4$ & 1.23 & 19.4 & 15.8 & 0.079 \\
\hline 16 & UNH solution on vegetation cover & $<4$ & 2.89 & 51.1 & 17.7 & 0.075 \\
\hline $21 \mathrm{a}$ & $\mathrm{UO}_{2}$ powder on asphalt/gravel mixture & $<4$ & 1.23 & 58.1 & 47.2 & 0.029 \\
\hline 7 & AIr dried UNH residue on ground & 23 & 2.89 & 51 & 17.6 & 0.038 \\
\hline 3 & $\mathrm{UO}_{2}$ powder on ground & $<4$ & 2.89 & 74.9 & 25.9 & 0.030 \\
\hline 12 & $\mathrm{UO}_{2}$ powder on vegetation cover & $<4$ & 2.89 & 78.3 & 27.1 & 0.013 \\
\hline 9 & Air dried UNH residue on ground & $<4$ & 2.89 & 51.5 & 17.8 & 0.0072 \\
\hline 5 & A1r dried UNH residue on ground & $<4$ & 2.89 & 51. & 17.6 & 0.0045 \\
\hline 10 & UNH solution on ground & $<4$ & 2.89 & 47.8 & 16.5 & 0.0013 \\
\hline
\end{tabular}

release. The combination of all factors produces a situation favorable or unfavorable to release. The highest fractional release was measured for a uranyl nitrate solution spilled on a stainless steel surface in a $23 \mathrm{mph}$ wind during a gasoline fire, 4.3 percent in the respirable range. Reducing the wind speed reduced the fractional airborne release an order of magnitude. Lesser quantities were released under the other conditions evaluated with fractional releases from bare soil on which uranyl nitrate has been spilled giving the smallest values.
A large scale field test was performed to validate that conditions generated in the lesser scale wind tunnel experiments were an adequate representation of those found in large scale gasoline fires outdoors. Five hundred gallons of gasoline were dumped onto an instrumented $30 \mathrm{ft} \times 30 \mathrm{ft}$ plot of typical Hanford terrain and ignited. Observed and measured parameters were in reasonable agreement with those generated in the wind tunnel simula. tions. The burning characteristics considered important were the duration of intense burning, the subsequent 
period of flame breakup and extinguishment, temperatures achieved, and areal extent of the fire per gallon of fuel.

\section{REFERENCES}

1. J. Mishima. Some observations on Airborne Releases Accompanying Serious Incidents Involving Plutonium, BNWL-CC-2011, BattelieNorthwest, Richland, WA, Feb. ?, 1969 .

2. J. Mishima. A Review of Research on Plutonium Releases During Overheating and Fires, $H W-83668$, HAPO, General Electric, Richland, WA, August, 1964.

3. J. Mishima. Plutonium Release Studies - I. Release from the Ignited Metal, BNWL-209, BattelleNorthwest, Richland, Washington, December, 1965 .
4. J. Mishima. Plutonium Release Studies -- II. Release from Ignited Bulk Metaliic Pieces, BNWL-357, Battelle-Northwest, Richland, WA., Nov. 10, 1966.

5. J. Mishima, L. C. Schwendiman and C.A. Radasch. Plutonium Release Studies -- ITI. Release from Heated Plutonium Bearing Powders, BNWL-786, BattelleNorthwest, Richland, Washington, July, 1968 .

6. J. Mishima, L. C. Schwendiman and C. A. Radasch. Plutonium Release Studies -- IV. Fractional Release from Heating Plutonium Nitrate Solutions in a Flowing Air Stream, BNWL-931, BattelieNorthwest, Richland, Washington, November, 1968 .

7. L. C. Schwendiman, J. Mishima and C. A. Radasch. Airborne Release of Particles in Overheating Incidents Involving Plutonium, BNWL-SA-1735, Battelie-Northwest, Richland, Washington, August 1, 1968. 


\title{
CHARACTERIZATION OF RADIOACTIVE PARTICLES IN A PLUTONIUM
}

PROCESSING PLANT EXHAUST SYSTEM*

J. Mishima and L. C. Schwendiman

\begin{abstract}
Filter and cascade impactor samples were taken of the stack gases and various exhaust streams of a plutonium processing plant to characterize by aerodynamic characteristics the amounts and distribution of particles with their associated radioactivity. only general conclusions can be drawn from the limited data obtained thus far: (a) the overall efficiency of the exhaust system is high; (b) little, if any, of the alpha activity leaving the stack is being recycled back into the ventilation system; (c) the plutonium present appears to be attached to large, nonactive particles.
\end{abstract}

\section{INTRODUCTION}

The Plutonium finishing plant at the Hanford site has a long history of safe operation, and radioactive material release is controlled well within the established limits. But an abiding public concern of possible effects of plutonium processing operations on the atmospheric environs justifies a continuing effort to reduce potentials for release to the lowest practicable level. Routine stack monitoring is performed as part of the radiological responsibility but does not provide all the data necessary to determine the fate of particles after emission. Knowledge of the distribution of the activity's aerodynamic particle size fractions is necessary to determine the airborne

* Work supported by the Atlantic Richfield Hanford Company's Environmental and Regulatory Technology Program. behavior of material released into the atmosphere. The contribution of the various components of the exhaust system to the total emission may be helpful in delineating areas of potential gain or identifying potential trouble points within the system. A body of information has been published on the amounts and size distribution of plutonium particles in various types of installations and in accident situations, $(1-11)$ but little information is available on the nature of particles within the ventilation system of plutonium processing plants.

\section{OBJECTIVES}

- The current study was undertaken to determine the distribution of aerodynamic sizes of plutonium-containing particles present in the plant gaseous effluents. The total concentration of plutonium as particulates was also to be determined. 
By direct use of the aerodynamic characteristics for classification, such factors as particle density and shape, agglomeration, etc., need not be of concern since the property of interest is measured. obtaining size distribution data in terms of aerodynamic characteristics will generate information which can be directly used in existing dispersion and deposition models that can forecast spatial distribution and predict any build-up on the terrain.

- A second objective was to determine the amount and distribution of radioactivity associated with particles contributed by various components of the building exhaust system.

\section{SUMMARY}

Filter and cascade impactor samples were taken of the processing plant stack gases and of various exhaust streams within the building ventilation system to characterize the amount and distribution by aerodynamic characteristics of particles with their associated radioactivity. Stack samples were extracted at the base of the stack. Exhaust stream samples were taken at various locations downstream of final filtration. Sampling periods ranged from 7 to 63 days and high volume samples (flows up to $72 \mathrm{cfm}$ ) taken of streams where extremely low activity concentrations were anticipated. Volumes of gases sampled ranged from $10^{4}$ to $4.4 \times 10^{6}$ cubic feet. Two components of the exhaust system--the exhaust from the Incinerator Building and the 26-inch (Process) vacuum system exhaust--may be contributing a signifi- cant amount of the total activity emitted. Another system with significant potential to contribute to the loading, the HF system exhaust, was not on the line during the sampling period and could not be evaluated. Air samples taken in the inlet plenum of the supply to the building showed low activity concentrations- $-10^{-8} \mathrm{dpm} / \mathrm{cu}$ ft to $10^{-7} \mathrm{dpm} / \mathrm{cu} \mathrm{ft}--i n d i c a t i n g$ that little, if any plutonium is recycled from the stack. The activity distribution into aerodynamic fractions was approximately log-normally distributed and surprisingly coarse--with one exception, Median Activity Diameter (MAD) ranged from 1.6 to $\sim 20$ micron Aerodynamically Equivalent Diameter (AED).

Because these measurements were the first of their kind ever taken within the facility and because the plant operations during the sampling period were not regarded as fully representative, the results to date are regarded as indicative rather than definitive. A few general conclusions can be drawn from the limited data obtained.

- Although the level of activity in the various exhaust streams could be determined with high accuracy with the data obtained, the overall efficiency of the exhaust system is high. The low quantity of alpha particle emitters leaving the stack and low activity concentrations in the exhaust streams indicate satis factory performance of the system.

- Little, if any, of the alpha-emitters emitted via the stack is being recycled back into the ventilation system.

- The plutonium present appears to be attached to large, nonactive particles. 


\section{REFERENCES}

1. E. C. Wyatt, W. D. Moss and H. F. Schulte. "Particle Size Studies on Uranium Aerosols from Machining and Metallurgy operations," Ind. Hygiene J. 20: 99-107, 1959.

2. W. D. Moss, E. C. Hyatt and H. F. Schulte. "Particle Size Studies on Plutonium Aerosols," Health Physics 5:212-218, 1961 .

3. J. M. Selby. Size Analysis of Particulates Found in Air at Hanford Plutonium Fabrication Facilities, HW-SA-2713, G.E., Hanford Laboratories, Richland, Washington, 1962.

4. R. J. Sherwood and J. P. Vaane. Alpha-Active Airborne Dust in the Entrance to a Pressure Suit Area, AERE-M-li89, Health Physics and Medical Division, Harwell, 1963.

5. B. V. Andersen. Particle Size Distribution Found in Air at Hanford Plutonium Production Eacilities, HW-SA-3197, G.E. Hanford Laboratories, Richland, Washington, 1963.
6. B. V. Andersen. Plutonium Particle Size Distribution in Room Air, HW-SA-3434, G.E. - Hanford Laboratories, Richland, Washington, 1964 .

7. B. V. Andersen. "Plutonium Aerosol Particle Size Distributions in Room Air," Health Physics, $10: 899-907,19 \overline{64}$.

8. R. A. Kirchner. "A Plutonium Particle Size Study in Production Areas at Rocky Flats," Am. Ind. Hygiene Assoc. J. 27 (4) $\overline{396-401}$, 1966 .

9. H. J. Ettinger, W. D. Moss and H. Busey. "Characteristics of the Aerosol Produced from Burning Sodium and Plutonium," Nuc. Sci. and Eng. 30:1-13, 1967.

10. B. V. Andersen and I. C. Nelson. Measurement of Plutonium Aerosol Parameters for Application to Respiratory Tract Model. BNWL-SA-1220, Battelle Northwest, Richland, Washington, 1967.

11. B. V. Andersen and I. C. Nelson. Plutonium Air Concentrations and Particle Size Relationships in Hanford Facilities, BNWL-495, Battelie-Northwest, Richland, washington, 1967. 


\title{
AIRCRAFT INSTRUMENTATION FOR ATMOSPHERIC RESEARCH Staff*
}

\begin{abstract}
A description is given of the first phases of instrumentation of a Cessna 411 aircraft. The aircraft is or will soon be capable of continuously measuring and recording aerosol particle size distributions and concentrations, condensation (Aitken) nuclei, cloud condensation nuclei, ice nuclei, concentrations of trace gases, temperature, relative humidity, dew point temperature, air speed, turbulence intensity, and parameters required to identify the aircraft position as a function of time. All the data are measured and recorded automatically on magnetic tape. Illustrative data obtained using the first phases of instrumentation are presented.
\end{abstract}

\section{INTRODUCTION}

A cessna 411 aircraft is being instrumented for the purpose of conducting airborne measurements of parameters which are important to our ongoing AEC atmospheric sciences research programs. The first phase of this modular instrumentation is directed especially toward measuring concentrations, size distributions, and other characteristics of atmospheric aerosols as a function of meteorological conditions. In the second phase, which is about to get underway a module will be installed for mea-

* Many individuals have contributed to the acquisition and instrumentation of the aircraft, including $C$. L. Simpson, C. E. Elderkin, R. W. Perkins and staff, and W.G.N. Slinn. The power distribution and data recording system were designed by K. M. Busness. The sampling probe and aerosol equipment are under the direction of A.J. Alkezweeny. F. 0 . Gladfelder (pilot) and J. M. Baily (copizot/aircraft mechanic) mounted the equipment. surement of trace gas concentrations; specifically, an airborne quadrupole mass spectrometer and associated equipment, real-time $\mathrm{SF}_{6}$ and $\mathrm{SO}_{2}$ samplers, and possibly a nucleogenic gas detector will be installed. other phases of instrumentation will be used for cloud physics, fundamental turbulence, and atmospheric transport and diffusion studies. The module to measure standard meteorological parameters is installed and will be common to a11 phases of instrument ation.

The al1-weather, radar equipped, twin engine aircraft is capable of cruising at speeds between 110 to $230 \mathrm{mph}$ for a period of 5 hours and up to altitudes of $25,000 \mathrm{ft}$. In the following sections electrical power distribution, sampling probe, measuring instruments, data recording, and data processing are described. Also, preliminary results of aerosol particle data collected during recent flights are presented. 


\section{ELECTRICAL POWER DISTRIBUTION}

The instrumentation presently installed in the aircraft requires both $28 \mathrm{VDC}$ and $115 \mathrm{VAC}-60 \mathrm{~Hz}$. The aircraft $28 \mathrm{~V}$ bus is supplied by two, 100 amperes alternators. The bus supplies power directly to certain instruments and also to a $115 \mathrm{VAC}$ - $60 \mathrm{~Hz}$ inverter which provides up to $1 \mathrm{KW}$ output to the other instruments.

Al1 power distribution to the various instruments is controlled via a central power control panel. The control panel is divided into three functional areas: inverter control, $A C$ power, and DC power. Selection of the inverter, application of the inverter load, and selection of an external AC source is provided in a manner which prevents the application of inverter and external AC power simultaneously. A switch selects an external AC source which is supplied via the external AC jack at the rear of the control panel chassis, and is used for ground operations (maintenance, calibration, etc.). A pair of switches and relays apply the 28 VDC to the inverter and connect the inverter output load. The AC power is distributed to the instrumentation via a group of standard AC outlets which are protected by individual circuit breakers.

Distribution of $28 \mathrm{VDC}$ power is also controlled by a group of circuit breakers. A main 15 A circuit breaker/switch feeds five branch circuit breakers which service the DC outlets for instrument power.
Metering is provided for visual monitoring of the $D C$ input current to the inverter, $A C$ and $D C$ volts and total AC and DC current load. A11 the power to the inverter and the instruments can be disconnected by a main 60 amperes breaker/switch accessible to the pilot. All breakers can be manually operated, and are MIL and FAA approved.

\section{THE SAMPLING PROBE}

The sampling probe consists of two parts. The first part is made of stainless steel and is located on the upper lefthand side of the aircraft (Figure 1). The probe extends about 10 inches from the fuselage and has an area expansion ratio of 16 to slow the flow speed before the stream is deflected inside the aircraft. The second part is made of aluminum with five stainless steel tubes. It is connected to the first part, inside the aircraft, with a rubber hose and clamps. Detail design of the probe is shown in Figure 2 .

To maintain isokinetic sampling, the $1 / 2$ inch tube may be connected to a pump whose pumping rate $c$ an be adjusted so that the air velocity at the probe's orifice is the same as the aircraft speed. Unfortunately there is not enough data in the literature to determine the losses of particles to the inside wall of the probe as a result of the 90 degree bend of the probe. However, in view of recent wind tunnel data by Sehmel (1) we can assume that for particles less than 5 microns in diameter, the loss is less than 10 percent. 


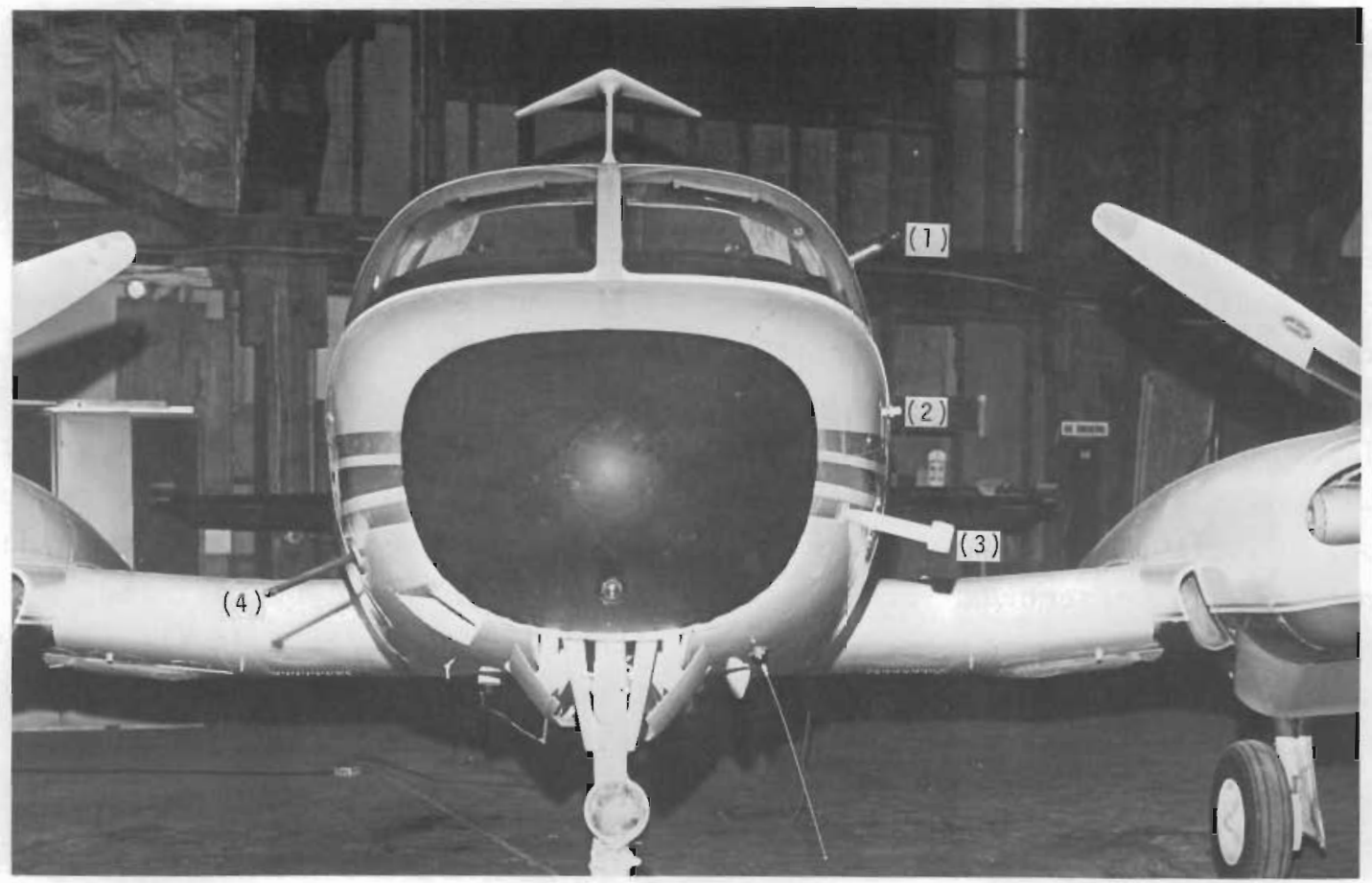

Neg 720804-I

FIGURE 1. The Locations of the Various Sensors on the Aircraft.

1) Sampling Probe

3) Temperature and

2) Dewpoint Sensor

Relative Humidity Sensor

4) Turbulence Sensor

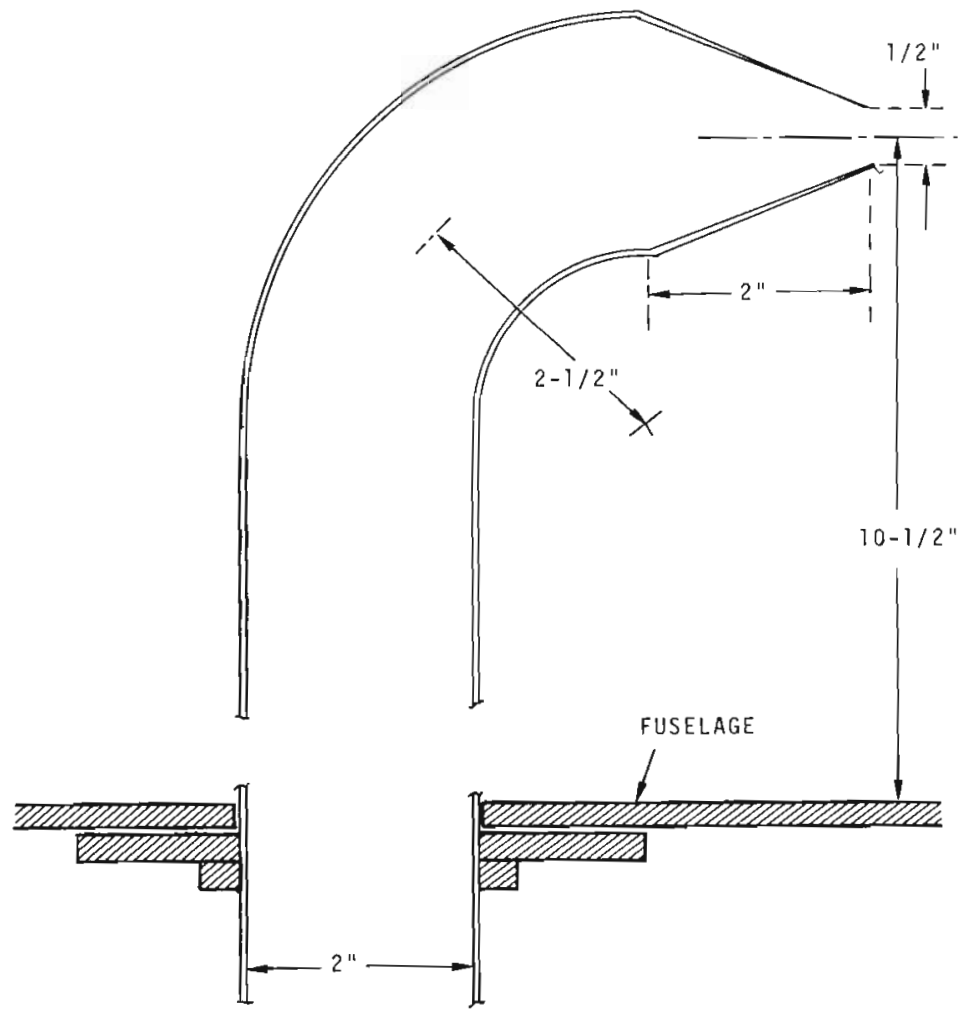

Neg 721419-5

FIGURE 2. The Sampling Probe 


\section{INSTRUMENTAT ION}

The instruments mounted and to be mounted onboard the aircraft are listed in Table 1 and photographs of their locations inside the aircraft are shown in Figures 3 and 4 . In the following paragraphs the instruments are described briefly.

The Condensation (Aitken) Nuclei Counter (General Electric) samples at the rate of $100 \mathrm{cc} / \mathrm{second}$. It is capable of detecting particles larger than 0.001 micron in size by measuring the light scattered from the water droplets formed on particles which are exposed to a high supersaturation achieved by a sudden expansion. The intensity of light scattering is automatically related to the particle concentration; response time is about 2 seconds.

The Royco Particle Counter, Model PC $200 \mathrm{~A}$ (Royco Instruments, Inc.) operates on the principle of $90^{\circ}$ light scattering from single particle of diameter 0.32 micron and greater, with a sampling rate of $100 \mathrm{cc} / \mathrm{minute}$. The instrument can be operated in either of two modes. In the first, it measures particle concentrations in 15 individual channels in the range of 0.32 to 8 microns and greater. In this case the data are printed in

TABLE 1. Instruments mounted and to be Mounted Onboard the Aircraft

\begin{tabular}{|c|c|c|c|c|}
\hline Instrument & Parameter & Range & Accuracy & Flow Rate \\
\hline $\begin{array}{l}\text { G. E. Condensation } \\
\text { Nuclei Counter }\end{array}$ & $\begin{array}{l}\text { Condensation (Aitken) } \\
\text { Nuclei }\end{array}$ & $\begin{array}{l}10-10^{7} \\
\text { particles } / \mathrm{cm}^{3}\end{array}$ & $\begin{array}{l} \pm 20 \% \text { full } \\
\text { scale }\end{array}$ & $100 \mathrm{~cm}^{3} / \mathrm{sec}$ \\
\hline $\begin{array}{l}\text { Royco Particle } \\
\text { Counter, Model } \\
\text { PC } 200 \mathrm{~A}\end{array}$ & $\begin{array}{l}\text { Sizes and concentration } \\
\text { of particles }\end{array}$ & $\begin{array}{l}0.32 \text { to } 8 \mu \\
\text { and }>8 \mu \\
\text { up to } 10^{6} \\
\text { particles/cm } 3\end{array}$ & $10 \%$ & $100 \mathrm{~cm}^{3} / \mathrm{min}$ \\
\hline $\begin{array}{l}\text { Metrodata System, } \\
\text { Model M8 }\end{array}$ & $\begin{array}{l}\text { Airspeed } \\
\text { Altitude } \\
\text { Temperature } \\
\text { Humidity } \\
\text { VOR I } \\
\text { VOR I I } \\
\text { DME }\end{array}$ & $\begin{aligned} 50 & -350 \mathrm{knots} \\
500 & =30,000 \mathrm{ft} \\
-50 & -+50{ }^{\circ} \mathrm{C} \\
30 & =95 \% \\
0 & =360^{\circ} \\
0 & =360^{\circ} \\
1 & -100 \mathrm{n} \text { mile }\end{aligned}$ & $\begin{array}{l}2 \mathrm{Kt} \\
100^{\circ \mathrm{ft}} \\
0.5^{\circ} \mathrm{C} \\
8 \% \\
\pm 1^{\circ} \\
\pm 1^{\circ} \\
1.5 \mathrm{nmile} \text { or } 3 \%\end{array}$ & \\
\hline $\begin{array}{l}\text { MRI Universal } \\
\text { Indicated System }\end{array}$ & Turbulence intensity & $0-10 \mathrm{~cm}^{2 / 3} \mathrm{sec}^{-1}$ & $10 \%$ & \\
\hline $\begin{array}{l}\text { EG\&G, Cambridge } \\
\text { Aircraft Hygrometer }\end{array}$ & Dew point temperature & $-50-+50{ }^{\circ} \mathrm{C}$ & $\pm 0.5^{\circ} \mathrm{C}$ & \\
\hline \multicolumn{5}{|c|}{ Instruments to be added in the near future } \\
\hline $\begin{array}{l}\text { MRI Cloud Condensation } \\
\text { Nuclei Counter }\end{array}$ & $\begin{array}{l}\text { Cloud condensation } \\
\text { nuclei }\end{array}$ & $\begin{array}{l}0.2-2 \% \text { super- } \\
\text { saturation }\end{array}$ & $-\cdots$ & \\
\hline MEE Ice Nuclei Counter & Ice Nuclei & $\begin{array}{l}0{ }^{\circ} \mathrm{C}-30{ }^{\circ} \mathrm{C} \text { activation } \\
\text { temperature and } \\
0.1 \text { to } 10^{4} \text { particles/ }\end{array}$ & $\pm 0.5{ }^{\circ} \mathrm{C}$ & \\
\hline $\begin{array}{l}\text { Quadrupole Mass Spec- } \\
\text { trometer, Scientific } \\
\text { Instruments }\end{array}$ & $\begin{array}{l}\text { Concentration of } \\
\text { gases }\end{array}$ & 1 - 300 atomic mass unit & $\begin{array}{l}0.1 \text { ppm } \\
\text { real-time }\end{array}$ & \\
\hline
\end{tabular}




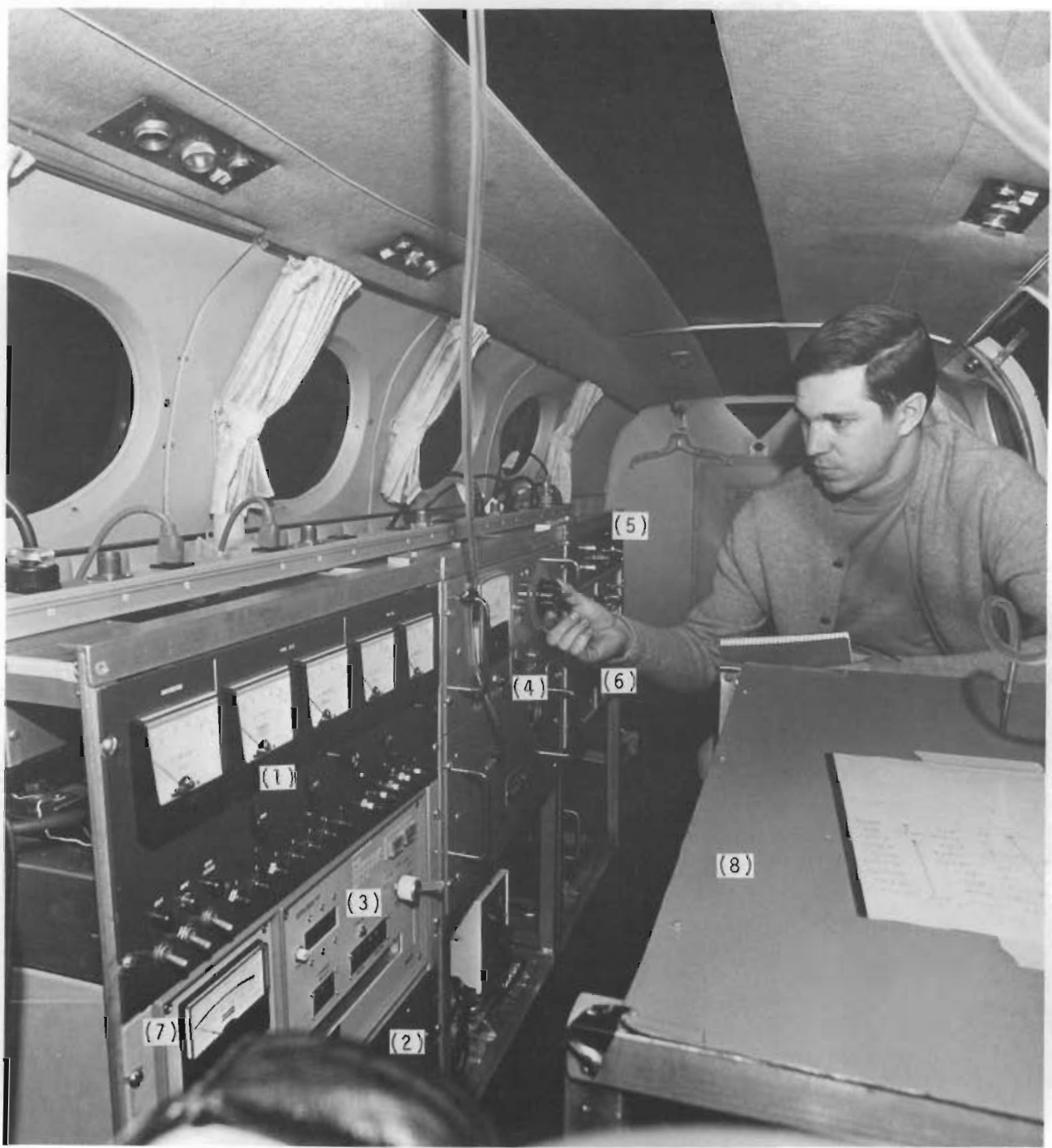

Neg 720804-2

FIGURE 3. The Locations of the Instruments Inside the Aircraft.

1) Power Control panel

2) Recorder Input Panel

3) Metrodata Magnetic Tape Recorder

4) Condensation Nuclei Counter
5) Turbulence Indicator System Panel

6) Hewlett-Packard Model 500A High Speed Printer

7) Metrodata System, M8, Direct Reader

8) Royco Particle counter a digital form on a Hewlett-Packard Model 500A High Speed Printer. In the second mode, the instrument provides a count of particles greater than a preset diameter. The data from this mode of operation are recorded on the aircraft recording system. It should be noted here that the count represents a cumulative count, but can easily be reduced to concentration in time and space. 


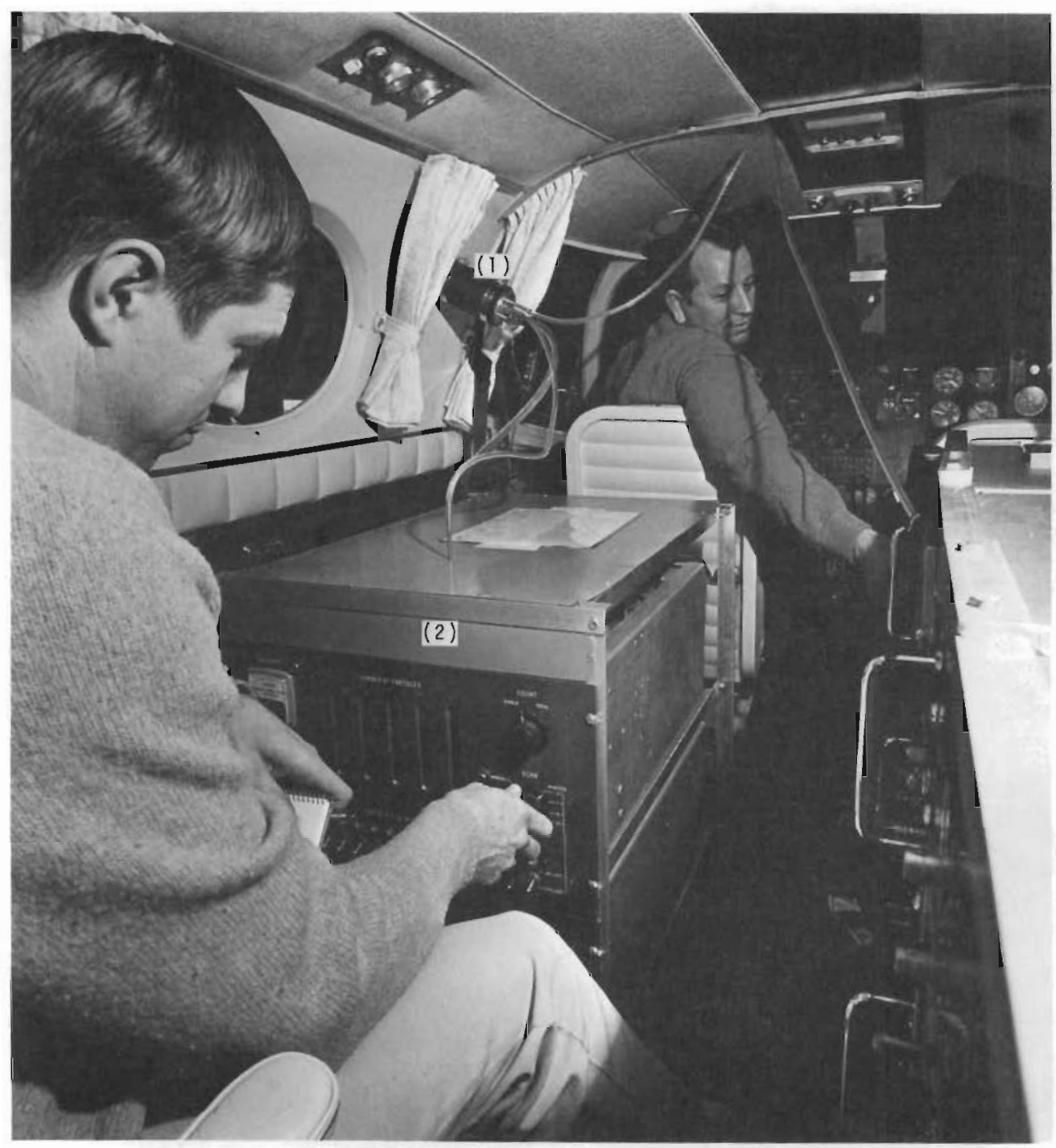

Neg 720804-3

FIGURE 4. The Locations of the Instruments Inside the Aircraft.

1) End of the Sampling Probe

2) Royco Particle Counter

Meteorological and aircraft parameters are measured via three different systems. The first is a Metrodata Systems, Inc., Model M8. This instrument measures temperature, humidity, airspeed, altitude, bearings from two points (VOR), distance from one point (DME), and compass heading. The temperature and humidity are ob- tained from sensors in a probe mounted on the nose of the aircraft (Figure 1). The temperature sensor uses a shielded, linear response, thermister head, and the humidity uses a carbon-strip hygrister, similar to that used in radiosondes. The aircraft pitot-static system is connected 
to a potentiometric transducer to measure airspeed and altitude. The VOR and DME data is derived from the navigational receivers of the aircraft. These and the altitude are used to determine the exact position of the aircraft at any time.

The second system is a Cambridge Systems Mode1 137-C3 Aircraft Hygrometer manufactured by EG\&G for measuring dew point temperature. The sensor is mounted on the lefthand side of the aircraft nose (Figure 1). It contains a platinum thermometer.

The third system is a Universal Indicated Turbulence System, Model 1120 , Meteorology Research, Inc. It measures the turbulence intensity of a specific frequency band which lies within the inertial subrange. It also measures the airspeed. The 1ocation of the sensor on the outside of the aircraft is shown in Figure 1 .

A11 the instruments which are described above are presently onboard the aircraft. Other instruments which will be installed in the near future are:

1) A Cloud Condensation Nuclei Counter (Meteorology Research Inc.) which is capable of measuring cloud condensation nuclei concentrations at adjustable supersaturations in the range 0.2 to 2 percent. The data are measured and recorded automatica11y.

2) An Ice Nuclei Counter (MEE Industries) which is a fast-response counter for detecting ice nuclei in the concentration range 0.1 to $10^{4}$ nuclei per 1 iter over any activation temperature from $0^{\circ} \mathrm{C}$ to $-30^{\circ} \mathrm{C}$ with automatic recording.
3) A Quadrupole Mass Spectrometer (Scientific Instruments, Inc.) which measures the concentration of gases in the range 1 to 300 atomic mass units, with sensitivity of 0.1 ppm real-time. With appropriate molecular sieves, concentrations in the ppb range can be attained.

\section{DATA RECORDING SYSTEM}

A recorder input panel functions as a convenient connecting point for a11 signal inputs to a Metrodata Mode1 DL620 magnetic tape data logger. Precision 10 -turn potentiometers at each input terminal permit the operator to attenuate and/or calibrate each data input to a full-scale range which is appropriate to the Metrodata recorder. All data lines utilize coaxial or shielded, twisted pair cable, and, insofar as is possible, a 11 ines and interconnections external to the various instruments are shielded to preserve data integrity.

The Metrodata recorder may be used in several input configurations ranging from \pm 10 millivolts to \pm 5 volts full scale with a 2000 point resolution. The instrumentation presently installed utilizes $\pm 10 \mathrm{milli}-$ volt and \pm 1 volt ranges. The recorder samples 18 analog inputs (plus 2 realtime channels) at rates up to 48 channels/sec. At the minimum sampling interva1, 60 minutes of recording may be accomplished on a single tape cartridge. Analog inputs are converted to digital form and recorded as four character BCD digits (sign +3 digits). Hours, minutes and seconds 
data from the real time clock are recorded at the beginning of each 20 channel scan.

A visual numeric display on the recorder permits the operator to check any one of the several input signals during acquisition and recording to verify the validity of the data.

\section{DATA ANALYSIS}

The airborne recorded magnetic tapes are brought to the BattellePNL computer facility for further processing and analysis. The central processor in the facility is a Systems Engineering Laboratories SEL 840A. The magnetic tape records acquired in-flight are read into the computing system via a Metrodata Mode1 DL 622 tape reader. Present1y, the tape record can be output either as a numerical record or as a graphical representation as a function of time by means of a high-speed electrostatic printer/plotter. In the event that more detailed analysis of the recorded data is required, the Metrodata tapes can be read into the $840 \mathrm{~A}$ computer, preprocessed and/or formated, and rewritten onto industrycompatible magnetic tape which can then be processed on a more extensive computer system such as the UNIVAC 1108 .

\section{LLUSTRATIVE DATA}

Figure 5 shows some preliminary data of the concentration of condensation (Aitken) nuclei as a function of altitude. Curve (1) was obtained

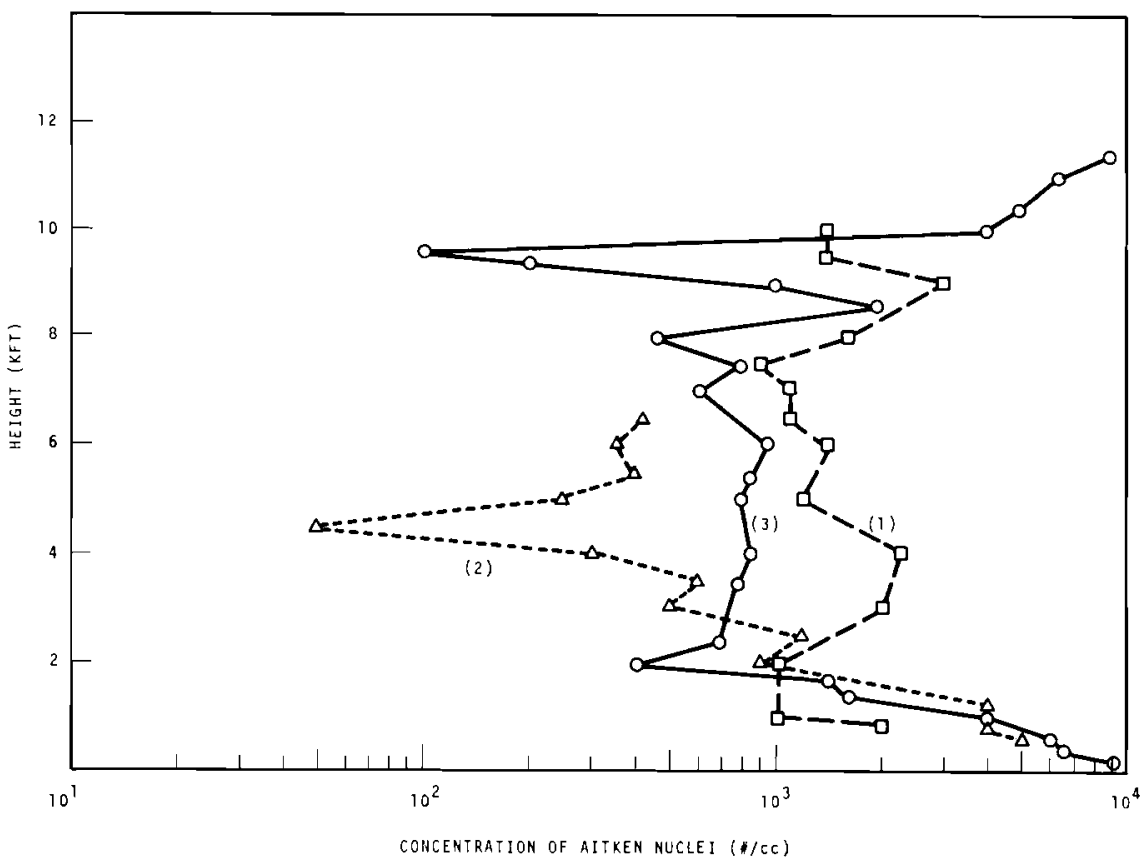

Neg 721419-10

FIGURE 5. Concentration of Condensation Nuclei as a Function of Altitude 
on February 20, 1972 over the Hanford project about 30 miles north of Richland, Washington. During the measurement, broken scattered clouds were present with bases at about 2000 feet. It can be seen from this curve that the concentration decreases with height to some altitude between 1000 to 2000 feet and then seems to fluctuate at higher altitudes. Other measurements were made on the same day, 25 miles southeast of Wenatchee, Washington in a clear sky (Curve 2). The count decreased with height up to about 4500 feet. At that time a patch of cloud drifted into the area, and the count increased. The next day it was overcast with some haze; cloud base was estimated at about 20,000 feet. Approximately 3 miles north of the Pasco Airport, Washington, another flight was made and Curve (3) of Figure 5 shows a plot of the collected data. Here again the count decreased with height, then remained almost constant, and finally at an elevation of about 11,500 feet, increased to values approaching the ground level concentration.

On February 21, 1972, particle size distributions were obtained at three different altitudes in the same area. These are shown in Figure 6 with the corresponding altitude marked on each distribution. Even from the meager statistics of these data, one can deduce that with increase in altitude, there is a significant decrease in the particle concentrations of all sizes.

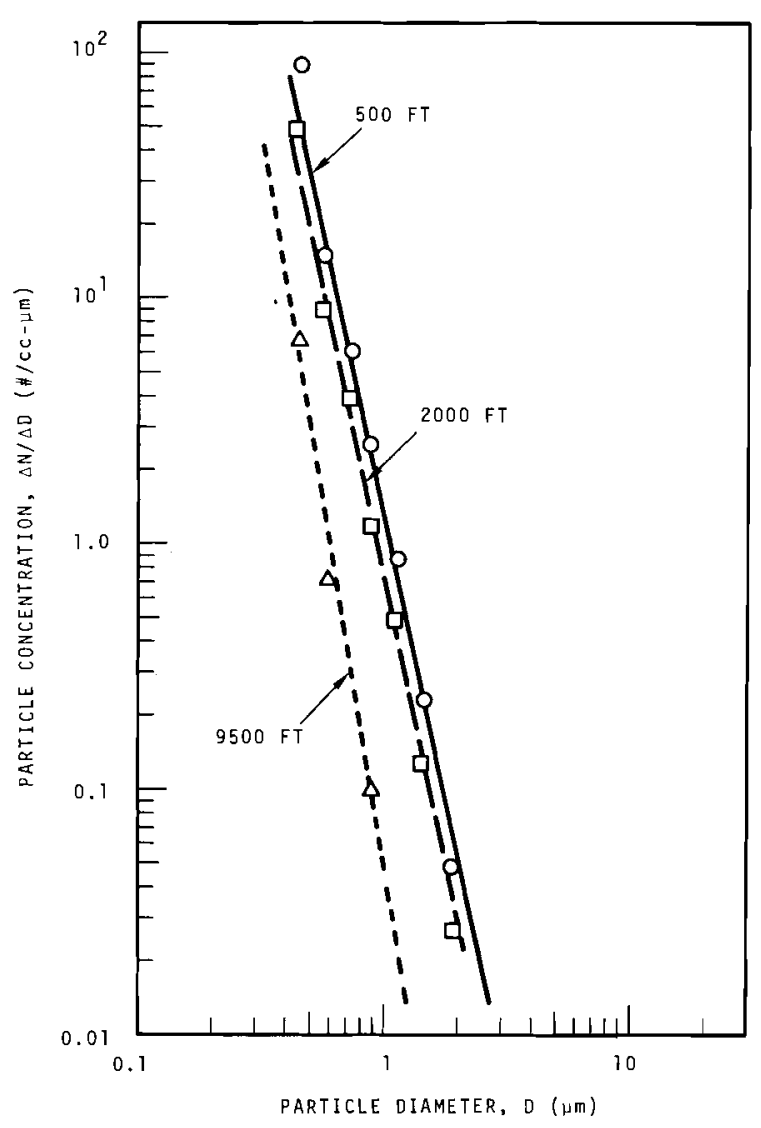

Neg 721308-2

FIGURE 6. Particle Size Distribution at Different Altitudes

Although the data obtained so far with this airborne laboratory do not warrant significant meteorological interpretations, we are certain that future results will be impressive.

\section{REFERENCE}

1. G. A. Sehmel, "Particle Sampling Bias Introduced By Anisokinetic Sampling and Deposition Within The Sampling Line." J. Amer. Ind. Hyg. Assoc., 31,, $758-771$. 1970 . 


\title{
TECHNIQUES USED TO STABILIZE TRACER \\ SOLUTIONS FOR AEROSOL GENERATION
}

\author{
C. W. Thomas
}

\begin{abstract}
Methods are described to dispense tracer aerosols of several rare elements from airborne, acetone generators.
\end{abstract}

Finely divided aerosols of several rare elements are generated by acetoneburner techniques on aircraft and serve as tracers in studying precipitation scavenging rates and mechanisms. Techniques were developed to put tracers of gold, iridium, ruthenium, tellerium and selenium either in solution or in a colloidal suspension in a solvent mixture that had excellent ignition and burning characteristics. A solution of acetone containing about 20 percent by volume of n-heptane was found to be compatible with almost any tracer that was moderately soluble in acetone and/or alcohol and had ignition and burning qualities that were congruous with a forced air aerosol generator. Laboratory and field studies were conducted and the following recipes were formulated and successfully demonstrated for both ground level and aircraft releases from acetone-burner generators of the types used in AgI generators.

$\underline{\text { GOLD }}$

One hundred and seventy-five grams $\mathrm{HAuCl}_{4} \cdot 3 \mathrm{H}_{2} \mathrm{O}$ was dissolved in 13 liters of acetone in a 50 iter polyethylene carboy. Three and two-tenths liters of pyridine was added to prohibit reduction of gold by the metal surfaces of the generator. Six and fivetenths liters of $n$-heptane was added. This solution was stable for two weeks after which the gold in solution was slowly reduced to the metal.

\section{R I D I UM}

Thirty-two grams of $\operatorname{IRCl}_{3} \cdot \mathrm{XH}_{2} \mathrm{O}$ was dissolved with difficulty in 10.5 liters of acetone by the following technique: The iridium chloride salt was stirred into a liter of acetone and filtered. The filtrate was placed in a 50 liter polyethylene carboy. The residue was dried and fumed with concentrated hydrochloric acid and taken to just dryness. The residual salts were added to a liter of acetone and stirred and filtered. The filtrate was added to the polyethylene carboy. This process was repeated until no appreciable amounts of residual salts remained after filtration. Additional acetone was added to make up to 16.5 liter volume and 4.5 liters of $n$-heptane added. The solution was stable for weeks. 


\section{RUTHENIUM}

One hundred and fifty grams of $\mathrm{RuCl}_{3} \cdot \mathrm{xH}_{2} \mathrm{O}$ was dissolved in acetone by the method used for iridium and made up to 16.5 liters with acetone. Four and five-tenths liters of n-heptane was added. The resulting solution was colloidal but stable for one week after which slow coagulation occurred over a period of several weeks.

\section{TELLURIUM}

Three hundred grams of $\mathrm{TeCl}_{4}$ was dissolved in 16.5 liters of acetone and 4.5 1iters of $\mathrm{n}$-heptane added.
This solution was stable for weeks.

\section{SELENIUM}

Selenium tetrachloride was not compatible with either acetone or $n$-heptane, both of which resulted in a rapid reduction to the metal. Alcohol was a suitable solvent for selenium, thus, 450 grams of $\mathrm{SeC}_{4}$ was dissolved in 4 1iters of absolute ethano1. This solution was metered simultaneously with $\mathrm{n}$-heptane to the burner compartment of the generator. Since this required separate reservoirs for each solution it has not been as suitable for aircraft release.

\title{
AN INEXPENSIVE INFUSION SAMPLER FOR ATMOSPHERIC TRACER STUDIES J. M. Hales and D. W. Glover
}

\begin{abstract}
An inexpensive infusion sampler for atmospheric tracers has been constructed. These samplers will be used for $S F G$ and halogenated hydrocarbons in large scale field studies such as those being conducted on the olympic Peninsula.
\end{abstract}

Description of plume and air mass behavior in dispersion and washout studies has necessitated the design of a simple and inexpensive infusion sampler for remote field use. Previously-used samplers are generally unsatisfactory for a variety of reasons, including expense, operationa 1 difficulties, and the frequent need for external power sources.
The sampler designed and fabricated to meet present requirements is described schematically in Figure 1 . It consists of a Plexiglas cylinder ( 2 inch bore tubing) containing a piston ( 2 inch diameter plexiglas rod) which is raised at a constant rate by a 12 volt d.c. timing motor. Power for the motor is provided by replaceable "D" cell batteries, and the unit is housed in a small plywood shelter. 


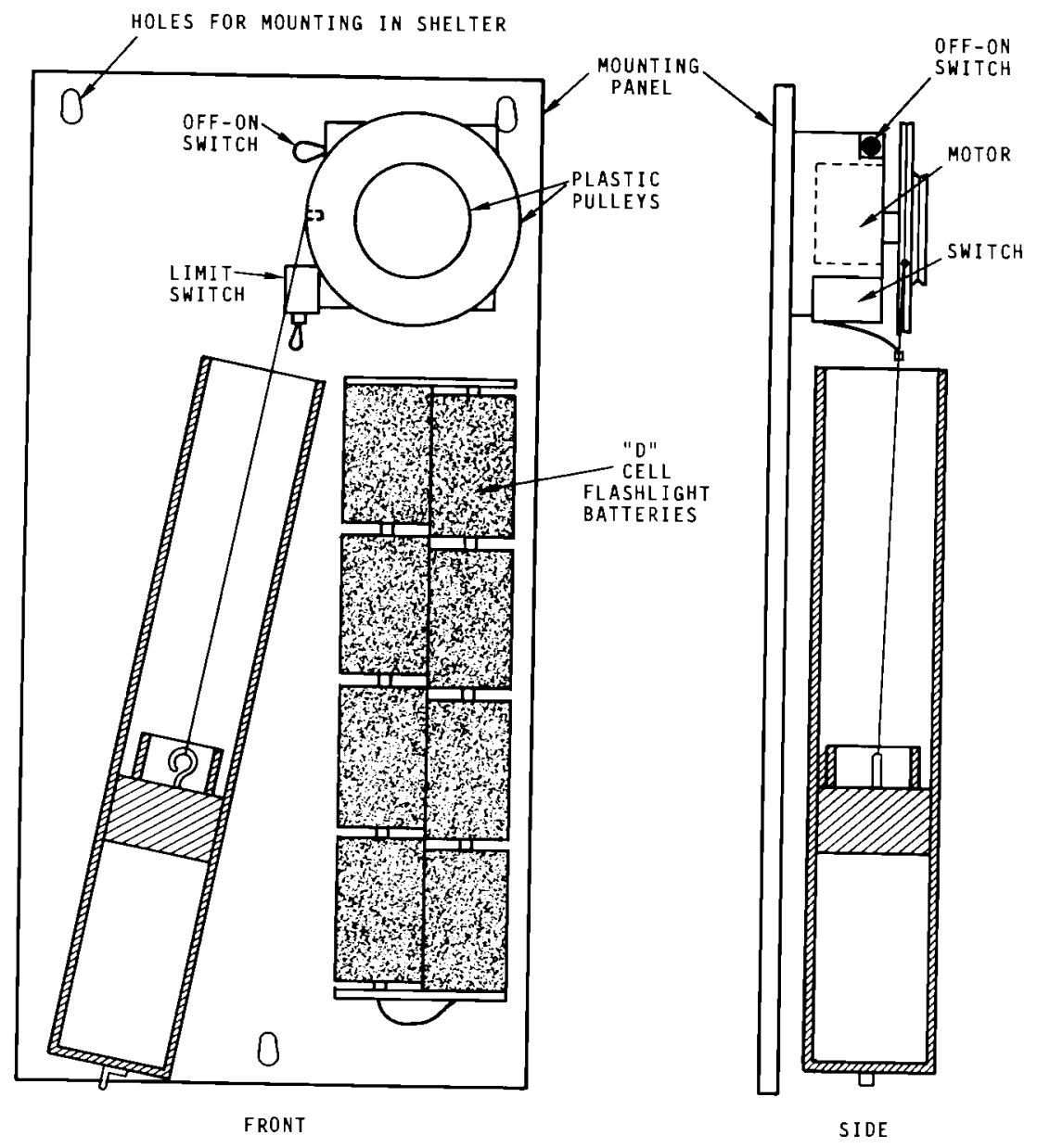

Neg 721419-11

FIGURE 1. Schematic of Infusion Sampler

Depending on the size of the drive wheels, this sampler can obtain its total sample volume of approximately 0.5 liter over periods ranging from 1 hour to 2 hours. These samplers can be deployed rapidly, simply by placing at their prescribed locations and throwing the starting switch. Sampling is terminated automatically upon filling the sampler volume by action of a top-mounted limit switch.

These samplers have been constructed primarily for use with $\mathrm{SF}_{6}$ and halogenated organics. The samples will be injected into a gas chromatograph and analyzed using a procedure similar to that described by Clemmons, et al. (1)

Cost of these samplers is about $\$ 30.00$ per unit, including parts and 
1abor. Twenty of them have been constructed at present, with plans for several more to be built during the coming year. This large quantity of samplers will allow accurate definition of time-averaged tracer concentration over large areas, and should be particularly useful in large-scale dispersion and washout studies such as those currently being conducted on the Olympic Peninsula.

\section{REFERENCE}

1. C. A. Clemmons, A. I. Coleman and B. E. Saltaman, "Concentration and Ultrasensitive Chromatographic Determination of Sulfur Hexafluoride for Application to Meteorological Tracing," Environmental Science and Technology, vol. z, pp. 551-556, 1968.

ANALYTICAL PROCEDURES FOR MEASUREMENT OF $214 \mathrm{~Pb}$

AND 214 Bi IN RAINWATER

C. W. Thomas, J. A. Young, and N. A. Wogman

\begin{abstract}
A technique is described for rapid continuous separation of $214 \mathrm{~Pb}$ and $214 \mathrm{Bi}$ from rainwater at flows up to 30 liters per minute.
\end{abstract}

The short-lived daughters of radon, ${ }^{214} \mathrm{~Pb}(26.8 \mathrm{~min})$ and ${ }^{214} \mathrm{Bi}(19.7 \mathrm{~min})$, are potentially useful tracers of precipitation scavenging processes because they are attached to the natural aerosols, they are present in easily measurable concentration in rainwater, and their half-lives are of the same order of magnitude as the time scale on which these processes occur. The major problem in using the radon daughters as tracers is the difficulty of rapidly separating them from large volumes of rainwater after short consecutive collection periods. A technique was recently developed to continuously separate ${ }^{214} \mathrm{~Pb}$ and $214 \mathrm{Bi}$ from rainwater at flow rates of up to 30 liters per minute and consecutive sampling periods of 5-10 minutes. Rainwater from a $3000 \mathrm{ft}^{2}$ polyethylene surface is collected in a polyethylene 55-gallon drum and pumped through a fiber-glass filter followed by an anion exchange bed $(0.64 \mathrm{~cm}$ thick by $28 \mathrm{~cm}$ diameter of Dowex 500W $\times 8 \mathrm{H}^{+}$form, 200-400 mesh). Bismuth-214 is removed at greater than 
90 percent efficiency by the anion exchange bed. Bismuth-214 is measured immediately by counting the coincident photons emitted by the sample with a pair of $13-1 / 2$ inch diameter by 6 inch thick NaI(T1) detectors. No measurable amount of ${ }^{214} \mathrm{~Pb}$ is removed by the anion exchange bed, however, greater than 90 percent of the ${ }^{214} \mathrm{~Pb}$ is retained on the cation exchange bed which in turn does not retain ${ }^{214} \mathrm{Bi}$. After the collection period the cation bed is set aside for about 1 hour to allow ingrowth of ${ }^{214} \mathrm{Bi}$ which is then measured using the above detector system and the ${ }^{214} \mathrm{~Pb}$ concentration is calculated from this growth.

\title{
FALLOUT RATES AND MECHANISMS
}

R. W. Perkins

\begin{abstract}
The concentrations of trace elements, cosmogenic radionuclides, and nuclear-weapons-produced radionuclides were measured in the air from ground level to $19 \mathrm{~km}$ and in rain and seawater in order to determine the origin and chemistry of the atmospheric aerosol and to study the rates of atmospheric and oceanic mixing, the rates of air-sea interchange, and the rates and mechanisms of dry and wet fallout. Brief reports on these topics are presented by the principal investigators.
\end{abstract}

AIR CONCENTRATIONS OF ${ }^{90} \mathrm{Sr}$ AND ${ }^{55} \mathrm{Fe}$ AT RICHLAND, WASHINGTON FROM 1963 TO 1970 - C. W. THOMAS AND J.C. LANGFORD

The atmospheric concentrations of ${ }^{90} \mathrm{Sr}$ and ${ }^{55} \mathrm{Fe}$ were measured in ground level air samples collected at Richland from 1963 to 1970 as part of a program to define the rates of long-term stratospheric processes in the northern hemisphere. Seasonal variations in the concentrations of ${ }^{90} \mathrm{Sr}$ were similar to those radionuclides of stratospheric origin, decreasing from 1963 to 1966 as a result of decay and deposition on the earth's surface. Atmospheric nuclear bomb testing since 1967 have maintained the surface air ${ }^{90} \mathrm{Sr}$ concentrations at about the same level from 1967 to 1970 (Figure 1). In contrast, the seasonal variation of the concentrations of ${ }^{55} \mathrm{Fe}$ were not so pronounced as radionuclides of stratospheric origin, (Figure 2), and suggest 


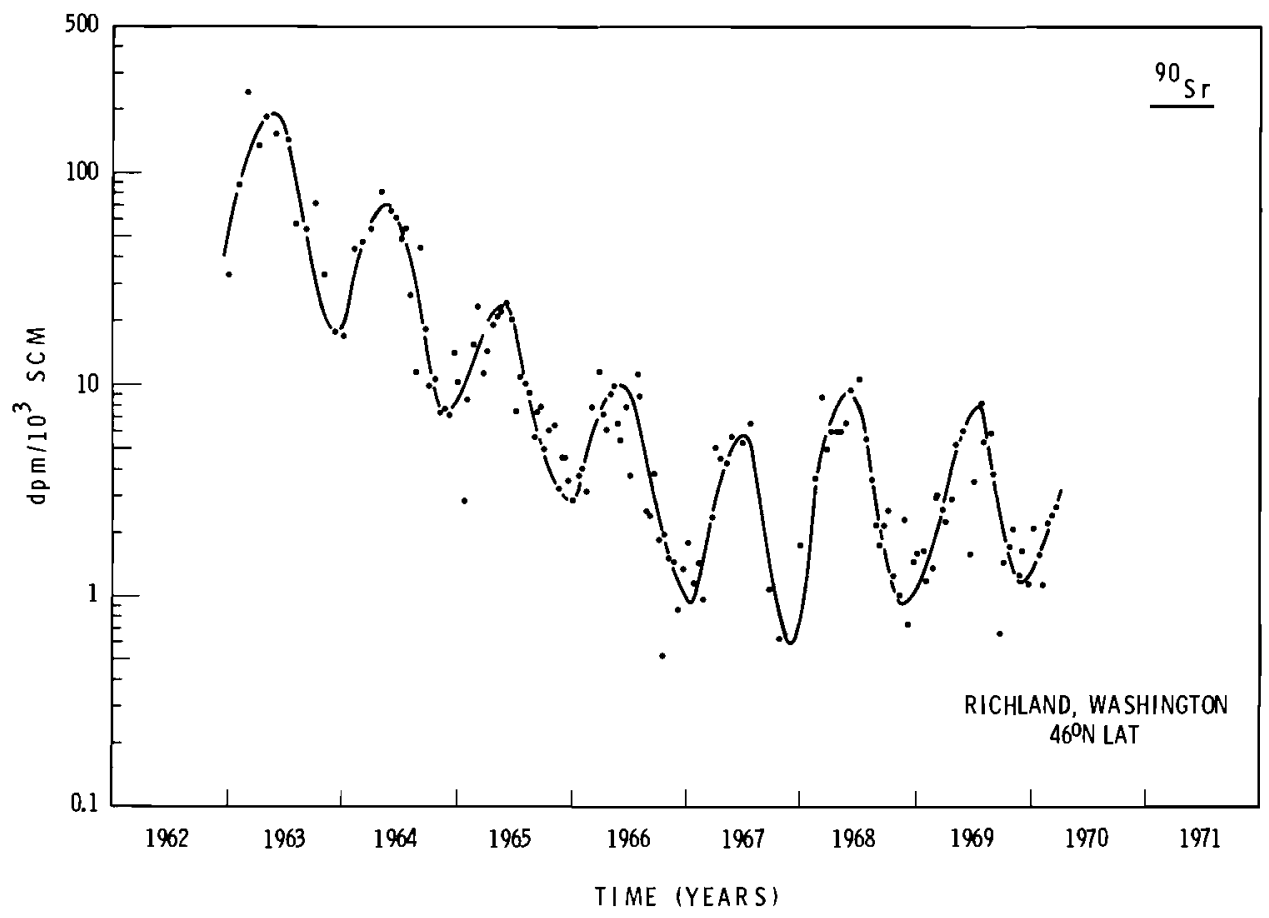

Neg 715669-1

FIGURE 1. The Concentration of ${ }^{90} \mathrm{Sr}$ in Ground Level Air at Richland, Washington from 1963-1970

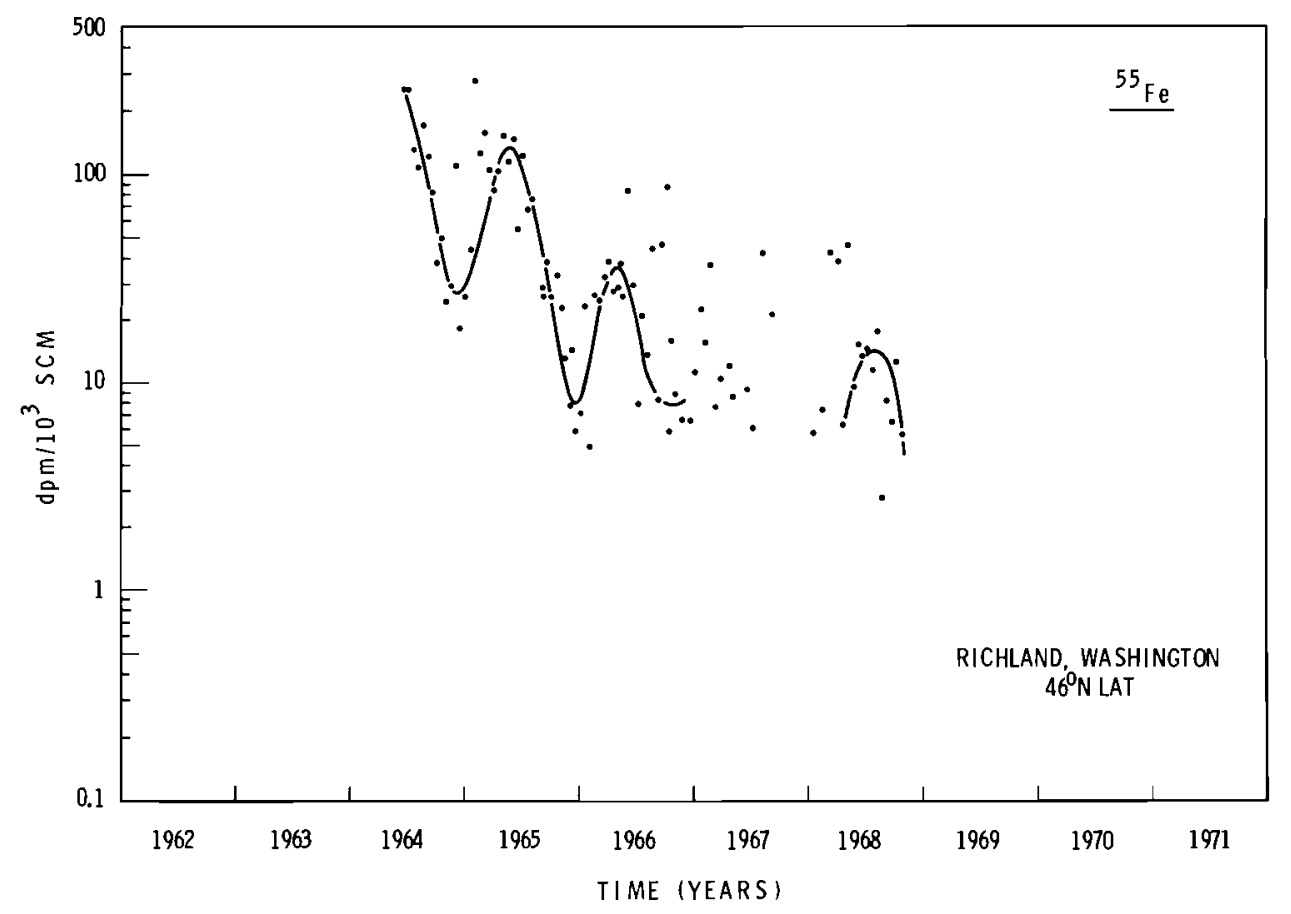

Neg 715669-2

FIGURE 2. The concentration of ${ }^{55} \mathrm{Fe}$ in Ground Level Air at Richland, Washington from 1964-1968 
that a portion of the ${ }^{55} \mathrm{Fe}$ may come from the Hanford project.

COMPARISONS OF ATMOSPHERIC RADIONUCLIDE CONCENTRATIONS AT NEAH BAY AND RICHLAND, WASHINGTON - C.W. THOMAS

The atmospheric concentrations of several radionuclides were measured continuously in ground level air from 1968 through 1970 at Richland (46 ${ }^{\circ} \mathrm{N}$, $118^{\circ} \mathrm{W}$ ) and west of Neah Bay, Washington on the Makah Indian Reservation $\left(49^{\circ} \mathrm{N}, 125^{\circ} \mathrm{W}\right)$ near the Pacific coast. At both sites, large $350 \mathrm{cfm}$ air pumps are mounted several feet above the ground and draw air through membrane filters. The radionuclide concentrations on the filters are measured using large volume NaI(T1) gamma ray spectrometers.

As seen in Figure 3 , the concentrations of ${ }^{7} \mathrm{Be},{ }^{95} \mathrm{Zr},{ }^{106} \mathrm{Ru},{ }^{137} \mathrm{Cs}$, and ${ }^{144} \mathrm{Ce}$ at the two sites show the seasonal variation that is characteristic of radionuclides of stratospheric origin. However, the concentrations are generally higher in the Richland samples, especially during the summer when the concentrations are at a maximum. A possible explanation for this effect is increased vertical mixing following passage of air over the coastal and Cascade Mountain Ranges.

\section{COSMOGENIC RADIONUCLIDE PRODUCTION} RATES IN ARGON FROM 3 TO $19 \mathrm{~km}$ -

J. A. YOUNG, C. W. THOMAS, AND N. A. WOGMAN

For the past four years the concentrations of the cosmogenic radionuclides ${ }^{24} \mathrm{Na}(19 \mathrm{hr}),{ }^{38} \mathrm{Cl}(37 \mathrm{~min})$, and ${ }^{39} \mathrm{Cl}$
(55 min) have been measured in air filter samples collected by aircraft. These radionuclides are produced at a relatively constant rate in the atmosphere by spallation reaction of cosmic-rays with atmospheric argon. In order to determine whether the measured cosmogenic radionuclide disintegration rates corresponded to the actual production rates, metal spheres were 1 ined with rubber meteorological balloons, filled with argon under pressure, and flown at altitudes ranging from 3 to $19 \mathrm{~km}$. At the end of each flight the argon was vented through a charcoal impregnated filter. The filters and rubber 1 iners were then composited and the cosmogenic radionuclide concentrations measured by direct analysis on a NaI(T1) multidimensional gamma-ray spectrometer. In addition to ${ }^{24} \mathrm{Na},{ }^{38} \mathrm{Cl}$, and ${ }^{39} \mathrm{Cl}$, the cosmogenic radionuclides ${ }^{18} \mathrm{~F}$, ${ }^{28} \mathrm{Mg},{ }^{34 \mathrm{~m}} \mathrm{C} 1$, and ${ }^{38} \mathrm{~S}$ were measured on some of the 15 to $19 \mathrm{~km}$ flights.

The measured ${ }^{24} \mathrm{Na}$ production rates were almost identical to the measured atmospheric disintegration rates, indicating that the air filters are removing essentially all of the ${ }^{24} \mathrm{Na}$ from the air. The ${ }^{38} \mathrm{Cl}$ and ${ }^{39} \mathrm{Cl}$ production rates, however, were much higher than their measured atmospheric disintegration rates. Possible explanations for this include that the lifetimes of the ${ }^{38} \mathrm{Cl}$ and ${ }^{39} \mathrm{Cl}$ nuclei are too short for them to become quantitatively attached to filterable atmospheric aerosol particles, or that their production rate is enhanced in the argon spheres by low energy radiation produced by the reaction of cosmic rays with the aircraft and the metal spheres. Higher energies are 


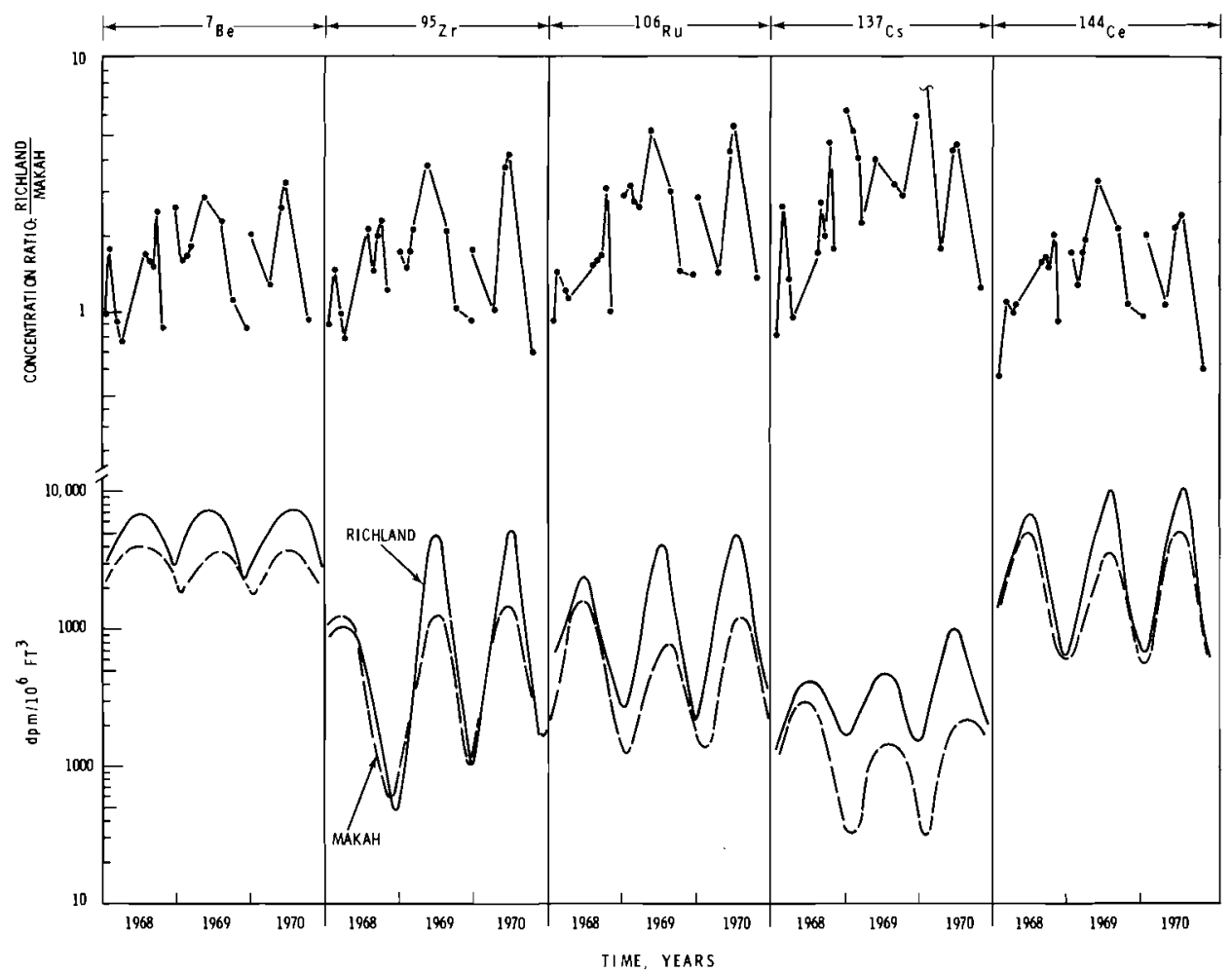

Neg 715739-3

FIGURE 3. Comparison of Radionuclide Concentrations in Air at Richland $\left(46^{\circ} \mathrm{N}, 117^{\circ} \mathrm{W}\right)$ and Makah $\left(49^{\circ} \mathrm{N}, 125^{\circ} \mathrm{W}\right)$, washington as a Function of Time

required for ${ }^{24} \mathrm{Na}$ production, so the ${ }^{24} \mathrm{Na}$ production rate would not necessarily be enhanced by the latter effect.

On March 11, 1971, severa1 spheres were filled with a total of $60 \mathrm{M}^{3}$ (STP) of argon and flown for $350 \mathrm{~min}$ utes at $15.3 \mathrm{~km}$. The largest amount of argon that had been flown on any previous slight was $42 \mathrm{M}^{3}$. These measurements permitted a significant improvement in the accuracy of cosmogenic radionuclide production rates; however, an attempt to measure ${ }^{32} \mathrm{P}$ $(14.3 \mathrm{~d})$ and ${ }^{33} \mathrm{P}(25 \mathrm{~d})$ was unsuccessful even with very nearly quantitative chemical separations. Production rate measurement of ${ }^{32} \mathrm{P}$ and ${ }^{33} \mathrm{P}$ will require a long exposure of the argonfilled spheres at some high altitude location.

VERTICAL PROFILES OF RADIONUCLIDE CONCENTRATIONS IN THE ATMOSPHERE -

J. A. YOUNG AND N. A. WOGMAN

Vertical profiles of atmospheric radionuclide concentrations have been determined on a monthly basis since 1967 from air filter samples collected by RB-57 aircraft at 1.5 to $3.0 \mathrm{~km}$ altitude intervals from $0.3 \mathrm{~km}$ to an 
altitude of over $18 \mathrm{~km}$. In the past, most of the vertical profiles were measured either south of Spokane, Washington at $47^{\circ} \mathrm{N}, 117^{\circ} \mathrm{W}$, or east of Barbados, British West Indies from 12 to $18^{\circ} \mathrm{N}$ and 45 to $59^{\circ} \mathrm{W}$. The profiles at Barbados were taken during the summer of 1969 as part of the BOMEX project. The concentrations of cosmogenic radionuclides, nuclear weapons produced radionuclides, and radon and thoron daughters were determined using $\mathrm{NaI}(\mathrm{T} 1)$, multidimensional gamma ray spectrometers and, beginning in 1 ate 1971, a dual, anticoincidence shielded, Ge(Li) gamma-ray

spectrometer.

A surprising feature of the profiles at all latitudes has been the fairly common occurrence of very pronounced concentration minimums at altitudes from 6 to $9 \mathrm{Km}$, for all commonly measured radionuclides, except ${ }^{24} \mathrm{Na}(15 \mathrm{hr})$. Sometimes the concentrations at these altitudes are orders of magnitude lower than the concentrations at lower elevations; and the presence of ${ }^{24} \mathrm{Na}$ at normal concentrations in the samples virtually eliminates the possibility of sampling error. Whatever the cause of this phenomenon (in-cloud precipitation scavenging being a likely candidate) it is apparent because ${ }^{24} \mathrm{Na}$ is relatively insensitive to it, that it occurs on a time scale large compared with the $15 \mathrm{hr}$ half-life of $24 \mathrm{Na}$.

A specific example of a few of the radionuclide profiles is shown in Figure 4. The profiles were obtained

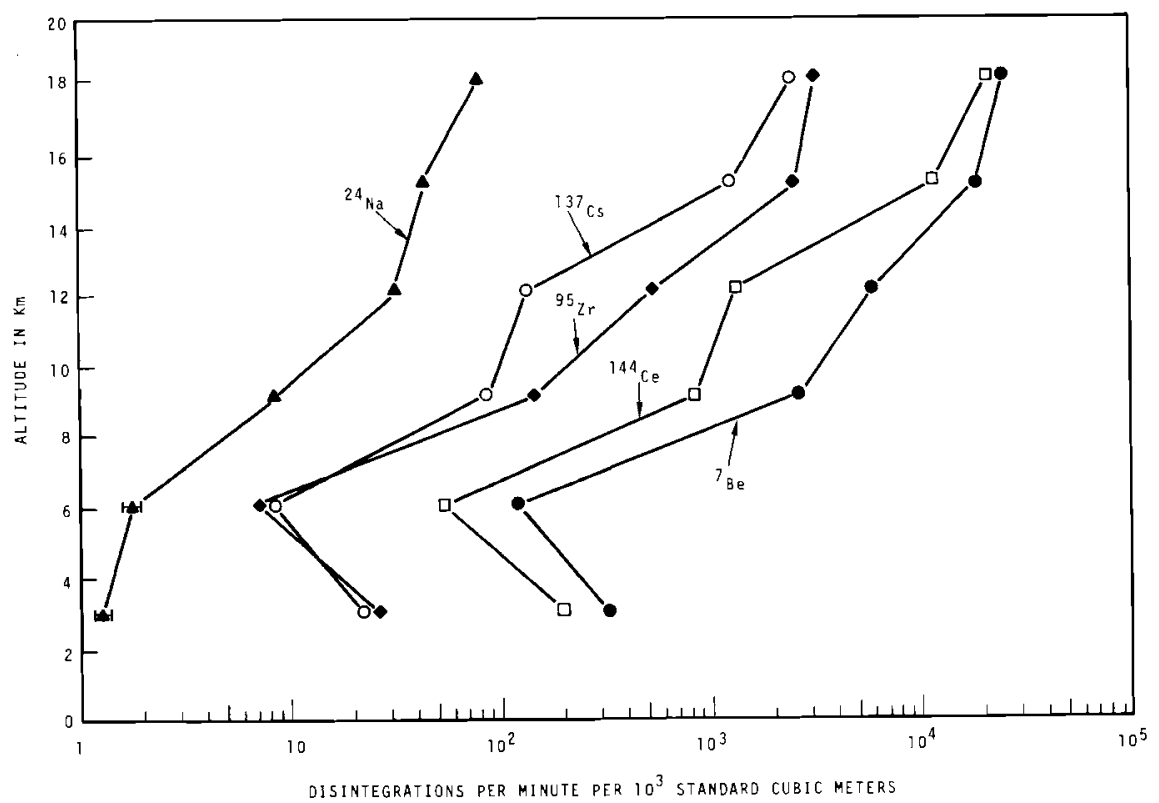

Neg 715722-1

FIGURE 4. Radionuclide Disintegration Rates on November 16,1971 at $39^{\circ} \mathrm{N}, 103^{\circ} \mathrm{W}$ 
on November 16, 1971 near Denver at $39^{\circ} \mathrm{N}, 103^{\circ} \mathrm{W}$ and show concentration minimums at about $6 \mathrm{~km}$. It is planned that back trajectories will be calculated for the sampled air mass, in an attempt to identify the cause of the observed effect.

THE DETERMINATION OF AIR-SEA EXCHANGE AND OCEANIC MIXING RATES USING ${ }^{7}$ Be DURING THE BOMEX EXPERIMENT -

J. A. YOUNG AND W. B. SILKER

The concentrations of ${ }^{7} \mathrm{Be}$ and other radionuclides were measured in air, rain, and seawater in a region east of Barbados, British West Indies in the summers of 1968 and 1969 during the BOMEX experiment. The deposition of ${ }^{7} \mathrm{Be}$ on the sea surface by rainfall in August 1968 and May through July 1969 was only 13 and 26 percent, respectively, of that necessary to maintain the measured seawater inventories. The calculated deposition velocity of ${ }^{7} \mathrm{Be}$ on the sea surface by wet and dry deposition was $1.0 \mathrm{~cm}$ $\mathrm{sec}^{-1}$. During May through June of 1969 the calculated flux of ${ }^{7}$ Be across the sea surface averaged about $3.8 \times 10^{-2}$ atom $\mathrm{cm}^{-2} \cdot \mathrm{sec}^{-1}$ and the inventories were increasing at a rate of $1.0 \times 10^{-2}$ atom $\mathrm{cm}^{-2} \cdot \mathrm{sec}^{-1}$. Due to seasonal variations in the atmospheric ${ }^{7} \mathrm{Be}$ concentrations the ${ }^{7}$ Be seawater inventories should vary seasonally with maximum inventories occurring around July and minimum inventories around February. The yearly average of the flux of ${ }^{7} \mathrm{Be}$ across the sea surface was calculated to be $1.6 \times 10^{-2}$ atom $\mathrm{cm}^{-2} \cdot \mathrm{sec}^{-1}$. The vertical eddy diffusion coeffi- cient, $K_{Z}$, in the sea decreased from greater than $7 \mathrm{~cm}^{2} \cdot \mathrm{sec}^{-1}$ at the surface to 0.25 to $0.85 \mathrm{~cm}^{2} \cdot \mathrm{sec}^{-1}$ at 30 to 40 meters and then possibly increased somewhat from 40 to 100 meters. The ${ }^{7}$ Be inventory in the sea varied rapidly due to the horizontal motion of seawater through the sampling region. The ${ }^{103} \mathrm{Ru}$ to ${ }^{95} \mathrm{Zr}$ ratio in the top 15 meters of the sea indicated that large amounts of ${ }^{103} \mathrm{Ru}$ and 95 zr from the French nuclear test series at $23^{\circ} \mathrm{S}$ beginning July 7 , 1968 entered the sampling region on August 15, 1968 and also was present in June, but not in May 1969. The debris possibly was carried into the sampling region by the Guiana Current which flows northwestward along the coast of South America.

\section{ATMOSPHERIC FALLOUT DURING 1971 -}

C. W. THOMAS AND J. A YOUNG

The atmospheric concentrations of 25 radionuclides in ground level air were measured continuously during 1971 at Point Barrow, Alaska (71 $\left.{ }^{\circ} \mathrm{N}\right)$ and Richland, washington $\left(46^{\circ} \mathrm{N}\right)$ by filtering large volumes of air through membrane filters followed by gammaray spectrometric analysis. The concentration of nuclear-weaponsproduced radionuclides, including fission products and neutron activation products, increased steadily from 1967 through 1971 because of the high yield thermonuclear tests conducted by the Chinese at Lop Nor $\left(45^{\circ} \mathrm{N}\right)$ during this period with a total yield of over ten megatons. During 1971 essentially all of the nuclearweapons-produced radionuclides present 
in northern hemispheric air originated from these Chinese tests. The concentration of ${ }^{88} Y$ (107 day half-life) increased 100 -fold over 1968 peak levels and during 1971 reached peak concentration levels comparable with peak concentrations of 1962-1963.

The Chinese nuclear test of November 19 , 1971 was detected in low concentrations in ground level air at Richland, Washington five days after detonation. During 1970 the nuclear reactors, which are a part of the Hanford atomic energy complex and use
Columbia River water as a straight through coolant, were shut down. The effect of this shutdown was noted by a decrease in air concentration of several radionuclides that were known to be associated with the Richland operations. Scandium-46 concentrations in air were down by two orders of magnitude, ${ }^{60}$ Co was down one order of magnitude, and ${ }^{124} \mathrm{Sb}$ is now below detection levels. Also affected was ${ }^{65} \mathrm{Zn}$ air concentration which now shows an excellent seasonal variation and is down by an order of magnitude.

\title{
A COMPARISON OF MEASURED AND PREDICTED EXPOSURES
}

FROM ELEVATED SOURCES

R. K. Woodruff and C. E. Elderkin

\begin{abstract}
A comparison was made of data from elevated continuous souce diffusion experiments. The experiments were conducted in neutral and stable conditions and the data have been classified into stability classes by both the standard de$v i a t i o n$ of the azimuth angle, $\sigma_{\theta}$, and the Richardson number, $R i$, as is common in safety and environmental impact analyses, for comparison with Pasquill estimates. The comparison indicates that estimates based upon Pasquili's curves are conservative downwind of the maximum in the ground level centerine exposure, and unconservative at short distances. This result indicates that the elevated plumes are growing faster than Pasquill's curves indicate, the latter being based primarily upon surface release experiments. The classification of the data by Richardson number gives a better stratification of the data than the of classification, atthough the scatter in the data indicates that the stability stratification may not be significant. It is anticipated that further analysis using the Richardson number to determine $\sigma_{z}$, and $\sigma_{\theta}$ to determine $\sigma_{y}$, will produce a better organization of the data.
\end{abstract}

The increasing importance of the environmental effects of industrial emissions is resulting in greater demands upon diffusion model accuracy 
and applicability. In nuclear power plant safety and environmental impact analyses it is common to use the plume growth curves attributed to Pasquill. These curves are primarily based upon data obtained from surface releases to distances of about a kilometer. However, Pasquill's curves are commonly extrapolated to distances as great as 100 kilometers and applied to elevated sources. These extensions of Pasquill's curves have been generally supported by subsequent data as being conservative under the neutral and stable conditions, which are generally of most concern, at distances of less than about 10 kilometers as shown in Meteorology and Atomic Energy, $1968^{(1)}$ (Figures 4.4 and 4.6 ). The slope of the stable data in Figure 4.6 suggests, however, that concentrations beyond about 10 kilometers might exceed those predicted by the extrapolation of Pasquill's results.

Additional elevated source experiments with particulate zinc sulfide and fluorescein dye have been conducted in the last few years at several elevations at Hanford. Figures 1 and 2 summarize the normalized ground level centerline exposure data,

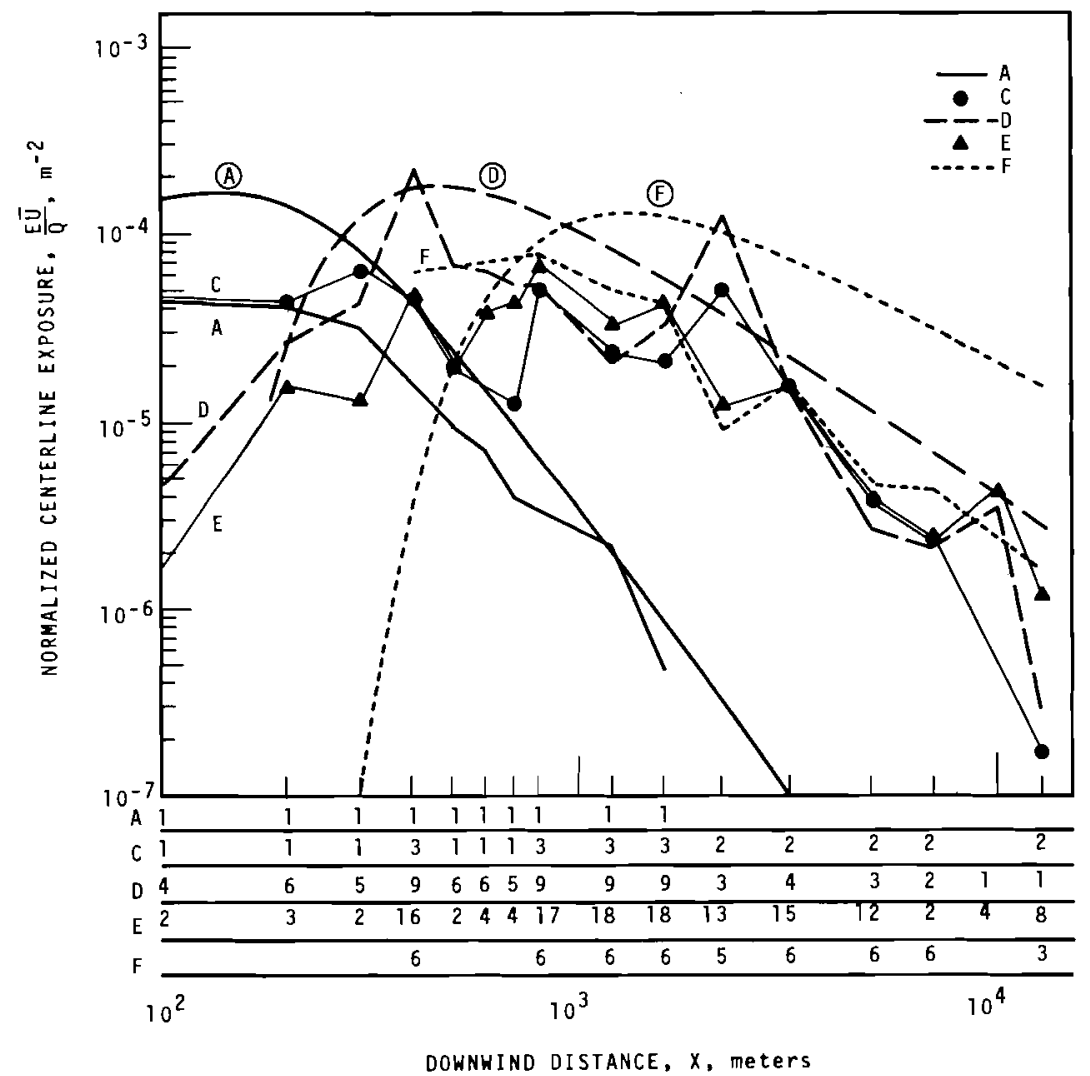

Neg 721420-7

FIGURE 1. Normalized Centerline Exposure Classified into Pasquill Categories by Richardson Number. 


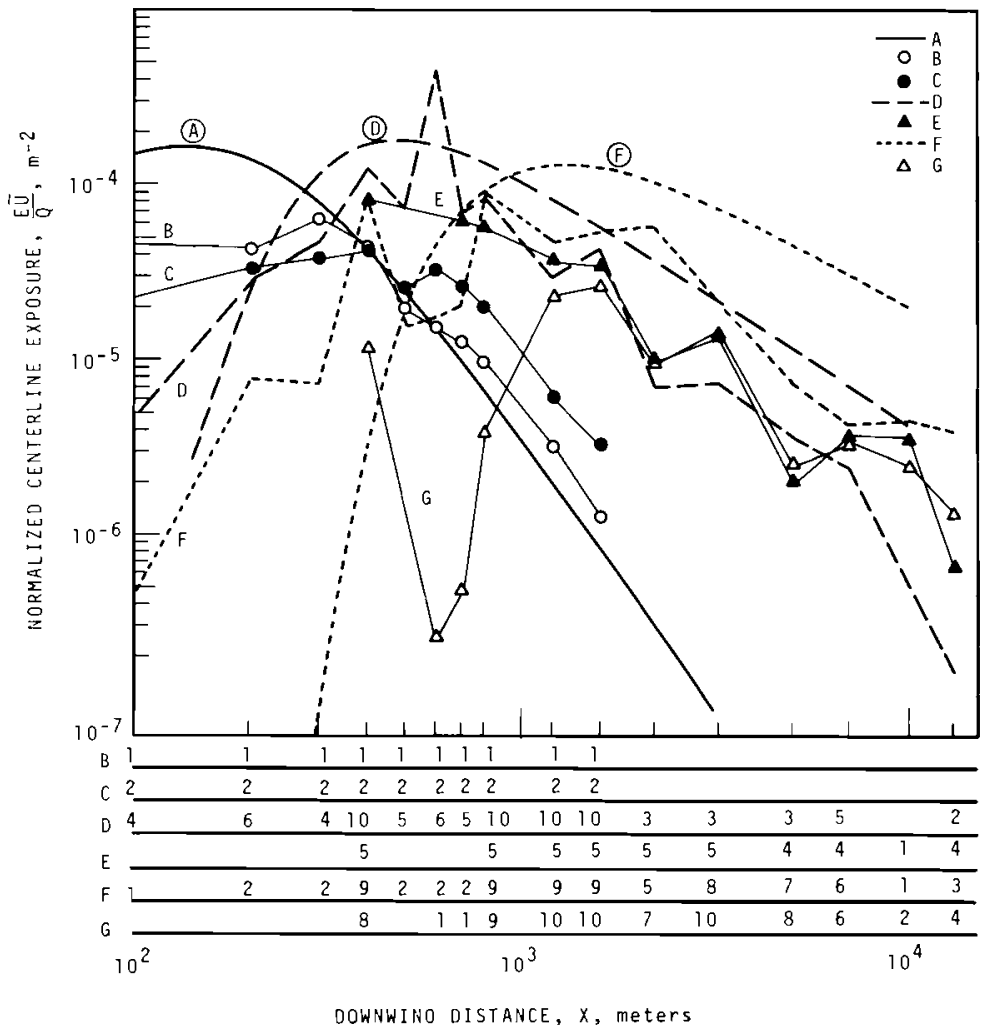

IJeg 721420-6

FIGURE 2. Normalized Centerline Exposure Classified into Pasquill Categories by $\sigma_{\theta}$.

$E \bar{U} / Q$, for 37 tests released at an elevation of 26 meters under predominately neutral and stable conditions. The tests are grouped in Pasquil1 categories by the Richardson number and the standard deviation of the wind direction, $\sigma_{\theta}$, in Figures 1 and 2 , respectively, according to the following classifications.

\begin{tabular}{|c|c|c|c|c|c|}
\hline Stability Class & & \multicolumn{3}{|c|}{$\mathrm{Ri}$} & $\sigma_{\theta}$ \\
\hline Extremely Unstable & A & -1.0 & to & -0.7 & 25.0 degrees \\
\hline Moderately Unstable & B & -0.5 & to & -0.4 & 20.0 \\
\hline Slightly Unstable & C & -0.17 & to & -0.13 & 15.0 \\
\hline Neutra 1 & D & & 0 & & 10.0 \\
\hline Slightly Stable & E & +0.03 & to & 0.05 & 5.0 \\
\hline Moderately stable & $\mathrm{F}$ & +0.05 & to & 0.11 & 2.5 \\
\hline Very Stable & G & $>0.11$ & & & \\
\hline
\end{tabular}

As these classifications are discon-

tinuous, tests falling between classes were divided at the midpoints between classes. The Richardson numbers were determined for the layer from 7 to $50 \mathrm{ft}$ for the period of the release. The $\sigma_{\theta}$ 's were determined from 20 -second averages of the wind direction and were calculated over the release period, which was 30 minutes with only a few exceptions.

Figures 1 and 2 also contain tables of the number of observations averaged for each plotted point. The smooth curves are the ground level centerline exposures predicted using Pasquill's curves for stability classes A, D, and $F$ as indicated by the circled letters. 


\section{COMPARISON OF RESULTS}

The most obvious difference between the data and the predictions is the conservatism of the Pasquill prediction near the peak and beyond, especially for the neutral and stable cases. This feature is consistent with the results of the experiments summarized in Figures 4.4 and 4.6 of Reference (1). However, the slope of a smoothed curve through the data would not suggest that concentrations at greater distances would exceed those which would be predicted by Pasquill's curves. The conservatism of estimates based on Pasquill's curves is not fully shown by these data since sampling errors due to subisokinetic flow rates tend to make the observed exposures high. Qualitative observations indicate that these errors can be as high as a factor of two. No conclusions can be drawn from the few unstable cases, although those that are shown do not disagree significantly with the predicted. Another significant feature of the data is the consistently higher concentrations in the region between the source and a point downwind occurring just before the maximum centerline exposure for the neutral and stable cases. The magnitudes of the differences are quite significant although the downwind distance to which the differences are great is relatively short; e.g., in both Figures 1 and 2 the observed exposures fall below the predicted at a distance of on $1 y 700$ meters. The Brookhaven oil fog results in Figure 4.4, of Reference (1), show a similar tendency. It is apparent that a translation along the $x$ axis would significantly improve the fit of the data to the Gaussian form. This could be accomplished by a translation of Pasquill's $\sigma_{y}$ and $\sigma_{z}$ curves to higher values. In other words, the Gaussian model for elevated releases is reasonably verified by the data although the rates of plume growth for the elevated sources are greater than those obtained from Pasquill's curves for neutral and stable cases.

Another feature of importance is that neither Ri number nor $\sigma_{\theta}$ classification of the data provide very good stratification of the data for neutral and stable conditions. Although there is a stronger tendency for correlation with $\mathrm{Ri}$, the scatter of data about each data point (not plotted) would likely make it difficult to demonstrate that the neutral and stable classifications are significantly different. This is important because frequently in safety and impact studies considerable significance is placed upon stability class frequency distributions. Also of interest is the fact that the trend towards decreasing dilution with increasing $\mathrm{Ri}$ reverses for large $\mathrm{Ri}$ as indicated by the relative positions of the curve designated as $G$ to those of less stable classes. This tendency may be the result of increasing low frequency plume meander in addition to plume spreading due to vertical shear in the wind direction with increasing stability.

The above results suggest that a better stratification of the data might be obtained if the Ri number 
were used to classify the vertical diffusion and $\sigma_{\theta}$ to the lateral diffusion. As $\mathrm{Ri}$ and $\sigma_{\theta}$ are virtually independent, there would be (7) ${ }^{2}$ possible classifications. As such a large number of classes would be meaningless, it would be desirable to establish a meaningful number of diffusion curves, each representing a group of different stability class pairs. This type of tabulation has not been completed at this time.

Crosswind integrated exposures classified with $\mathrm{Ri}$ would also be expected to show better organization than if classified by $\sigma_{\theta}$ since the lateral variance does not appear in the Gaussian model for crosswind integrated exposure. This is also true of the form of the Gaussian model used for long term exposure calculations. As these forms of the Gaussian model are used in safety and environmental impact analyses, it will be important to demonstrate in additional analyses the relative merits of stability classification based upon $\sigma_{\theta}$ and $\mathrm{Ri}$.

\section{REFERENCES}

1. U.S. Atomic Energy Commission, Meteorology and Atomic Energy, 1968, TID-24190, USAEC Division of Technical Information, U.S. Department of Commerce, July, 1968 .

COMPARISON OF MAXIMUM EXPOSURES AT GROUND LEVEL RESULTING FROM SIMULTANEOUS RELEASE OF TRACERS FROM TWO ELEVATIONS

P. W. Nickola

\begin{abstract}
Results from field experiments in which two atmospheric tracers were simultaneously released from different elevations are used to compute the ratio of exposures resulting from the two levels of release. The magnitude of the ratios is generally related quite strongly to atmospheric stability. These experimentally generated ratios are compared to similar ratios calculated with the aid of Pasquill's curves for various diffusion categories. The experimental data show considerably smaller benefits from additional stack height than do the data resulting from use of Pasquizl's curves.
\end{abstract}

In the previous annual report $(1)$ in this series, Nickola reviewed the technique employed at Pacific Northwest Laboratory in which two tracers 
are simultaneously released from two elevations on a tower and subsequently collected on a common set of filters for assay. Nickola employed results of these dual tracer releases in investigating the effect of release height on plume centerline exposures as measured at ground or breathing level ( $\sim 2 \mathrm{~m})$. Specifically, the effect of increasing release height from 2 meters to 26 meters was investigated. It is the purpose here to report results of comparisons of other release height differences, and to compare these experimental results with predictions which can be made with the aid of the commonly used Pasquill diffusion categories.

In comparing the exposures resulting from the one-half hour tracer releases, the data have been normalized to the mass of tracer emitted, but not to wind speed.

The maximum exposures measured at distances as far as $12.8 \mathrm{~km}$ from the source were put in the form of a ratio with the exposure resulting from the lower release elevation as the denominator. Thus, the benefit to persons located at plume centerlines is directly indicated. A ratio of 1.0 indicates no benefit from an increased elevation of release. A ratio of 0.5 indicates that release from the upper level $\left(\mathrm{H}_{U}\right)$ reduces the exposure to one half that which is observed from release at the lower elevation $\left(\mathrm{H}_{\mathrm{L}}\right)$.

As was done in the previous study, the data were grouped into rather arbitrary stability classes on the basis of Richardson numbers (Ri) computed for the layer between $2 \mathrm{~m}$ and
$15 \mathrm{~m}$. The classes were moderately stable (MS), slightly stable (SS), slightly unstable (SU), and moderately unstable (MU) with corresponding $\mathrm{Ri}$ ranges of $>0.10,0.10$ to 0,0 to, -0.10 , and $<-0.10$.

The data reported in the previous annual report for $\mathrm{H}_{U}=26 \mathrm{~m}$ and $\mathrm{H}_{\mathrm{L}}=2 \mathrm{~m}$ are shown by the solid curves on Figure 1. (There is an anomaly in these data above the point where the MS curve exceeds the ratio for the SS curve. Since only 3 field tests contributed to the MS curve, it is felt the ss curve is more reliable for distances beyond $2 \mathrm{~km}$.) The solid curves on Figures 2,3 , and 4 indicate exposure ratios observed during other combinations of release heights and stabilities. Only SS and MS stability categories were observed during the 18 dual field releases not previously reported. Note in Figure 3 that the observed differences in ratio for the SS and MS data for $\mathrm{H}_{\mathrm{L}}=26 \mathrm{~m}$ and $\mathrm{H}_{\mathrm{U}}=56 \mathrm{~m}$ were so small that a single curve was plotted as representative.

It should be mentioned that the pairings of release elevations actually used in the field experiments were 2 and $26 \mathrm{~m}, 26$ and $56 \mathrm{~m}$, and 56 and $111 \mathrm{~m}$. Exposure ratios for the other pairings of $\mathrm{H}_{\mathrm{L}}$ and $\mathrm{H}_{U}$ can easily be computed from ratios of these de facto pairings.

Example interpretations from these curves can be made from Figure 4. In a slightly stable atmosphere, release at an effective elevation of $111 \mathrm{~m}$ would reduce plume centerline exposure at a distance of $2 \mathrm{~km}$ to about $32 \%$ of the exposure which would result from release at an elevation of $56 \mathrm{~m}$. At 


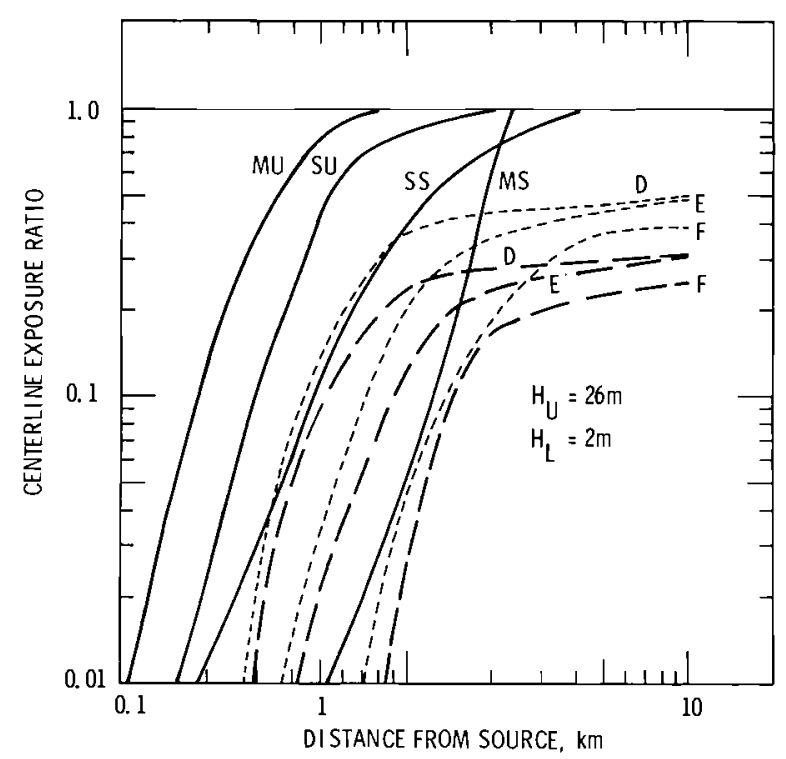

Neg 721169-1

FIGURE 1. Centerline Exposure Ratios for $\mathrm{H}_{\mathrm{L}}=2 \mathrm{~m}$ and $\mathrm{H}_{\mathrm{U}}=26 \mathrm{~m}$ for Various Atmospheric stabilities

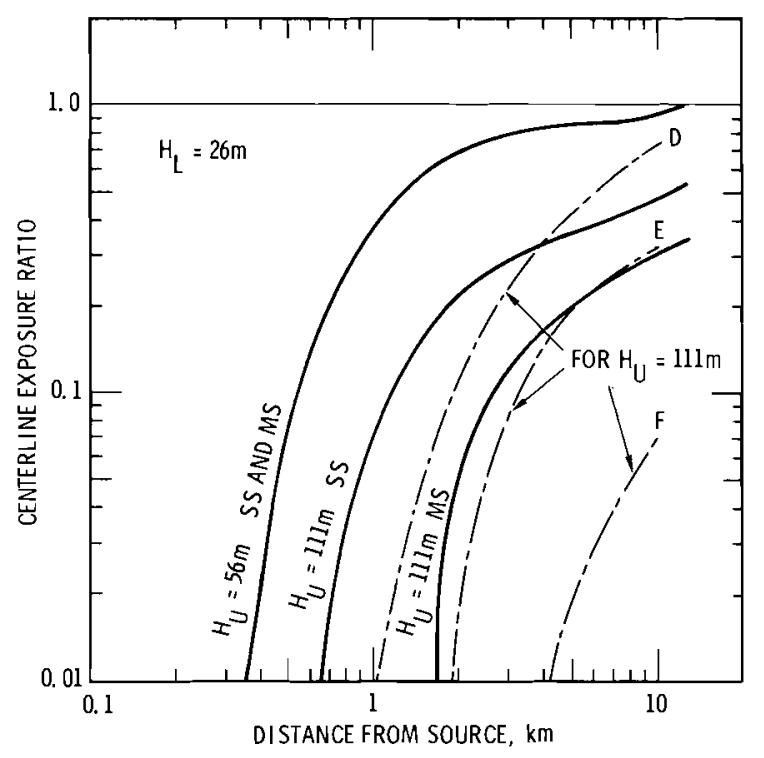

Neg 721169-2

FIGURE 3. Centerline Exposure Ratios for $\mathrm{H}_{\mathrm{L}}=26 \mathrm{~m}$ for Various Values of Stability and $\mathrm{H}_{\mathrm{U}}$

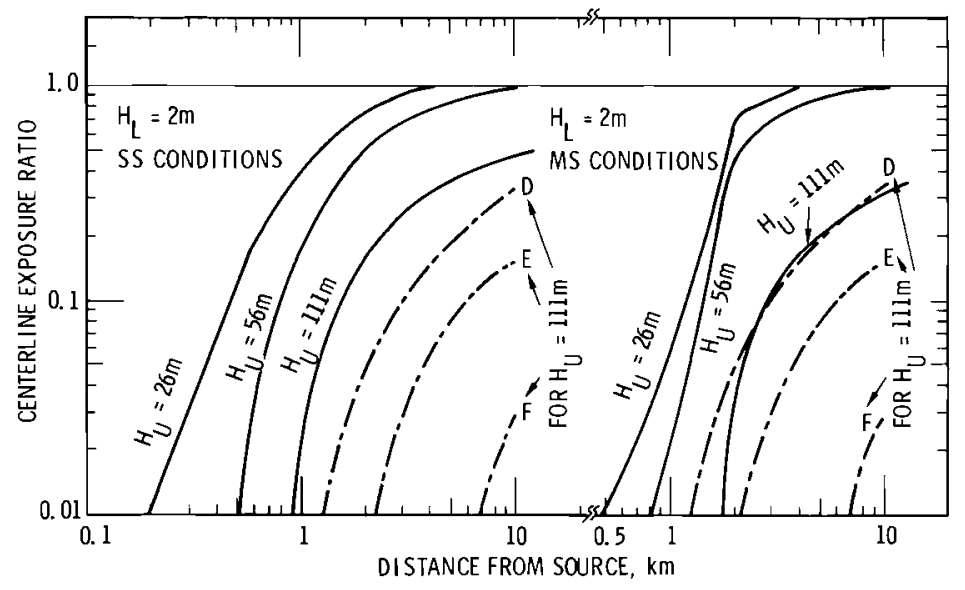

Neg 721169-4

FIGURE 2 Centerline Exposure Ratios for $\mathrm{H}_{\mathrm{L}}=2 \mathrm{~m}$ for Various Values of stability and $\mathrm{H}_{\mathrm{U}}$

$10 \mathrm{~km}$, there would still be a $50 \%$ reduction. In moderately stable atmospheres, the reductions at 2 and $10 \mathrm{~km}$ resulting from the increased effective stack height would be to $8 \%$ and $32 \%$ of the exposures from the lower stack.

It is of interest to compare the curves developed above with predictions that can be generated with the 


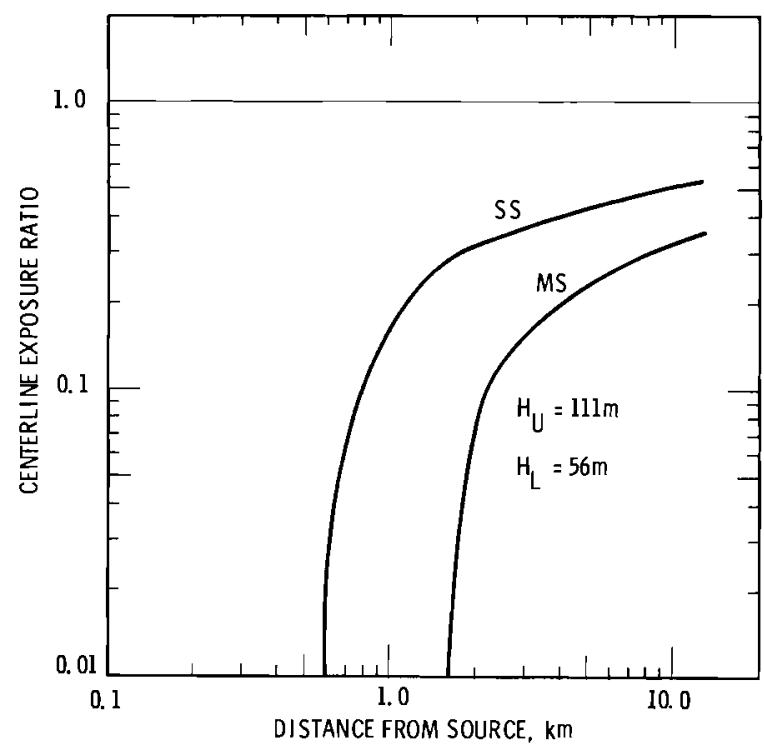

Neg 721169-3

FIGURE 4. Centerline Exposure Ratios for $\overline{\mathrm{H}}_{\mathrm{L}}=56 \mathrm{~m}$ and $\mathrm{H}_{\mathrm{U}}=111 \mathrm{~m}$ for $\mathrm{sS}$ and MS Atmospheric Stabilities

aid of Pasquill's frequently used diffusion categories. Curves representative of these categories are given in Appendix A-3 of Meteorology and Atomic Energy, 1968. (2) Pasquill's curves give centerline exposure ( $E_{p}$ ) normalized to mean wind speed $(\bar{u})$ and source strength (Q) in the form $E_{p} \vec{u} / Q$ versus distance from source. In order to employ these curves in the current study, it is necessary to assume a "typical" wind speed for the elevations under consideration. An examination of the winds measured on the $122-\mathrm{m}$ meteorology tower during tracer releases suggested $\bar{u}$ values of $2.6,4.4$, and $7.0 \mathrm{mps}$ at elevations of $2 \mathrm{~m}, 30 \mathrm{~m}$, and $100 \mathrm{~m}$, respectively, during SS conditions. Corresponding values of $\bar{u}$ during MS conditions were $1.2,3.2$, and $5.1 \mathrm{mps}$.
The differences between Pasquill's graphed data for heights of $30 \mathrm{~m}$ and $100 \mathrm{~m}$ and the PNL release heights of $26 \mathrm{~m}$ and $111 \mathrm{~m}$ were ignored in the comparisons that follow. In fact, there is considerable room for debate as to the wind which should be used as representative in the normalization of exposure. The avoidance of the necessity of making these $\bar{u}$ selections is part of the appeal of the exposure ratio approach presented in this paper.

In Figure 1, the dotted curves indicate ratios of exposure for $\mathrm{H}_{U}=30 \mathrm{~m}$ and $\mathrm{H}_{\mathrm{L}}=2 \mathrm{~m}$ under the $\mathrm{SS}$ winds mentioned above. The dashed curves were generated assuming the MS wind speeds mentioned. The nomenclature D, E, and F are Pasquill's neutral, slightly stable, and moderately stable conditions, respectively. One might conclude that the discrepancy between Pasquill's curves and the experimental SS and MS data is not out of bounds at distances out to about $2 \mathrm{~km}$, but beyond that distance, Pasquill's curves significantly overestimate the benefits expected from the increase in elevation of release.

For $\mathrm{H}_{\mathrm{U}}$ other than $26 \mathrm{~m}$, the assumption of either an SS or MS wind profile made minimal difference in the computed centerline ratios developed using Pasquill's curves. Thus only one set of Pasquill-generated curves (represented by dot-dash 1 ines) is presented in Figures 2 and 3 .

In Figures 2 and 3 , the tendency for significant overestimation of the benefits of additional stack height is repeated. Although it should be 
noted that the definitions of "slightly REFERENCES

stable" and "moderately stable"

offered by Pasquill and by the current study likely embrace quite different ranges in stability, it is felt that the discrepancies between the observed ratios and those which can be predicted by use of Pasquil's diffusion categories are cause for caution in the application of Pasquill's curves.
1. P. W. Nickola. "Comparison of Maximum Exposures at Ground Level Resulting from Simultaneous Re- lease of Tracers from 2 and 26 Meters," Pacific Northwest Labora- tory Annual Report for 1970 to the USAEC Division of Biology and Medicine. Volume II: Physical Sciences, Part 1. Atmospheric Sciences, BNWL-1551-1, pp. 108-112, Battelze-Northwest, Richland, Washington, June 1971.
2. U.S. Atomic Energy Commission. Meteorology and Atomic Energy, 1968, TID-24190, USAEC Division of Technical Information, July 1968.

A ${ }^{85} \mathrm{Kr}$ FIELD MONITORING SYSTEM AND ITS APPLICATION TO MAXIMUM AIR DOSE MEASUREMENTS OF A RADIOACTIVE GAS

J. D. Ludwick and P. W. Nickola

\begin{abstract}
Improvements to the ${ }^{85} \mathrm{Kr}$ diffusion grid are described which include an increase in the number of detectors, an expansion of the programmer memory, and an increase in data transfer speed.
\end{abstract}

our ${ }^{85} \mathrm{Kr}$ field monitoring system has been expanded by doubling the number of detector stations from 64 to 128 positions and by installing automatic cover-adsorber plates on each detector for energy discrimination.

An improved plume definition was sought by selective positioning of the added sensors although little, if any, improvement in sampling density was accomplished by the additional 64 stations. Monitoring stations were extended to the 1600 meter arc on the meteorological grid. Definition of the upper extent of typical plumes will be accomplished through measurements now available from sensors 1ocated up to 70 meters above ground elevation. 
Modifications of the data collection center include the expansion of the programmer memory to identify information from 256 separate locations rather than the previous 64 . In this way the instrumentation is ready for any further expansion of the field locations beyond the existing 128 . The real-time monitoring information collected on two 4096 address memory banks is also handled in a new manner. An electronic coupler was built to facilitate transfer of the 4096 information pieces to DEC-tape transports such as used in PDP-15 data processing computers .

There are several important advantages of this new system. The rapid information transfer ability of the coupler-tape system conserves real-time monitoring time, allowing continuous measurements of plume characteristics in time increments as sma11 as 0.1 second. In addition, the computer compatible nature of the new tape system allows data readout in a form designed to significantly reduce the many man-hours previously needed for necessary information presentation.

\title{
PRELIMINARY CONCENTRATION MEASUREMENTS
} OF PUFFS RELEASED DURING NEAR CALM WINDS

P. W. Nickola and J. D. Ludwick

\begin{abstract}
The Hanford inert gas field grid has been revised in order to better measure puffs of $85 \mathrm{Kr}$ released under stagnant atmospheric conditions. To date, two puffs have been released on this grid. Results from these tests suggest that if tracer concentration is considered as a function of distance, the stagnation conditions produce lower concentrations than do releases into stable atmospheres with steady wind directions. In considering short period ( 5 sec) mean concentrations as a function of time, stagnation tests produced higher concentrations than the steady wind case at times greater than 500 seconds after release.
\end{abstract}

Field diffusion experiments employing the inert radioactive gas ${ }^{85} \mathrm{Kr}$ were first carried out at Hanford during the fall of 1967. Numerous references which describe the system, present the data generated and describe research generated from use of this system were listed in last year's annual report in this series. (1) Further research involving data generated by this system is presented in this and other contributions elsewhere in 
this annual report, or is referenced in the section on Publications and Presentations at the end of this volume.

The early krypton field releases, involving both puffs and plumes, were carried out during periods when predicted steady winds were expected to carry the krypton tracer through two reasonably dense arrays of samplers located at distances of 200 and $800 \mathrm{~m}$ from the release point. In July 1971, the first tracer release was made on a revised grid designed to investigate diffusion under extremely low wind speed or stagnation conditions. This grid, incorporating a number of field samplers between the previously estab- 1ished $200 \mathrm{~m}$ and $800 \mathrm{~m}$ arrays, is diagrammed on Figure 1. Each dot represents a Geiger-Müller field detector located at an elevation of $1.5 \mathrm{~m}$. Tracer release in these erratic wind direction situations was near the center of the array.

To date, two puffs of krypton tracer (puffs P8 and P9) have been released at ground level on the stagnation grid. Figure 1 diagrams for test P9 the extent of detectable concentrations of the tracer at several moments in time. It is interesting to note that although the tracer is still detectable at the source location after 14 minutes, tracer also was detected at a distance greater than $1.2 \mathrm{~km}$ from

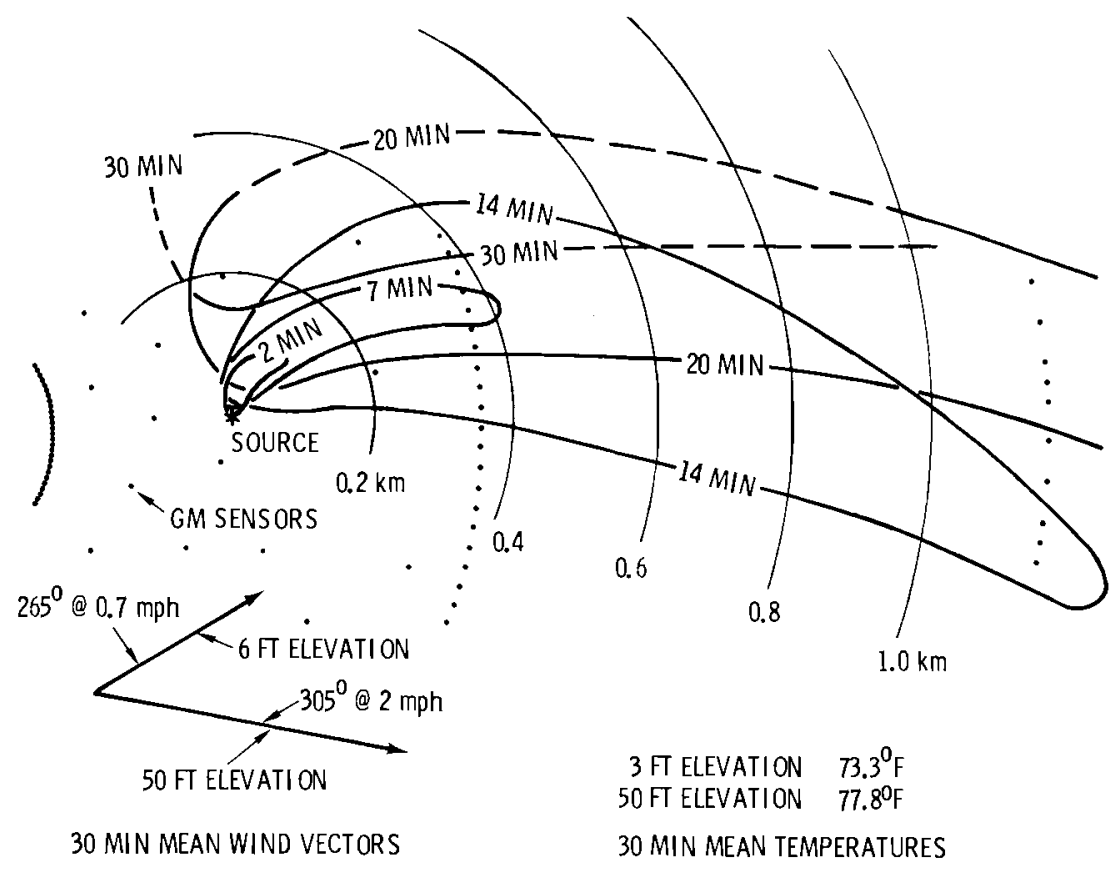

Neg 715022-1

FIGURE 1. Areal Extent of Detectable ${ }^{85} \mathrm{Kr}$ Concentration at $1.5 \mathrm{~m}$ Elevation During Field Test P9, $30 \mathrm{July} 1971$. Puff release at 0451 PST. 
the source. This indicates that despite the tracer being at ambient temperature at release (i.e., nonbuoyant) a portion of it must have moved at a mean speed of greater than $3 \mathrm{mph}$. As indicated on Figure 1 , the mean wind speeds were $0.7 \mathrm{mph}$ and $2 \mathrm{mph}$ at the $6-\mathrm{ft}$ and $50-\mathrm{ft}$ elevations, respectively, and the atmosphere was quite stable thermally. It is surprising that a portion of the tracer moved at a speed characterized by winds at an elevation above $50 \mathrm{ft}$.

Puff P10, released from the same location but on a different day, drifted in a direction opposite the movement of puff P9. Thus, no data are available for distances beyond $0.3 \mathrm{~km}$. Winds averaged $1.8 \mathrm{mph}$ at the 7-ft elevation during this test. A $6^{\circ} \mathrm{F}$ temperature inversion existed between the 3 and $50-\mathrm{ft}$ elevations.

Figure 2 compares maximum short period (5-sec) mean concentrations $\left(x_{p}\right)$ for all 10 puff releases to date. The $x_{p}$ values were normalized to unit source strength by dividing by the amount of tracer emitted (Q). Puffs Pl through P 8 were those released at ground level during more steady wind directions. Puffs P1, P2 and P8 were released into stable atmospheres; $P 3$, P4, P5 and P6 into neutral atmospheres; and $\mathrm{P} 7$ was released during unstable atmospheric conditions. As mentioned previously, stagnation puffs $P 9$ and P10 were released into stable atmospheres.

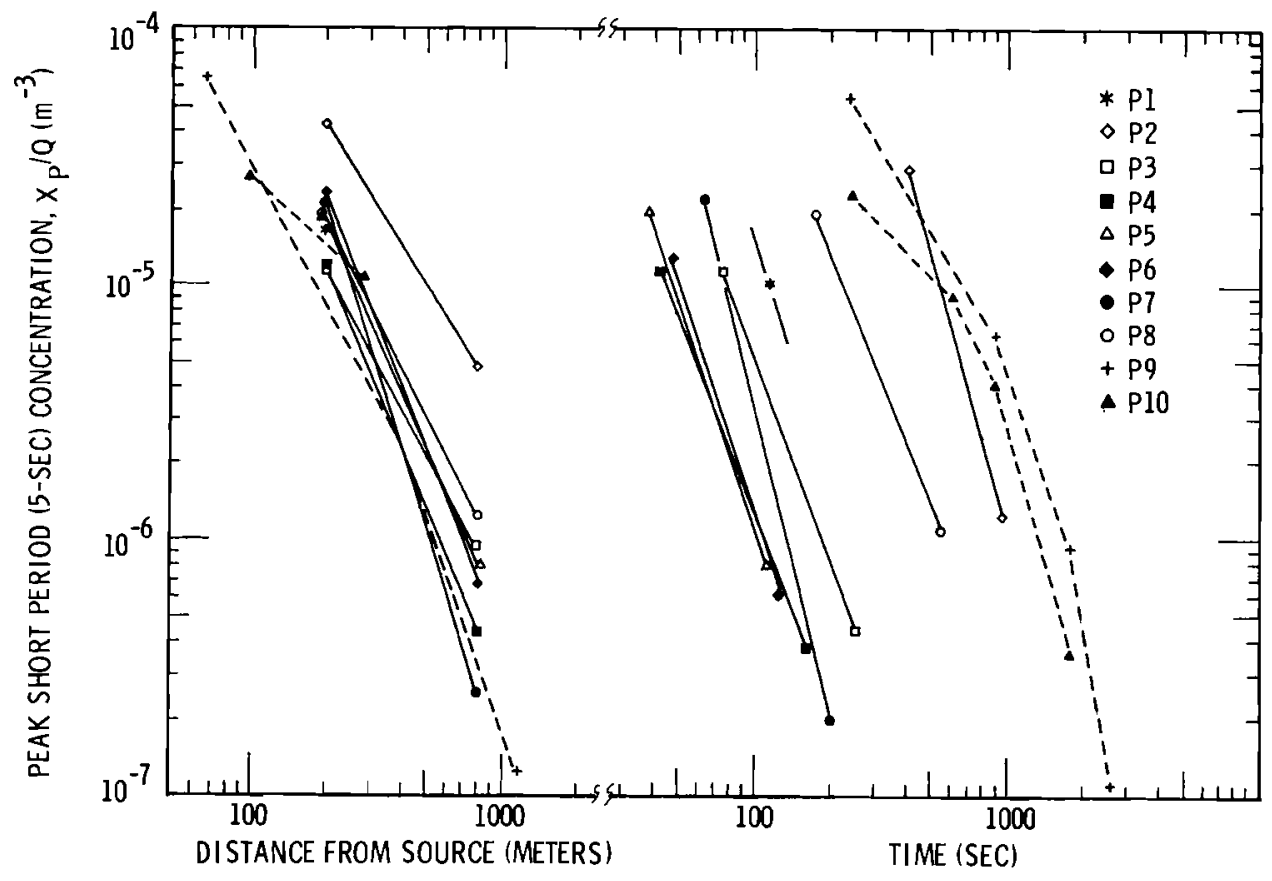

Neg 721169-7

FIGURE 2. Puff Maximum Short Period (5-sec) Concentrations Versus Distance and Versus Time 
One might intuitively expect concentrations under stagnation conditions to be higher than for those conditions in which higher wind speeds are observed. The right-hand portion of Figure 2, in which $x_{p} / Q$ is plotted as a function of time after release, confirms the intuitive feeling. However, the left-hand portion of this figure indicates that, in terms of distance, the stagnation $x_{p}$ values for tests $P 9$ and P10 rank relatively low.

One might also speculate that the maximum exposure $\left(E_{p} / Q\right)$ - the maximum quantity of tracer a stationary receptor could experience - would be higher in near-calm conditions. Figure 3 suggests that this is not the case. Exposures experienced during the rela-

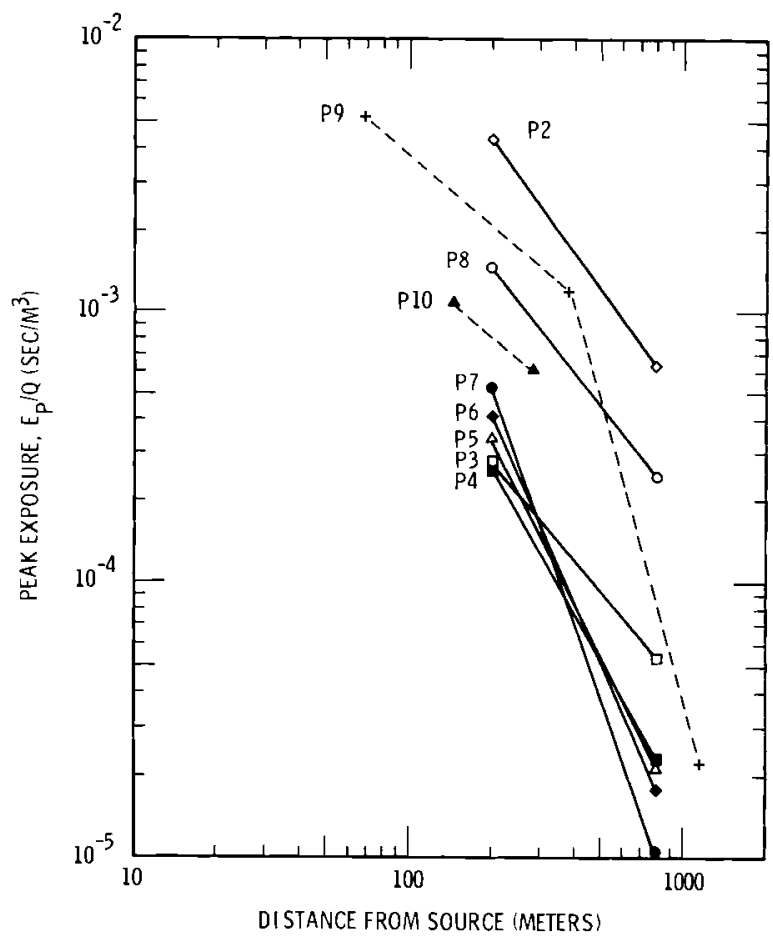

Neg 721169-6

FIGURE 3. Puff Maximum Exposure Versus Distance (Exposure Values Not Normalized to Unit Wind Speed) tively steady winds during stable tests P2 and P8 were at least as great as those observed during the two stagnation tests. (Wind speed during P2 was $2.7 \mathrm{mph}$ and during P 8 was $3.4 \mathrm{mph}$ at the $1.5 \mathrm{~m}$ elevation.) No normalization to wind speed is incorporated in the exposures presented in Figure 2 .

A qualitative explanation as to why $P 2$ exposures exceeded those from the stagnant puffs $P 9$ and $P 10$ can be advanced. Higher wind speeds lead to lower exposures. Variable wind directions lead to lower exposures. In the case of test $P 2$, the effect of steadiness of direction may have outweighted the effect of the higher wind speed.

Alternatively, it is possible that the relatively wide spacing between sensors during $P 9$ and PlO precluded the obtaining of measurements near 1ocations of peak exposure. For like reasons, the $x_{p} / Q$ values reported in Figure 2 for tests P9 and P10 may be 1ow. During tests P1 to P8 when steady winds carried tracer through the relatively dense network of samplers, it is unlikely that the measured maxima differed greatly from the actual maxima.

Further releases of puffs in stagnant atmospheres are planned in order to better define diffusion in this relatively uninvestigated area.

\section{REFERENCES}

1. F. W. Nickola, "Measurements of the Movement, Concentration and Dimensions of Instantaneously Generated Puffs of an Inert Gas," Pacific Northwest Laboratory Annual Report for 1970 to the USAEC Division of Biology and Medicine, Volume II: Physical Sciences, Part 1. Atmospheric Sciences, BNWL-1551-1, Battelle-Northwest, Richland, Washington, pP. 112-116, June 1971. 


\title{
A COMPARISON OF EXPOSURES RESULTING FROM INERT GAS \\ RELEASES WITH EXPOSURES PREDICTED WITH \\ THE AID OF PASQUILL'S DIFFUSION CATEGORIES \\ P. W. Nickola
}

\begin{abstract}
Normalized exposures resulting from near ground level release and sampling of plumes of an inert gas tracer were lower than exposures predicted with the aid of graphs based on Pasquill's diffusion categories. Since concentration reducing processes other than turbulence and diffusion should be minimized by use of an inert tracer, these results suggest that Pasquili's curves are too conservative.

Exposures resulting from instantaneous puff releases were found to average three times the magnitude of those resulting from 10 to 80-minute plume releases.
\end{abstract}

Pasquill's diffusion categories and associated curves of exposure versus travel distance are relatively widely used in estimating plume centerline exposures. A number of these graphical aids are given in Appendix A-3 of Meteorology and Atomic Energy,

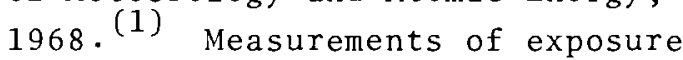
made during a series of releases of the inert gas ${ }^{85} \mathrm{Kr}(2)$ present an opportunity to compare these observed exposures with those resulting from use of Pasquill's curves.

For a given meteorological condition, the use of an inert gas tracer should result in higher downwind concentrations than would be expected with particulate or chemically reactive pollutants. The effect of depleting mechanisms such as fallout, chemical reaction with other atmospheric constituents and impaction on vegetation or other terrain features are absent.

Table 1 lists the duration of release and diffusion measurements made during the period of transport of the tracer across the measurement arcs. These arcs were located at distances of 200 and $800 \mathrm{~m}$ from the sources. It is assumed that since tracer release height was $1 \mathrm{~m}$ and sampling height was $1.5 \mathrm{~m}$, the measured concentrations were near plume axial values.

The left-hand portion of Figure 1 gives plume centerline exposures $\left(E_{p}\right)$ normalized to amount of tracer released (Q) and to wind speed $(\bar{u})$ measured at an elevation of $1.5 \mathrm{~m}$. The dotted lines correspond to Pasquill's diffusion categories qualitatively described as extremely unstable (A) through neutral (D) to moderately stable (F). Note that only the very 
TABLE 1. Krypton-85 Tracer Releases

\begin{tabular}{|c|c|c|c|c|}
\hline Test & $\begin{array}{l}\text { Duration } \\
\text { (min: sec) } \\
\end{array}$ & $\begin{array}{l}\text { Wind Speed } \\
\text { at } 1.5 \mathrm{~m} \\
\text { (mps) } \\
\end{array}$ & $\begin{array}{l}\text { Richardson No. } \\
\text { for Layer } \\
2 \text { to } 15 \mathrm{~m} \\
\end{array}$ & $\begin{array}{c}\text { Qualitative } \\
\text { Thermal } \\
\text { Stability } \\
\end{array}$ \\
\hline${ }^{*} \mathrm{Cl}$ & $15: 28$ & 1.3 & 0.13 & Very Stable \\
\hline${ }^{*} \mathrm{C} 2 *$ & $15: 05$ & 3.9 & -0.04 & Neutral \\
\hline${ }^{*} \mathrm{C} 3 *$ & $14: 15$ & 7.1 & -0.03 & Neutral \\
\hline$*_{\mathrm{C} 4}$ & $9: 58$ & 3.9 & -0.16 & Unstable \\
\hline $\mathrm{C} 5 *$ & $19: 51$ & 2.6 & 0.07 & Stable \\
\hline
\end{tabular}

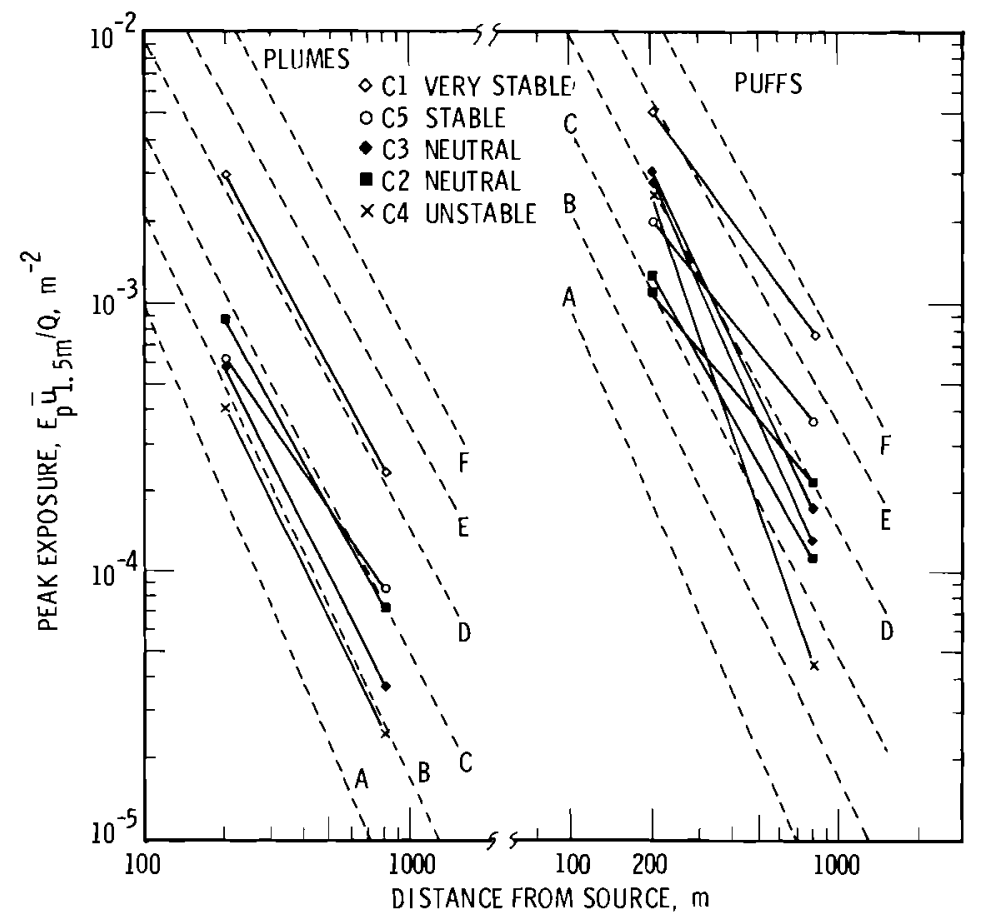

Neg 721169-9

FIGURE 1. Plume and Puff Peak Exposures Versus Distance from source

stable test Cl falls above Pasquill's D or neutral classification. Pasquill's curves overestimate the observed exposures by a factor of 3 to 5 for this reasonably ideal tracer.
In Table 1 , an asterisk preceding a test number indicates that an instantaneous puff of krypton gas was released shortly before the plume release of tracer. An asterisk following 
a test number indicates a puff release shortly after plume release. Cof course, tracer from one release was permitted to clear the sampling grid prior to the following release.) Meteorological conditions were reasonably constant throughout each pairing of releases. Peak normalized exposures resulting from the puff releases are shown at the right of Figure 1. It is interesting to note that although Pasquill's curves were designed for use with continuous releases in this instance, they more reasonably predict exposures for the puff releases.

Quite aside from the comparison of the krypton releases with Pasquil1's curves, the sequential releases of puffs and plumes provide the opportunity to compare the magnitudes of puff and plume exposures. Ratios of $E_{p} \bar{u} / Q$ for each puff to $E_{p} \bar{u} / Q$ for its accompanying plume were computed. Although individual ratios ranged from a high of 6.4 to a low of 1.5 , the geometric mean ratio was 3.0 for samples at both $200 \mathrm{~m}$ and $800 \mathrm{~m}$ arcs. Ratios of peak exposure in which no normalization to $\bar{u}$ was effected were also computed. These $E_{p} / Q$ ratios for $200 \mathrm{~m}$ and $800 \mathrm{~m}$ again, fortuitously, were identica1 at 3.1. No dependence on atmospheric stability was obvious in either case.

\section{REFERENCES}

1. U.S. Atomic Energy Commission, Meteorology and Atomic Energy, 1968, TID-24190, USAEC Division of Technical Information, July 1968 .

2. P. W. Nickola, J. V. Ramsdell, Jr. and J. D. Ludwick, Detailed Time Histories of Concentrations Resulting from Puff and Short-Period Releases of an Inert Radioactive Gas: A Volume of Atmospheric Diffusion Data, BNWL-1Z7Z, BattelleNorthwest, Richland, Washington, February 1970 . 


\title{
EXAMINATION OF THE RELATIONSHIP BETWEEN THE SIZE AND SHAPE OF THE REAL PLUME AND ITS POSITION
}

J. V. Ramsde 11

\begin{abstract}
The assumption that the size and shape of a real (instantaneous) plume are independent of the position of its centroid at any fixed distance from the source is crucial to fluctuating plume models. This assumption is examined using $85 \mathrm{Kr}$ data and time series analysis.
\end{abstract}

The discussions on the relationship between the real (instantaneous) plume and the apparent (mean) plume which have been presented in past volumes of this series $(1,2)$ have tacitly assumed that the diffusion and meandering are statistically independent processes. This assumption was explicitly identified in a recent paper by Högström. (3) Specifically, the assumption required is that the shape of the real plume and its physical size must be independent of the instantaneous horizontal or vertical position of its centroid. Elementary time series analysis provides an easy means of checking the validity of this as sumption.

One of the short-duration continuous releases of $85 \mathrm{Kr}$ made in $1967^{(4)}$ provides sufficient data for an initial analysis. The time-history of this plume at both 200 and $800 \mathrm{~m}$ is shown in Figure 1. The release, $\mathrm{C} 5$, was made during slightly stable conditions with a mean wind speed of $2.6 \mathrm{~m} / \mathrm{sec}$. As can be inferred from the figure, there was a dominant low frequency meander of the wind direction which had a period of oscillation of about $20 \mathrm{~min}$. It might be expected that this relatively organized meander would enhance or exaggerate any relationships between the size and shape of the real plume and its position. If this is the case, the plume will provide a good test of the assumption in question.

The size and shape of the real plume were parameterized by taking the first 4 moments of the crosswind concentration distribution for each time increment. These parameters are shown in Table 1 for a middle portion of plume passage at 200 and $800 \mathrm{~m}$. The centerline columns represent the position of the real plume axis for each cross section, in degrees azimuth. The size of the real plume cross sections is represented in o (standard deviation) and $\sigma^{2}$ (variance) columns, and the shape of the real plume cross sections is represented by the skew. (skewness) and kurt. (kurtosis) columns. The $\sigma$ and $\sigma^{2}$ entries are in degrees, while the skew. and kurt. 


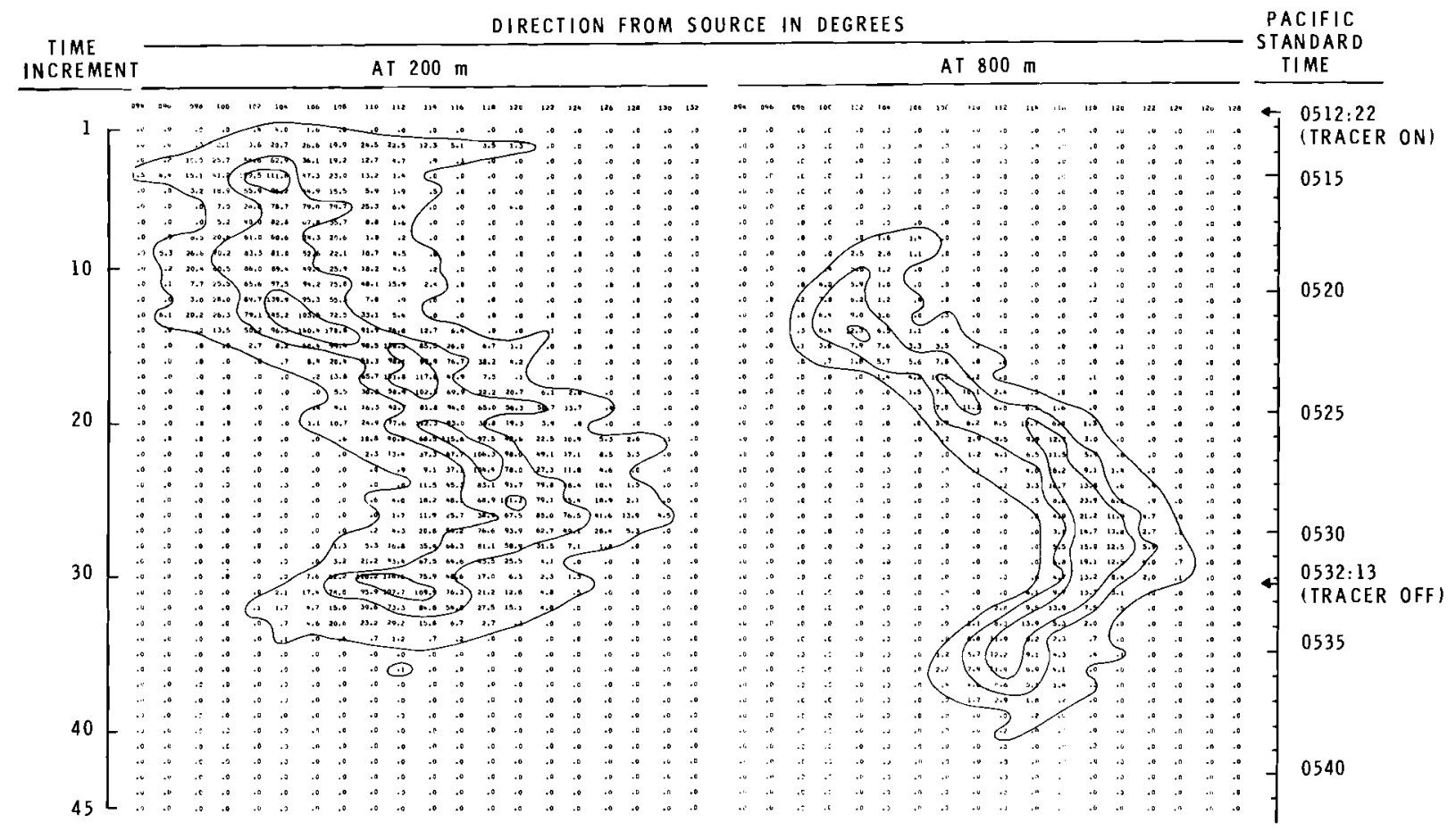

Neg 0692250-3

FIGURE 1. Time-History of ${ }^{85} \mathrm{Kr}$ Concentration in a Diffusing Plume, Test C5

TABLE 1. Real Plume Position, Size and Shape Parameters for a segment of C5

\begin{tabular}{|c|c|c|c|c|c|c|c|c|c|c|}
\hline \multirow[b]{2}{*}{$\begin{array}{c}\text { TIME } \\
\text { INCREMENT }\end{array}$} & \multicolumn{5}{|c|}{$200 \mathrm{M}$} & \multicolumn{5}{|c|}{$800 \mathrm{M}$} \\
\hline & CENTERLINE & a & $a^{2}$ & $\underline{\text { SKEW. }}$ & KURT. & CENTERLINE & 0 & $\underline{0}^{2}$ & SKEW. & $\underline{\text { KURI }}$ \\
\hline 11 & 103.47 & 3.16 & 9.90 & 0.46 & 285 & 102.22 & 0.92 & 0.84 & 0.41 & 4.29 \\
\hline 12 & 105.51 & 3.24 & 10.52 & 0.04 & 2.56 & 101.45 & 1.24 & 1.53 & 0.26 & 2.37 \\
\hline 13 & 104.37 & 242 & 5.86 & 0.09 & 2.71 & 101.28 & 1.52 & 2.31 & 0.89 & 3.85 \\
\hline 14 & 104.62 & 3.12 & 9.72 & -0.3 & 3.05 & 101.65 & 1.74 & 3.04 & 0.52 & 4.3 \\
\hline 15 & 106.87 & 3.01 & 9.09 & 0.18 & 3.27 & 102.26 & 1.86 & 3.45 & 0.62 & 3.69 \\
\hline 16 & 110.64 & 3.12 & 9.73 & 0.01 & 259 & 103.68 & 250 & 6.24 & 0.39 & 232 \\
\hline 17 & 113.26 & 291 & 8.45 & -0.28 & 284 & 105.98 & 249 & 6.19 & -0.17 & 291 \\
\hline 18 & 112.76 & 2.18 & 4,77 & 0,00 & 2.68 & 107.74 & 1.60 & 256 & -0.53 & 3.02 \\
\hline 19 & 114.49 & 3.00 & 9.02 & 0.50 & 3.39 & 109.34 & 1.64 & 2.69 & 0.06 & 3.08 \\
\hline 20 & 116.71 & 3.62 & 13.13 & 0.05 & 239 & 110.89 & 240 & 5.75 & 0.39 & 220 \\
\hline 2l & 114,45 & 2.85 & 8.14 & 0.10 & 3.20 & 112.69 & 264 & 6.98 & -0.13 & 2.24 \\
\hline 22 & 116.73 & 3.33 & 11.09 & 0.51 & 3.64 & 114.15 & 223 & 4.96 & -0.22 & 229 \\
\hline 3 & 118.53 & 3.17 & 10.06 & 0.14 & 3.21 & 115.2 & 2.25 & 5.07 & -0.39 & 265 \\
\hline 24 & 118.4 & 238 & 5.68 & 0.43 & 3.63 & 116.39 & 1.64 & 269 & -0.27 & 3.76 \\
\hline 25 & 120.03 & 286 & 8.16 & 0.05 & 2.46 & 116.71 & 1.49 & 2.22 & 0.14 & 4.07 \\
\hline 26 & 119.98 & 3.17 & 10.02 & -0.11 & 271 & 117.92 & 1.42 & 202 & 0.23 & 3.66 \\
\hline 27 & 121.68 & 3.49 & 12.18 & -0.22 & 2.78 & 118.77 & 1.66 & 2.74 & 0.35 & 260 \\
\hline 28 & 120.01 & 3.42 & 11.67 & 0.09 & 248 & 118.95 & 1.55 & 242 & 0.10 & 280 \\
\hline 29 & 117.58 & 3.11 & 9.69 & -0.18 & 3.00 & 119.03 & 1.90 & 3.62 & 0.21 & 243 \\
\hline 30 & 115.09 & 299 & 8.93 & 0.02 & 247 & 118.73 & 1.82 & 3.32 & 0.46 & 2.97 \\
\hline MEAN & 111.13 & 296 & 8.98 & 0.15 & 2.97 & 111.31 & 1.80 & 3.41 & 0.18 & 285 \\
\hline STD. DEVIATION & 607 & 0,48 & 2.79 & 0.27 & 0.40 & 6.13 & 0.42 & 1.53 & 0.32 & 0.73 \\
\hline & & & & & & & & & & \\
\hline INTEGRATED & 111.51 & 6.74 & 45.47 & 0.07 & 212 & 113.17 & 5.743 & 3270 & -0.77 & 270 \\
\hline
\end{tabular}


entries are pure numbers (coefficients of skewness and kurtosis). The mean and standard deviation rows at the bottom of the figure indicate the mean and standard deviation for each of the columns for the entire plume passage. The last row of numbers in the figure indicates the size and shape of the apparent plume resulting from this release. The various columns in this figure are only portions of each of the time-series analyzed in the remainder of the discussion.

An initial point of interest is whether autocorrelations of the size and shape parameters are significant or not. It is obvious that the autocorrelation of the position of the real plume segments should be high, even at long time-lags. As a result,

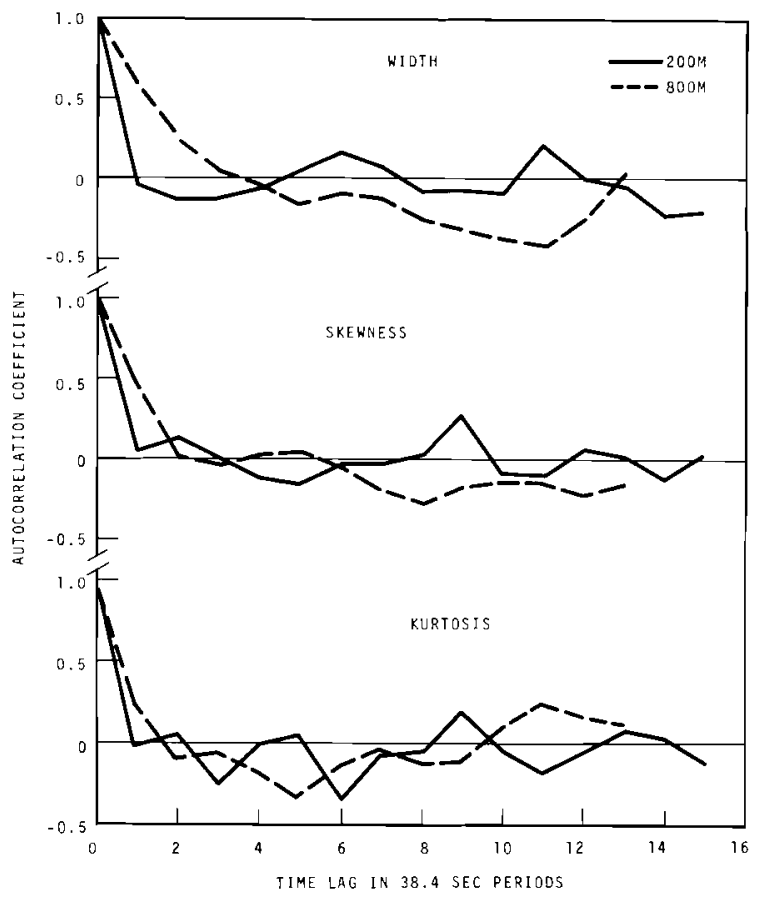

Neg 721169-10 FIGURE 2. Autocorrelation of Real Plume Characteristics it will not be discussed further. On the other hand, in Table 1 there does not appear to be a significant autocorrelation for any of the other parameters. This inference is examined in Figure 2, which shows the autocorrelograms for real plume width, skewness and kurtosis. Indeed, this figure shows that the autocorrelations are insignificant for each of the parameters at $200 \mathrm{~m}$ and for the coefficient of kurtosis at $800 \mathrm{~m}$. However, at $800 \mathrm{~m}$ and a time-lag of $38.4 \mathrm{sec}$ ( 1 time increment), the autocorrelations of real plume width $(\sigma)$ and the coefficient of skewness are both statistically significant. The question is then raised whether these correlations are physically real and related to plume position.

To examine this question and the ultimate validity of the original assumption, correlograms were constructed for the relationships between the real plume size and shape parameters and the position parameter. These correlograms are shown in Figure 3. None of the correlograms is significantly different from zero in the statistical sense, but the nature of the correlograms for the $800 \mathrm{~m}$ width and skewness is of some interest. In particular, the fact that the curves are relatively smooth and are almost mirror images of each other suggests that there may be a physical relationship between the real plume size and shape and its position.

In the light of the implications of a relationship between the real plume size and shape and its position and because of the lack of evidence of such relationship in the correlograms 


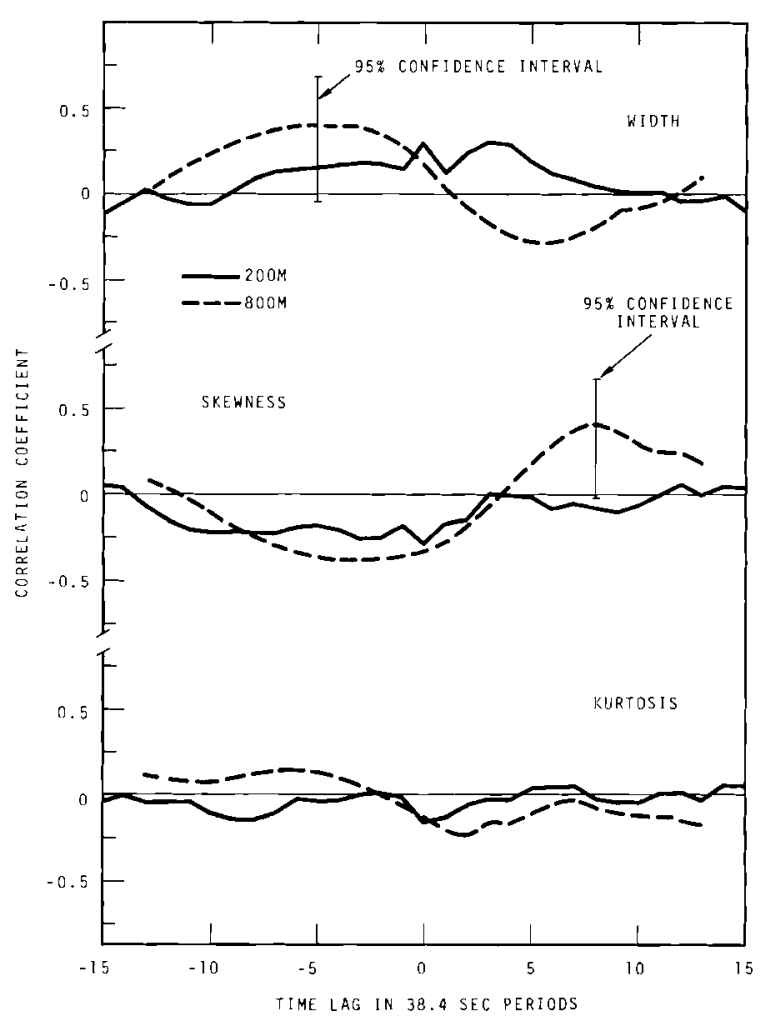

Neg 721169-8

FIGURE 3. Correlation Between Real Plume Characteristics and the centroid of the Real Plume

of the parameters from the $200 \mathrm{~m}$ data, a search was made for an alternative explanation for the correlations exhibited at $800 \mathrm{~m}$. Such an alternative was found. It would appear that these correlations can be explained as an artifact of the sample duration. The amplitude of the meander of the real plume is essentially the same at 200 and $800 \mathrm{~m}$ in angular measurement. As a result, the 1 inear amplitude at $800 \mathrm{~m}$ is 4 times greater than that at $200 \mathrm{~m}$. The speed of crosswind movement of the real plume at $800 \mathrm{~m}$ must, therefore, appear to be 4 times that at $200 \mathrm{~m}$ since the period of oscillation is about the same at the two distances. The movement of the real plume during a $38.4 \mathrm{sec}$ period may not be significant at $200 \mathrm{~m}$, but, because of the increase in the apparent speed of the crosswind movement of the plume between 200 and $800 \mathrm{~m}$, both the shape and size of the real plume may be significantly distorted at $800 \mathrm{~m}$ during the same period. The amount of alteration would be a function of the position of the real plume axis. The distortion of the plume would be minimum, at the extreme displacements, and it would be a maximum near the mean plume axis. Reduction of the sampling time would have reduced the apparent motion and resulting distortion.

Having found a suitable hypothesis to explain the behavior exhibited by the correlograms between the real plume position and its size and shape, it is tentatively concluded that the assumption that the real plume size and shape are independent of position is correct. At the same time, it is concluded that a sampling increment shorter than $38.4 \mathrm{sec}$ is necessary for examination of the relationships between the real and apparent plumes at $800 \mathrm{~m}$ in order to reduce distortion caused by meandering. It is suspected that the duration of the sampling period must be decreased as the distance from the source is increased, although the distances with which this applies are yet to be determined. 


\section{REFERENCES}

1. J. V. Ramsdezl, "The Use of Instantaneous Plume Measurements to Approximate a Mean Plume," Pacific Northwest Laboratory Annual Report for 1967 to the USAEC Division of Biology and Medicine. Volume II: Physical Sciences, Part 3. Atmospheric sciences, BNWL-?15-3, Battelle-Northwest, Richland, Washington, October 1968.

2. J. V. Ramsdell, "The Real Plume and Its Relationship to the Apparent Plume," Pacific Northwest Laboratory Annual Report for 1970 to the USAEC Division of Biology and Medi- cine, Volume II: Physical sciences, Part 1. Atmospheric Sciences, BNWL-1551-1, Battelle-Northwest, Richland, Washington, June 1971.

3. U. Högström, "A Method for Predicting odour Frequencies from a Point Source," to be published in Atmospheric Environment, 1972.

4. P. W. Nickola, J. V. Ramsdell, Jr. and J. D. Ludwick, Detailed TimeHistories of Concentrations Resulting from Puff and short-Period Releases of an Inert Radioactive Gas: A Volume of Diffusion Data, BNWL-12?2, Battelie-Northwest, Richland, Washington, February 1970.

\title{
ABSOLUTE PEAK-TO-MEAN CONCENTRATION RATIOS
}

\author{
J. V. Ramsdell
}

\begin{abstract}
Absolute peak-to-mean concentration ratios are defined as the ratio between a maximum short-term concentration at any given position and the time-average concentration at the mean plume axis. They are examined as a function of both position in the plume and the time ratio. A comparison between conventional and absolute peak-to-mean ratios is shown.
\end{abstract}

In discussions of peak-to-mean concentration ratios, both the peak and mean concentrations are usually assumed to apply to the same position. As a result, there are some problems differentiating between actual peak concentrations at different positions when the conventional peak-to-mean ratios are used. To alleviate this problem, another type $P / M$ ratio is needed. A peak-to-centerline-mean ratio was suggested in the 1968 annual report. (1) During the past year, further analysis of the ${ }^{85} \mathrm{Kr}$ data has been directed along these lines.

In many ways, it seems advantageous to consider peak concentrations normalized to a common concentration rather than the local mean concentration. The obvious concentration for use in the normalization 
of peak concentrations would appear to be the average concentration at mean plume axis. To prevent confusion, peak concentrations normalized to this axial mean concentration will be referred to as absolute $\mathrm{P} / \mathrm{M}$ ratios $\left(\mathrm{P} / \mathrm{M}_{\mathrm{a}}\right)$, as opposed to conventional $\mathrm{P} / \mathrm{M}$ ratios $\left(P / M_{L}\right)$ in which peak concentrations are normalized to the local mean concentration.

An absolute peak-to-mean concentration ratio might be thought of as the product of a conventiona $1 \mathrm{P} / \mathrm{M}$ ratio and the ratio between the local and axial mean concentrations. Thus, it is to be expected that $\overline{P / M}$ are a function of the same variables as $\overline{P / M_{L}}$. A summary of absolute peak-to-mean ratios for the ${ }^{85} \mathrm{Kr}$ tests is presented in Table 1 by relative crosswind position and time ratio. The central value in each group is the geometric mean $\overline{\mathrm{P} / \mathrm{M}_{\mathrm{a}}}$ for the class and the upper and the lower values are one geometric standard deviation removed from their respective $\overline{\mathrm{P} / \mathrm{M}_{2}}$. The range of values of $\mathrm{T} / \mathrm{t}$ and $\mathrm{y} / \sigma_{\mathrm{y}}$ for each group is indicated by the arithmetic mean \pm one standard deviation.

The relationship between $\overline{\mathrm{P} / \mathrm{M}}$ and normalized crosswind positions is shown in Figure 1 . The most striking feature of this figure is that the maximum $\overline{\mathrm{P} / \mathrm{M}}$ atios occur at the mean plume axis. The relatively flat portion of the curves near the center of the mean plume is the result of plume meander and its extent essentially defines the limit of meandering of the axis of the instantaneous plume. As the edge of the mean plume is approached, the rapid decrease in $\overline{\mathrm{P} / \mathrm{M}}$

TABLE 1. Average Values of Absolute Peak-to-Mean Concentration Ratios as a Function of the Normalized Crosswind Position and Time Ratio

\begin{tabular}{|c|c|c|c|c|c|}
\hline$(T / t)$ & $0.21 \pm 0.13$ & $0.70 \pm 0.14$ & $\begin{array}{c}|y| / \sigma_{y} \\
1.23 \pm 0.16\end{array}$ & $1.75 \pm 0.16$ & $2.31 \pm 0.16$ \\
\hline $1.94 \pm 0.08$ & $\begin{array}{l}1.83 \\
1.44 \\
1.13 \\
n=24\end{array}$ & $\begin{array}{l}2.13 \\
1.26 \\
0.743 \\
n=28\end{array}$ & $\begin{array}{l}1.83 \\
0.988 \\
0.535 \\
\mathrm{n}=25\end{array}$ & $\begin{array}{l}0.877 \\
0.351 \\
0.140 \\
\mathrm{n}=23\end{array}$ & $\begin{array}{l}0.239 \\
0.060 \\
0.015 \\
n=15\end{array}$ \\
\hline $3.98 \pm 0.22$ & $\begin{array}{l}2.85 \\
2.32 \\
1.75 \\
n=24\end{array}$ & $\begin{array}{l}3.48 \\
2.03 \\
1.19 \\
\mathrm{n}=28\end{array}$ & $\begin{array}{l}3.12 \\
1.70 \\
0.923 \\
\mathrm{n}=25\end{array}$ & $\begin{array}{l}1.66 \\
0.680 \\
0.278 \\
n=23\end{array}$ & $\begin{array}{l}0.474 \\
0.097 \\
0.020 \\
\mathrm{n}=16\end{array}$ \\
\hline $8.04 \pm 0.48$ & $\begin{array}{l}3.65 \\
2.81 \\
2.16 \\
n=24\end{array}$ & $\begin{array}{l}4.28 \\
2.66 \\
1.65 \\
n=28\end{array}$ & $\begin{array}{l}3.96 \\
2.34 \\
1.39 \\
n=25\end{array}$ & $\begin{array}{l}2.51 \\
1.09 \\
0.475 \\
\mathrm{n}=23\end{array}$ & $\begin{array}{l}0.763 \\
0.169 \\
0.038 \\
n=16\end{array}$ \\
\hline $20.2 \pm 3.9$ & $\begin{array}{l}4.33 \\
3.53 \\
2.88 \\
n=22\end{array}$ & $\begin{array}{l}4.95 \\
3.56 \\
2.55 \\
n=26\end{array}$ & $\begin{array}{l}4.59 \\
3.00 \\
1.97 \\
\mathrm{n}=23\end{array}$ & $\begin{array}{l}3.70 \\
1.81 \\
0.883 \\
n=19\end{array}$ & $\begin{array}{l}1.02 \\
0.268 \\
0.070 \\
n=15\end{array}$ \\
\hline
\end{tabular}




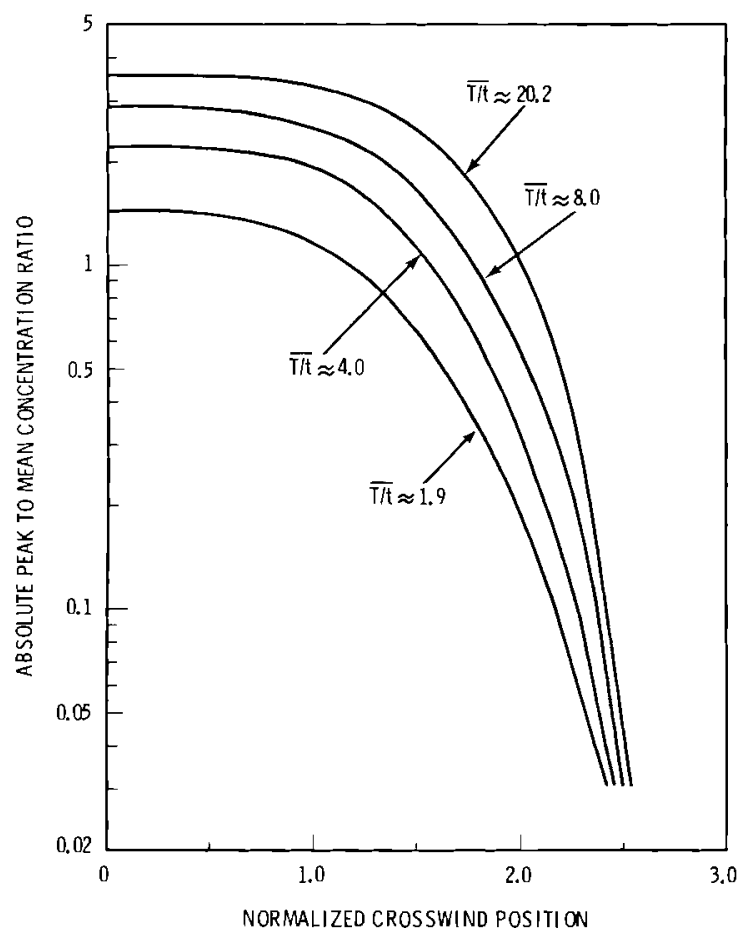

Neg 715456-2

FIGURE 1. Absolute Peak-to-Mean Concentration Ratios as a Function of Normalized Crosswind Position

is caused by the comparison of peak concentrations at the extreme edge of the meandering plume with the axial mean concentrations. Figure 2 shows the scatter of the actual data points about the curve for $\mathrm{T} / \mathrm{t}$ about 20 . This scatter is representative of the scatter about each of the curves.

The differences in the relationships between conventional and absolute peak-to-mean ratios and the crosswind position are obvious in Figure 3. In this figure, the lines which increase toward the right represent conventiona $\overline{\mathrm{P} / \mathrm{M}}$, while those decreasing to the right represent absolute $\overline{P 7 M_{a}}$. As can be seen, the two peak-to-mean ratios are the same at

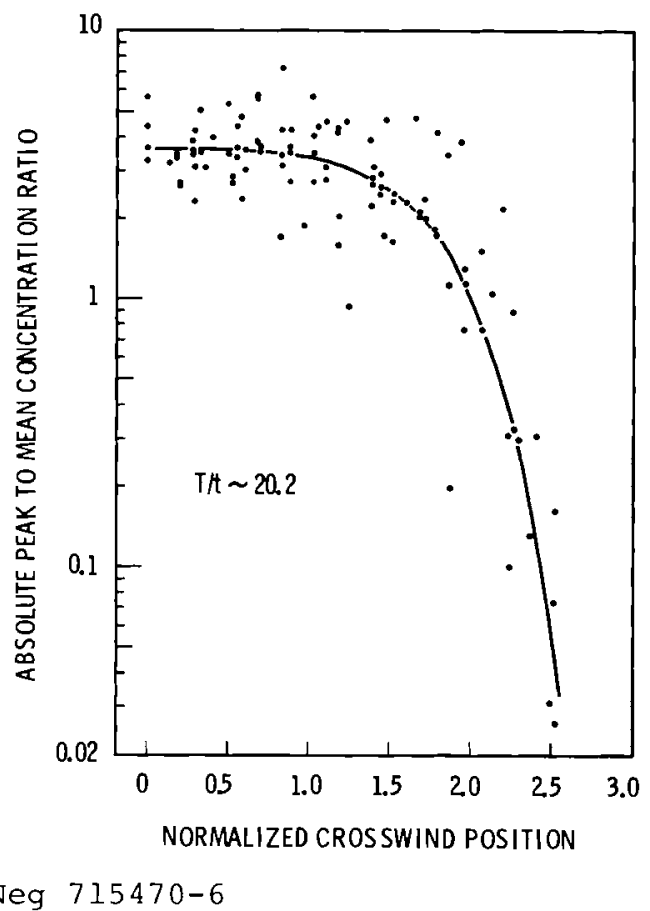

FIGURE 2. Typical Scatter of Absolute Peak-to-Mean Concentration Ratios

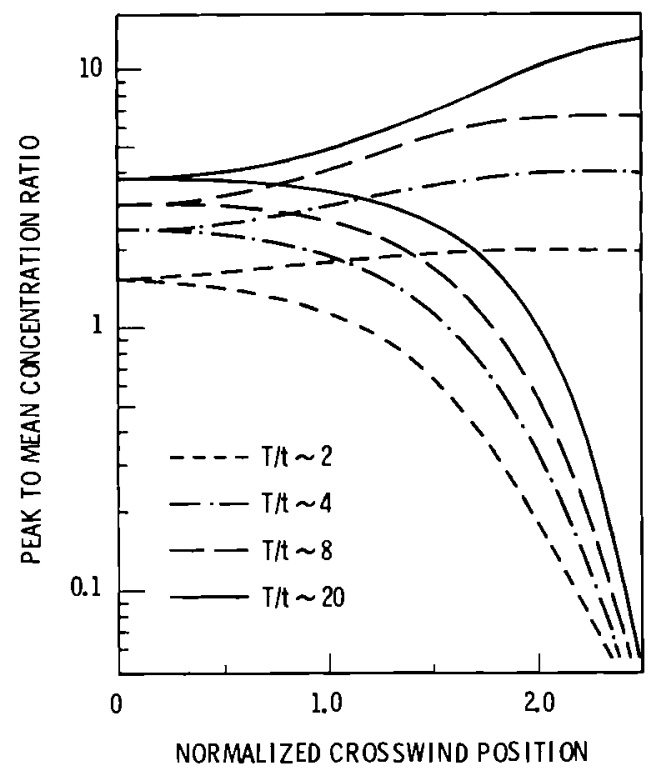

Neg 715470-7

FIGURE 3. Comparison Between Absolute and Conventional Peak-to-Mean Ratios 
the mean plume axis, but there is more than 2 orders of magnitude difference between them at positions $2.5 \sigma_{y}$ from the mean plume axis.

The relationship between absolute peak-to-mean concentration ratios and the time ratio is clearly shown in Figure 4. As with conventional $\overline{\mathrm{P} / \mathrm{M}}$, $\overline{\mathrm{P} / \mathrm{M}}$ monotonically increase with increasing $\mathrm{T} / \mathrm{t}$. Unlike conventional $\overline{\mathrm{P}} / \mathrm{M}$, however, the $\overline{\mathrm{P} / \mathrm{M}} \mathrm{a}$ do not start from a common point at $\mathrm{T} / \mathrm{t}=1$. Rather, $\overline{\mathrm{P} / \mathrm{M}}$ appear to converge at some large value of $\mathrm{T} / \mathrm{t}$.

In the original discussion of peak-to-centerline-mean ratios, an expression was derived relating $\overline{\mathrm{P} / \mathrm{M}_{\mathrm{a}}}$ with crosswind position through Gifford's Fluctuating Plume Model. $(2,3)$ This expression, however, contained many unknown quantities. It is hoped that in the future an empirical or semi-theoretical model can be developed which will permit the prediction of absolute peak-to-mean concentrations.

\section{REFERENCES}

1. J. V. Ramsdell and W. T. Hinds, "Peak-to-Mean Concentration Ratios as a Function of Crosswind Position within the Mean Plume and the Ratio of the Duration of the Mean to the Duration of the Peak, "Pacific Northwest Laboratory Annual Report for 1968, to the USAEC Division of Biology and Medicine, Volume II, Physical Sciences, Part 1. Atmospheric Sciences, BNWL-1051-1, Battelze-Northwest, Richland, Washington, November 1969.

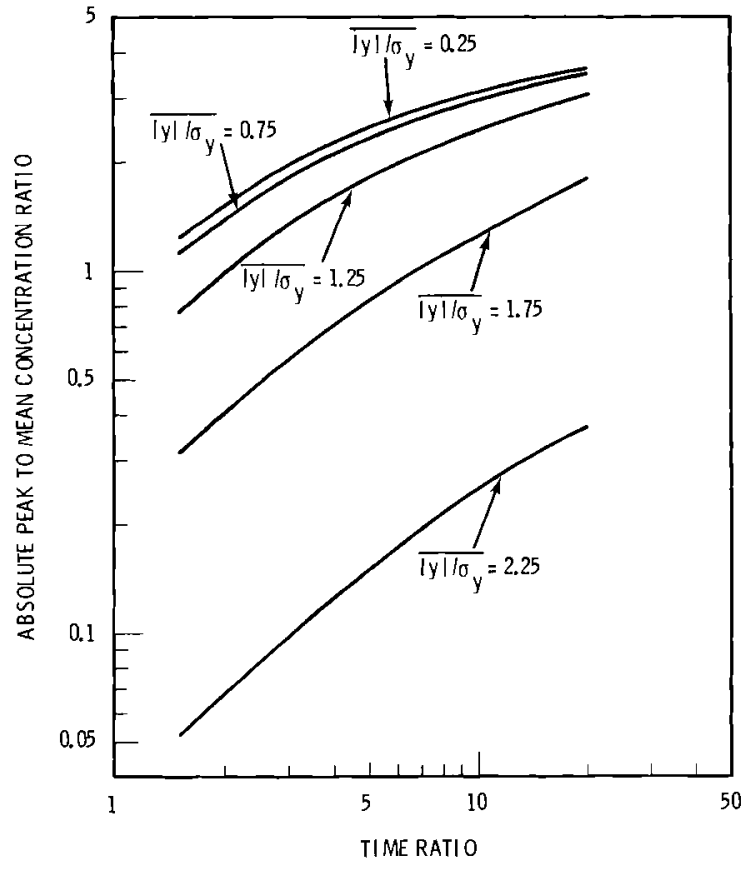

Neg 715456-1

FIGURE 4. Absolute Peak-to-Mean Concentration Ratios as a Function of the Time Ratio

2. F. Gifford, "Statistical Properties of a Fluctuating Plume Dispersion Model," Adv. in Geophysics, vol. 6, Academic Press, New York, pp. 117-137, 1959 .

3. F. Gifford, "Peak to Average Concentration Ratios According to a Fluctuating Plume Dispersion Model," Int. J. Air Poll., vol. 3, pp. $253-260,1960$. 
AN EXTENSION OF THE PEAK-TO-MEAN CONCENTRATION RATIO MODEL

J. V. Ramsdell

The peak-to-mean concentration ratio model developed in 1969 for ground-level plumes is extended to predict ground-level peak-to-mean ratios in elevated plumes.

During 1969 an empirical model was developed which related $\overline{\mathrm{P} / \mathrm{M}}$ ratios to the crosswind position in the mean plume and the ratio between the averaging times for the mean and peak concentrations. (1) This model was based on ground-level measurements of plumes released at ground level and therefore, could not properly be used in connection with problems related to elevated sources. During the past year ${ }^{85} \mathrm{Kr}$ data taken on towers have been used to evaluate the model in prediction of peak-to-mean concentration ratios in elevated plumes.

The original model was developed using the graphical relationships between $\overline{\mathrm{P} / \mathrm{M}}$ and $|y| / \sigma_{y}$, and $\overline{\mathrm{P} / \mathrm{M}}$ and $\mathrm{T} / \mathrm{t}$, as well as the following 4 theoretical considerations as guidelines.

1. At $\mathrm{T} / \mathrm{t}=1, \overline{\mathrm{P} / \mathrm{M}}$ must equal 1 for al1 crosswind positions in the plume.

2. $\overline{\mathrm{P} / \mathrm{M}}$ ratios are a minimum at $|y| / \sigma_{y}=0$.

3. $\overline{\mathrm{P} / \mathrm{M}}$ ratios approach a maximum at large $|y| / \sigma_{y}$.

4. $\overline{\mathrm{P} / \mathrm{M}}$ ratios cannot exceed $\mathrm{T} / \mathrm{t}$ in magnitude.

The final form of the original mode 1 was
$\overline{\mathrm{P} / \mathrm{M}}=1.9 \mathrm{Y}^{2} \mathrm{X}^{4}+0.90 \mathrm{X}^{2}+1.0$

where

$Y^{2}=\tanh ^{2}\left[\frac{|y| / \sigma y}{x+1}\right]$

and

$x^{2}=\ln (T / t)$

An isometric view of the model is shown in Figure 1 .

To extend the $\overline{\mathrm{P} / \mathrm{M}}$ model to elevated sources, it was assumed that the rate at which a ground-level plume diffuses upward and the rate of downward diffusion of an elevated plume are equal. In addition, it was assumed that a cross-section of the plume perpendicular to its axis would be roughly elliptical in shape. With these assumptions in mind, the ${ }^{85} \mathrm{Kr}$ diffusion test was analyzed. Estimates of the standard deviation of the vertical distribution of the tracer $\left(\sigma_{z}\right)$ were obtained using the bivariate normal equation and measured values of the centerline concentration, windspeed, and $\sigma_{y}$. Complete reflection of the plume at the ground was assumed for these estimates. 


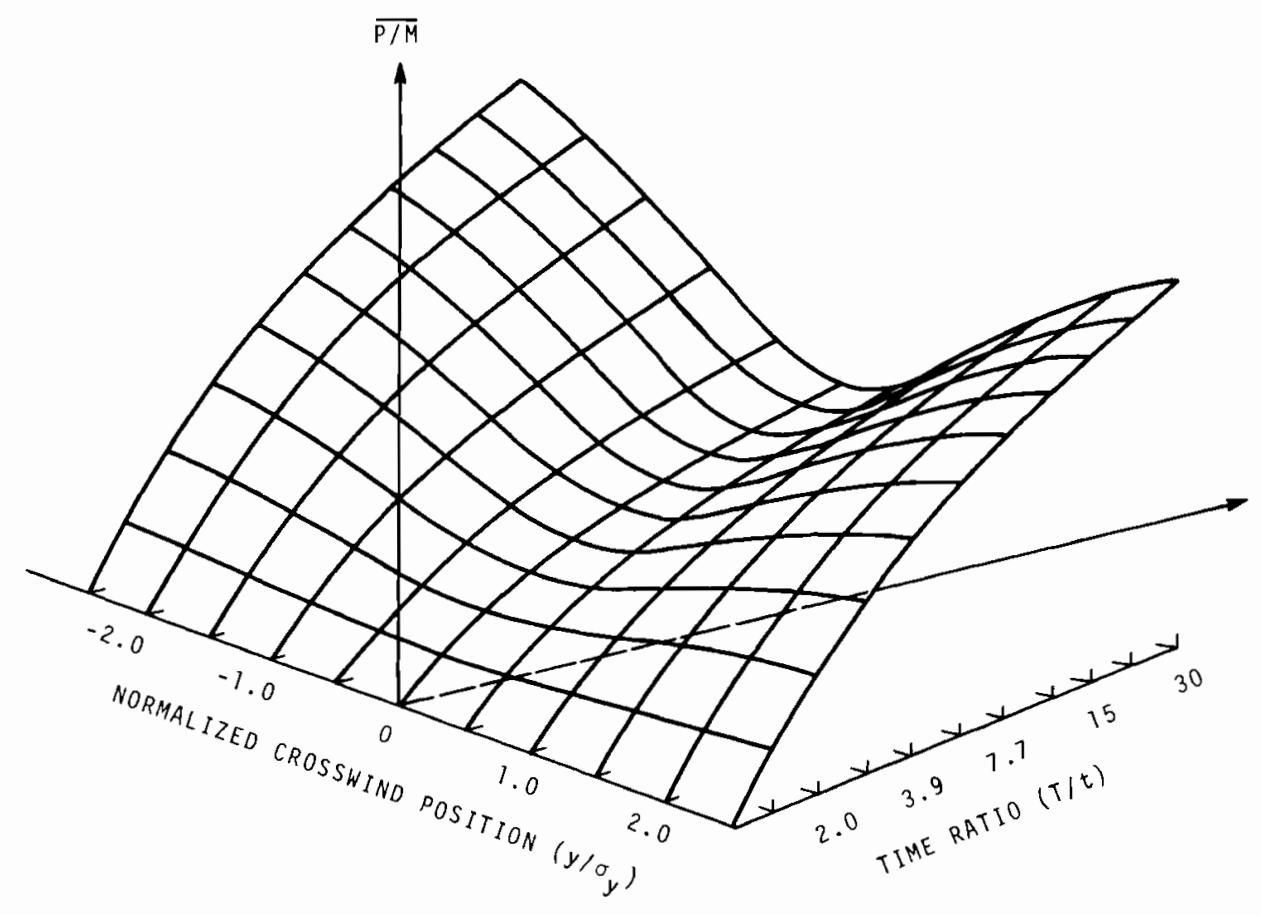

Neg 701409-8

FIGURE 1. Isometric View of the Peak-to-Mean Concentration Ratio Model

The $\overline{\mathrm{P} / \mathrm{M}}$ ratios were grouped by $\mathrm{T} / \mathrm{t}$ and the normalized position of the sampler within the plume, where normalized position is defined as

$r / \sigma_{r}=\left[\left(y / \sigma_{y}\right)^{2}+\left(z / \sigma_{z}\right)^{2}\right]^{1 / 2}$.

At the same time, it was assumed that the crosswind term in the original model could be replaced by a radial position term. That is, the $Y^{2}$ term is replaced with an $R^{2}$.

$R^{2}=\tanh ^{2}\left[\frac{r / \sigma_{r}}{x+1}\right]$

The extended model is then
$\overline{\mathrm{P} / \mathrm{M}}=1.9 \mathrm{R}^{2} \mathrm{X}^{4}+0.90 \mathrm{X}^{2}+1.0$.

To check the validity of the model under these assumptions, the extended mode1 was used to predict a $\overline{\text { P/M }}$ corres ponding to each of the observed values.

The peak-to-mean ratios predicted by the model were reasonably close to the observed values as shown in Figure 2. A tendency of the initial model to over predict $\overline{P / M}$ ratios at large $|y| / \sigma_{y}$ and small $\mathrm{T} / \mathrm{t}$ is still evident as the data tend to drop below the line in the middle of the P/M ratio range. But, the most important feature of Figure 2 is that in no case did the 


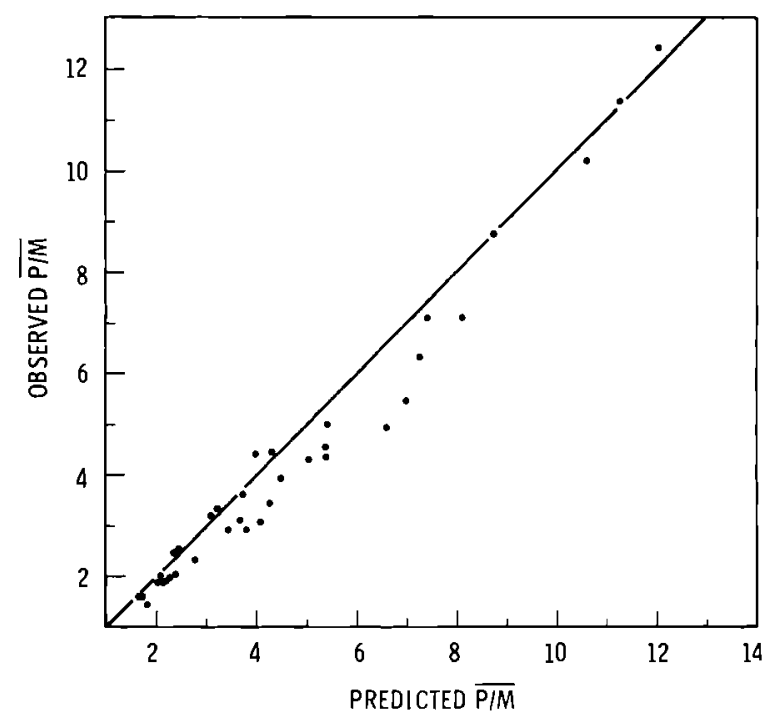

Neg 715470-2

FIGURE 2. Correlation of Predicted and Observed Peak-to-Mean Ratios model significantly under predict a $\overline{\mathrm{P} / \mathrm{M}}$ ratio. Some caution in use of the extended model is still in order, however, as the vertical extent of the data was 1 imited to $z / \sigma_{z} \leq 1.1$.

\section{REFERENCE}

1. J.V. Ramsdell, "Modeling Peak-toMean Concentration Ratios in Diffusing Plumes," Pacific Northwest Laboratory Annual Report for 1969 , to the USAEC Division of Biology and Medicine, Volume II, Physical Sciences, Part 1. Atmospheric Sciences, BNWL-1307-1, BattelieNorthwest, Richland, Washington, June 1970 .

\title{
TRACER PARTICLE RESUSPENSION CAUSED BY WIND FORCES UPON
}

AN ASPHALT SURFACE

G. A. Sehme 1

\begin{abstract}
Particle resuspension rates caused by wind stresses upon dry tracer particles were determined in field tests on an asphalt surface. For average windspeeds from 2 to $9 \mathrm{mph}$, the fraction of tracer resuspended/sec was from $5 \times 10^{-9}$ to $6 \times 10^{-8}$. For average windspeeds from 3 to $14 \mathrm{mph}$, the fraction of tracer resuspended increased when a man walked once through the tracer. The fraction resuspended per walk through was from $1 \times 10^{-5}$ to $7 \times 10^{-4}$.
\end{abstract}

The resuspension into the atmosphere of deposited particulate material presents potential inhalation hazard prob- lems. Unfortunately, 1ittle is known about the effectiveness of the wind to raise deposited contaminants into the 
air from the surface. It is clear, however, that the properties of the atmosphere, the properties of the surface, and the properties of the particulate contaminants are al1 important to the problem.

Initial experiments were performed in the field to determine wind-caused or-aided particle resuspension rates. The current site for some resuspension experiments is shown schematically in Figure 1. Shown is an asphalt surface onto which tracer ZnS particles were placed and a downwind air and ground deposition sampling grid for measuring resuspended particles. Not shown are the meteorological instrumentation and the real-time samplers (1) for measuring airborne $\mathrm{ZnS}$.
The meteorological instrumentation located at the asphalt edge were a vector-vane at the $4 \mathrm{ft}$ height and two separate three cup-anemometers at the $1 \mathrm{ft}$ height. At the $10 \mathrm{ft}$ distance, integrating anemometers were located at heights of $13 \mathrm{in.,} 4 \mathrm{ft}$, and $7 \mathrm{ft}$ to determine the average stress.

Particle resuspension rates were determined by using a mass balance around the initial $\mathrm{znS}$ placed on the aspha1t, the air and ground exposures, and the sampling time. Average particle resuspension rates were determined to be from $5 \times 10^{-9}$ to $6 \times 10^{-8}$ fraction resuspended/sec for average wind speeds from 2 to $9 \mathrm{mph}$. The dependency upon windspeed is yet to be determined. Nevertheless, a very

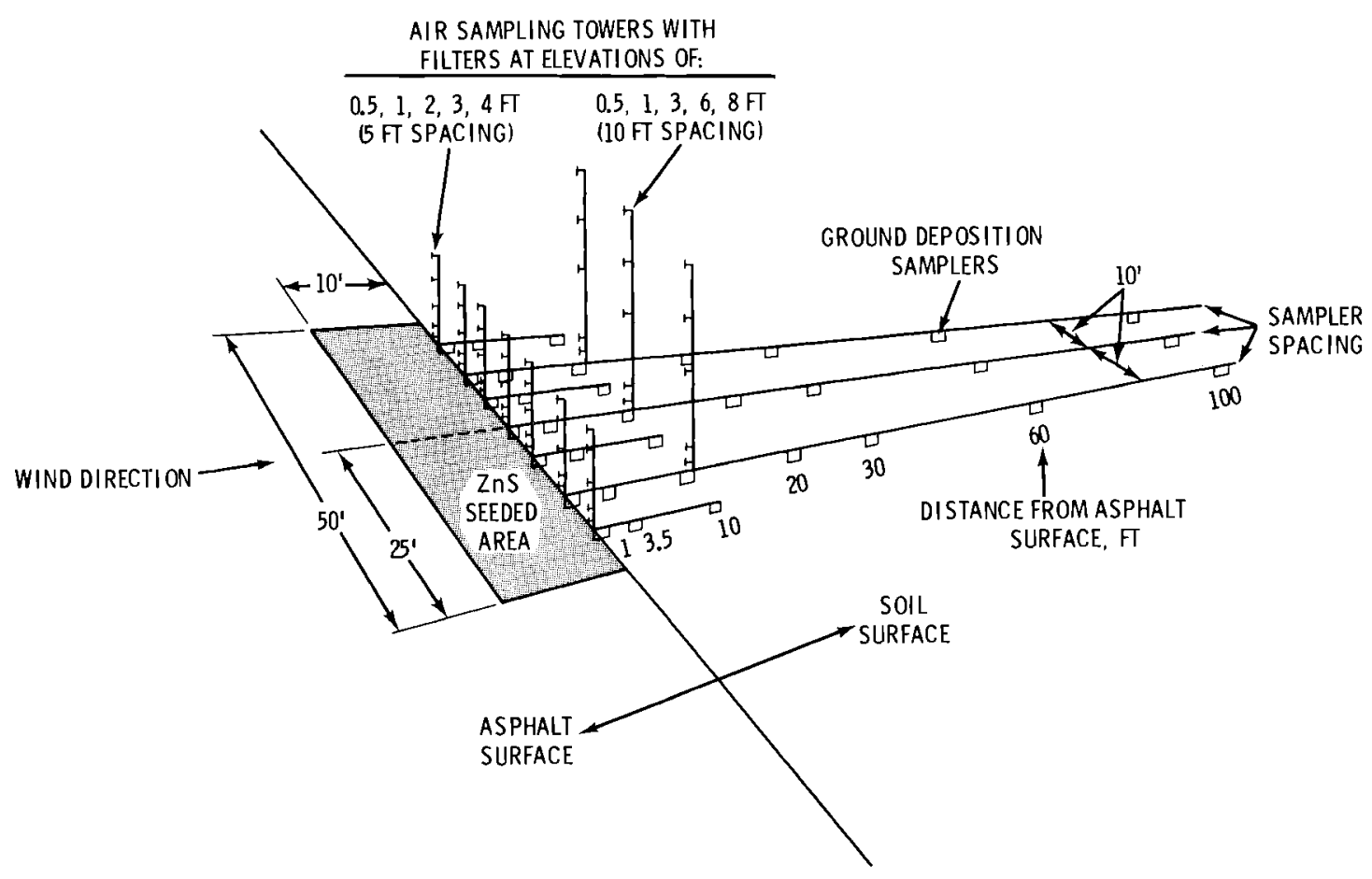

Neg 720056-3

FIGURE 1. Schematic Showing Experimental Design for

Particle Resuspension from an Asphalt Surface Caused by

Wind Stresses 
rough windspeed effect was suggested by an apparent correlation between wind gusts and the response of the real-time sampler. There is some indication that wind gusts greater than about $15 \mathrm{mph}$ rapidly resuspended particles. This apparent correlation will be investigated more fully by magnetic tape recording of the signal outputs and determining the correlations.

Forces in addition to wind stresses can increase the particle resuspension rate. One such force is the mechanical disturbance of a man walking down the $50 \mathrm{ft}$ length of tracer. In this case, the resuspension rate is the fraction of particles resuspended each time the person walks through the tracer. For windspeeds of 3 to $14 \mathrm{mph}$, these resuspension "rates" were determined to be from $1 \times 10^{-5}$ to $7 \times 10^{-4}$ fraction resuspended per walk through. This addition of mechanical force appears to cause more rapid particle resuspension.

\section{REFERENCE}

1. P. W. Nickola, M. D. Rankin, M. F. Scoggins and E. M. Sheen, "A System for Recording Air Concentrations of Zinc Sulfide Fluorescent pigments on a Real-Time Scale," J.Applied Meteorology, vol. 6, No.2, pp.430-433, 1967.

\section{SOIL RESUSPENSION BY SURFACE "CREEP"}

\section{G. A. Sehmel and F. D. Lloyd}

A sampler was tested for measuring particle resuspension by surface creep. The sampler collects particles from at least zo to $205 \mu \mathrm{m}$ in diameter.

Soil erosion by wind forces has been classified ${ }^{(1)}$ as soil particle movement by suspension, saltation and surface creep. Particles moving in surface creep are large in diameter and move on or very close to the ground surface. A surface creep sampler has been designed and tested for measuring this surface creep.
Bagnold's (1) original design for measuring surface creep was a smal1 bottle recessed into the ground. The bottle cap had a small hole through which the surface creep particles fell and were collected in the bottle. This bottle design was satisfactory for measuring gross soil and sand movement since the collected sand and 
soil were easily analyzed by gravimetric methods. In contrast, the problem of analysis and representative sampling of radioactivity resuspension by surface creep is more difficult. Firstly, a larger ground surface should be measured for surface creep in order to obtain the average surface creep from any "hot spots" of contamination. Secondly, a sufficiently large mass of sand moving by surface creep must be collected in order that the minute quantities of radioactivity in the sample can be analyzed to be greater than background.

A surface creep sampler was constructed which is a $2 \mathrm{ft} \times 2 \mathrm{ft} \times 1 \mathrm{in}$. deep $(61 \mathrm{~cm} \times 61 \mathrm{~cm} \times 2.5 \mathrm{~cm})$ open topped box. Dividers are placed in the box on 1 in. centers in order to form a gridwork of 1 in. $\times 1$ in. open topped squares within the larger box. The sampler bottom was closed with masking tape which was cut away from each square in order to remove the particles within each square.

The sampler was tested in a clear area near the meteorology building. It was placed in the sand so that the top of the box was approximately at ground level. The sampler collected particles for several days.

After particle collection, the sampler was removed and analyzed for the relative mass loading in each smal1 square and for the particle size distribution in the squares along the upwind edge of the sampler and at the middle of the sampler.

The mass collected in each small square has been normalized to the mass collected along the upwind edge. These relative particle collections in each individual square are shown in Figure 1. The collection is seen to decrease

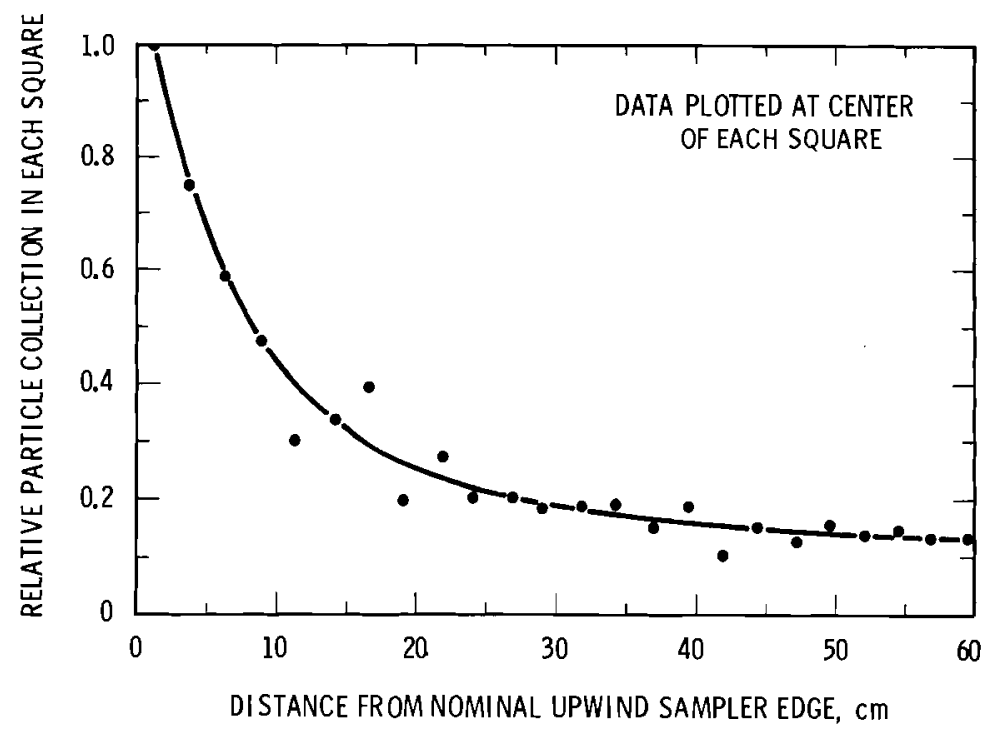

Neg 715857-2

FIGURE 1. Surface Sampler Total Mass Collection Profile 
rapidly with downwind distance. Apparently, the large decrease must be caused by many particles actually "rolling" into the edge squares and fewer particles being airborne for short "jumps" into the downwind squares.

The particle diameters collected by the surface sampler were determined with a series of screens in a sonic sifter (Allen Bradley Co.). The particle size distributions from this sieving is shown in Figure 2. The mass median particle diameter along the upwind edge is $136 \mu \mathrm{m}$ while the mass median particle diameters is 108 $\mu \mathrm{m}$ at the center of the sampler. Obviously, the sampler does show a size as well as mass sampling bias from the upwind edge. This bias is considered to be negligible compared to the more difficult problem of closing a mass balance around resuspending radioactive particles.

This surface sampler does collect particles at least from 20 to $25 \mu \mathrm{m}$ in diameter. The smaller respirable particles which are the initial does-to-man hazard may be collected, but too little sand mass was collected for analysis.

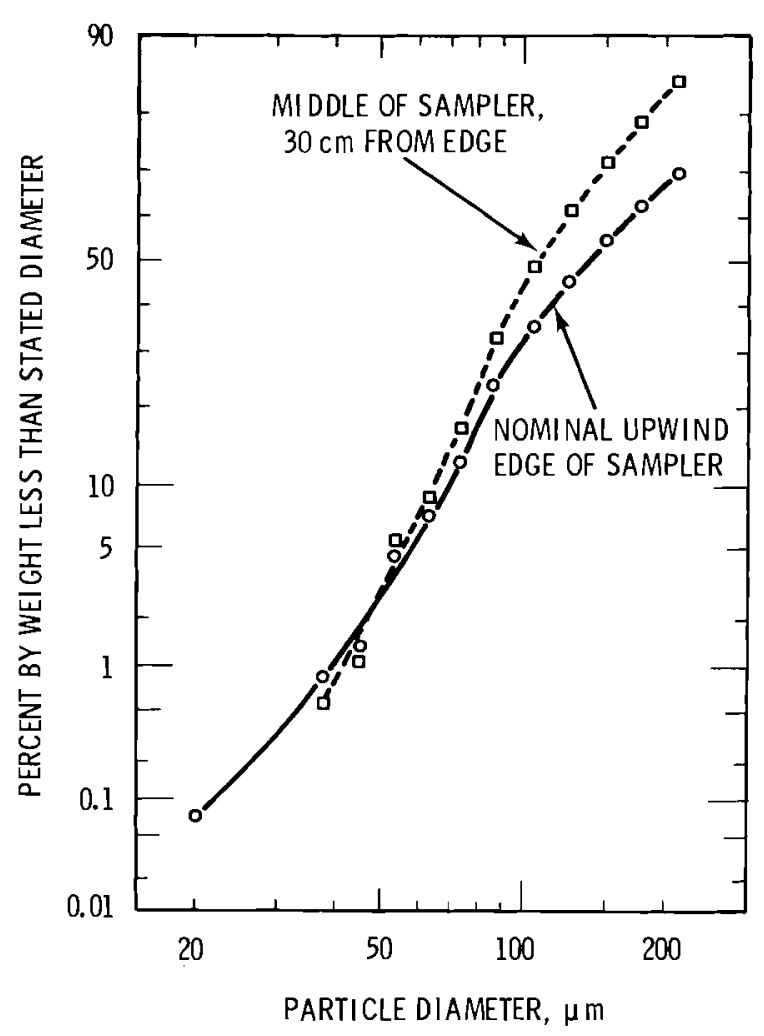

Neg $715857-4$

FIGURE 2. Particle Size Distribution of Sand Collected in Surface Sampler

\section{REFERENCE}

1. R. A. Bagnold, The Physics of Blown Sand and Desert Dunes, Methuen and Co., Ltd., London, 1954 . 


\title{
SOIL RESUSPENSION BY "SALTATION"
}

\author{
G. A. Sehmel and F. D. Lloyd
}

\begin{abstract}
A sampler for collecting particles moving by saltation was constructed and its performance measured in the field. Most soil movement occurs within $1 \mathrm{ft}$ of the ground surface. Particle exposures as a function of height are interpreted to show that the concentration of respirable size particles decreases 1 to 1.5 order of magnitude within $1 \mathrm{ft}$.
\end{abstract}

Soil erosion by wind forces has been classified (1) as soil particle movement by suspension, saltation, and surface creep. Particles moving in saltation are initially lifted almost vertically into the air before the gravitational force causes deposition. Saltation is by a series of "jumps" or "hops" to various heights and downwind distances.

An omni-directional saltation sampler has been tested in the field for total mass collection and particle size distribution as a function of height. The sampler is shown schematically in Figure 1. The sampler is constructed from metal funnels with a maximum diameter of $16 \mathrm{~cm}$. The funnel outlet has been cut-off, inverted, and resoldered to form collection cups for particles. Typical sand collection pathways are shown by the dotted 1 ines. The particles enter into each section and are collected as the sand accumulation shown in the figure. The present assumption is that collection efficiency is 100 percent.

The particles collected in the sampler after several days in the field were analyzed for the vertical profile of mass collected and also the particle size distributions. The particle mass collection has been normalized in

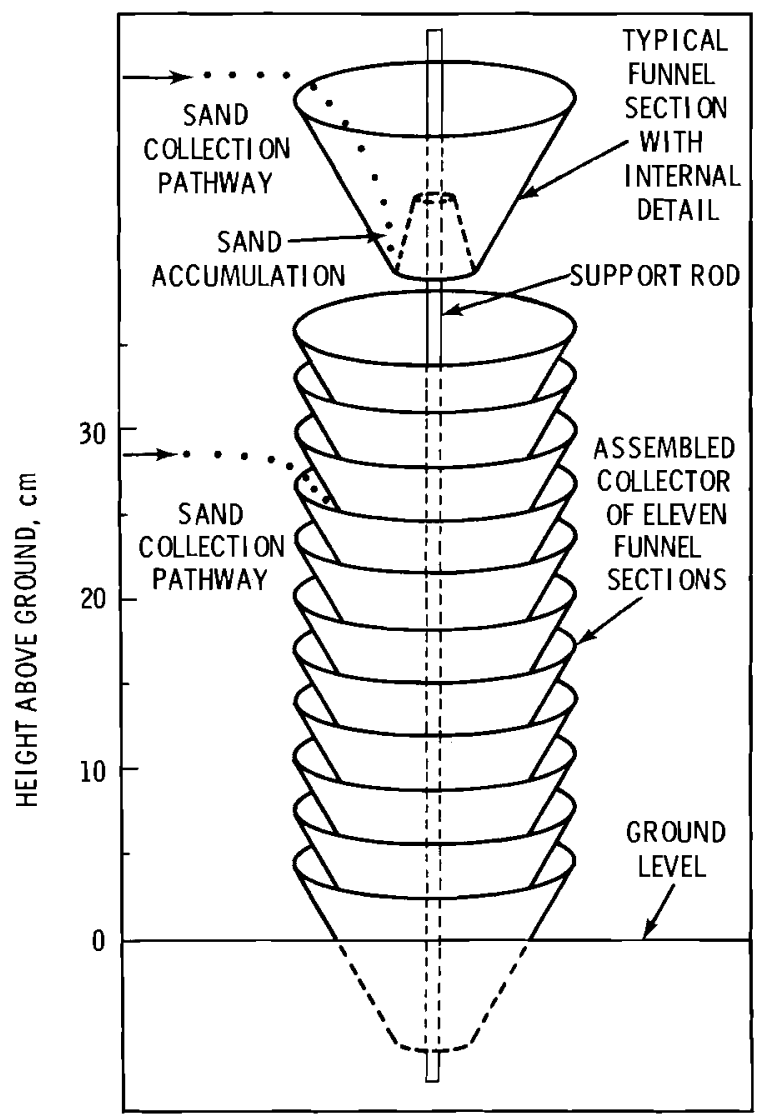

Neg 720056-2

FIGURE 1. Schematic of Funnel collector 
Figure 2 to show the mass fraction collected in the funnel sampler as a function of height. The curve shows that most of the particle mass is collected close to the ground level. This is consistent with Bagnold $(1)$ and Chepil (2) who showed that over 90 percent of soil movement occurs below a height of 12 in. $(30 \mathrm{~cm})$.

The particle size distributions have been determined by sieving (sonic sifter, Allen Bradley Co.) the particles collected on each funnel or series of funnels. These distributions are shown in Figure 3 . The mass medium particle diameters are from 140 to $200 \mu \mathrm{m}$, and are a function of height.

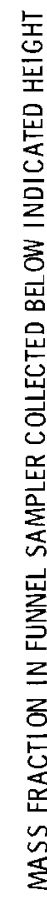

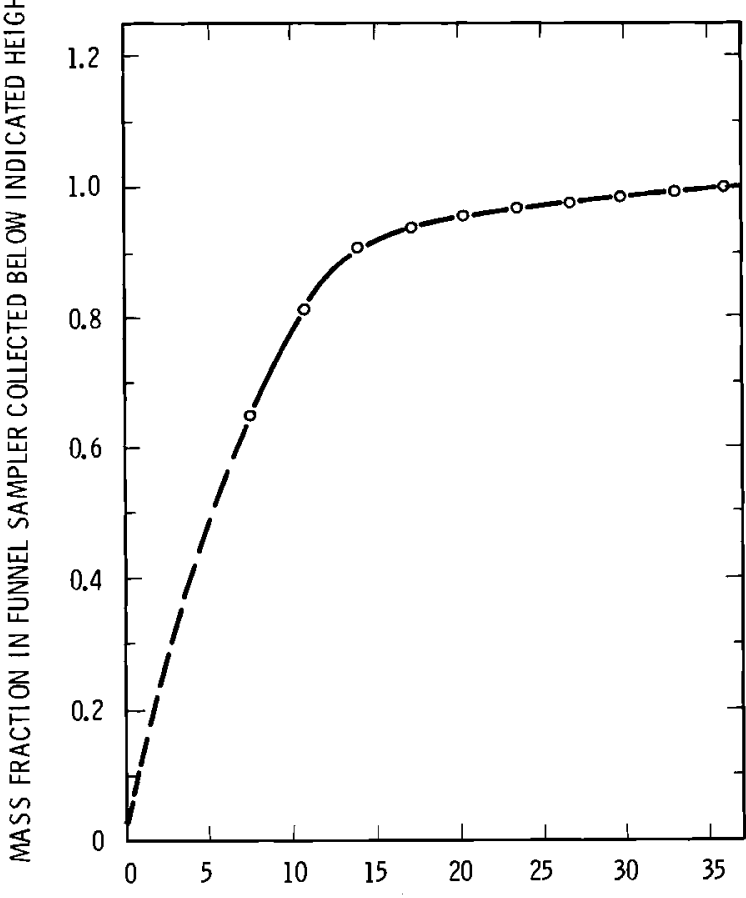

HEIGHT ABOVE GROUND, CM

Neg 715857-3

FIGURE 2. Funnel Sampler Particle Collection Profile
The exposure (particle collection per unit height) is shown in Figure 4 for several particle size ranges. The exposures decrease rapidly with height and show a 1 to about 1.5 order of magnitude decrease to a height of $30 \mathrm{~cm}$. Although similar rapid decreases have been reported by Chepil for total soil exposure, these are the first data that show the effect of particle diameter on exposure. If the assumption is made that these curves can be extrapolated to smaller respirable particle diameters, the conclusion is that respirable particles also show a rapid decrease with height in the first 12 in.

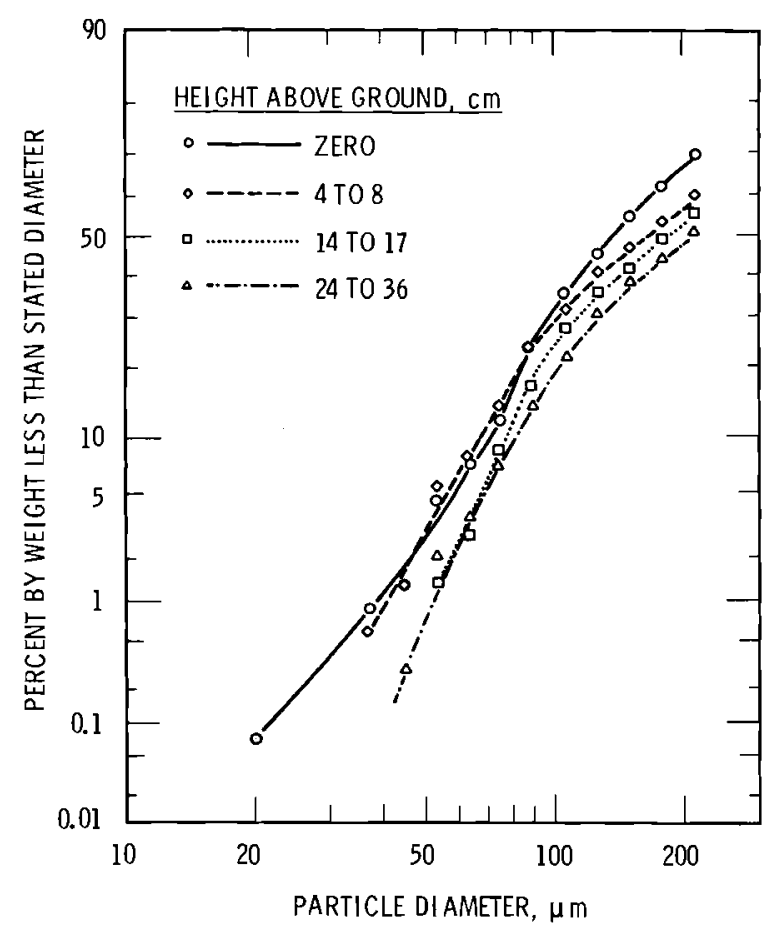

Neg 715857-1

FIGURE 3. Particle Size Distribution of sand collected as a Function of Height Above Ground 


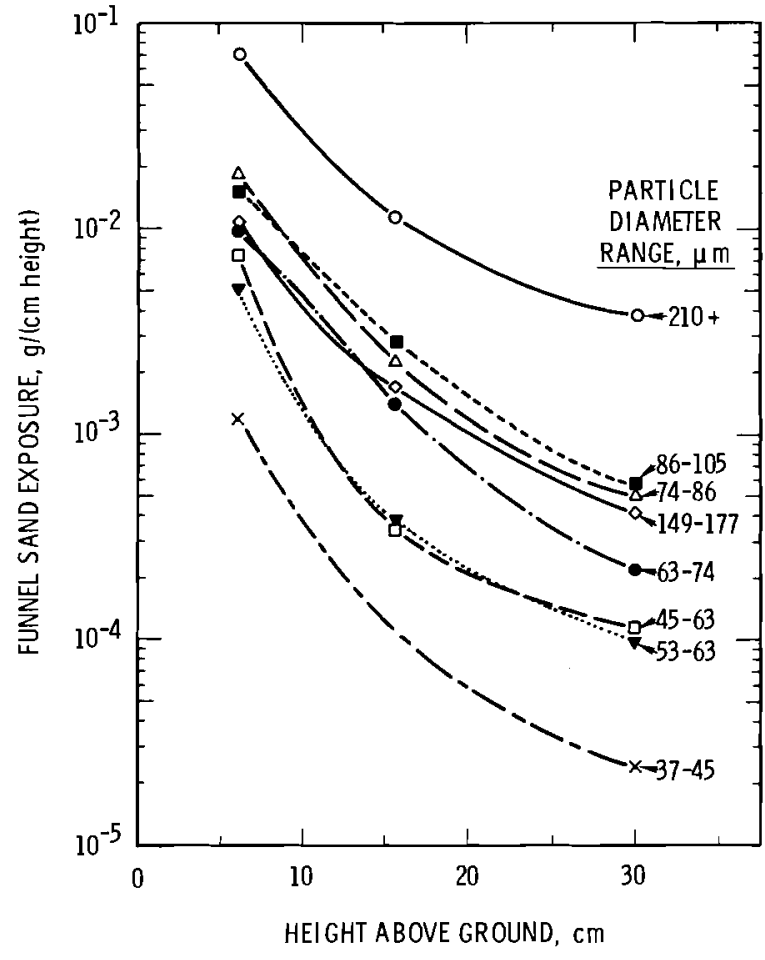

Neg 715857-1

FIGURE 4. Funnel Sand Exposure as a Function of Particle Diameter
$(30 \mathrm{~cm})$. This rapid decrease is unexpected since particle concentrations of 20 to $60 \mu \mathrm{m}$ in diameter have been shown to decrease less than one order of magnitude (3) from 1 to $400 \mathrm{ft}$.

\section{REFERENCES}

1. R. A. Bagnold, The Physics of Blown Sand and Desert Dunes, Methuen and Co., Ltd., London, 1954.

2. W. S. Chepiz, Dynamics of Wind Erosion: I. Nature of Movement of Soil by Wind, Soil Sci., vol. 60 , pp. 305-320, 1945 .

3. G. R. Hilst and P. W. Nickola, "On the Wind Erosion of Small Particles," Bulzetin of the Ameri-

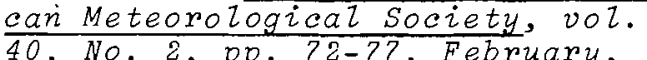
1959 .

\title{
AIRBORNE DUST CONCENTRATIONS
}

G. A. Sehmel and F. D. Lloyd

\begin{abstract}
An Airborne dust concentration of $189 \mathrm{mg} / \mathrm{m}^{3}$ occurred during the high winds on January 11, 1972. This dust concentration at an average wind speed of $29 \mathrm{mph}$ is used to extrapolate airborne dust loadings measured in 1950 for wind speeds less than 18 mph.
\end{abstract}

The resuspension of radioactive particulate from soil surfaces is intimately related to the airborne soil particle concentrations. Airborne soil particle concentrations were measured during the severe wind storm of January 11,1972 . 
A $20 \mathrm{cfm}$ high-volume air sampler with a 12 in. diameter particle impactor was placed with the impactor facing into the wind. The lower impactor edge was about 4 in. above ground level. Particles were sampled for two hours, which resulted in 12.88 $g$ of soil being collected. This quantity of material overloaded the impactor and consequently a particle size distribution of the airborne soil cannot be presented. This dust loading corresponds to an average dust concentration of $189 \mathrm{mg} / \mathrm{m}^{3}$.

The wind velocities Juring the test period are shown in Table 1 . The integrated average wind velocity is $29 \mathrm{mph}$.

\begin{tabular}{ccc}
\hline \multicolumn{3}{c}{ TABLE 1. Wind Record } \\
Time & $\frac{\text { Wind Velocity, mph }}{\text { Average }}$ & Maximum Gust \\
\cline { 3 - 3 } 1335 & 32 & 50 \\
1405 & 34 & 44 \\
1435 & 30 & 36 \\
1505 & 21 & 27 \\
1535 & 27 & 32 \\
\hline
\end{tabular}

For comparison purposes, airborne dust concentrations recorded at the $4 \mathrm{ft}$ elevation during 1950 are shown in Figure 1. The dust concentrations

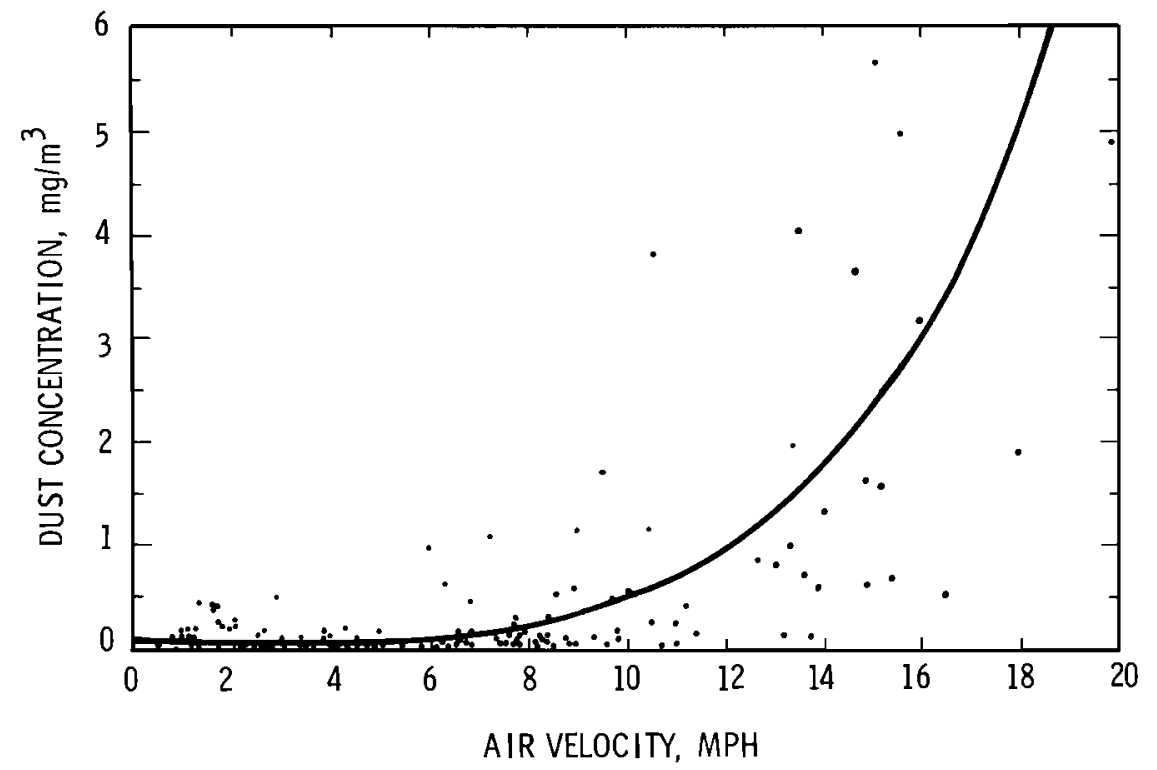

Neg 720207-2

FIGURE 1. Airborne Dust Concentration as a Function of Air Velocity (Dust measured at 4-ft elevation, Hanford 1950) 
do show a considerable scatter, nevertheless an exponential dependency upon wind velocity is suggested. Consequently, the smoothed curve is redrawn in Figure 2 on $\log \log$ coordinates. Also shown is the $189 \mathrm{mg} / \mathrm{m}^{3}$ dust concentration during the January 11, 1972 dust storm. Based upon current knowledge, it appears reasonable to extend the 1950 curve to the current data point.

Dust concentrations are also a function of height. Thus, the comparison of concentrations at the 1 and $4 \mathrm{ft}$ level may be biased. Nevertheless, it would appear reasonable to expect similar rapid increases of dust concentrations with wind velocity for any height. These dust concentrations as a function of height and particle size will be determined.

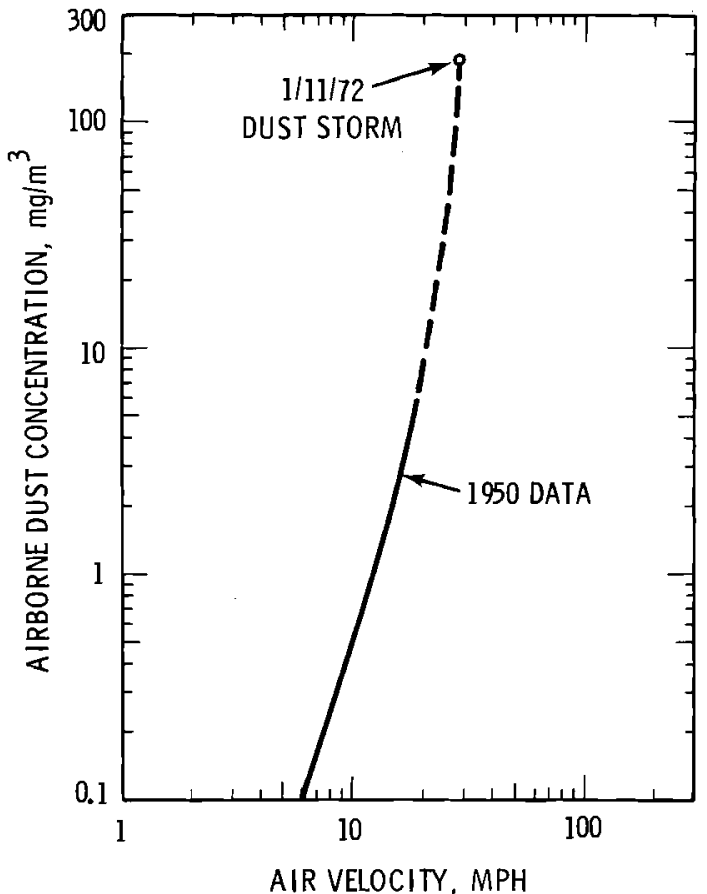

Neg 720207-1

FIGURE 2. Airborne Dust Concentration as a Function of Average Air velocity 


\title{
PARTICLE RESUSPENSION FROM AN ASPHALT ROAD CAUSED
}

\section{BY VEHICULAR TRAFFIC*}

G. A. Sehmel

\begin{abstract}
Particle resuspension rates were determined for $2 n S^{*}$ particles which were placed onto one lane of a two lane, seasoned asphalt road. Either a car or a $3 / 4$ ton truck was driven through the deposited material or in the adjacent lane. The fraction of particles resuspended for one vehicle pass was determined for vehicle speeds of $5,15,30$, and $50 \mathrm{mph}$. The fraction resuspended per vehicle pass ranged from $10^{-5}$ to $10-2$ with the higher resuspension corresponding to higher vehicle speeds and driving directly through the deposited $2 n S$.
\end{abstract}

Particle resuspension from roads caused by vehicular traffic can produce downwind health or environmental hazards. These hazards include those due to the dose-to-man inhalation hazard of radioactive particles as we11 as airborne salt and lead damage on trees and vegetation near roads.

Particle resuspension from a dry seasoned asphalt road was determined(1) using the field grid schematically shown in Figure 1. The important features are a wind blowing across the road into the particle sampling grid consisting of filters on air sampling towers and ground deposition samplers. These samplers collected particles after the vehicles were driven through the lane onto which ZnS was placed or after the vehicles

\footnotetext{
* This related resuspension research was supported in part by the Atrantic Richfield Hanford Company's Environmental and Regulatory Technology Program.
}

were driven by on the adjacent 1 ane. Concurrently, the air velocity profile was measured with the meteorological tower.

The tracer particle was phosphorescent $\mathrm{ZnS}$ * which has a theoretical density of $4.1 \mathrm{~g} / \mathrm{cc}$, a mass medium diameter of about $5 \mu \mathrm{m}$, and a number medium diameter of about $2 \mu \mathrm{m}$. This material was selected since $\mathrm{znS}$ can be non-destructively and rapidly analyzed (2) on the filters using a phosphorescent technique.

The fraction of particles resuspended per vehicle passage is shown in Figure 2 for data obtained on the same day that the $\mathrm{ZnS}$ was placed on the road. The fraction resuspended increases with vehicle speed. Of particular interest is that the slope of

\footnotetext{
* Zns Type 2210, United States Radium Corporation.
} 


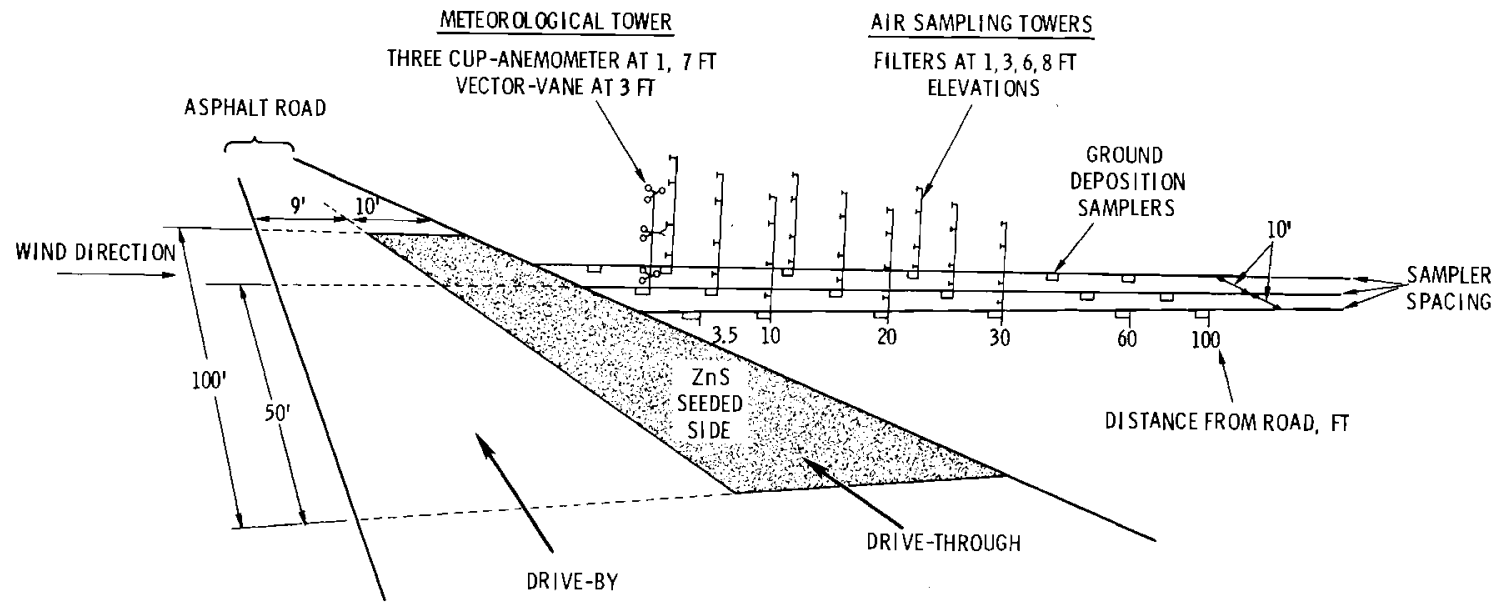

Neg 714275-1

FIGURE 1. Schematic Showing Experimental Design for Particle Resuspension from an Asphalt Road Caused by Vehicle Passage

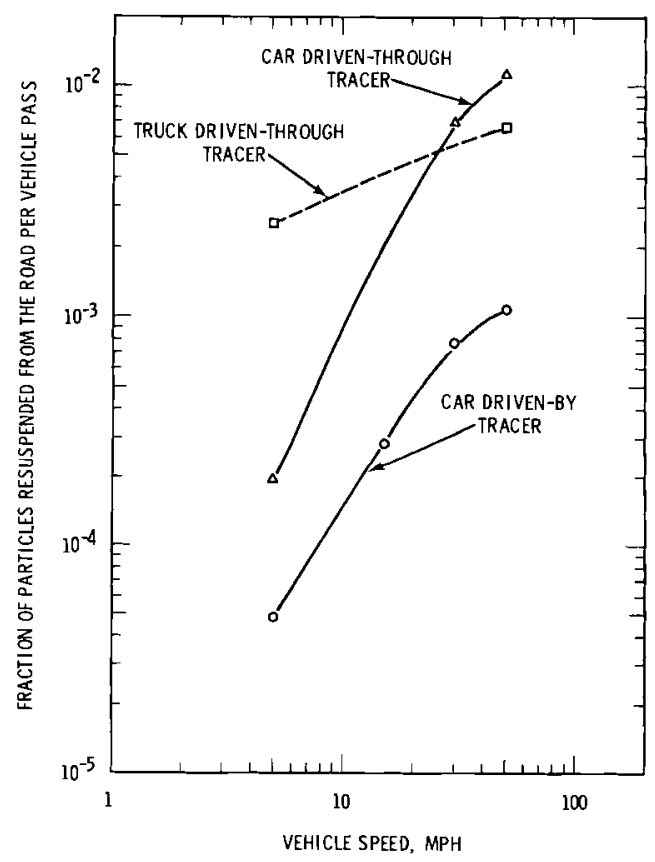

Neg 715289-3

FIGURE 2. Particle Resuspension Rates from an Asphalt Road Caused by Vehicle Passage the curve for a car driven through the tracer is approximately two. That is, the fraction resuspended is proportional to the car generated turbulence.

The fraction resuspended is from $10^{-5}$ to $10^{-2}$ and shows that resuspension decreased nearly an order of magnitude when the vehicle is driven by the tracer as compared to the vehicle driven through the tracer.

\section{REFERENCES}

1. G. A. Sehmel, "Particle Resuspension from Asphalt Roads caused by Car and Truck Traffic," accepted for Atmospheric Environment.

2. M. O. Rankin, Zinc Sulfide Particle Detector, HW-55917, Hanford Laboratories, General Electric Co., Richland, Washington 1958. 


\title{
DEPOSITION VELOCITIES IN A WIND TUNNEL
}

\author{
G. A. Sehmel and S. L. Sutter
}

\begin{abstract}
Deposition velocities for monodispersed particles were measured for deposition onto a smooth electrically grounded brass surface located on the floor and ceiling of a wind tunnel. The deposition on both the floor and ceiling shows that re-entrainment from a coated surface. occurs at about $9 \mathrm{\mu m}$ for a $30 \mathrm{mph}$ windspeed. For the ceiling, re-entrainment of $4 \mathrm{um}$ particles occurs from a dry surface. A model will be developed from the deposition velocity data to predict the effect of gravity on observed deposition.
\end{abstract}

Wind tunnel studies were conducted to determine the deposition velocities of uniform diameter particles from turbulent air flow onto a smooth surface. The deposition velocity, $K_{1}$, is defined as the particle deposition flux divided by the airborne particle concentration at $1 \mathrm{~cm}$ distance from the surface. This small distance is used to better define the controlling mass transfer resistance at the surface. The current deposition surface is an electrically grounded, smooth, brass shim stock which is placed either on the floor or the ceiling of the $2 \mathrm{ft} \times 2 \mathrm{ft}$ cross section wind tunne 1 .

Particle deposition onto the dry surface has been extended to larger particles for the $15 \mathrm{mph}$ wind velocity and to sub-micron particles for the $30 \mathrm{mph}$ wind velocity. The smoothed curves are shown in Figure 1 . A1so shown is a curve at $30 \mathrm{mph}$ for deposition onto a brass surface which

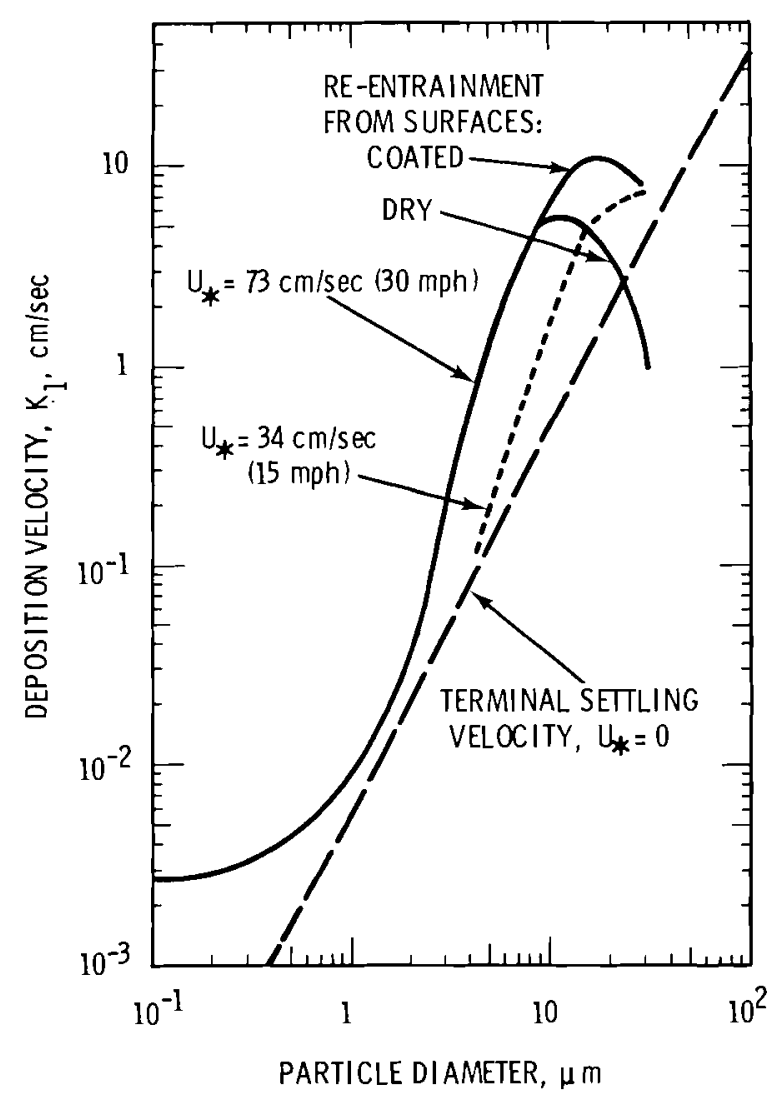

Neg 715858-1

FIGURE 1. Deposition Velocities onto the Top of a Smooth Surface 
has been treated with a thin layer of petroleum jelly to minimize particle re-entrainment. Inspection of the two solid curves at $30 \mathrm{mph}$, shows that particle re-entrainment begins at about $9 \mu \mathrm{m}$ for the dry surface and at about $14 \mu \mathrm{m}$ for the coated surface. The curve for the sub-micron particles is presently being better defined with additional data points. Once defined, all the experimental data will be processed to better predict eddy diffusivities (1) and deposition velocities.

The particle deposition flux is described by

$$
N=-(\varepsilon / v+D / v) u_{*} \frac{d C}{d z^{\mp}}-v_{t} C,
$$

in which $\varepsilon$ is the particle diffusivity, $D$ is the Brownian diffusivity, $v$ is the kinematic viscosity of air, $z^{+}=z u_{*} / v$ is the dimensionless distance above the surface, and $v_{t}$ is the terminal settling velocity. Previously, the assumption has been made that the particle eddy diffusivity is independent of gravity. This independency is being experimentally determined.

The deposition velocity of particles depositing onto smooth brass placed on the wind tunnel ceiling is shown in Figure 2. These data will be used in conjunction with the completion of data for Figure 1 to predict the effect of gravity on particle eddy diffusivities near surfaces. This gravitational effect is important in predicting particle deposition to the many geometries of environmental surfaces.

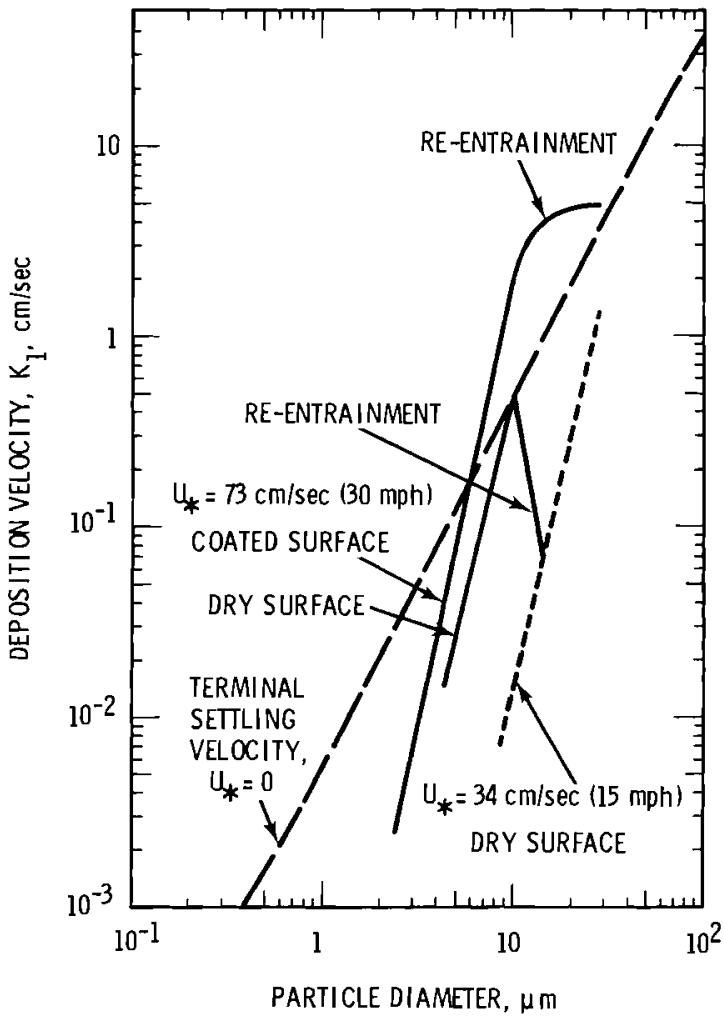

Neg 715858-2

FIGURE 2, Deposition Velocities onto the Bottom of a Smooth Surface

(Gravity Opposing Deposition)

Particle deposition velocities to the ceiling show the same functional increase with particle diameter as for deposition on the floor. The principle differences are that the deposition velocities are less and that particle re-entrainment occurs more readily from the ceiling. Particle re-entrainment occurs for $4 \mu \mathrm{m}$ diameter particles (and smaller) at a wind speed of $30 \mathrm{mph}$.

Particle deposition to the ceiling shows the same maximum at about $9 \mu \mathrm{m}$ as for deposition for the floor. These maxima for a $30 \mathrm{mph}$ wind speed show that the gravitational force 
can have a minor effect on particle deposition for some circumstances.

A gravel surface is the next surface to be experimentally studied in the wind tunnel. This surface is chosen, (1) to more realistically model the rougher environmental surfaces, and (2) to develop deposition velocity data for a "true suspension" deposition sampler which will be used in closing the airborne particle mass balance for plutonium resuspension rate experiments .

\section{REFERENCE}

1. G. A. Sehmel," Particle Diffusivities and Deposition Velocities Over A Horizontal, Smooth Surface," J. of Colzoid and Interface Science, vol. 37 , no. 4, pp. 891-906, 1971.

DEPOSITION VELOCITIES AS A FUNCTION OF PARTICLE CONCENTRATION

REFERENCE HEIGHT AND ATMOSPHERIC STABILITY

G. A. Sehmel and T. W. Horst

\begin{abstract}
Deposition velocities were calculated from a model based upon particle effective eddy diffusivities being greater than the eddy diffusivities of air momentum in the region closer than $1 \mathrm{~cm}$ to the deposition surface. These predicted deposition velocities are used to determine the relative constancy of deposition velocity when the height for defining the particle concentration is increased from $1 \mathrm{~cm}\left(K_{1}\right)$ to $10 \mathrm{~m}\left(K_{2}\right)$. The ratio $K_{z} / K_{1}$ is nearly unity for stable, unstable, and adiabatic atmospheres.
\end{abstract}

A particle eddy diffusivity model has been developed $(1)$ to predict particle deposition velocities for the lower limit of deposition velocities which might be expected in the atmosphere. This is the case of deposition onto a smooth surface. The model shows that the effective particle eddy diffusivity becomes increasingly greater than that for air momentum as the particle approaches the surface from a $z^{+}$of about 20 . That model has been used to predict deposition velocities, $K_{1}$, when the particle concentration reference height is $1 \mathrm{~cm}$ above the deposition surface. The purpose here is to take the results of that model and to investigate the 
behavior of deposition velocities when the particle concentration reference height increases to $10 \mathrm{~m}$ and the particle eddy diffusivity is equal to that of air between $1 \mathrm{~cm}$ and $10 \mathrm{~m}$ height for stable, unstable, and adiabatic atmospheres.

The deposition velocity, $K$, is defined as the deposition flux, $N$, divided by the particle concentration, $C$, at a reference height. Thus, $K_{z}$ at any height can be calculated from $K_{1}$ by the relationship

$$
\frac{K_{z}}{K_{1}}=\frac{N / C_{z}}{N / C_{1}}=\frac{C_{1}}{C_{z}},
$$

where $\mathrm{N}$ is constant.

The ratio $K_{z} / K_{1}$ was determined from the model

$N=-(\varepsilon / \nu+D / \nu) u_{*} \frac{d C}{d z^{+}}-v_{t} C$,

in which $\varepsilon$ is the particle diffusivity, $D$ is the Brownian diffusivity, $v$ is the kinematic viscosity of air, $z^{+}=z u_{*} / v$ is the dimensionless distance above the surface, and $v_{t}$ is the terminal settling velocity. Values of the turbulent diffusivity in the atmosphere were obtained from a generalized correlation (2) for momentum transport as a function of thermal stability, i.e., for representative values of $z / L$ for stable, unstable, as well as adiabatic atmospheres .

The ratio, $k_{z} / K_{1}$, is a function of $K_{1}$ and $v_{t}$ or only $K_{1}$ if $K_{1} \gg v_{t}$. Thus, we must first define a series of $K_{1}$ so that we can see the effect cf height and stability on $K_{z}$. The deposition velocities chosen for comparison are those in Figure 1 , for a

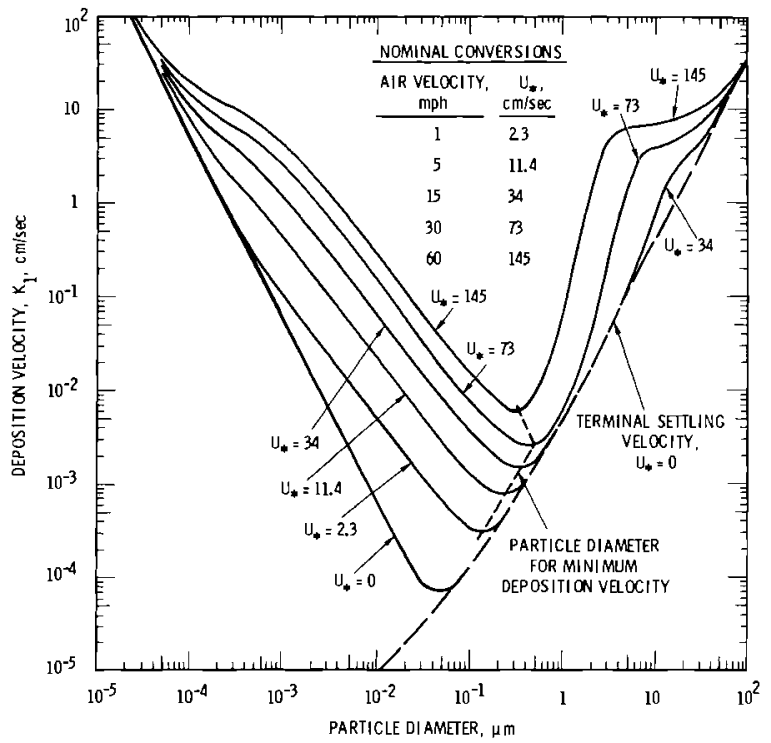

Neg 714008-7

FIGURE 1. Effect of Particle Diameter and Air Friction Velocity on Deposition for a Particle Density of $1.5 \mathrm{gm} / \mathrm{cm}^{3}$

particle density of $1.5 \mathrm{~g} / \mathrm{cm}^{3}$. Deposition velocities are seen to vary several orders of magnitude.

The large variations in $K_{1}$ are reflected in the $K_{z} / K_{1}$ ratios shown in Figure 2 for a reference height of $10 \mathrm{~m}$. The $\mathrm{K}_{z} / \mathrm{K}_{1}$ ratio is nearly unity for all atmospheric stabilities for particle diameters from about $10^{-2}$ to $5 \mathrm{\mu m}$. This constancy reflects the fact that the controlling resistance to particle mass transfer is below $1 \mathrm{~cm}$. From $1 \mathrm{~cm}$ to $10 \mathrm{~m}$, the air borne particulate concentration is nearly uniform.

The ratio $K_{z} / K_{1}$ is a minor function of stability and decreases to about 0.5 to 0.7 for particle diameters near $10^{-3}$ and $10 \mu \mathrm{m}$. These decreases are caused by the relatively high deposition velocities, $K_{1}$, and the resulting particle concentration profiles which must develop above $1 \mathrm{~cm}$ 
to supply the steady flux of particles to the deposition surface. From this comparison in Figure 2, we conclude that the minimum deposition velocities are nearly independent of atmospheric stability and have been adequately predicted. This means that wind tunnel generated deposition data can be applied to the atmospheric case.
Real deposition surfaces are usually rougher than the smooth surfaces experimentally studied to date in the wind tunnel. Consequently, we must also show that deposition velocities for rough surfaces are also nearly independent of particle concentration reference height. Deposition concentration ratios, $\mathrm{K}_{2} / \mathrm{K}_{1}$, are shown in Figure 3 as a function of friction

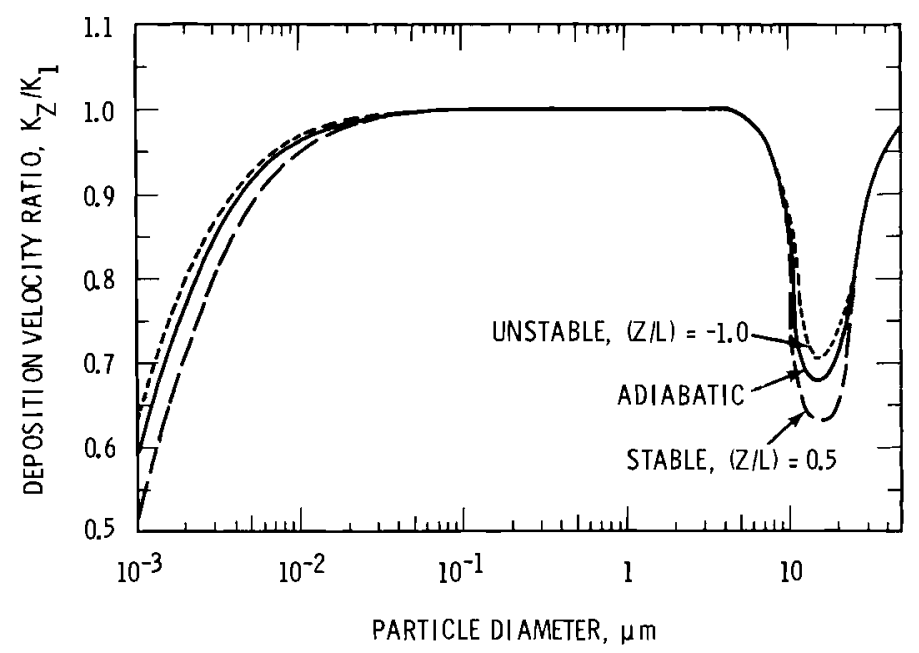

Neg 720091-1

FIGURE 2. Deposition Velocity Ratio, $\mathrm{k}_{z} / \mathrm{k}_{1}$, for a Smooth Horizontal Surface as a Function of Atmospheric Stability for a Height of $10 \mathrm{~m}$ and $u_{\star}=34 \mathrm{~cm} / \mathrm{sec}$

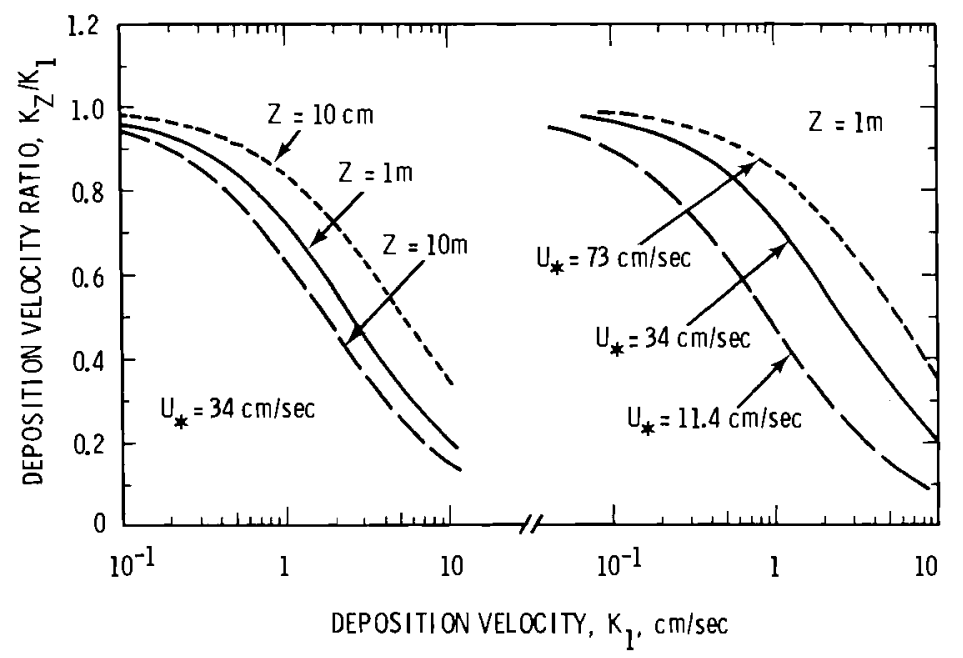

Neg 715795-3

FIGURE 3. Deposition Velocity Ratio, $K_{z} / K_{1}$, as a Function of Deposition Velocity, $\mathrm{K}_{1}$, for $\mathrm{K}_{1}>\mathrm{v}_{t}$ and an Adiabatic Atmosphere 
velocity and reference height for assumed $K_{1}$ values from $10^{-1}$ to $10 \mathrm{~cm} / \mathrm{sec}$. We see that at a $\mathrm{K}_{1}$ of $10^{-1} \mathrm{~cm} / \mathrm{sec}$, that the $\mathrm{K}_{2} / \mathrm{K}_{1}$ ratio is nearly unity. As the deposition velocity $K_{1}$ increases to $1 \mathrm{~cm} / \mathrm{sec}$, the ratio $K_{z} / K_{1}$ decreases to about 0.4 to 0.8 . These $K_{z} / K_{1}$ values suggest that the controlling particle mass transfer resistance is still within $1 \mathrm{~cm}$ of the deposition surface. Consequently, particle deposition velocity data from a wind tunnel can be used to realistically predict particle deposition to many atmospheric surfaces.

\section{NOMENCLATURE}

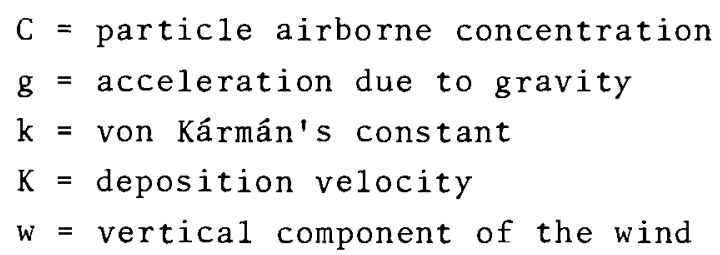

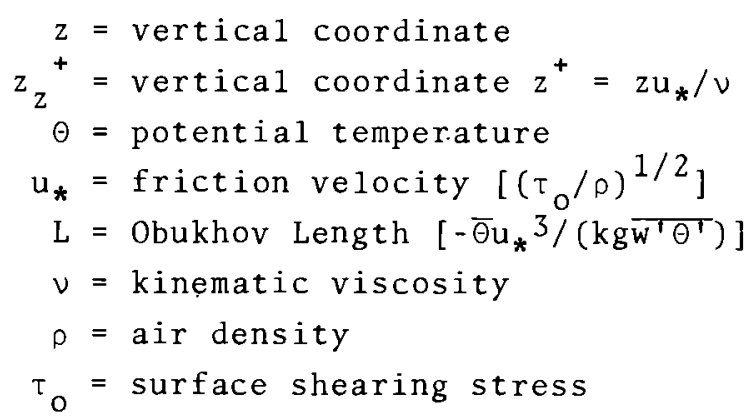

An overbar denotes a time average and a prime the deviation from the average.

\section{REFERENCES}

1. G. A. Sehmel, "Particle Diffusivities and Deposition Velocities over a Horizontal Smooth Surface," J. Colzoid and Interface Science, vol. 37, no. 4, pp. 891-906, 1971.

2. J. A. Businger, J. C. Wyngaard, Y. Izumi, and E. F. Bradiey, "Flux-profize Relationships in J.Atmos. Sci., vol. 28, pp. 181$189,1971$.

\title{
DEPOSITION VELOCITIES OF RESUSPENDED PARTICLES
}

G. A. Sehme 1

\begin{abstract}
Particle deposition velocities were calculated from field experiments for the determination of ZnS particle resuspension from asphalt surfaces. The deposition velocity range was from 0.4 to $17 \mathrm{~cm} / \mathrm{sec}$ with a medium of $3.8 \mathrm{~cm} / \mathrm{sec}$.
\end{abstract}

The determination of particle resuspension rates is important for predicting the downwind dose-to-man inhalation hazard. These resuspension rates are the source term for models of the downwind diffusion and particle 
deposition. Particle deposition velocities have been determined from results of field experiments for the resuspension of $\mathrm{ZnS}$ particles from asphalt surfaces . *

The particle airborne exposure profile as a function of height and the total ground deposition as a function of downwind distance were determined in the resuspension experiments. In the experiments, air filters were used to determine airborne exposure and similar filters were pressed into the soil surface adjacent to the asphalt in order to estimate ground deposition. These profiles were used to determine the average airborne exposure, $M_{a}$, at ground level $(z=0)$ and the deposition, $M_{g}$, resulting from that exposure.

The deposition velocity, $K$, is defined as the deposition flux, $N$, divided by airborne concentration, $\mathrm{C}$. The deposition flux is

$N=\frac{M_{g}}{A \theta}$

and the airborne concentration is

* See contributions "Tracer Particle Resuspension Caused by Wind Forces Upon an Asphalt Road," and "Particle Resuspension from an Asphalt Road Caused by Vehicular Traffic," in this report, same author.
$C=\frac{\left(M_{a}\right)}{F \theta}$

where $A$ is the filter cross sectional area, $F$ is the air sampling rate in volume/time, and $\theta$ is the time length of the experiment. Since the time cancels, the deposition velocity is $K=\frac{N}{C}=\frac{M_{g}}{\left(M_{a}\right)_{z=0}} \frac{F}{A}$.

That is, $K$ can be calculated from the airborne exposure at $z=0$ and the ground deposition exposure.

The experimental deposition velocities ranged from a minimum of $0.4 \mathrm{~cm} / \mathrm{sec}$ to a maximum of $17 \mathrm{~cm} / \mathrm{sec}$ for the resuspended ZnS.* Although the $\mathrm{ZnS}$ has a mass medium diameter of about $5 \mu \mathrm{m}$ and a number medium diameter of about $2 \mu \mathrm{m}$, the particle sizes characteristic of the deposition velocities is unknown. For some experiments, the deposition velocity decreased as a function of distance from 0 to $30 \mathrm{ft}$ downwind from the aspha1t. In other experiments the trend was not definable. The median deposition velocity was $1.7 \mathrm{~cm} / \mathrm{sec}$ and the medium was $3.8 \mathrm{~cm} / \mathrm{sec}$.

* Zns type 2210, United States Radium Corporation 


\title{
MEASUREMENTS AND GRAPHS OF TURBULENCE AUTOCORRELATIONS
}

IN SPACE AND TIME*

C. E. Elderkin and D. C. Powell

\begin{abstract}
A series of turbulence measurements has been taken at heights of 15 and 30 meters at Hanford from a horizontal line of seven logarithmically spaced sensors. When the wind direction was essentialzy along-tower-line, the autocorrelation function in space and time for each wind component has been graphed by entering correlation isopleths on the space-lag versus time-lag plane. The results izlustrate (1) the degree of similarity between the autocorrelation function in time and that in space (Taylor's hypothesis), (2) the relationship between the mean wind speed and an effective eddy translation speed, (3) the persistence of high correlation folzowing advection (frozen field hypothesis),

(4) the autocorrelation function at a horizontally moving point, and (5) the relationship between Eulerian and Lagrangian time-correzations.
\end{abstract}

\section{INTRODUCTION}

In 1967 Gifford ${ }^{(1)}$ elucidated a point of view holding that there are four distinct coordinate reference systems in which turbulence description is pertinent. The Eulerian fixed-point system (I) refers to turbulence as experienced by fixed-point measuring instruments. The Eulerian space system (II) is a "snapshot" of turbulence. The quasi-Lagrangian system (III) refers to turbulence as measured at a point moving with the mean motion. The Lagrangian system (IV) refers to the motion of a single

* This work performed under united States Atomic Energy Commission Contract No. AT (45-1)-1830 and United States Air Force Contract No. E33615-M-5009, "Take-off and Landing Critical Atmospheric Turbulence (TOLCAT)." fluid particle. Gifford also identified several writers who, from an intuitive basis, consider systems (III) and (IV) to be equivalent. Csanady (2) also accepts this as being approximately true.

Because system (I) is a convenient frame of reference for measurement, inferences about turbulence in the other reference frames are often made from Eulerian fixed-point description. By extension of Eulerian fixed-point measurement to include a line of sensors logarithmically spaced in the direction of the mean motion, a description of turbulence in system (III) may be simulated. The primary purpose of this paper is to describe this experimental approach and indicate some initial results.

Relating systems (I) and (IV), we have the Hay-Pasquill beta hypothesis 
$R\left(\tau_{E}\right)=R\left(\tau_{L}\right) ; \quad \tau_{L}=\beta \tau_{E} \cdot$

In Equation ( 1 ), $R$ is a correlation function for any of the three turbulence components, $\tau$ is time $1 \mathrm{ag}$, the subscripts $E$ and $L$ indicate Eulerian and Lagrangian, respectively, and $B$ is assumed to be a constant.

The assumption expressed by Equation (1) is more restrictive than the following expression given by Gifford.

$\beta=n_{T} / n_{L}$

where $n_{T}$ and $n_{L}$ are characteristic frequencies in systems (I) and (IV). Equation (1) states that the spectra for a given turbulence component in systems (I) and (IV) are the same function distinguished only by transposition. Equation (2) does not involve this assumption. The $\beta$ defined therein can be an average value of a proportionality factor, i.e., a function of frequency. Neither Equations (1) or (2) preclude the likelihood expressed by F. B. Smith ${ }^{(3)}$ that $\beta$ is different for each turbulence component.

The assumption that systems (III) and (IV) are approximately equivalent may be expressed by

$R\left(\tau_{L}\right)=R(\tau, \xi), \quad \xi=\bar{U} \tau$

The space lag, $\xi$, is measured in the longitudinal direction. By combining Equations (1) and (3), we get another expression relating systems (I) and (III) contending that the Eulerian correlation function differs from the quasi-Lagrangian correlation function by only the scale factor, $\beta$. This corresponds to the investigation that is of interest in the present paper and is expressed by

$$
R\left(\tau_{E}\right)=R(\tau, \xi), \quad \begin{aligned}
& \text { requiring } \xi=\bar{U} \tau \\
& \text { assuming } \tau \beta \tau_{E^{\prime}}
\end{aligned}
$$

To initiate this investigation, an experiment was conducted which utilized the turbulence measurement and analysis system. *

For this experiment, data from seven three-component turbulence sensors were utilized in the analysis. The sensors were located on the expandable towers adjusted to $15 \mathrm{~m}$ height and logarithmically spaced along the mean wind direction at $4,8,16,32$, 64 , and $128 \mathrm{~m}$ separations between consecutive sensors. Sonic anemometers were located at the shortest intervals - $4 \mathrm{~m}$, separating the first and second, and $8 \mathrm{~m}$ between the second and third. Gill anemometers were located at the remaining four sampling positions.

ESTIMATION AND CALCULATION OF THE EULERIAN SPACE COVARIANCES

Each set of two towers in the logarithmic array is separated by a unique distance. Therefore, genuine spatial covariances, computed by averaging over space, are not available from this data. However, by crossanalyzing parallel components measured at distinct separation distances,

\footnotetext{
* See the contribution "Turbulence Measurement and Analysis Capabilities," in this report.
} 
a pseudo-spatial covariance may be defined as given below

$\mathrm{R}_{\alpha \alpha}(\xi)=\mathrm{E}\left[\mathrm{u}_{\alpha}\left(\mathrm{t}, \mathrm{x}_{\mathrm{o}}\right) \mathrm{u}_{\alpha}\left(\mathrm{t}, \mathrm{x}_{\mathrm{o}}+\xi\right)\right]$

$\alpha=1,2,3$ no summation.

Here the expectation is a time average; and $x_{0}$ and $x_{0}+\xi$ are the locations of two measuring points. Pseudo-spatial correlations computed in this manner will be referred to simply as spatial correlations hereafter. From a line of 7 positions, 21 distinct separation distances are available for calculating spatial correlations. The correlations for both space and time may be defined by extending the same principle to a correlation function of two arguments. The result, normalized, may be written

$$
\begin{aligned}
\mathrm{R}_{\alpha \alpha}(\tau, \xi)= & E\left[u _ { \alpha } ( t , x _ { o } ) u _ { \alpha } \left(t+\tau, x_{o}\right.\right. \\
& +\xi)] / E\left[u_{\alpha} u_{\alpha}\right] .
\end{aligned}
$$

An example of this type of turbulence analysis is given by Lumley and Panofsky(4) in their Figure 5.22. Such two dimensional correlation function analyses have been calculated for each turbulence wind component for the one experiment discussed here where the array of sensors was at $15 \mathrm{~m}$ height, the wind direction was $9^{\circ}$ to the line of the sensors at $6.4 \mathrm{mps}$, and slightly stable conditions prevailed. The analysis was for a 28 -minute data sampling period with each variable sampled at 0.2 second intervals.
PROPERTIES OF TURBULENCE ILLUSTRATED IN DIAGRAMS OF TIME SPACE CORRELATIONS

The time-space correlation functions for the three turbulence wind components: $u^{\prime}$ a, the horizontal component along the tower line; $v^{\prime} a$, the horizontal component normal to the tower 1 ine; and $w^{\prime}$, the vertical component, are given in Figures 1, 2, and 3 , respectively. These diagrams may be interpreted in several interesting ways. First, it will be noted that the function marked off by the isopleths on the abscissa is a pure time correlation, and is necessarily symmetrical. The function marked of $f$ by the isopleths on the ordinate is the spatial correlation. The scales of the two axes are adjusted to be equal when $\xi=\bar{U} \tau$. The correlation at a point moving with the mean motion is the function marked off by the isopleths on the $45^{\circ}$ line labeled $\xi=\overline{\mathrm{U}} \tau$.

Also, Taylor's hypothesis predicts that the same identical function is marked off on the abscissa and the ordinate. The isopleths of correlation in Figures 1, 2, and 3 may be approximated by ellipses with their major axes along the line $\xi=\bar{U} \tau$. If the major axes of the ellipses fall, for instance, above the $45^{\circ} 1$ ine, an eddy transport speed greater than $\bar{U}$ is indicated.

Assuming that the quasi-Lagrangian correlation function is a good approximation to the true Lagrangian correlation function, Equation (4) predicts that the function marked off on the 


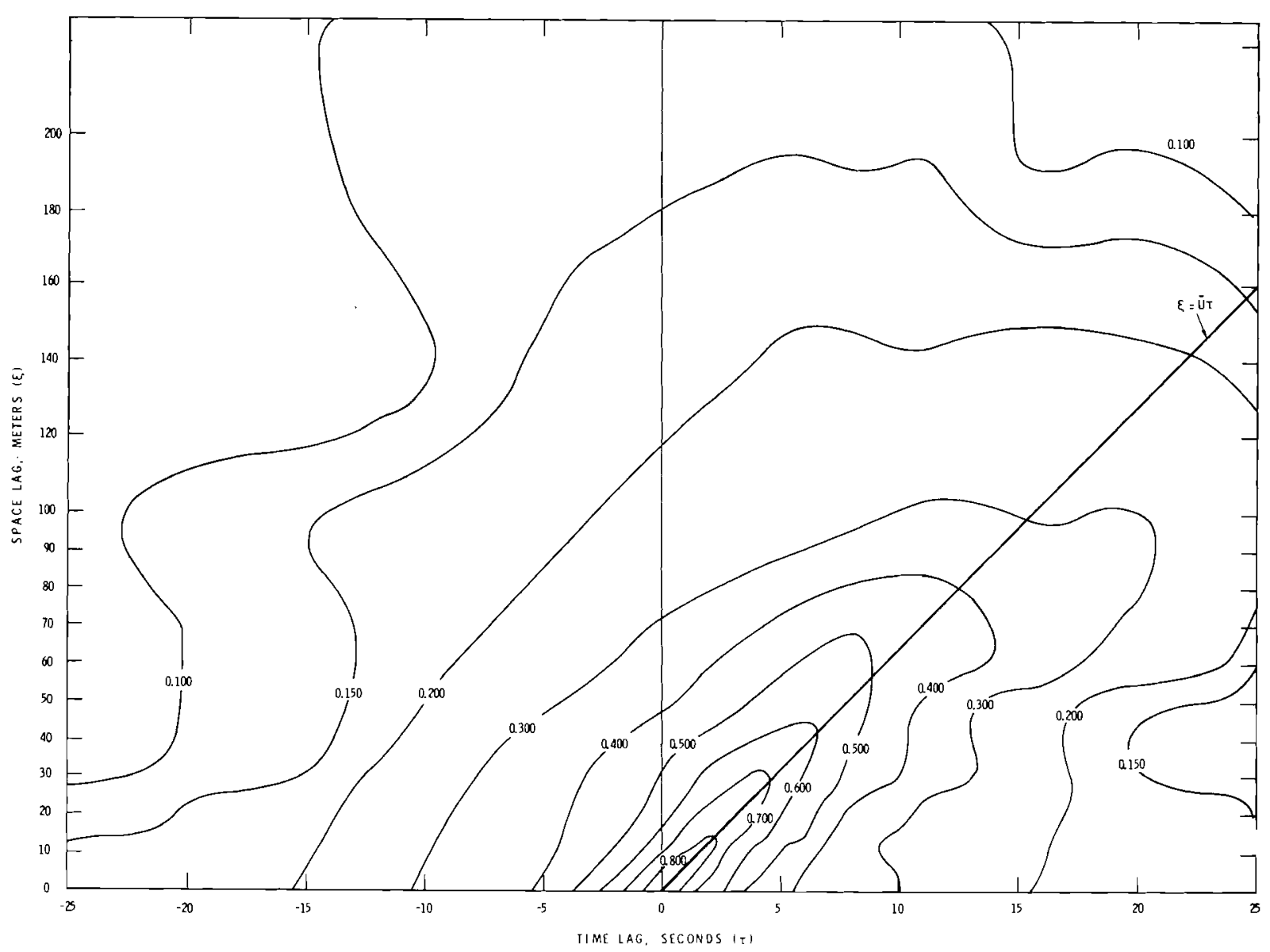

Neg 714757-16

FIGURE 1. Autocorrelation Function of $\mathrm{u}^{\prime} \mathrm{a}$ in Time and Space

$45^{\circ} 1$ ine will differ from that marked off on the abscissa by no more than a proportionality factor, $\beta$. Comparing lag times, $\tau$, for the equal values of correlation, the first of which is on the $45^{\circ}$ ine and the second of which is on the abscissa, provides a ratio which is an estimate $\beta$. If Equation (4) holds for system (III), the value of $\beta$, so estimated, should be approximately the same regardless of where on the correlation diagram it is determined. A large volume of these graphs should show reliably whether or not $\beta$ varies systematically with correlation length, from one turbulence component to another and as a function of stability or turbulence intensity.

The eccentricity of the ellipses indicates to what extent the frozen field hypothesis holds. The strict forzen field hypothesis requires that the isopleths in the diagrams are straight lines parallel to the 1 ine, $\xi=\bar{U}_{\tau}$, and symmetrically located on 
each side of that line. The eccentricity should, in general, be inversely proportional to the relative turbulence intensity and directly proportional to the value of $\beta$.

The principal axes of the correlation contours appear to be slightly above the $\xi=\bar{U} \tau$ line for all three components but is most clearly shown for $w^{\prime}$ in Figure 3 , indicating an effective eddy translation speed slightly exceeding the mean wind speed.

From Figures 1,2 , and 3 , we see that the eccentricity (and thus $\beta$ ) is least for the $\mathrm{u}^{\prime}{ }_{\mathrm{a}}$ component graph and the greatest for $v^{\prime}{ }_{a}$. This does not correspond to an inverse ranking of the relative turbulence intensities since $\overline{u^{\prime 2}}=1.28 \mathrm{~m}^{2} / \mathrm{sec}^{2}, \overline{v^{\prime 2}}$ $=0.74 \mathrm{~m}^{2} / \mathrm{sec}^{2}$ and $w^{\prime 2}=0.31 \mathrm{~m}^{2} / \mathrm{sec}^{2}$. This indication that $\beta$ is not the same for each component is more clearly shown in Figure 4. It is also seen that some tendency toward smaller $\beta$ at larger $\tau$ is suggested. However, this suggestion that the quasi-Lagrangian and Eulerian fixedpoint correlation functions are not truly similar is premature since

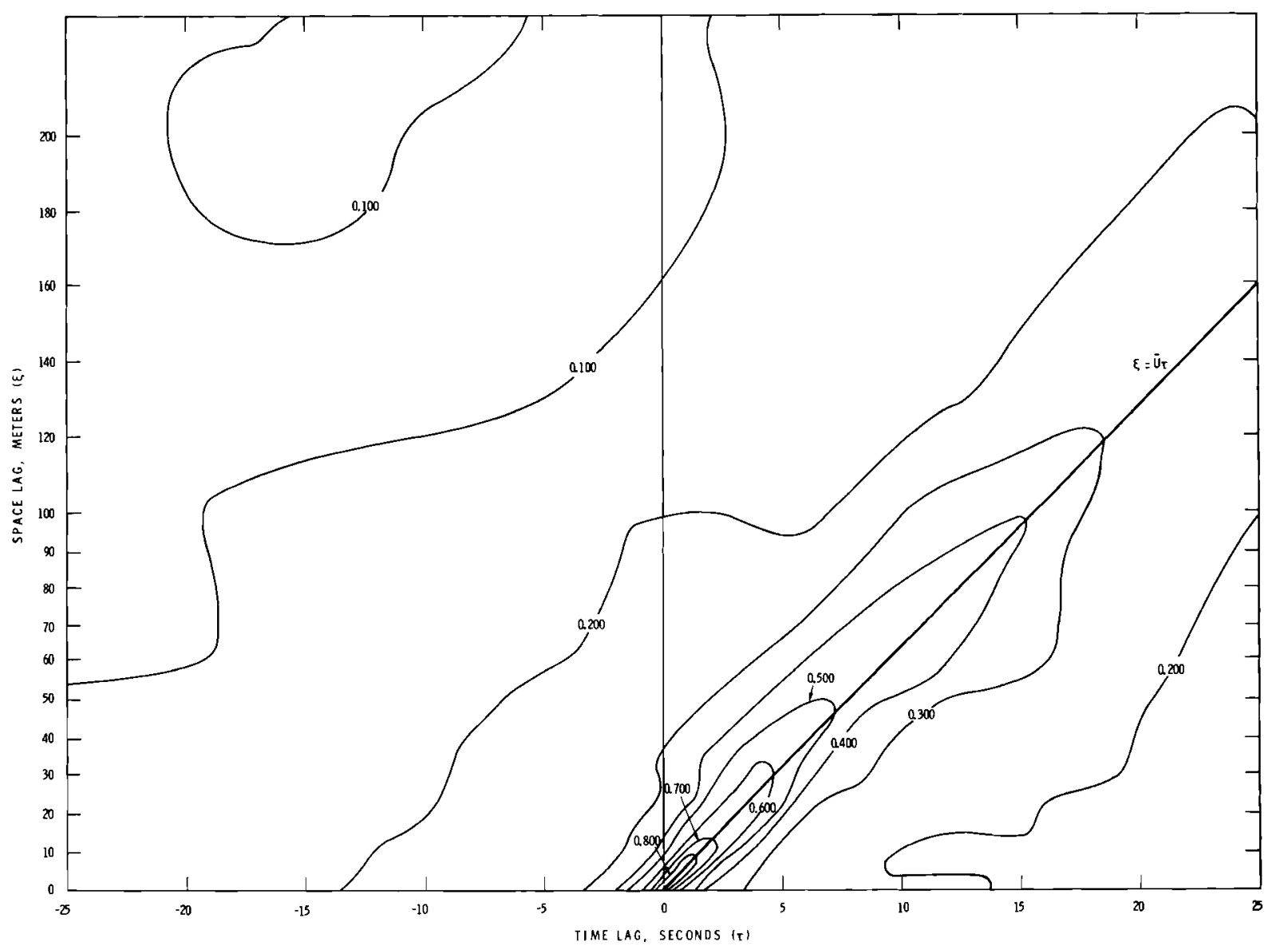

Neg 714805-26

FIGURE 2. Autocorrelation Function of $\mathrm{v}^{\prime} \mathrm{a}$ in Time and Space 


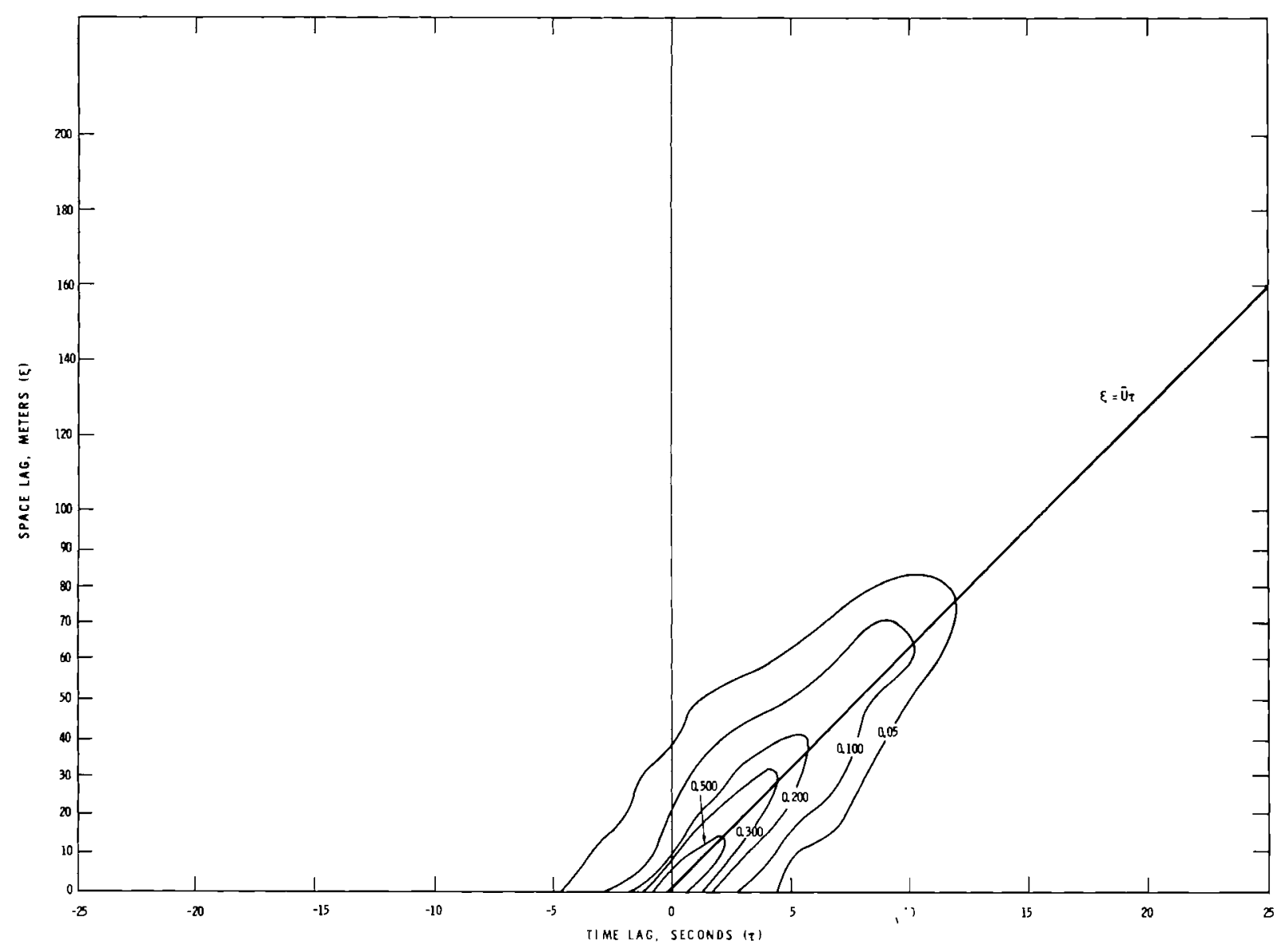

Neg 715187-9

FIGURE 3. Autocorrelation Function of $\mathrm{w}^{\prime}$ in Time and Space

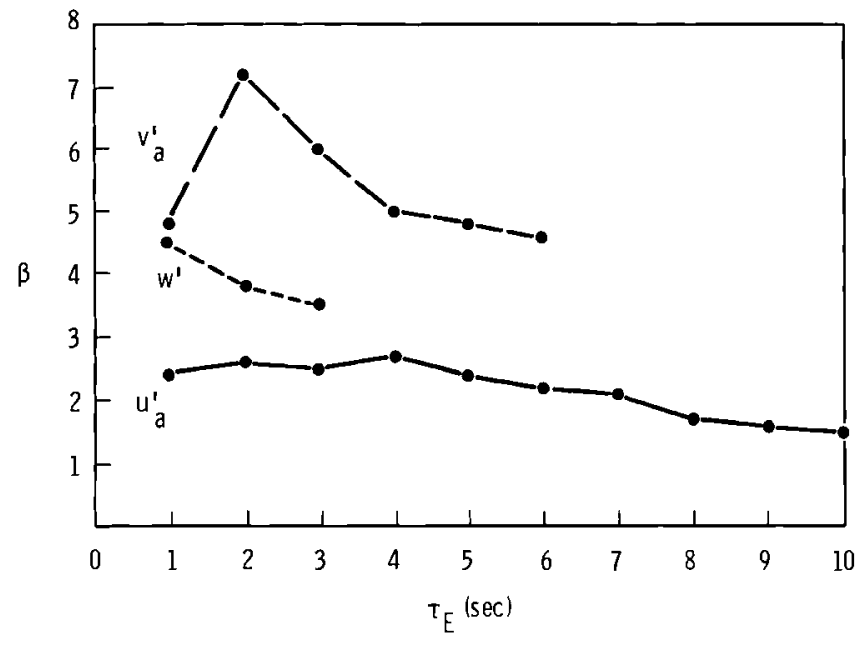

Neg 715478-1

FIGURE 4. Estimated of $B$ for the Three wind Components as a Function of Eulerian Time Lag 
experimental factors could account for the small variations (smaller than between components) observed. The $B$ values of about 5.3 for the latera 1 wind component and 3.9 for the vertical component are consistent with other evaluations of $\beta$ and suggest that the technique for studying $\beta$ described here is a useful approach.

\section{REFERENCES}

1. F. A. Gifford. "Variation of the Lagrangian-Eulerian Time scale Relationship with Stability," USAEC Meteorological Information Meeting, Chalk River, Canada,
September 11-14, 1967, AECL-2787, pp. 485-499. 1967.

2. G. T. Csanady. "Turbuzent Diffusion of Heavy Particles in the Atmosphere," J. of the Atmos. sciences, vol. 20, pp. 201-208. 1963 .

3. F. B. Smith. "The EulerianLagrangian Time-Scale Relationship in one-Dimensional Turbulence," USAEC Meteorological Information Meeting, Chalk River, Canada, September 11-14, 1967, AECL-2787, pp. 476-483. 1967.

4. J. L. Lumley and H. A. Panofsky. The Structure of Atmospheric Turbulence, Interscience Publishers, John Wiley Co., New York, N. Y. 1964 .

PROFILE-DER IVED ESTIMATION OF CROSSWIND INTEGRATED EXPOSURE

FROM ELEVATED RELEASES: INITIAL MODEL

D. C. Powell and C. E. Elderkin

The crosswind integrated exposures measured during nineteen tests (Richardson number varying from 0.005 to 0.15 ) at nine arcs, 400 to 12800 meters downwind of an elevated release point 26 meters above ground, are compared with estimations calculated from a model. When suitable values are used for various input parameters to the model, the calculated exposures are within a factor of two of the measured exposures $63 \%$ of the time and within a factor of four $90 \%$ of the time. The model is successful only with large variations of the HayPasquill $\beta$ parameter with stability. The calculations also change sharply as the coefficient in the deposition velocity dependence on drag coefficient is changed.

DESCRIPTION OF FACILITY AND DATA

The data used in this analysis are from 19 experiments on diffusion of zinc sulfide tracer released at an elevation of 26 meters from the
125 meter Hanford meteorological tower during neutral and stable conditions, i.e., Ri positive. The sampling is from nine arcs located at distances from the tower of 400, 800 , $1200,1600,2200,3200,5000,7000$, 
and 12,800 meters, respective1y. The data elements fed into the analysis are integrations of exposure along each arc for each experiment, thus approximating crosswind integrations. This procedure makes 171 data elements possible, however, only 116 could be used. The most common reason for disqualification of a data element was incomplete sampling of the plume by a given arc during a particular experiment, making crosswind integration impossible in that case.

The original data contained more than 19 experiments. However, for al1 experiments with Ri greater than 0.15 the distribution was so i11defined by the sampling arcs that estimates were available on only one or two arcs, and these data were not used. Two experiments exhibited Ri above the 0.213 value which is the upper asymptotic limit according to most recent turbulence similarity theory. (2) These data were not analyzed.

For the 19 tests the mean wind speed at 15 meters varied from 2.8 to $7.2 \mathrm{mps}$.

\section{MATHEMATICAL DESCRIPTION OF THE}

ANALYSIS

The exposure estimation model consisted of four adjustable parameters, which is mathematically equivalent to a four dimensional domain. The four parameters are:

1. Characteristic height of transport and diffusion.

2. Basic value of Hay-Pasquill $\beta$ for neutral conditions.
3. Linear variation of beta with Richardson number at 5.5 meters.

4. Deposition velocity.

(The model also included origina11y a setting velocity but when the analysis showed that a zero value sufficed, the parameter was dropped.) These quantities are a 11 defined in a companion paper in this report.*

For an arbitrary specification of the domain values, the element of the analysis is an individual ratio, $r_{i j}$ for each experiment, $i$, and each arc, j, where

$\begin{aligned} r_{i j}= & \text { calculated estimate, } \\ & i j / m e a s u r e d \text { estimate, } i j .\end{aligned}$

The primary analysis presented in Table 1 for particular specifications of domain values is obtained by integrating all values of $r_{i j}$ over all arcs and over all experiments for each average value (to be described below) computed. Also, a few calculations are made with the experiments divided into three stability classifications.

(a) $0<\mathrm{Ri} \leq 0.05$.

(b) $0.05<\mathrm{Ri} \leq 0.12$.

(c) $0.12<\mathrm{Ri} \leq 0.15$.

The evaluation averages constitute a vector valued function of the fourdimensional domain. There are five elements in the evaluation function.

1. The mean ratio of calculated to measured crosswind integrated concentration:

* See "Profile-Derived Estimation of Crosswind Integrated Exposure from Elevated Releases: Method of Investigation," in this report. 
$M=\exp \left\{\frac{}{\operatorname{Ln}\left(r_{i j}\right)}\right\}$.

Since a few of the $r_{i j}$ were zero, these values had to be adjusted upward to an arbitrarily specified minimum value before $M$ was computed. For these computations, the value of $M$ is, of course, a function of this minimum value which was selected at 0.06 .

2. The mean geometric deviation of individual $\mathrm{r}_{i j}$ from $M$. To calculate this the individual quantities, $d_{i j}$ are formed for each $i$ and $j$ from the larger of the two quantities:

$d_{i j}=r_{i j} / M ;$ or $d_{i j}=M / r_{i j} \cdot$.

Therefore, none of the $d_{i j}$ are less than unity. The final measure of the scatter is the average of the $d_{i j}$,

$s=\overline{d_{i j}} \quad$.

3. A dissemination of the 116 ratios, $\mathrm{r}_{\mathrm{ij}}$, into 10 categories. These were

$r_{i j}<2^{-4}$

$2^{n} \leq r_{i j}<2^{n+1} n=-4,-3, \cdots \cdot 2.3$.

$2^{4} \leq r_{i j}$

4. An evaluation of the above distribution that is best described in a later section of the report where tabled results are presented.
5. A count, $A r_{i j}$ of the $r_{i j}$ values adjusted upward for step 1 to prevent $M$ from becoming zero.

\section{PHYSICAL DISCUSSION OF ANALYSIS}

\section{PARAMETERS}

The best analyses to date have been obtained with the release height entered at its actual value into the computations. Lower values simulating initial fall of the tracer spray were used at times during the analysis when they seemed to produce better results which compensated for poor adjustment of some other parameter. But for purposes of this report the release height will be considered nonadjustable.

Since the model requires calculation of $\sigma_{z}$ from application of the Hay-Pasquill equation, and since the vertical velocity spectrum in this equation is a function of height; either the variation of the turbulence with height must be part of the model or a characteristic height, $\mathrm{H}_{\mathrm{c}}$, within the diffusion layer must be arbitrarily selected for calculation of spectral values and mean wind speed values which are assumed to apply to the whole diffusion process. Physical intuition suggested that this height should be less than the release height. In the analysis, heights that were multiples of three were tested, and best results were obtained with 15 or 18 meters for the

\footnotetext{
* See Equation 5 in "Profize-Derived Estimation of Crosswind Integrated Exposure from Elevated Releases: Method of Investigation, "in this report.
} 
characteristic height, a slight edge being apparent for the 15 meter

figure.

For each experiment the value of $\beta$ varied as a linear function

$\beta=B+C_{1} \operatorname{Ri}(5.5$ meters $)$.

Better results were achieved using the two degrees of freedom than using $\beta$ equal 0.44 (turbulence intensity) as suggested by Pasquil1 ${ }^{(1)}$ However, more study would be required to firmly establish the dependence.

Results varied only slightly with varying values of $B$, consequently, the commonly accepted value for neutral $\beta$ of 4 was chosen for further analyses. As $C_{1}$ was varied, the mean ratio was optimized with $\mathrm{C}_{1}$, at a value of 200 but $C_{1}$ had to be extended to a value of 900 for the scatter of the ratios to each a minimum. A value of about 600 appears at the present to provide the most reasonable results. With $B=4$ and $C_{1}=600$, values of $\beta$ ranged from 7 to 94 for the individual experiments. These values of $B$ were used with the Hanford turbulence spectrum model,* in the Hay-Pasquill equation.

For each experiment a separate deposition velocity of the form $v_{d}=C_{2} \frac{u_{*}^{2}}{\bar{U}(2)}$

was used, where $u_{*}$ is the friction

\footnotetext{
* See Equation (3) in "ProfiZe-Derived Estimation of Crosswind Integrated Exposure from Elevated Releases: Method of Investigation," in this report.
}

velocity, computed as a function of Richardson number and mean wind speed, * and $\bar{U}(2)$ is the measured wind speed at 2 meters. Judging from an incomplete computation sample the variable deposition velocity yielded better results than use of a constant deposition velocity for all experiments. Although several constants near the average value of $V_{d}$ in Equation (6) were tried and found to be less effective than the variable $V_{d}$, more evaluation is needed to definitely establish the optimum form for the deposition velocity. The variation of analysis results with variation of $\mathrm{C}_{2}$ was quite pronouncedmore so than with variation of $B$ in Equation (5). The mean ratio is best for the lower values of $\mathrm{C}_{2}$ while the scatter is minimized for the larger values of $\mathrm{C}_{2}$. For the present the best selection appears to be about $\mathrm{C}_{2}=3.0$.

Because $V_{d}$ is used in the theoretical model only in the form, $V_{d} / U_{c}$, where $U_{c}$ is the mean wind speed at the characteristic height, using this model of deposition velocity amounts to replacing the deposition velocity with a measure of the drag coefficient.

$\frac{v_{d}}{U_{c}}=A \frac{u_{*}^{2}}{\bar{U}(2) U_{c}}=C \cdot \frac{u_{*}^{2}}{U_{c}^{2}}$

\footnotetext{
* See Equation (2) in "ProfizeDerived Estimation of Crosswind Integrated Exposure from Elevated Releases: Method of Investigation," in this report.
} 
EXAMPLE OF THE EVALUATION FUNCTION FOR A GOOD SET OF DOMAIN VALUES

of all the physically realistic sets of domain values used, possibly the best analysis was achieved for $\mathrm{H}_{\mathrm{C}}=15, \mathrm{~B}$ in $\beta=4, \mathrm{C}_{1}$ in $\beta=600$, and $C_{2}$ in $V_{d}=3.0$. This set may be written $(15,4,600,3.0)$. This cannot be considered an optimum set yet since further statistical evaluation of various sets of domain values is advisable. Also, further imporvements in the basic model are possible. Nevertheless, using the above set of domain values, calculation with $116 \mathrm{r}_{\mathrm{ij}}$ yields

$M=1.35 \quad S=2.25 \quad$.

The histogram of the $r_{i j}$ and the $\mathrm{fr}_{\mathrm{ij}}$, i.e., folded $\mathrm{r}_{i j}$ (the larger of $\mathrm{r}_{i j}$ or its reciprocal) is given in Table 1.

Attention is drawn to the following:

1. $63 \%$ of the calculated crosswind integrated exposures (CIE's) are within a factor of 2 of the measured CIE values.

2. $90 \%$ of the calculated CIE's are within a factor of 4 of the mea- sured CIE's.

3. No $r_{i j}$ values were found to be zero in this analysis.

The fourth element in the evaluation function, referred to earlier in the report, is simply the sum of the first four numbers in the bottom line of Table I and provides a measure of the spread of the $r_{i j}$ values about the desired value of unity. The sum reaches a maximum value of 4 if all the $\mathrm{fr}_{\mathrm{ij}}$ are less than 2 and reaches a minimum of zero if all the $\mathrm{fr}_{\mathrm{ij}}$ values are greater than 16 . The sum, which will be called the weighted count, W.C., in this case is 3.49 . The largest of the $r_{i j}$ was 17.6 (seeming 1 y anomalous).

At this point it is instructive to tabulate the evaluation function for a selection of sets of domain values, illustrating the manner of variation of the evaluation function when all elements in the domain are held constant but one (Table 2).

The detailed computer output gives a considerable variety of output parameters for each arc of each experiment. For the same domain $(15,4,600,3.0)$ detailed output from three experiments is given in Table 3..- one from each stability classification.

\begin{tabular}{|c|c|c|c|c|c|c|c|c|c|c|}
\hline & & TABLE 1. & Histo & $\begin{array}{l}\text { am of } \\
i j \text { and }\end{array}$ & $\begin{array}{l}\text { he } r_{i} \\
f r_{i j}\end{array}$ & $\begin{array}{l}\text { and } \\
\text { terva }\end{array}$ & $r_{i j}$ & & & \\
\hline & $\begin{array}{l}0.0- \\
0.0625 \\
\end{array}$ & $\begin{array}{l}0.0625- \\
0.125 \\
\end{array}$ & $\begin{array}{l}0.125- \\
0.25 \\
\end{array}$ & $\begin{array}{l}0.25- \\
0.5 \\
\end{array}$ & $\begin{array}{l}0.5- \\
1.0 \\
\end{array}$ & $\begin{array}{l}1.0- \\
2.0 \\
\end{array}$ & $\begin{array}{l}2.0- \\
4.0 \\
\end{array}$ & $\begin{array}{l}.0- \\
8.0 \\
\end{array}$ & $\begin{array}{l}8.0- \\
16.0 \\
\end{array}$ & $\begin{array}{l}16.0- \\
32.0 \\
\end{array}$ \\
\hline$r_{i j}$ count & 0 & 1 & 2 & 8 & 30 & 43 & 23 & 7 & 1 & 1 \\
\hline $\mathrm{fr}_{i j}$ count & & & & & & 73 & 31 & 9 & 2 & 1 \\
\hline Cumulative & normalize & ed $f r_{i j}$ & unt & & & 0.63 & 0.90 & 0.97 & 0.99 & 1.00 \\
\hline
\end{tabular}


TABLE 2. Estimation Statistics for a Variety of Domain Values

\begin{tabular}{|c|c|c|c|c|c|c|c|}
\hline${ }_{\mathrm{C}}^{\mathrm{H}}$ & $B$ in $B$ & $\mathrm{C}_{1}$ in $\beta$ & $\mathrm{C}_{2}$ in $\mathrm{V}_{\mathrm{d}}$ & $M$ & $\mathrm{~S}$ & $\mathrm{Ar}_{i j}$ & W.C. \\
\hline 24 & 4 & 600 & 3.0 & 1.13 & 2.54 & 3 & 3.50 \\
\hline 21 & 4 & 600 & 3.0 & 1.19 & 2.45 & 2 & 3.51 \\
\hline 18 & 4 & 600 & 3.0 & 1.26 & 2.41 & 2 & 3.48 \\
\hline 15 & 4 & 600 & 3.0 & 1.34 & 2.25 & 0 & 3.49 \\
\hline 12 & 4 & 600 & 3.0 & 1.43 & 2.21 & 0 & 3.45 \\
\hline 9 & 4 & 600 & 3.0 & 1.50 & 2.33 & 0 & 3.36 \\
\hline 15 & 16 & 600 & 3.0 & 1.32 & 2.19 & 0 & 3.52 \\
\hline 15 & 12 & 600 & 3.0 & 1.33 & 2.20 & 0 & 3.49 \\
\hline 15 & 8 & 600 & 3.0 & 1.34 & 2.21 & 0 & 3.48 \\
\hline 15 & 6 & 600 & 3.0 & 1.34 & 2.23 & 0 & 3.48 \\
\hline 15 & 4 & 600 & 3.0 & 1.34 & 2.25 & 0 & 3.49 \\
\hline 15 & 3.5 & 600 & 3.0 & 1.34 & 2.25 & 0 & 3.48 \\
\hline 15 & 4 & 1000 & 3.0 & 1.37 & 2.17 & 0 & 3.51 \\
\hline 15 & 4 & 900 & 3.0 & 1.37 & 2.16 & 0 & 3.52 \\
\hline 15 & 4 & 800 & 3.0 & 1.37 & 2.17 & 0 & 3.54 \\
\hline 15 & 4 & 700 & 3.0 & 1.36 & 2.19 & 0 & 3.50 \\
\hline 15 & 4 & 600 & 3.0 & 1.35 & 2.25 & 0 & 3.49 \\
\hline 15 & 4 & 500 & 3.0 & 1.31 & 2.44 & 2 & 3.45 \\
\hline 15 & 4 & 400 & 3.0 & 1.27 & 2.47 & 2 & 3.46 \\
\hline 15 & 4 & 300 & 3.0 & 1.20 & 2.62 & 3 & 3.43 \\
\hline 15 & 4 & 200 & 3.0 & 1.08 & 2.95 & 5 & 3.35 \\
\hline 15 & 4 & 100 & 3.0 & 0.85 & 3.40 & 9 & 3.25 \\
\hline 15 & 4 & 50 & 3.0 & 0.65 & 4.05 & 18 & 2.85 \\
\hline 15 & 4 & 0 & 3.0 & 0.42 & 4.94 & 32 & 2.26 \\
\hline 15 & 4 & 600 & 4.0 & 1.08 & 2.47 & 1 & 3.36 \\
\hline 15 & 4 & 600 & 3.5 & 1.20 & 2.35 & 0 & 3.38 \\
\hline 15 & 4 & 600 & 3.0 & 1.34 & 2.25 & 0 & 3.49 \\
\hline 15 & 4 & 600 & 2.5 & 1.49 & 2.19 & 0 & 3.43 \\
\hline 15 & 4 & 600 & 2.0 & 1.66 & 2.16 & 0 & 3.38 \\
\hline
\end{tabular}

The unfamiliar symbols are: M.E. - ing deposition velocity; BF.R. - B measured crosswind integrated exposure; filter ratio, i.e., the ratio of $\sigma_{z}^{2}$ P.S. - portion of tracer calculated to as computed using the Hay-Pasquill be still suspended at the $i^{\text {th }}$ arc as equation to $\sigma_{w}^{2} T^{2}$, the plume spread determined from the integral involv- if $\beta$ were infinite. 
TABLE 3. Detailed Data from Three Experiments for one set of Domain Values

Experiment $U-78$

$\mathrm{U}_{\mathrm{C}}=5.5 \mathrm{mps} ; \overline{\mathrm{U}}(2)=3.7 \mathrm{mps} ; \mathrm{Ri}=0.005 ; \beta=7$;

$\mathrm{u}_{*}=0.35 \mathrm{mps} ; \mathrm{v}_{\mathrm{d}}=0.099 \mathrm{mps} ; \phi_{\mathrm{m}}=1.09$

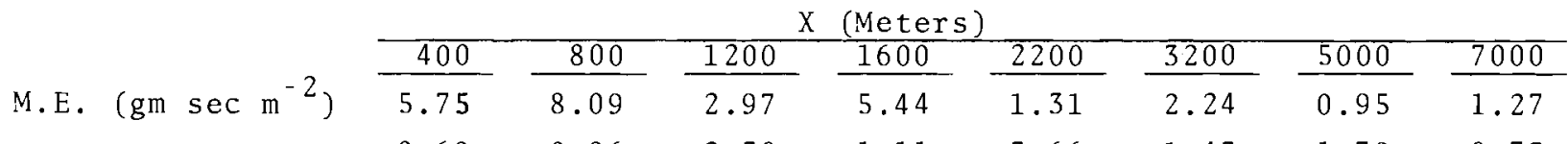

$\mathrm{r}_{\mathrm{ij}}$

$\sigma_{z}(m)$

P.S.

$0.68 \quad 0.86 \quad 2.30$

1.11

3.66

1.43

1.79

0.73

BF.R. .

$\begin{array}{llll}13.0 & 19.1 & 23.5 & 27.4\end{array}$

$32.2 \quad 39.0$

48.7

57.7

0.98

0.89

0.78

0.68

0.56

0.41

0.25

0.16

0.152

0.081

$0.055 \quad 0.042$

0.031

0.021

0.014

0.010

Experiment $U-79$

$\mathrm{U}_{\mathrm{C}}=3.8 \mathrm{mps} ; \overline{\mathrm{U}}(2)=1.6 \mathrm{mps} ; \mathrm{Ri}=0.08 ; \beta=52 ;$

$\mathrm{u}_{*}=0.18 \mathrm{mps} ; \mathrm{v}_{\mathrm{d}}=0.063 \mathrm{mps} ; \phi_{\mathrm{m}}=3.12$

\begin{tabular}{|c|c|c|c|c|c|c|c|c|}
\hline & \multicolumn{7}{|c|}{$X$ (Meters) } & \\
\hline & 400 & 800 & 1200 & 1600 & 3200 & 5000 & 7000 & 12,800 \\
\hline M.E. $\left(\mathrm{gm} \mathrm{sec} \mathrm{m}^{-2}\right)$ & 3.38 & 11.66 & 7.29 & 9.82 & 5.09 & 2.79 & 3.66 & 0.59 \\
\hline$r_{i j}$ & 2.45 & 1.08 & 1.57 & 0.99 & 1.03 & 1.06 & 0.48 & 0.93 \\
\hline$\sigma_{z}$ & 14.3 & 22.0 & 27.7 & 32.5 & 46.8 & 58.8 & 70.3 & 94.6 \\
\hline P.S. & 0.98 & 0.88 & 0.78 & 0.69 & 0.45 & 0.30 & 0.21 & 0.09 \\
\hline$B F \cdot R$. & 0.320 & 0.189 & 0.133 & 0.103 & 0.053 & 0.035 & 0.025 & 0.014 \\
\hline
\end{tabular}

Experiment U-82

$\mathrm{U}_{\mathrm{C}}=3.4 \mathrm{mps} ; \overline{\mathrm{U}}(2)=0.6 \mathrm{mps} ; \mathrm{Ri}=0.15 ; \beta=94 ;$

$u_{*}=0.095 \mathrm{mps} ; v_{d}=0.045 \mathrm{mps} ; \phi_{\mathrm{m}}=9.17$

\begin{tabular}{|c|c|c|c|c|c|c|c|}
\hline & \multicolumn{7}{|c|}{$x$ (Meters) } \\
\hline & 400 & 800 & 1200 & 3200 & 5000 & 7000 & 12,800 \\
\hline M.E. $\left(\mathrm{gm} \mathrm{sec} \mathrm{m}^{-2}\right)$ & 0.56 & 5.83 & 5.36 & 5.20 & 2.09 & 3.42 & 1.83 \\
\hline$r_{i j}$ & 0.16 & 0.48 & 1.25 & 1.95 & 3.25 & 1.18 & 0.53 \\
\hline$\sigma_{z}$ & 6.9 & 10.3 & 12.9 & 21.5 & 26.9 & 31.9 & 43.2 \\
\hline P.S. & 1.00 & 0.99 & 0.96 & 0.65 & 0.42 & 0.26 & 0.07 \\
\hline$B F . R$. & 0.224 & 0.124 & 0.085 & 0.034 & 0.022 & 0.015 & 0.008 \\
\hline
\end{tabular}

Analysis for a few of the domain sets has also been made with the data divided into the three stability clas- sifications identified previously. For the domain $(15,4,600,3.0)$, the following are obtained: 


\begin{tabular}{|c|c|c|c|c|c|}
\hline Stability & $\begin{array}{l}\text { Total } \\
\text { rij } \\
\end{array}$ & $M$ & $\mathrm{~S}$ & $\operatorname{Ar}_{i j}$ & W. \\
\hline $00<\mathrm{Ri} \leq 0.05$ & 54 & 1.25 & 2.05 & 0 & .60 \\
\hline $0.05<\mathrm{Ri} \leq 0.12$ & 39 & 1.42 & 2.07 & 0 & 3.54 \\
\hline $0.12<\mathrm{Ri} \leq 0.15$ & 23 & 1.43 & 2.96 & 0 & 3.17 \\
\hline
\end{tabular}

The model appears to work with reasonable consistency for Ri up to 0.12. A few calculations for the most stable group using various values of $C_{1}$ suggest that raising this parameter even higher than 600 might offer better results. Graphs of the $r_{i j}$ for most of the experiments are presented in Figures 1, 2, and 3. Each figure is for a different stability classification, and all experiments not exhibited were those with data for few arcs.
Comparatively speaking, the graphs suggest that the measurements of exposure are somewhat low at 1200 meters, high at 1600 meters, low at 2200 , and high at 3200 meters. Differences in sampling flow rates and associated nonisokinetic sampling errors appear to be the cause.

The graph for the most stable case shows a tendency of the model to overestimate for the arcs at intermediate distances and underestimate at the extreme distances. Since the critical Richardson's number is reached at a height not too far from the surface for this case, the absence of turbulent diffusion above that height might well be responsible for higher concentrations, and thus lower ratios at

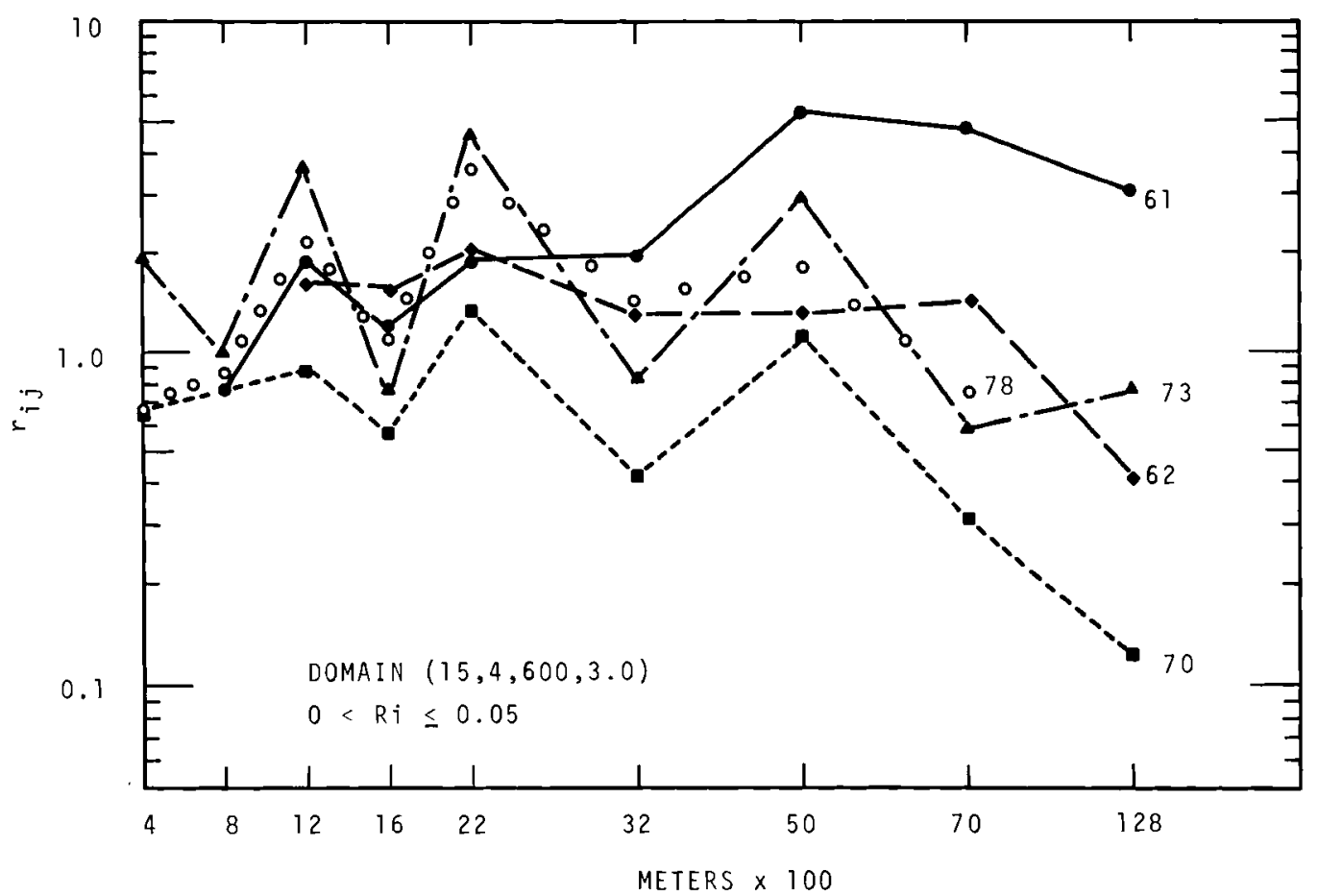

Neg 721306-3

FIGURE 1. Ratios, $r_{i j}$, for Test Numbers $61,62,70$, 


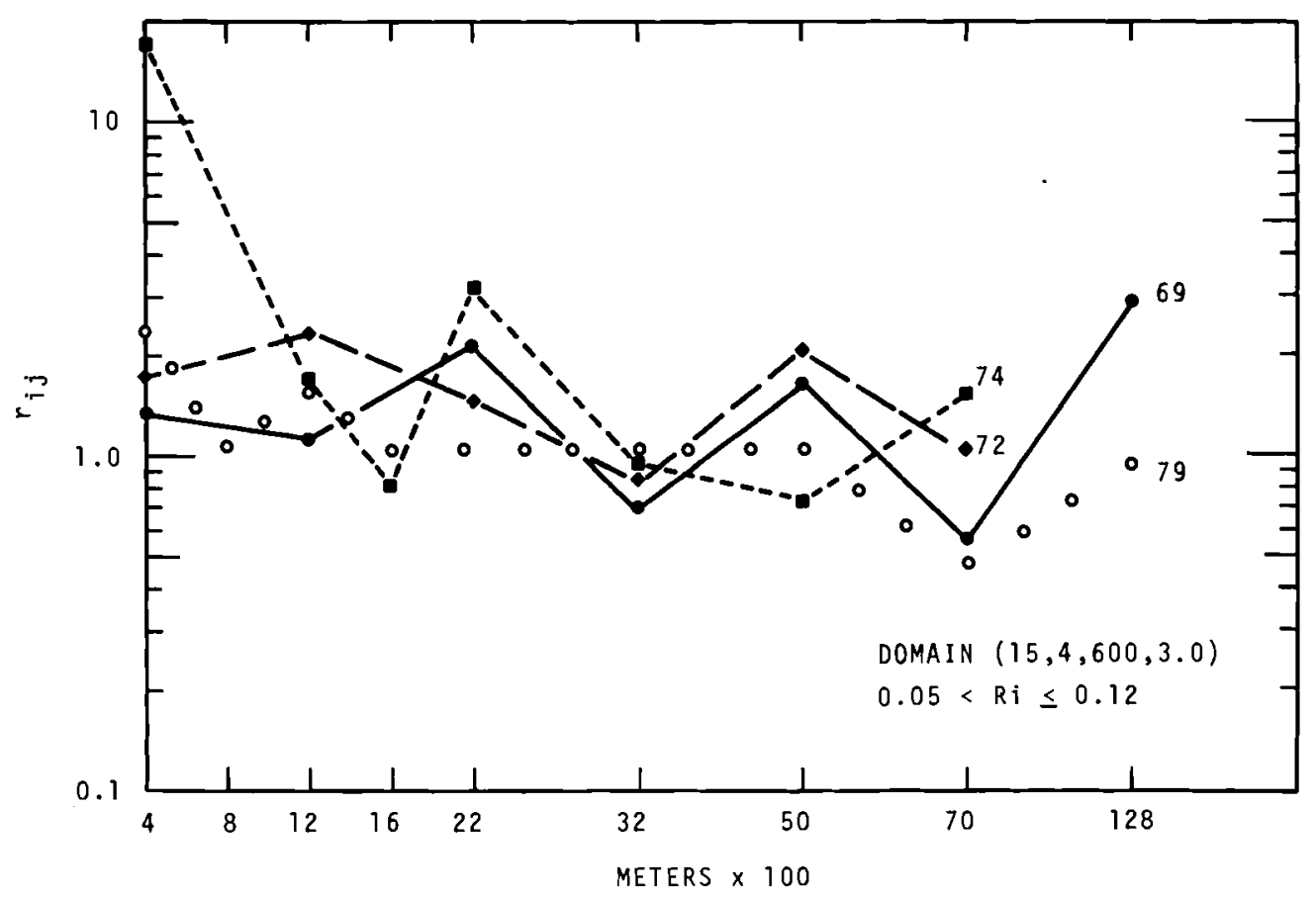

Neg 721306-1

$\frac{\text { FIGURE 2 }}{\text { and } 79 .}$ Ratios, $r_{i j}$, for Test Numbers $69,72,74$,

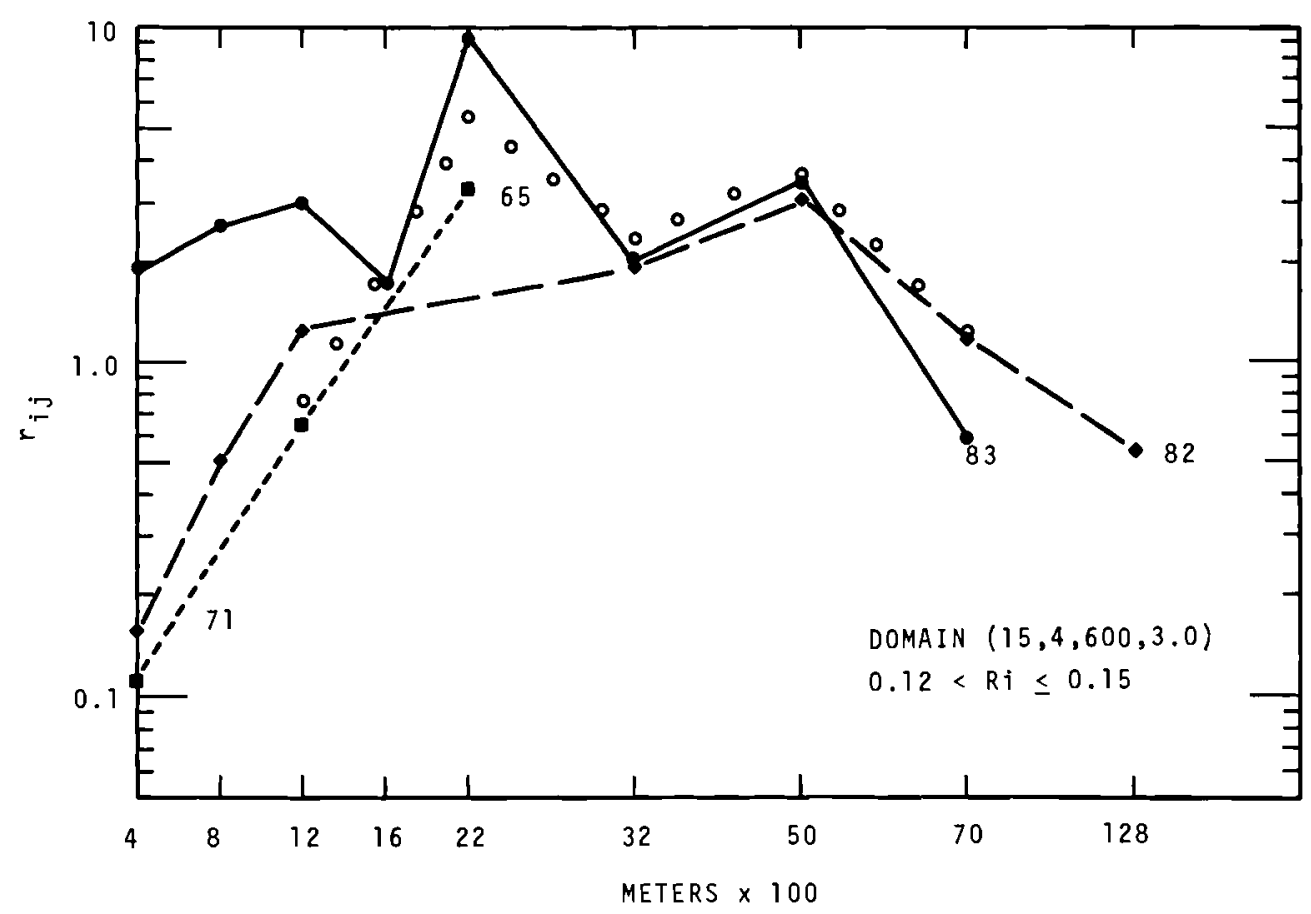

Neg 721306-2

$\frac{\text { FIGURE } 3}{\text { and } 83 \cdot}$. Ratios, $x_{i j}$, for Test Numbers $65,71,82$, 
the greater distances from the source, than would be estimated using only the turbulence at lower level characteristic height.

\section{DISCUSSION}

In examining Table 2 , it is clear that selecting the set of domain values $(15,4,600,3)$ as initially optimum resulted from tempering statistical analysis results with insight into reasonableness of values based on prior independent investigations of turbulence structure; $\beta$, and deposition. However, our basic understanding of these factors is incomplete enough that selecting the best final set of input parameters awaits further experimental evaluation.

There has been no criticism so far of the basic turbulence model accepted from similarity theory along the A.F.C.R.L. and Hanford formulae. Attention must be drawn to the fact that for stable cases the nondimensional shear, $\phi_{m}$, is a rapidly increasing function of $\mathrm{Ri}$, that for the most stable cases analyzed this parameter shifted the spectrum to the right by a full decade. If this is physically unrealistic for the extreme cases, then physically unrealistic values of $\beta$ must be used to counteract the effect. Extension of direct turbulence modeling for greater stabilities through the height range of interest should be carried out to settle this question. The question of the role that critical Richardson's
Numbers plays affecting the diffusion should also be answered in further turbulence investigations.

Also, from Table 2 it is seen that the analys is changes rapidly as a function of $\mathrm{C}_{1}$ and of $\mathrm{C}_{2}$, but slowly as a function of $\mathrm{H}_{\mathrm{C}}$ and of $\mathrm{B}$. This suggests that the manner of variation of $\beta$ with stability is more critical to ascertain than its neutral value. Thus, independent evaluation of $\beta$ as a function of stability or turbulence intensity is important.

The important effect of $\mathrm{C}_{2}$ variation point to the need for further independent evaluation of the deposition process. The best description of deposition velocity as a function of meteorological and surface variables should be sought.

Future studies should be carried out to extend the model to unstable conditions and to greater heights. The crosswind spread should also be included in future adaptations of the model, accounting for the spectrum of the lateral wind component, $\beta$ for the lateral wind component, and the effects of wind direction shear.

\section{REFERENCES}

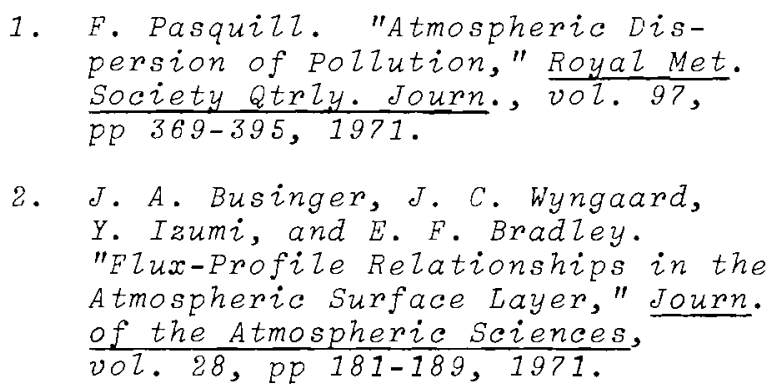

1. F. Pasquizz. "Atmospheric Lispersion of Polzution," Royal Met. Society Qtriy. Journ., vol. 97 , pp 369-395, 1971 .

2. J. A. Businger, J. C. Wyngaard, Y. Izumi, and E. F. Bradley. "Flux-Profile Relationships in the Atmospheric Surface Layer," Journ. $\frac{\text { of the Atmospheric sciences, }}{\text { vol. 28, pp 181-189, 1971. }}$ 


\author{
PROFILE-DERIVED ESTIMATION OF CROSSWIND INTEGRATED \\ EXPOSURE FROM ELEVATED RELEASES: METHOD OF INVESTIGATION \\ D. C. Powell and C. E. Elderkin
}

\begin{abstract}
A method is proposed for estimating without turbulence measurements the crosswind integrated exposure at ground level to a depositing tracer released at an elevated source in the surface boundary layer. The meteorological inputs for the calculations are: (1) the quantity of tracer released; (2) the height of release; (3) the mean wind speeds measured at 15 and 2 meters; (4) the Richardson number calculated from data taken at the same two heights. From these data the friction velocity, $u_{*}$, is first estimated, values of $\sigma_{z}$ for the tracer at downstream distances corresponding to sampling arc locations are calculated using a spectral model and the Hay-Pasquill beta equation, and finally, the crosswind integrated exposure is calculated from a Gaussian equation and corrected using a deposition velocity that is a function of the input variables.
\end{abstract}

\section{INTRODUCTION}

Estimation of downwind exposure to continuous release of effluent from an elevated source is of interest at many locations at which turbulence measurements are not available. This paper describes the initial steps in developing a method, in which the estimation is limited to crosswind integration of the exposure, which reduces the study to that of vertical dispersion as a function of wind and temperature profile derived parameters. The method may be divided into four major parts: (1) estimation of the friction velocity, $u_{*}$, as a function of Richardson number; (2) estimation of the variance of the vertical dispersion, $\sigma_{z}{ }^{2}$, from $u_{*}$ and from the vertical velocity spectrum and predicted values of the LagrangianEulerian scale ratio for appropriate travel time; (3) estimation of cross- wind integrated exposure from a Gaussian equation; and (4) calculation of a deposition velocity which is a function of the meteorological input parameters.

CALCULATION OF U $*$ FOR THE CONSTANT FLUX LAYER

From the relationship given by Businger, et al. (1) for $z / L$ ( $L$ is the Monin-Obukhov length) and the Richardson number, Ri, for stable conditions, the following solution for $z / L$ may be obtained. This value is assumed to apply at the geometric mean height between the two heights used for computing $\mathrm{Ri}$ and is therefore designated, $\mathrm{z}$.

$z_{g} / L=\frac{-0.74+9.4 \mathrm{Ri}+\sqrt{4.9 \mathrm{Ri}+0.55}}{9.4-44 \mathrm{Ri}}$ 
When the log-linear wind equation from the same paper is solved for the friction velocity, $u_{*}$, the result is

$u_{*}=\frac{k \bar{U}(z)}{\operatorname{Ln}\left(z / z_{0}\right)+4.7 z / L} ; \quad \frac{z}{L}=\frac{z_{g}}{\bar{L}} \frac{z}{z_{g}}$

where $\bar{U}(z)$ is the mean value of the longitudinal wind component at a height of measurement, $z ; z_{0}$ is the surface roughness parameter; and $k$ is Von Karman's constant.

\section{CALCULATION OF $\sigma{ }^{2} \frac{\text { FROM } u_{*} \text { AND FROM }}{2}$
THE SPECTRUM OF $\sigma_{w-}$}

The spectrum used is the Hanford logarithmic model for the vertical component. (2) This may be written

$$
\mathrm{nS}_{\mathrm{w}}(\mathrm{n})=\frac{1.15 \mathrm{u}_{*}^{2}\left(\mathrm{f} / 0.46 \phi_{\mathrm{m}}\right)}{1+1.5\left(\mathrm{f} / 0.46 \phi_{\mathrm{m}}\right)^{5 / 3}}
$$

where $f$ is the nondimensional frequency, $n z / U_{c}$ and $\phi_{m}$ is the dimensionless wind shear, calculated according to Businger, et al. (1) by

$$
\phi_{m}=1+4.7 z_{c} / L
$$

where $U_{c}$ is the calculated wind at a height $\mathrm{z}_{\mathrm{c}}$ that is assumed to be a characteristic height for the diffusion process between the height of release, $\mathrm{H}$, and the height of sampling. Currently $z_{c}$ is assumed to be between $0.5 \mathrm{H}$ and $\mathrm{H}$.

Assuming that the vertical dispersion is a function of turbulence only, leads to use of the Hay-Pasquill equation exhibiting $\sigma_{z}{ }^{2}$ as a function of travel time, $T$. The equation may be written (3)

$$
\sigma_{z}{ }^{2}=T^{2} \int_{0}^{\infty} n S_{w}(n) \frac{\sin ^{2}(\pi n T / \beta)}{(\pi n T / \beta)^{2}} d(\operatorname{Ln} n)
$$

where $\mathrm{nS}_{\mathrm{W}}(\mathrm{n})$ is the logarithmic energy spectrum for the vertical component, and $\beta$ is theoretically the ratio of the Lagrangian time scale to the Eulerian time scale of the turbulence. If the value of $\beta$ is adjusted empirically, it may also be a function of other physical factors not included in the model, such as the shear of the mean wind.

Since the spectrum and travel time are functions of the height, so is $\sigma_{z}^{2}$. For an arc at distance $x$ downwind from the source the travel time has been calculated according to

$\mathrm{T}=\mathrm{x} / \mathrm{U}_{\mathrm{C}} \cdot$

The final computation of the crosswind integrated exposure for a nondepositing tracer with settling velocity $V_{S}$ is from a Gaussian equation

$$
\begin{aligned}
E\left(x / U_{c}\right)= & \sqrt{\frac{2}{\pi}} \frac{Q}{U_{c} \sigma_{z}\left(x / U_{c}\right)} \\
& \exp \left\{-\frac{1}{2}\left(\frac{H-x V_{s} / U_{c}}{\sigma_{z}\left(x / U_{c}\right)}\right)^{2}\right\}
\end{aligned}
$$

where $Q$ is the total tracer mass released. The dependency is given as a time function rather than as a distance function because Fuquay, et a1. (4) and Nickola (5) have found that diffusion is better exhibited as a function of travel time than of travel 
distance. The inclusion of the settling velocity has the effect of tipping the cloud downward at an angle to the horizontal of $\tan ^{-1} \mathrm{v}_{\mathrm{s}} / \mathrm{U}_{\mathrm{c}}$.

\section{EFFECT OF DEPOSITION}

Equation (7) assumes a nondepositing tracer, or equivalently, a virtual source below the surface at height, $H$. An equation accounting for the depletion of the tracer is given by Van der Hoven, (6) which when modified to include the settling effect may be written:

$$
\begin{aligned}
\operatorname{Ln} \frac{E_{x}}{E}= & -\sqrt{\frac{2}{\pi}} \frac{V_{d}}{U_{c}} \int_{0}^{x} \sigma_{z}^{-1} \\
& \exp -\frac{1}{2}\left(\frac{H-x^{\prime} V_{s} / U_{c}}{\sigma_{z}}\right)^{2} d x '
\end{aligned}
$$

where $E_{x}$ is the final exposure, calculated as a function of deposition, and $\mathrm{V}_{\mathrm{d}}$ is the deposition velocity. $\sigma_{z}(\mathrm{x})$ is as computed in Equation (4) with $\mathrm{T}=\mathrm{x} / \mathrm{U}_{\mathrm{C}}$.

Exposures calculated according to Equation (8) can be compared to measure exposures summed along an arc of the Hanford diffusion grid, multiplied by the distance between samplers. The comparisons so obtained are the test for the method.

\section{REFERENCES}

1. J. A. Businger, J. C. Wyngaard, Y. Izumi, and E. E. Bradley. "Flux-Profile Relationships in the Atmospheric Surface Layer," J. of the Atm. Sciences, vol. 28 , 1971 .

2. C. E. Elderkin. "Diabatic Effects on Atmospheric Turbulence Spectrum," Pacific Northwest Laboratory Annual Report for 1970 to the USAEC Division of Biology and Medicine, Vol. II: Physical Sciences, Part 1. Atmospheric Sciences, BNWL-1551-1, Battelle, Pacific Northwest Laboratories, Richland, Washington, June 1971.

3. F. Pasquizz. Atmospheric Diffusion, D. Van Nostrand Company LTD, 1962.

4. J. J. Fuquay, C. L. Simpson, and W. T. Hinds. "Prediction of Environmental Exposures from Sources near the Ground Based on Hanford Experimental Data," J. of Applied Meteorology, vol. 3, 1964 .

5. P. W. Nickola. "Measurements of the Movement, Concentration and Dimensions of Clouds Resulting from Instantaneous Point Sources," Ibid, vol. $10,1971$.

6. I. Van der Hoven. "Deposition of Particles and Gases," Meteorology and Atomic Energy - $19 \overline{68, D . H .}$ Stade, ed., U.S. Atomic Energy Commission, Division of Technical Information, available as TID-24190 from the clearinghouse, 1968. 


\author{
DETERMINATION OF THE VON KARMAN AND KOLMOGOROV CONSTANTS \\ FROM MEASUREMENTS OF WIND STRESS AND SPECTRA \\ T. W. Horst
}

\begin{abstract}
Two relationships between the von Karman and Kolmogorov constants are presented which independently provide constraints on the allowable values for these two constants. Combined, they permit the determination of both constants from the measurement of the stress, mean wind, and power spectrum in the inertial subrange with a single, fast response, three dimensional anemometer during neutral atmospheric stability conditions.
\end{abstract}

Recent independent measurements of the stress and wind shear (1) have indicated that the parameter relating these two quantities under neutral stability conditions, von Karman's constant, $k$, is about 12 percent smaller than the previously wellestablished value of 0.40 . If this latest value is correct, use of the previous value would lead to a 30 percent overestimate in the profilemeasured wind stress. This same error would be carried into estimations of the turbulent kinetic energy within the atmospheric boundary layer, since it is the wind shear-wind stress interaction which produces most of the turbulent energy under all but very unstable conditions. Knowledge of turbulent energy levels is vital for the prediction of many aspects of aerosol transport within the atmospheric boundary layer: diffusion, deposition, resuspension, etc. Although a 30 percent error may in many instances be unimportant compared to the approximations which become necessary when theory must be applied to a real problem, this may also be an unacceptably large error when carefully controlled experiments are performed to develop the theory.

A search for other means of measuring this important constant has brought to light a relationship between $k$ and the Kolmogorov constant of the power spectrum in the inertial subrange. Under neutral stability conditions within the constant flux layer, the equations defining the von Karman and Kolmogorov constants may be combined to obtain a relation between them and a third parameter, which can easily be measured to high accuracy with a single threedimensional anemometer. A recent theoretical extension of Heisenberg's formula for the spectral transfer of turbulent energy to the problem of the turbulent boundary layer by Roth ${ }^{(2)}$ provides an independent relationship which closes the system of equations and permits evaluation of both constants.

Using Taylor's hypothesis for the relationship between spatial and temporal descriptions of turbulence, the one-dimensional power spectrum of the 
longitudinal component of the wind in the inertial subrange obeys the power law,

$\omega S_{u}(\omega)=a(\varepsilon \bar{U} / \omega)^{2 / 3}$

where $\omega$ is angular frequency, $S_{u}(\omega)$ is the power spectrum, a is the Kolmogorov constant, $E$ is the viscous dissipation, and $\bar{U}$ is the mean wind speed. If, under conditions of neutral stability, the terms which account for the vertical divergence of turbulent and pressure transport of kinetic energy can be ignored, the steady state, horizonta11y homogeneous turbulent kinetic energy budget reduces to

$E=u_{*}^{2} \frac{\partial \bar{U}}{\partial z}$

where $z$ is the vertical coordinate and $u_{*}$ is the friction velocity (equal to the square root of the surface stress divided by the air density). Von Karman's constant, $k$, is defined by the equation

$\frac{\partial \bar{U}}{\partial z}=\frac{u_{*}}{\overline{k z}}$

which is strictly valid in the constant stress layer only for a neutral, steady state, horizontally homogeneous situation.

These three equations can be combined to give a relationship between the von Karman and Kolmogorov constants, $\mathrm{ak}^{-2 / 3}=\frac{\omega \mathrm{S}_{\mathrm{u}}(\omega)}{\mathrm{u}_{*}^{2}}\left(\frac{\omega z}{\overline{\mathrm{U}}}\right)^{2 / 3} \equiv \mathrm{C}$

Under the conditions stipulated above, the quantity $\mathrm{C}$ is a constant which has a very desirable property. If a single three dimensional anemometer which has frequency response into the inertial subrange is used to measure the power spectrum, stress and mean wind, the resulting estimate for the constant $C$ is insensitive to calibration errors since they will only be evident in the determination of the mean wind. An instrumental error will be made in the quantity $S_{u}(\omega) u_{*}{ }^{-2}$ only if the horizontal and vertical axes of the instrument have inconsistent calibrations or if these axes are inadequately aligned to the true horizontal and vertical. Equation (4) has been plotted in Figure 1 for several values of the constant $C$. Reasonable values for the von Karman and Kolmogorov constants are seen to limit $C$ to the approximate range 0.8 to 1.2 .

This equation may be combined with an independent relationship between a and $\mathrm{k}$ developed by Roth ${ }^{(2)}$ to give both of these constants from an experimental measurement of the single constant $C$. Roth has utilized the hypothesis of Heisenberg for the spectral transfer of turbulent kinetic energy to derive the relationship

$\mathrm{ak}^{4 / 3}=\frac{4 \sqrt{3}}{55}=0.126$

This derivation a1so applies only when the conditions (1)-(3) are satisfied. Equation (5) has been plotted in Figure 1 , the intersection with the lines parameterized by $\mathrm{C}$ determining $a$ and $k$ according to

$a=0.50 C^{2 / 3}$

$k=0.355 \mathrm{C}^{-1 / 2}$ 


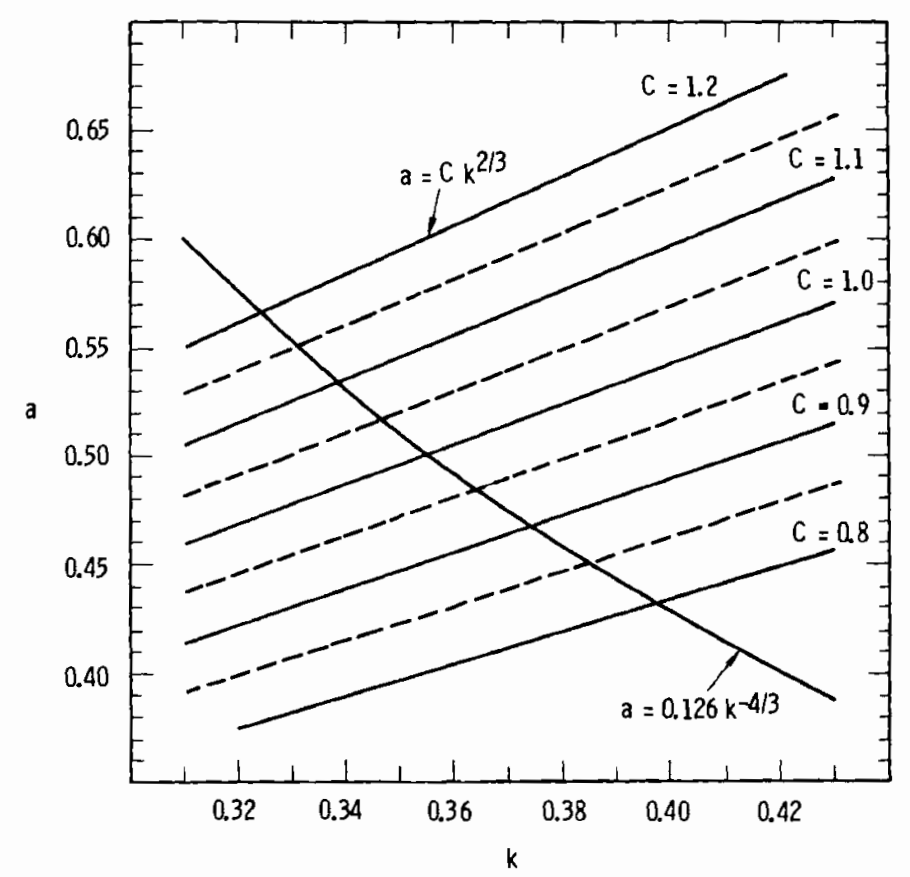

Neg 714606-1

FIGURE 1. Kolmogorov's Constant, a, Versus von Karman's Constant, $k$, for Roth's Theory, $a=0.126 \mathrm{k}^{-4 / 3}$, and for $\mathrm{a}=\mathrm{Ck}^{2 / 3}$

The same data set which led to a value of 0.35 for von Karman's constant gave a value of 0.50 for Kolmogorov's constant (3), confirming Equation 5 ,

$\mathrm{ak}^{4 / 3}=0.123$,

and producing a value of 1.01 for the constant $C$.

A reexamination of Hanford data (4) for one test during neutral stability indicates that $C$ may be as large as 1.1 to 1.2. Combined with the results of other investigators ${ }^{(5)}$ that Kolmogorov's constant may be 10 percent greater than the value quoted above, this also lends support to the value 0.35 for $k$. More data need to be collected during neutral stability conditions for the simultaneous, independent measurement of the two constants defined by Equations (1) and (3). One such series of measurements has been performed by BattelleNorthwest in cooperation with the University of Washington Atmospheric Sciences Department.* The relationships presented here will provide a framework for examining these data and checking the results for internal consistency.

* See following contribution "Turbulence Measurements on the Bonnevilze Salt Flats" by the same author. 


\section{REFERENCES}

1. J. A. Businger, J. C. Wyngaard, Y. Izumi and E. F. Bradley, "Fluxprofile Relationships in the A tmospheric Surface Layer," $J$.

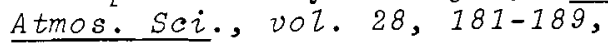
1971 .

2. R. Roth, "On the Existence of a Relation between the Kolmogorov and Von Karman Constants," Boundary-Layer Meteorology, vol. 1, 131-136, 1970.

3. J. C. Kaimal, J. C. Wyngaard, Y. Izumi, and O.R. Cote, "Spectral Characteristics of Surface Layer Turbulence," submitted to QJRMS, 1971.
4. C. E. Elderkin, D. C. Powezl, and T. W. Horst, "Modeling of Wind Component spectra," Pacific Northwest Laboratory Annual Report for 1970 to the USAEC Division of Biology and Medicine, Volume II: Physical Sciences, Part 1. Atmospheric Sciences, BNWL-1551, Battelie-Northwest, Richland, Washington, June 1971.

5. G. A. MeBean, R. W. Stewart, and M. Miyake, "The Turbulent Energy Budget near the Surface," $J$. Geophys. Res., vol. $76,65 \overline{40}-6549$, 1971.

\title{
TURBULENCE MEASUREMENTS ON THE BONNEVILLE SALT FLATS
}

\author{
T. W. Horst
}

\begin{abstract}
A recent field trip to the Bonnevilze salt Flats to make fast response measurements of the wind with three-component hot film and sonic anemometers had three objectives: the determination of the von Karmán and Kolmogorov constants, turbulence measurements within the lowest centimeters of the atmosphere, and comparison of the two types of anemometers. Fifteen hours of data were obtained and analysis is in progress.
\end{abstract}

A series of turbulence measurements was made during the period septem-

ber 13-21 in cooperation with the University of Washington Atmospheric Sciences Department. Although the data will be useful for many purposes, the participation of Battelle-Northwest had three specific objectives: to obtain data during periods of neutral stability for the determination of the von Kármán and Kolmogorov constants, to obtain turbulence data within the lowest centimeters of the atmospheric boundary layer for the study of deposition and resuspension, and to investigate the performance of the threedimensional hot film anemometer which is to be used for turbulence measurements from the Battelle-Northwest aircraft. The site for these measurements was the Bonneville Salt Flats 
near Wendover, Utah, a choice dictated by the requirements of the first objective for horizontally homogeneous terrain and by the desire to measure very close to the surface. The salt Flats (Figure 1) provided a vast, extremely uniform plain, bordered by peaks which rise to heights of $300-$ $1000 \mathrm{ft}$ above it, and measurements were made with fetches from 80 to $50 \mathrm{~km}$. Rougher elements were generally less than a centimeter in height.

The determination of the von Kármán and Kolmogorov constants re-

* See preceding contribution, "Determination of the von Karmán and Kolmogorov Constants from Measurements of Wind Stress and Spectra." quires measurements of the wind shear, Reynolds stress, power spectra, and dissipation during periods of neutral atmospheric stability.* Since in the constant flux layer the stability approaches neutral as the height decreases, the smoothness and uniformity of the Utah site were a great advantage, allowing measurements to be made quite close to the surface. A KaijoDenki three-dimensional sonic anemometer-thermometer was used at a height of $2 \mathrm{~m}$ for measurements of the Reynolds stress, power spectra, and heat flux (or stability). Measurements of the wind shear were provided by the U. of W. profile system (I)

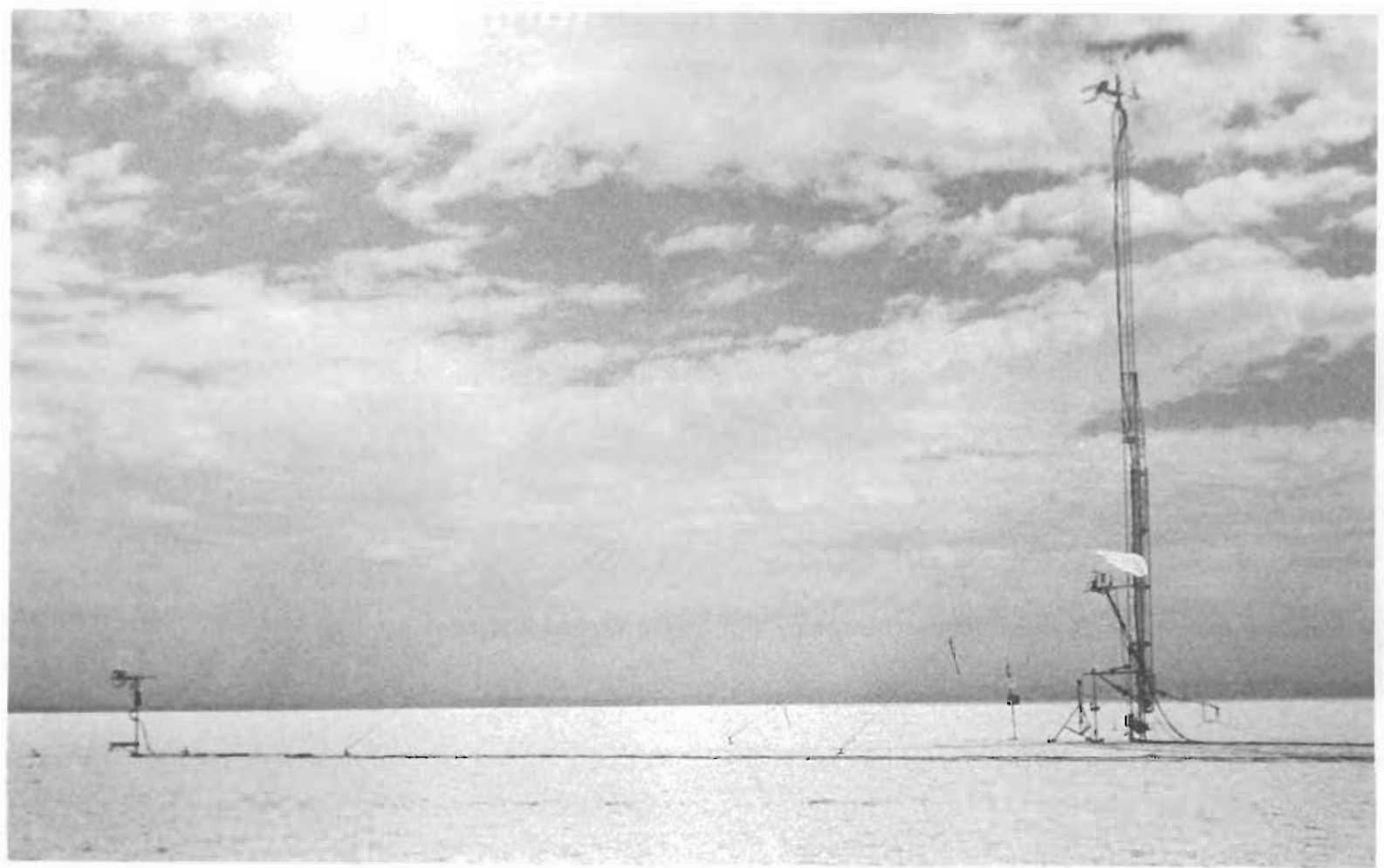

Neg $714436-5$

FIGURE 1. Experimental Field site on the Bonneville Salt Flats, Instrumented with the $15 \mathrm{~m} \mathrm{U}$. of Washington Tower and, at the Left, the $2 \mathrm{~m}$ BNW Mast 
using cup anemometers, and the dissipation was measured with the time differentiated output from a Thermo Systems three-dimensional hot film anemometer. This anemometer also provided a supplementary measurement of the Reynolds stress and, with a thermistor temperature probe, of the heat flux, as well as higher frequency measurements of the power spectra. The hot film anemometer was placed at either $1 \mathrm{~m}$ or $2 \mathrm{~m}$. At the greater height, it was situated within the sonic array for a calibration check and for direct comparison of all aspects of its performance with that of the sonic. The $1 \mathrm{~m}$ location provided a closer realization of neutral stability. 1 .

* See contribution, "Deposition Velocities as a Function of Particle Concentration Reference Height and Atmospheric Stabizity," in this report.
Field studies of deposition and resuspension as well as the application of laboratory studies of these phenomena to the atmosphere require knowledge of the wind structure close to the surface.* This goal, too, was facilitated by the extremely smooth, uniform terrain of the salt Flats. Additional measurements of the wind were made for this purpose with the hot film anemometer at heights of 10 , 24,44 , and $77 \mathrm{~cm}$.

Analysis of these data is in progress.

\section{REFERENCE}

C. A. Paulson, "Profizes of wind Speed, Temperature and Humidity over the Sea," NSF Scientific Report GP-2418, 1967 .

\title{
TURBULENCE MEASUREMENT AND ANALYSIS CAPABILITIES
}

C. E. Elderkin, A. G. Dunbar and D. C. Powell

\begin{abstract}
A system for measuring and storing turbuzence data from an array of sonic and Gill anemometers mounted on towers was developed at Hanford. Computer methods for processing and analyzing the turbulence data were also established.
\end{abstract}

\section{INTRODUCTION}

A system for measuring and storing the turbulence from several points in a large field measurement grid was developed at Hanford for the Air Force in connection with the Take-off and Landing Critical Atmospheric Turbulence (TOLCAT) program. In addition, the techniques and computer 
programs for processing and analyzing the data from this system were established. This measurement and analysis capability has also been found to be appropriate to the needs of the AEC and is currently being used in ongoing turbulence and diffusion studies. A brief description of this capability is given here.

\section{INSTRUMENTATION AND FIELD ARRAY}

The multi-point turbulence measurement system utilizes sensors mounted on an array of towers for measurement of turbulence fluctuations in the three components of the wind at various heights and horizontal spacings, and under various meteorological conditions. The measurement array is shown in Figure 1. The data are collected in the field on analog recorders, played back into a medium-size computer for pre-processing the data and are recorded on industry standard tapes for later details processing and analysis on a UNIVAC 1108 computer.

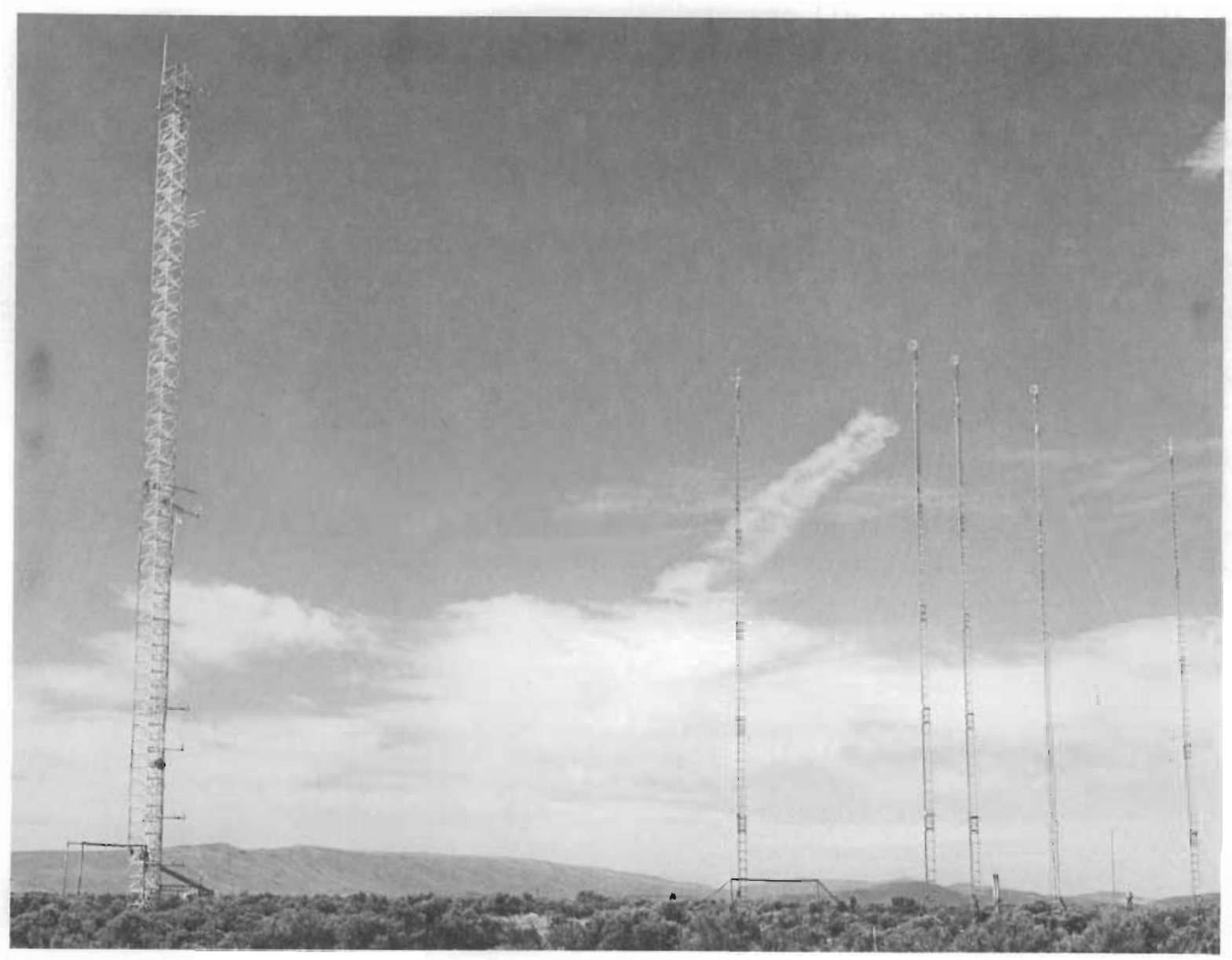

Neg 711845-12

FIGURE 1. The Field Measurement Array 
Two types of turbulence sensors are utilized: fast response sonic anemometers for the most accurate determinations of momentum and heat fluxes used in characterizing the stability of the atmosphere, for power spectral definition into the inertial subrange, and for spatial correlations over small separation distances; and less expensive Gill three-propeller anemometers for the large separation distances where their slower response is adequate.

The mountings for both types of instruments are constructed in a manner that assures true sensor leveling and optimum orientation into the wind at inaccessible remote locations on tower tops and on the ends of tower booms. This has been accomp 1 ished by utilizing remotely monitored electrolytic levelers on each sensor and an antenna rotor base on each sensor for remote reorientation from centra11y located control trailers.

The sensors can be mounted on four permanently erected, $62-\mathrm{m}$ towers or eight $30-\mathrm{m}$ expandab1e, portable towers which can be repositioned for various measurement configurations to meet different experimental requirements. The sensor booms can be moved to various heights on the $62-\mathrm{m}$ tower and the sensors on the tops of the $30-\mathrm{m}$ towers can be raised and lowered to measure the turbulence at selected heights.

The two control trailers, downwind of the tower array, contain the signal conditioning and data recording equipment. Two 14-channel analog magnetic tape recorders are generally used to record the three wind component signals from each of three sonic anemometers and five Gill anemometers, and the temperature signals from each of two sonics. One channel on each recorder is used for a coordination timing signal.

\section{DATA PROCESSING}

After each experiment, tape recordings of the field data are taken to a computer laboratory where the data are played back from one of the analog tape units into an analog-todigital converter, interfaced to an SEL $840 \mathrm{~A}$ medium-size computer. The computer is programmed to test the data for reasonableness and to perform preliminary editing; average a selectable number (usually five) of the 100 to 200 basic samples per second together to minimize aliasing and provide a range of optional digitizing rates, make instrument corrections, such as conversion of sonic nonorthogonal measured components to cartesian wind components; perform scaling functions to account for gains and offsets used during measurements; and final1y, to record digital values of the three orthogonal wind components and the temperature on an industry standard digital tape recorder interfaced with the SEL 840A, for more thorough and repeated analyses to be performed later on a UNIVAC 1108 computer.

The 1108 programs perform more refined editing and corrects Gill anemometer data for deviations of the propellers from a true cosine response, 
which is necessary for adequate turbulence statistics, before rerecording the true wind components in $\mathrm{cm} / \mathrm{sec}$ and temperature in hundredths of a Centigrade degree on "master tapes." These are then processed by the probability subroutines which, for selectable time periods within the total data segment, calculate and remove means for each of the variables; reorient the coordinate system in the direction of the mean wind, if desired; provide up to three different high-pass filterings of the data and the probability density functions individual and joint - for each when requested; and calculate variances for each component and covariances between them, as well as the third and fourth moments. An option to plot any of the time series in the data segment being analyzed is also available. The unfiltered turbulence variables are then selected, two at a time, for analysis by the spectral subroutines. Here, the data are optionally detrended with the best fitting first or second order polynomial for each time series and tapered to prevent ringing oscillations in the fast Fourier transform calculated spectra. Then the Fourier coefficients are calculated from which banded power spectral and crossspectral estimates are formed. The auto- and cross-correlation functions can, in turn, be transformed from these estimates if required. Variances and covariances for the detrended time series are also available from this program.

With this versatile system of measurement and analysis, data from a number of points arranged in various configurations in a field of turbulence can be accurately recorded and rapidly processed. The variety of analyses available allows the turbulence to be studied comprehensively in space and time. 


\title{
A COMPUTER ALGORITHM FOR CORRECTING NONCOSINE RESPONSE
}

\author{
IN THE GILL ANEMOMETER
}

T. W. Horst

\begin{abstract}
A fast computational algorithm is presented which adequately corrects for noncosine response in the Gizl UVW propelzer anemometer. Computational time is reduced by performing calculations in integer arithmetic and by indexing the cosine correction as a function of the cosine of the angle between the wind vector and the propelzer axis, rather than as a function of the angle itself.
\end{abstract}

After considering such factors as initial cost and reliability, the Gill three-propeller anemometer was chosen as a basic tool to be used in several research programs at Hanford to measure the three components of the wind. Careful comparison experiments with the Wind Component Meter and the Kaijo Denki sonic anemometer have shown that the most serious error in the Gill anemometer at frequencies below about $0.3 \mathrm{~Hz}$ is the inability of an individual propeller to totally respond to the component of the wind parallel to its axis of rotation. (1-2) Above this frequency, the inertia of the rotating propeller begins to significantly reduce the response of the instrument, but this is not a serious problem for many applications which on $1 y$ require information about the larger eddies. The former problem, termed noncosine response, can be adequately corrected for during digital computer processing of the data by using the manufacturer's response data and a computational algorithm presented here. It has evolved through several versions, each being faster than the former. This is an important point since the algorithm is applied to each and every digital data sample (up to 60 per minute of data) and charges for computer services are based on computation time.

The component of the wind parallel to a given axis is

$u=S \cos \theta$

where $u$ is the wind component, $S$ is the magnitude of the wind vector, and $\theta$ is the angle between the wind and the propelier axis. The Gill propeller anemometer measures less than this ideal quantity, hence the term noncosine response, and the deviation from cosine response becomes worse as the angle increases from $0^{\circ}$ to $90^{\circ}$. The cosine response will be worst for the vertical axis propelier, the wind fluctuating about an angle of $90^{\circ}$, and hence this arm is calibrated for a 25 percent greater output than the horizontal arms to bring the response closer to the cosine law within the expected input range of $60^{\circ}$ to $120^{\circ}$. Using 
the manufacturer's wind-tunnel-derived response data, corrections to the measured wind have been determined as a function of $\cos \theta$ and are 1 isted in Table 1 .
The algorithm, written in FORTRAN, is 1 isted in Figure 1 . Wherever possible, computations are performed in integer arithmetic to decrease execution time. Since the correction for each measured wind component is

TABLE 1. Gill Cosine Correction Factors, Multipled by 100 , as a Function of $\cos \theta$

Cosine Correction for Horizontal Axes

\begin{tabular}{|c|c|c|c|c|c|c|c|}
\hline $\cos \theta$ & HORCOR & $\cos \theta$ & HORCOR & $\cos \theta$ & HORCOR & $\cos \theta$ & HORCOR \\
\hline-1.00 & 100 & -0.50 & 123 & 0.00 & 200 & 0.50 & 128 \\
\hline-0.98 & 101 & -0.48 & 123 & 0.02 & 200 & 0.52 & 127 \\
\hline-0.96 & 101 & -0.46 & 123 & 0.04 & 200 & 0.54 & 126 \\
\hline-0.94 & 102 & -0.44 & 122 & 0.06 & 180 & 0.56 & 124 \\
\hline-0.92 & 102 & -0.42 & 121 & 0.08 & 173 & 0.58 & 123 \\
\hline-0.90 & 103 & -0.40 & 121 & 0.10 & 167 & 0.60 & 122 \\
\hline-0.88 & 104 & -0.38 & 121 & 0.12 & 160 & 0.62 & 121 \\
\hline-0.86 & 105 & -0.36 & 121 & 0.14 & 156 & 0.64 & 120 \\
\hline-0.84 & 106 & -0.34 & 120 & 0.16 & 153 & 0.66 & 119 \\
\hline-0.82 & 106 & -0.32 & 119 & 0.18 & 150 & 0.68 & 117 \\
\hline-0.80 & 107 & -0.30 & 119 & 0.20 & 148 & 0.70 & 116 \\
\hline-0.78 & 108 & -0.28 & 118 & 0.22 & 147 & 0.72 & 114 \\
\hline-0.76 & 110 & -0.26 & 118 & 0.24 & 145 & 0.74 & 112 \\
\hline-0.74 & 111 & -0.24 & 117 & 0.26 & 144 & 0.76 & 111 \\
\hline-0.72 & 113 & -0.22 & 116 & 0.28 & 144 & 0.78 & 110 \\
\hline-0.70 & 115 & -0.20 & 115 & 0.30 & 143 & 0.80 & 109 \\
\hline-0.68 & 116 & -0.18 & 114 & 0.32 & 142 & 0.82 & 108 \\
\hline-0.66 & 118 & -0.16 & 114 & 0.34 & 141 & 0.84 & 106 \\
\hline-0.64 & 120 & -0.14 & 117 & 0.36 & 139 & 0.86 & 105 \\
\hline-0.62 & 121 & -0.12 & 120 & 0.38 & 138 & 0.88 & 104 \\
\hline-0.60 & 122 & -0.10 & 125 & 0.40 & 136 & 0.90 & 103 \\
\hline-0.58 & 122 & -0.08 & 133 & 0.42 & 133 & 0.92 & 102 \\
\hline-0.56 & 122 & -0.06 & 150 & 0.44 & 132 & 0.94 & 102 \\
\hline-0.54 & 123 & -0.04 & 200 & 0.46 & 131 & 0.96 & 101 \\
\hline-0.52 & 124 & -0.02 & 200 & 0.48 & 130 & 0.98 & 100 \\
\hline & & & & & & 1.00 & 100 \\
\hline
\end{tabular}

Cosine Correction for Vertical Axis

\begin{tabular}{|c|c|c|c|c|c|c|c|}
\hline $\cos \theta$ & VERCOR & $\cos \theta$ & VERCOR & $\cos \theta$ & VERCOR & $\cos \theta$ & VERCOR \\
\hline-0.50 & 104 & -0.24 & 104 & 0.00 & 200 & 0.26 & 111 \\
\hline-0.48 & 104 & -0.22 & 105 & 0.02 & 200 & 0.28 & 111 \\
\hline-0.46 & 104 & -0.20 & 106 & 0.04 & 200 & 0.30 & 111 \\
\hline-0.44 & 104 & -0.18 & 107 & 0.06 & 150 & 0.32 & 110 \\
\hline-0.42 & 105 & -0.16 & 110 & 0.08 & 133 & 0.34 & 109 \\
\hline-0.40 & 105 & -0.14 & 113 & 0.10 & 128 & 0.36 & 107 \\
\hline-0.38 & 105 & -0.12 & 118 & 0.12 & 122 & 0.38 & 106 \\
\hline-0.36 & 105 & -0.10 & 125 & 0.14 & 121 & 0.40 & 105 \\
\hline-0.34 & 106 & -0.08 & 133 & 0.16 & 119 & 0.42 & 105 \\
\hline-0.32 & 106 & -0.06 & 150 & 0.18 & 117 & 0.44 & 104 \\
\hline-0.30 & 106 & -0.04 & 200 & 0.20 & 114 & 0.46 & 103 \\
\hline-0.28 & 105 & -0.02 & 200 & 0.22 & 113 & 0.48 & 102 \\
\hline-0.26 & 104 & & & 0.24 & 112 & 0.50 & 100 \\
\hline
\end{tabular}


a function of the angle between that propeller axis and the wind vector and since the correct wind vector may have an orientation different from that of the uncorrected wind vector, an iterative scheme must be used until the results converge. The direction cosines are calculated from the three wind components, the appropriate

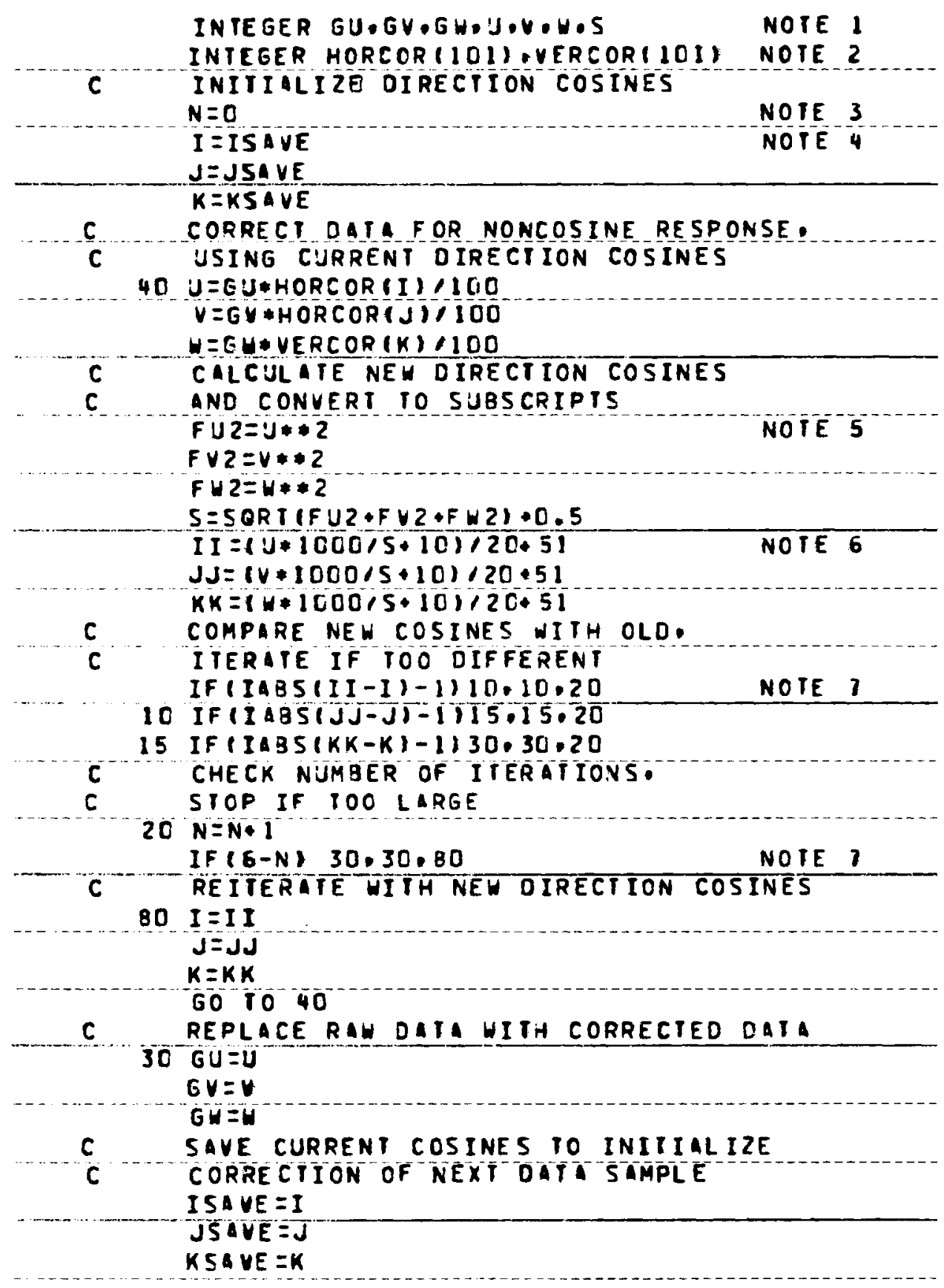

Neg 720264-1

FIGURE 1. FORTRAN Algorithm for Correcting Noncosine Response in the Gill UVW Propeller Anemometer 
corrections are selected and applied to the data, and new direction cosines are calculated from the corrected wind components. A time consuming operation, that of calculating

$\theta=\cos ^{-1}\left[u /\left(u^{2}+v^{2}+w^{2}\right)^{1 / 2}\right]$,

is eliminated by tabulating and applying the correction as a function of $\cos \theta$ rather than $\theta$. Less than $\operatorname{six}$ repetitions of these steps is normally adequate for successive direction cosines to agree within $10^{-2}$. Additional comments on the algorithm are 1 isted separatel $\dot{y}$ for certain of the FORTRAN statements.

\section{REFERENCES}

1. T. W. Horst, "Corrections for Response Errors in a ThreeComponent Propeller Anemometer," to be submitted for publication to Journal of Applied Meteorology.

2. C. E. Elderkin, D. C. Powell, A. G. Dunbar and T. W. Horst, Takeoff and Landing Critical Atmospheric Turbulence (TOLCAT) - Experiments and Analysis, Battelle Memorial Institute, Pacific Northwest Laboratory Technical Report AFFDL-TR-71-172, (In Publication).
Note 1: GU, GV, GW are the raw data points (in $\mathrm{cm} / \mathrm{sec} \times 2$ ) for the three components of the Gill anemometer. U, V, W, S are the corrected wind components and their vector sum.

Note 2: HORCOR, VERCOR are the tabulated corrections (Table 1) multiplied by 100 .

Note 3: N keeps track of the number of iterations.

Note 4: I, J, K, etc., are the direction cosines converted to the appropriate subscripts for HORCOR(I) and $\operatorname{VERCOR}(K)$. The first iteration for each set of three data points is performed with the corrected direction cosines from the previous data point. Note 5: The root sum of $U^{2}, V^{2}, W^{2}$ must be calculated in floating point arithmetic.

Note 6: The 10 added to the direction cosine rounds it off before conversion to a subscript.

Note 7: Iteration ceases only if the old and new cosines all agree within \pm 0.02 or if six iterations have been performed. 


\section{PUBLICATIONS AND PRESENTATIONS}

\section{DOCUMENTS}

Staff of the Atmospheric Sciences Department. Pacific Northwest Laboratory Annual Report for 1970 to the USAEC Division of Biology and Medicine, Volume II: Physical sciences, part 1 . Atmospheric Sciences, BNWL-1551, Battelie, Pacific Northwest Laboratories, Richland, Washington. June 1971 .

W. T. HINDS and J.M. THORP. Annual Summaries of Microclimatological Data from the Arid Lands Ecology Reserve, BNWL-1629, Battelle, Pacific Northwest Laboratories, Richzand, Washington. November 1971.

C. E. ELDERKIN, D. C. POWELL, A. G. DUNBAR and T. W. HORST. Takeoff and Landing Critical A tmospheric Turbulence (TOLCAT) Experimental Investigation. AFFDL-TR-70-117, Air Force Flight Dynamics Laboratory, Air Force Systems Command, WrightPatterson Air Force Base, Ohio. May, 1971.

\section{PUBLICATIONS}

G. A. SEHMEL. "Complexities of Particle Deposition and Re-Entrainment in Turbulent Pipe Flow, "Aerosol Science, vol. 2, pp. 63-72. 1971.

R. J. ENGELMANN and R. W. PERKINS. "Precipitation processes Revealed by Cosmogenic Radionuclide scavenging," J. of Atmos. Sci., vol. 28, No. 1, pp.131-133. January 1971.

G. A. SEHMEL. "Particle Diffusivities and Deposition Velocities Over a Horizontal Smooth Surface," J. of Colzoid and Interface Science, vol. 37, No.4, pp. 891-906. 1971.

J. M. NIELSEN and N. A. WOGMAN. "Some Nuclear Techniques for Atmospheric Dilution and Dispersion Studies," Proceedings of the International Atomic Energy Agency Meeting, Salaburg, Austria Symposium on "Nuclear Techniques in Environmental Pollution," IAEA-SM142a/14. Conf - 701023. 1971 .
J. V. RAMSDELL, JR. and W. T. HINDS. "Concentration Fluctuations and PeakTo-Mean Concentration Ratios in Plumes from a Ground Level Continuous Point Source," Atmospheric Environment, vol. 5, pp. 483-495. July 1971.

J. M. HALES, L. C. SCHWENDIMAN and T. W. HORST. "Aerosol Transport in a Naturalzy-Connected Boundary Layer," BNWL-SA-3592. Submitted for publication in the International Journal of Heat and Mass-Transfer. August 1971.

D. G. ATKINSON, W. E. DAVIS, L. F. RADKE, B. C. SCOTT, W.G.N. SLINN, T. M. TANNER, J. M. THORP, N.A. WOGMAN and J. A. YOUNG. "Precipitation Scavenging of Tracers Released into Frontal Storms," Bul. Am. Met. Soc., vol. 52, p. 1047, 1971

(abstract) and submitted for publication to J.Appl. Met.

W.G.N. SLINN and A. G. GIBBS. "The Stochastic Growth of a Rain Droplet," J. Atmos. Sciences, vol. 28, No. 6 , pp. 973-982. September 1971 .

W.G.N. SLINN and S. F. SHEN.

"Brownian Diffusion in a Nonuniform Gas," J. Stat. Phys., vol. 3, No. 3, pp. 291-305. Autumn 1971.

P. W. NICKOLA. "Measurement of the Movement, Concentration and Dimensions of Clouds Resulting from Instantaneous Point Sources," J. of Applied Meteorology, vol. 10, No. 5, pp. 962-973. october 1971.

P. W. NICKOLA, J. D. LUDWICK and J. V. RAMSDELL. "An Atmospheric Tracer Technique Employing $85 \mathrm{Kr}$ and use of this Technique in Defining Puff Dimensions and Transport speed," Isotopes. and Radiation Technology, vol. 9 , No. 1. Fall (November) 1971.

W.G.N. SLINN. "Time Constants for Cloud seeding and Tracer Experiments," J. Atmos. Sciences, vol. 28 , No. 8, pp. 1509-1511, November 1971 .

W.G.N. SLINN and J.M. HALES. "A Reevaluation of the Role of Thermophoresis as a Mechanism of In- and BelowCloud Scavenging," J. Atmos. Sciences, vol. 28 , No. 8, pp. 1465-1471, November 1971. 


\section{PRESENTATIONS}

W.G.N. SLINN. "Physical processes in Scavenging," Chemist-Meteorologist workshop Meeting, Fort Lauderdale, Fla. January 1971.

W.G.N. SLINN. "Stochastic Processes in Atmospheric Physics," Irregular Statistical Mechanics Meeting in the Northwest, Portiand, Oregon. April 1971 .

STAFF. "Atmospheric Sciences program Review for the Atomic Energy Commission," Battelle, Pacific Northwest Laboratories, Richland, Washington, May 3-7, 1971.

C. E. ELDERKIN. "Measurements of Space Time Relationships in Atmospheric Turbulence." Presented at the Atmospheric Turbulence Conference, London, England, RAes/CASI/AIAA. May 18-21, 1971.

G. A. SEHMEL. "Particle Diffusivities and Deposition Velocities over a Horizontal Smooth Surface," BNWL-SA-3697. Presented at the 45 th National Colloid Symposium, Atlanta, Georgia. June 21$23,1971$.

C. L. SIMPSON. "Meteorology and Drift," presented at the meeting on Chemicals and our Environment. Battelie, Pacific Northwest Laboratories, Richland, Washington. october 28,1971 .
C. E. ELDERKIN. "Drift Studies at Hanford," presented at the meeting on Chemicals and our Environment. Battelie, Pacific Northwest Laboratories, Kichland, Washington. october $28,1971$.

M. A. WOLF. "Complexity of Wind Flow, "presented at the meeting on Chemicals and our Environment. Battelle, Pacific Northwest

Laboratories, Richland, Washington, october $28,1971$.

J. V. RAMSDELL. "Concentration Eluctuation and peak-To-Mean Concentration Ratios in Real Plumes," BNWL-SA-4095. Presented at the Symposium on Air Pollution, Turbulence and Diffusion, Las Cruces, New Mexico. December 7-10, 1971.

D. C. POWELL and C. E. ELDERKIN. "An Investigation of the Application of Taylor's Hypothesis to Atmospheric Boundary Layer TurbuZence," BNWL-SA-4084. Presented at the Symposium on Air Pollution, Turbulence and Diffusion, Las Cruces, New Mexico. December ?-10, 1971.

C. E. ELDERKIN and D. C. POWELL. "Measurements and Graphs of Turbulence Autocorrelations in Space and Time," BNWL-SA-4086. Presented at the Symposium on $A$ ir Polzution, Turbulence and Diffusion, Las Cruces, New Mexico. December 710,1971 . 
No. of

Copies

1 AEC Chicago Patent Group

$$
\text { G. H. Lee }
$$

15 Division of Biomedical and Environmental Research

N. F. Barr

R. W. Beadle

W. W. Burr

R. D. Cooper

C. W. Edington

R. J. Eng e1mann

J. D. Goldstein

H. H. Hollister

J. S. Kirby-Smith

W. F. Marlow

J. E. Miller

C. L. Osterberg

J. R. Totter

H. Wasson

R. W. Wood

1 AEC Division of Production

W. L. Lennemann

1 AEC Division of Reactor Development \& Technology

Chief, Environmental $\&$ Sanitary Engineering

Branch

180 AEC Technical Information Center

1 Ames Laboratory, USAEC Iowa State University Physics B1dg., Rm. A530

Ames, Iowa 50010

$$
\text { L. Hodges }
$$

2 Argonne National Laboratory

P. F. Gustafson

J. Kline

2 Atomic Energy of Canada

Limited Chalk River, Ontario

C. A. Maws on

I. Ophe1

1 Atomic Energy Establishment Trombay Bombay 73, India

A. K. Ganguly
No. of

Copies

1 Atomic Energy Research

Establishment

Harwel1, Berks, England

Librarian

1 Australian AEC

Post Office Coogee

New South Wales, Australia

A. W. R. Wilson

3 Brookhaven National Laboratory

L. P. Hatch

M. E. Smith

G. M. Woodwe11

5 Commissariat a 1 'Energie

Atomique

Centre d' Etudes

Nucleaires de Cadarache

BP $n^{\circ}, 13-$ St Paul

1es Durance, France

C. Gailledreau

4 Centre d' Etudes Nucleaires de Saclay P.O. Box 2, Sac1ay Gif-sur-Yvette ( $S \& O)$ France

A. Barbreau

F. Duhame1

A. Menoux

P. S1izewicz

1 Comision Nacional de Energia Atomica Buenos Aires, Argentina

E. Vander Elst

1 Commonwealth Scientific and Industrial Research Organization Aspenda1, Victoria, Australia

B. B. Hicks

1 Commonwealth Scientific $q$ Industrial Research Organization 314 Albert Street, P.0. Box 89 East Melbourne, Victoria Australia 3002

Librarian

2 Dow Chemical USA, Rocky Flats Div. Box 888 Golden, Colo. 80401

L. M. Steward 
No. of

Copies

2 du Pont Company, Aiken

B. C. Rusche

W. B. Scott

1 du Pont Company, Wilmington

V. R. Thayer

1 ENEA (OECD) Health \& Safety office

$\overline{38, B 1}$ d. Suchet

Paris XVI, France

E. Wa 11 auschek

1 Environmental Protection Agency Office of Categorical Programs Washington, D.C. 20460 Assistant Administrator

David D. Dominick

1 Environmenta1 Protection Agency Washington, D.C. 20460 Assistant Administrator for Research and Monitoring

Stanley M. Greenfield

1 Eurochemic Library

Mo1, Belgium

Librarian

1 Florida State University Department of Oceanography Tallahassee, F1orida 32306

$J$. W. Winchester

1 Geological Survey of the United Kingdom, Water Division

Stevens on Buchan

1 Geological Survey of the

United States

Washington 25, D.C.

M. King Hubbert

1 George Washington University Washington, D.C.

C. R. Naeser

1 Geotechnical Corporation

Box 28277

Dallas 28 , Texas

W. B. Heroy

1 Gesel1schaft Kernforschung mbH Karlsruhe 5, West Germany

H. Krause
No. of

Copies

1 Health \& Safety Laboratory New York City

John Harley

2 Institut fur Chemie 65 Mainz

Saarstrasse 23, Postfach 3060

West Germany

C. E. Junge

M. Planck

2 Institute fur Meteorologie Und Geophysik der Johann Wolfgang Goeth-University

6000 Frankfurt am Main

Feldbergstrabe 47, Germany

S. Beilke

H. W. Georgii

1 International Atomic Energy Agency

Vienna 1 , Kaerntnerring 11 , Austria

Director, Division of Health, Safety and Waste Management

2 Lawrence Radiation Laboratory Livermore

G. H. Higgins

J. B. Knox

1 Los Alamos Scientific Laboratory

J. W. Healy

5 Ministry of Agriculture, Fisheries, $\bar{G}$ Food Laboratory Lowestoft, Suffolk, England

Librarian

2 National Institute of Radiological Sciences 250 , Kurosuna Cho, Chiba-shi, Japan

M. Saiki

M. Suzuki

1 Nationa 1 Oceanic and Atmospheric Administration

North Bethesda Office Center

11420 Rockville Heights

Rockville, Maryland 20852

J. Z. Holland 
No. of

Copies

3 Oak Ridge National Laboratory

S. I. Auerbach

K. Z. Morgan

E. G. Struxness

1 USAEC Hea 1 th and Safety

Laboratory

376 Hudson Street

New York, N.Y. 10014

M. T. Kleinman

1 World Health Organization Geneva, Switzerland

R. L. Dobson

1 World Meteorological

Organization

Geneva, Switzerland

Librarian

\section{ONSITE}

1 AEC Chicago Patent Group

R. M. Poteat

3 AEC Richland Operations Office

N. W. Fraser

W. E. Lotz

B. J. Melton

1 Atlantic Richfield Hanford Company

D. J. Brown

1 Douglas United Nuclear

P. C. Jerman

1 Hanford Environmental Health Foundation

P. A. Fuqua

335 Batte11e-Northwest
F. W. Albaugh
E. L. Alpen
W. J. Bair
N. E. Ballou
G. L. Culp

No. of

Copies

Batte11e-Northwest (Contd)

G. M. Dalen

R. L. Dillon

C. E. Elderkin

R. D. Dierks

S. J. Farmer

R. F. Foster

J. J. Fuquay

A. G. Gibbs

J. M. Hales

W. A. Haney

J. C. Hampton

A. J. Haverfield

V. G. Horstman

F. P. Hungate

D. R. Kalkwarf

L. J. Kirby

H. V. Larson

C. W. Lindenmeier

R. H. Moore

J. M. Nie1sen

T. P. O'Farrell

D. E. Olesen

R. F. Palmer

J. F. Park

R. S. Paul

D. W. Pearce

R. W. Perkins

E. H. Phinney

A. K. Postma

P. M. Potter

W. D. Richmond

W. C. Roesch

L. C. Schwendiman

A. J. Scott

W. G. N. Slinn (100)

W. H. Swift

C. L. Simpson (100)

J. A. Strand

M. F. Sullivan

W. L. Templeton

R. C. Thompson

C. M. Unruh

B. E. Vaughan

W. R. Wiley

W. E. Wilson

N. A. Wogman

M. A. Wo $1 f$

R. K. Woodruff (75)

J. A. Young

Biology Library (2)

Technical Information (5)

Technical Publications (2) 
